Spent Fuel Dissolution Studies FY 1991 to 1994
W. J. Gray
C.N.Wilson

December 1995

Prepared for the U.S. Departinent of Energy under Contract DE-AC06-76RLO 1830

Pacific Northwest National Laboratory

Operated for the U.S. Department of Energy byBattelleMemorial Institute 
?

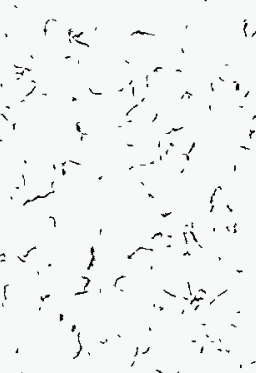

DISCLAAIMER

This report was prepared às an account of work sponsored by an agency of the United States Government. Neither the United States Government nor any agéncy thereof, nor Battelle Memorial Institute, nor any of their employes, makes any warranty, express or implied, or assumes any legal liability or responsibility for the accuracy, completeness, or usefulness of any information, apparatus, product, or process disclosed, or represents that its use would not infringe privately owned rights. Reference herein to any specific cómmercial product, process, or service by trade name, trademark; manufacturer, or othénwis does not necessarily constitute or imply its endorsement, recommendation, or favoring by the United States Government or any agency thereof, or Battelle Memorial Institute. The views and opinions of iauthors expressed herein do not necessarily state or reflect those of the United States Government on any ancy thereof

$$
\begin{aligned}
& \text { PACIFÍC NORTHWEST LABORATORY } \\
& \text { operated by } \\
& \text { - BÁTTELLE MEMÓRIÁLINSTITUTE } \\
& \text { for the } \\
& \text { UNITED STATES DEPARTMENTT OF ENERGY }
\end{aligned}
$$

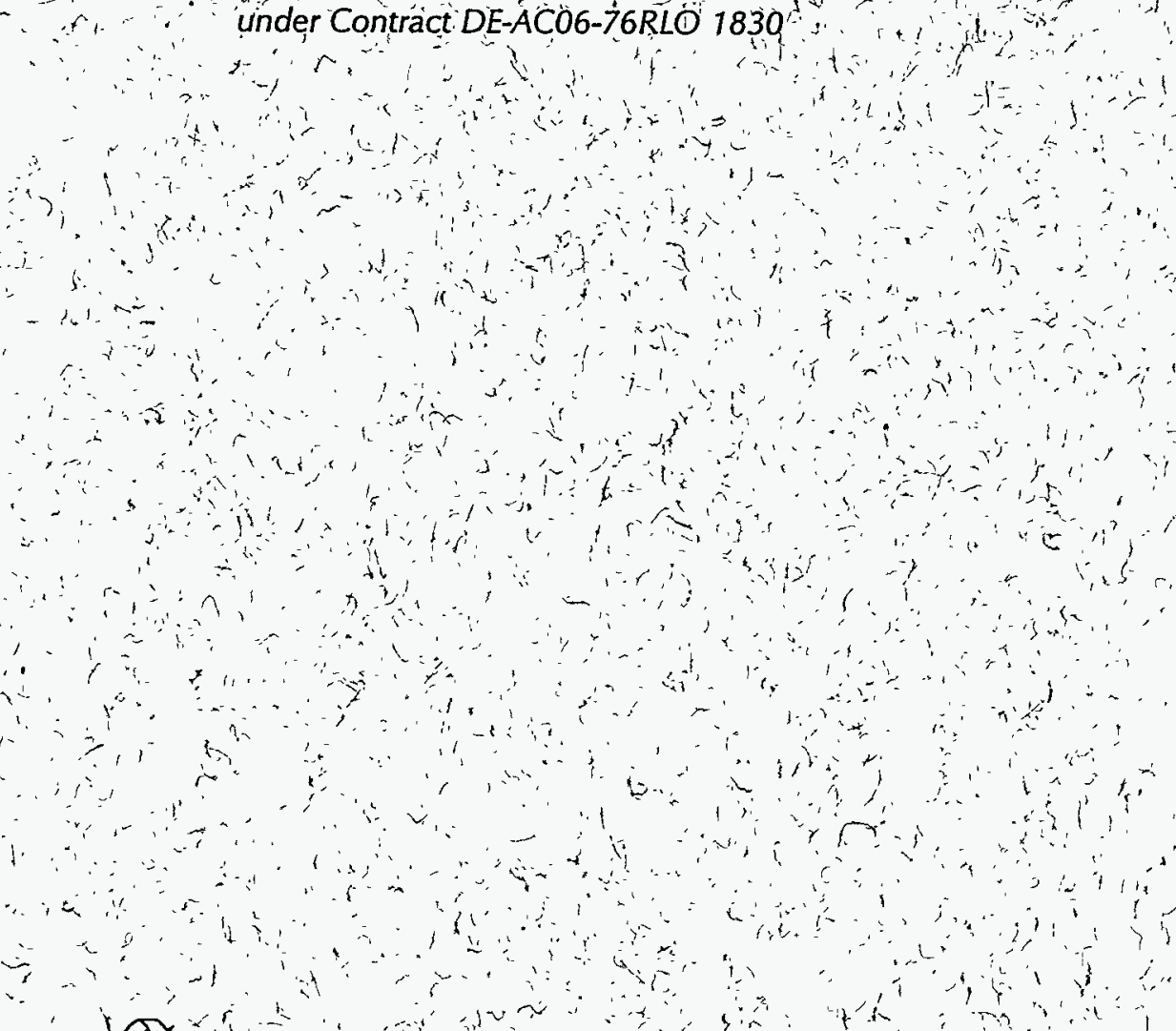

The contents of this report is printed on recycled paper.

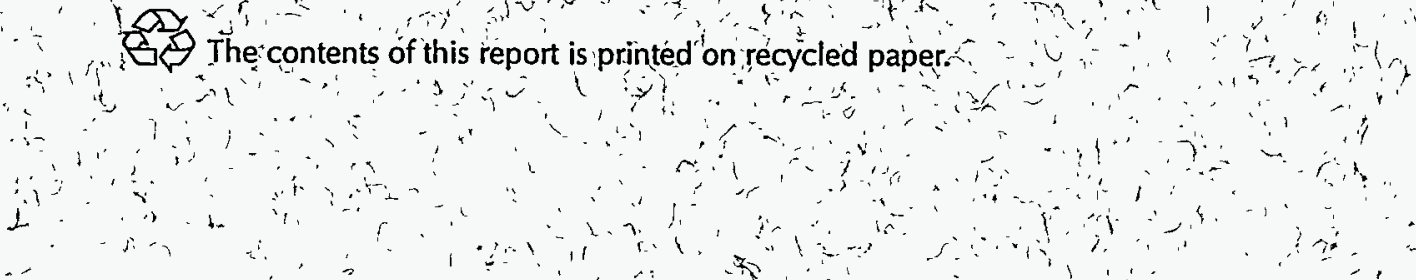




\title{
Spent Fuel Dissolution Studies FY 1991 to 1994
}

\author{
W. J. Gray \\ C. N. Wilson
}

December 1995

Prepared for the U.S. Department of Energy under Contract DE-AC06-76RLO 1830

Pacific Northwest National Laboratory

Richland, Washington 99352 


\section{,}




\begin{abstract}
This report describes a variety of dissolution studies on spent fuel and unirradiated $\mathrm{UO}_{2}$. One study investigated the effect of different water chemistry parameters on the dissolution rate of spent fuel. This investigation was made possible by the combination of a flow-through test method together with spent-fuel test specimens that consisted of fine powders, which allowed the dissolution rate of the $\mathrm{UO}_{2}$ matrix of the fuel to be unambiguously measured for the first time.

Two other major areas of investigation included 1) measuring how the dissolution rates of spent fuels and unirradiated uranium oxides are affected by preoxidation in air and 2) measuring separate gap inventories and grain-boundary inventories of ${ }^{137} \mathrm{Cs},{ }^{99} \mathrm{Tc}$, and ${ }^{90} \mathrm{Sr}$ for a variety of spent fuels.

Supplementary studies included 1) a flow-through test on an archive specimen from a previous semistatic test to facilitate interpretation of data from the latter, 2) measuring the dissolution rate of $\mathrm{UO}_{2}$ in a solution containing a high concentration of uranium, 3) measuring simultaneous changes in $\mathrm{UO}_{2}$ dissolution rate and streaming potential in response to changes in water chemistry, and 4) participation in a mini-round robin dissolution test of a common $\mathrm{UO}_{2}$ specimen by three laboratories.
\end{abstract}


. 


\section{Summary and Conclusions}

Dissolution and transport as a result of groundwater flow are generally accepted as the primary mechanisms by which radionuclides from spent fuel placed in a geologic repository could be released to the biosphere. To help provide a source term for performance assessment calculations, dissolution studies on spent fuel and unirradiated uranium oxides have been conducted over the past few years at Pacific Northwest National Laboratory (PNNL) in support of the Yucca Mountain Site Characterization Project. This report describes work for fiscal years 1991 through 1994. The objectives of these studies and the associated conclusions, which were based on the limited number of tests conducted so far, are described in the following subsections.

\section{Spent Fuel Matrix Phase Dissolution Kinetics}

These tests involved the use of a flow-through test method combined with spent fuel test specimens that had been ground and screened to a fine powder, which consisted predominantly of separated fuel grains. The combination of this test method and test specimen configuration allowed the intrinsic dissolution rate of the $\mathrm{UO}_{2}$ matrix of spent fuel to be accurately and unambiguously measured for the first time.

Because of the increased confidence gained by these new methods, a systematic study of spent fuel dissolution rates as a function of a few important water chemistry variables was conducted. Although the effects of these variables have been explored by other researchers (Johnson and Shoesmith 1988; Grambow 1989), the improved test method/test specimen combination provided a more defensible set of source-term values for input to performance assessment calculations than had been available previousiy.

To reduce the number of experiments required to perform the systematic study, a statistically designed experimental approach was used to determine the dissolution rate dependence of one type of spent fuel (ATM-103) on four variables, carbonate/bicarbonate concentration ( $2 \times 10^{-4}$ to $\left.2 \times 10^{-2} \underline{\mathrm{M}}\right)$, $\mathrm{pH}(8$ to 10$), \mathrm{O}_{2}$ overpressure $(0.003$ to $0.2 \mathrm{~atm})$, and temperature $\left(25\right.$ to $\left.75^{\circ} \mathrm{C}\right)$. During this testing, a complex dependence of dissolution rate on a combination of $\mathrm{O}_{2}$ overpressure and other variables, primarily temperature, was unexpectedly observed. Further testing, both with spent fuel and with unirradiated $\mathrm{UO}_{2}$, confirmed that ATM-103 spent fuel dissolved at a rate that was almost independent of $\mathrm{O}_{2}$ overpressure at $25^{\circ} \mathrm{C}$ but very dependent (reaction order as high as 0.79 ) at $75^{\circ} \mathrm{C}$. This was in contrast to the results obtained with unirradiated $\mathrm{UO}_{2}$ in which the reaction order with respect to $\mathrm{O}_{2}$ was observed to be approximately 0.5 under all conditions tested both at PNNL and in similar tests at Lawrence Livermore National Laboratory (LLNL) (Steward and Gray 1994). Results of tests with ATM-103 spent fuel conducted at a single $\mathrm{O}_{2}$ overpressure (atmospheric), showed that the dissolution rates were most strongly affected by temperature, somewhat less strongly affected by carbonate/ bicarbonate concentration, and only very weakly dependent on $\mathrm{pH}$. These observations are qualitatively in agreement with those of other researchers (Johnson and Shoesmith 1988; Grambow 1989). 
Over the range of conditions cited above, ATM-103 spent fuel dissolution rates of 0.5 to $20 \mathrm{mg} \bullet \mathrm{m}^{-2} \bullet \mathrm{d}^{-1}$ ) were measured. Application of these rates to appropriate spent fuel geometries for input to performance assessment calculations translates to fractional rates in the range $7.2 \times 10^{-4}$ to $7.3 \times 10^{-1}$ per year. These fractional rates depend on the surface area that is assumed for the fuel and are discussed in detail in Section 4.1.1.

\section{GAP and Grain-Boundary Inventories}

A portion of certain fission products, most notably $\mathrm{Cs}$, migrates out of the $\mathrm{UO}_{2}$ matrix under the influence of temperature gradients during reactor operation and concentrates in the fuel/cladding gap and in the grain boundaries of the fuel. In these locations, soluble elements are readily available for immediate dissolution should water ever contact the fuel in the repository. To provide the required source terms for performance assessment calculations, the inventories of these elements that are located in the gaps and the grain boundaries must be measured for a representative number of fuels.

Accordingly, gap inventories and grain-boundary inventories of ${ }^{137} \mathrm{Cs},{ }^{99} \mathrm{Tc}$, and ${ }^{90} \mathrm{Sr}$ were measured for a total of eight different fuel rods from five different spent fuels to determine the amounts of the cited radionuclides that could potentially be available for rapid release if the fuel were contacted by groundwater in a repository. Cesium gap inventories of the fuels tested were equal to only about onefourth the fission gas release (FGR) percentages. A more nearly one-to-one correspondence between ${ }^{137} \mathrm{Cs}$ gap inventory and FGR was expected. The grain-boundary inventories of ${ }^{137} \mathrm{Cs}$ were about $1 \%$ or less of total ${ }^{137} \mathrm{Cs}$ inventories. Both gap and grain-boundary inventories of ${ }^{99} \mathrm{Tc}$ and ${ }^{90} \mathrm{Sr}$ were less than about $0.2 \%$ of their total inventories.

In a related experiment, measurements were made of the dissolution rate of ${ }^{137} \mathrm{Cs}$ from the grain boundaries of one of the spent fuels, ATM-103. This experiment was conducted to determine whether the release from the grain boundaries might be slower than the "essentially instantaneous release" that is commonly assumed. The rate at which ${ }^{137} \mathrm{Cs}$ dissolved from the grain boundaries was measured over a period of 120 days during which time $\sim 40 \%$ of the total ${ }^{137} \mathrm{Cs}$ grain-boundary inventory was dissolved. The question of ${ }^{137} \mathrm{Cs}$ dissolution rate from grain boundaries could become relatively less important if the small grain-boundary inventories of ${ }^{137} \mathrm{Cs}$ noted for the eight fuel rods mentioned above are confirmed to be true for U.S. light-water reactor fuels in general.

\section{Dissolution Rates of Oxidized Spent Fuels}

If spent fuel were placed in a proposed repository at Yucca Mountain, there would be the potential for it to be contacted and oxidized by .air before it was contacted by groundwater. It has been common to assume that oxidized fuel would dissolve faster than unoxidized $\left(\mathrm{UO}_{2}\right)$ fuel. Scoping tests involving specimens from two spent fuels, ATM-105 and ATM-106, have been conducted to examine this assumption. These tests involved flow-through dissolution-rate measurements on specimens preoxidized in air to $\mathrm{U}_{4} \mathrm{O}_{9+x}$ and $\mathrm{U}_{3} \mathrm{O}_{8}$. 
The intrinsic (normalized by surface area) dissolution rate measured for an oxidized $\left(\mathrm{U}_{4} \mathrm{O}_{9+\mathrm{x}}\right)$ specimen of ATM-105 fuel was little or no higher than for an unoxidized $\left(\mathrm{UO}_{2}\right)$ specimen. An oxidized specimen of ATM-106 fuel dissolved somewhat faster than an unoxidized specimen, but still the difference was a factor of only about five.

When a specimen of ATM-106 fuel was oxidized to $\mathrm{U}_{3} \mathrm{O}_{8}$, its intrinsic dissolution rate was about 10 times faster than a specimen of unoxidized ATM-106 fuel grains and about twice as fast as a specimen of ATM-106 fuel grains oxidized to $\mathrm{U}_{4} \mathrm{O}_{9+\mathrm{x}}$. A more important effect of the oxidation to $\mathrm{U}_{3} \mathrm{O}_{8}$ was a very large increase in surface area compared to the particles used to prepare the $\mathrm{U}_{3} \mathrm{O}_{8}$. This resulted in a fractional dissolution rate (rate per unit specimen weight) of $\mathrm{U}_{3} \mathrm{O}_{8}$ equal to 150 times that of the unoxidized particles.

Because of the unexpected observation that prior oxidation by air did not result in a large increase in the intrinsic dissolution rates of the spent fuel that was tested, supplemental tests were also conducted with unirradiated $\mathrm{U}_{3} \mathrm{O}_{7}$ and $\mathrm{U}_{3} \mathrm{O}_{8}$. Similar results were obtained. That is, the intrinsic dissolution rates of unirradiated $\mathrm{U}_{3} \mathrm{O}_{7}$ and $\mathrm{U}_{3} \mathrm{O}_{8}$ specimens were about two and three times, respectively, faster than a $\mathrm{UO}_{2}$ specimen. Likewise, the fractional dissolution rate for a specimen of $\mathrm{U}_{3} \mathrm{O}_{7}$ was about double that of $\mathrm{UO}_{2}$, but due to the large increase in surface area, the fractional rate for the $\mathrm{U}_{3} \mathrm{O}_{8}$ specimen was about 200 times faster than $\mathrm{UO}_{2}$.

In summary, preoxidation by air of either spent fuel or unirradiated $\mathrm{UO}_{2}$ caused the intrinsic dissolution rates to increase by only a small amount. However, when oxidized to $\mathrm{U}_{3} \mathrm{O}_{8}$, the associated large increase in surface area caused the fractional dissolution rates of both $\mathrm{UO}_{2}$ and spent fuel to increase markedly.

\section{Interlaboratory Comparison of Tests with Unirradiated $\mathrm{UO}_{2}$}

Dissolution rates of unirradiated $\mathrm{UO}_{2}$ powder were measured with similar flow-through methods at PNNL, LLNL, and AECL (Atomic Energy of Canada Ltd.) to address experimental replication issues. The measured rates at the three laboratories agreed within a factor of three to four, which is considered reasonable agreement for this type of testing.

\section{Flow-Through Dissolution Tests with a Series-3 Archive Specimen}

The dissolution rate of an archive specimen from a previous semistatic experiment (Series-3 test) was measured with a flow-through method to 1) compare the high-flow-rate results with those from the no-flow conditions of the Series-3 test, and 2) provide information on which to base a better estimate of the $\mathrm{UO}_{2}$ matrix dissolution rate relevant to the Series-3 test.

Uranium and ${ }^{90} \mathrm{Sr}$ dissolved congruently in the $25^{\circ} \mathrm{C}$ flow-through test, which implies that they also dissolved congruently in the semistatic Series-3 test. This indicates that the $\mathrm{UO}_{2}$ matrix dissolved at the same fractional rate as ${ }^{90} \mathrm{Sr}$ in the $25^{\circ} \mathrm{C}$ semistatic test. Cesium- 137 and ${ }^{99} \mathrm{Tc}$ continued to dissolve at fractional rates approximately twice that of $U$ throughout the flow-through test, indicating continued preferential dissolution of these radionuclides from the grain boundaries. This implies that ${ }^{137} \mathrm{Cs}$ and ${ }^{99} \mathrm{Tc}$ also dissolved preferentially in the semistatic tests and, therefore, were not indicative 
of the $\mathrm{UO}_{2}$ matrix dissolution rates. Because there were indications of ${ }^{90} \mathrm{Sr}$ precipitation, the

${ }^{90} \mathrm{Sr} / \mathrm{UO}_{2}$ matrix rate comparison technique is not applicable to the $85^{\circ} \mathrm{C}$ semistatic tests.

The observed dissolution rate of the Series- 3 test specimen in the flow-through test was about six times higher than in the semistatic Series-3 test. This difference is relatively small considering the difference in the nature of the tests. That is, in the flow-through test, it is expected that there was no precipitation of secondary phases, no colloid formation, nor any significant changes in water chemistry, all of which would have been prevalent in the semistatic Series- 3 test. The small difference in measured rates between the two tests indicates that the water contact mode, flow-through or static, was relatively unimportant. Further, it suggests that results from flow-through tests, which are easier to interpret than those from semistatic tests, can be used with reasonable confidence to project upper bound dissolution rate behavior under repository conditions. However, unsaturated tests that were recently started by Finn et al. (1994) involve still a different type of water contact mode. Future results from the unsaturated tests will be compared with those from flow-through tests to determine whether a reassessment of the above conclusions may be needed.

\section{Comparison of $\mathrm{UO}_{2}$ Dissolution Rate and Streaming Potential}

Two tests with unirradiated $\mathrm{UO}_{2}$ were designed to explore a possible correlation between changes in streaming potential, which is associated with the zeta potential near the $\mathrm{UO}_{2}$ surface, and changes in dissolution rate in response to changes in water chemistry. The zeta potential is a measure of the ionic charge density variation in a liquid immediately adjacent to a solid surface and correlates directly with the dissolution rate of the solid for some electro-chemical systems. The tests were partially successful. However, some of the data appeared to be compromised by pressure changes due to increased flow resistance in the test column when $\mathrm{Si}$ gel deposited on the $\mathrm{UO}_{2}$ particles from Si-containing solutions. A modified or different test method is apparently needed for testing in such solutions.

\section{Spent Fuel Dissolution Issues Related to Geologic Disposal}

It is argued that the largest uncertainty relating to use of measured spent fuel dissolution rates in performance assessment calculations is the question of the appropriate surface area to assume for the fuel under anticipated repository conditions. Means of resolving this uncertainty are needed but may be difficult.

Both gap inventories and grain-boundary inventories have now been measured for five different fuels. Measurements on at least two or three additional fuels are needed to help confirm the trends observed so far.

A limited number of tests have been conducted to determine how the dissolution rate of the spent fuel matrix varies as a function of the fuel condition (e.g., pre-oxidation by air), water chemistry, and fuel type. While some additional testing is recommended in each of these areas, it is argued that one of the biggest remaining uncertainties is the effect that silicon and calcium, common groundwater constituents, may have on dissolution rates. 


\section{Acknowledgments}

The authors acknowledge the following Pacific Northwest National Laboratory staff (by area of expertise) for their contributions to this study:

\section{Hot-Cell Operations:}

D. V. Archer

C. E. Chamberlin

M. E. Freed

S. A. Homi

F. V. Hoopes

J. K. Rau

R. T. Steele

\section{Spent Fuel Oxidations:}

H. C. Buchanan

R. E. Einziger

\section{Radiochemical Analyses:}

R. J. Barrington

J. H. Ennen

C. O. Harvey

L. S. Kellogg

A. E. Kozelisky

L. A. Larson

K. A. Poeppel

P. J. Raney

S. W. Thompson

T. Trang

SEM, Ceramographic, and XRD Characterizations:

R. R. Adee

J. E. Coleman

E. D. Jenson

D. J. Sypolt

L. E. Thomas

Particle-Size Distributions:

M. C. Burt 



\section{Acronyms}

\begin{tabular}{|c|c|}
\hline AECL & Atomic Energy of Canada Limited \\
\hline ATM & approved testing material \\
\hline BET & $\begin{array}{l}\text { method for measuring surface areas of specimens consisting of small particles } \\
\text { the names of the developers, Brunauer, Emmett, and Teller }\end{array}$ \\
\hline BWR & boiling-water reactor \\
\hline CANDU & Canadian natural-uranium, heavy-water-moderated and -cooled power reactor \\
\hline DIW & deionized water \\
\hline DOE & U.S. Department of Energy \\
\hline FFTF & Fast Flux Test Facility \\
\hline FGR & fission gas release \\
\hline IC & Ion Chromatography \\
\hline ICP & Inductively Coupled Plasma spectrometer \\
\hline LLNL & Lawrence Livermore National Laboratory \\
\hline LWR & light-water reactor \\
\hline MCC & Materials Characterization Center \\
\hline PNNL & Pacific Northwest National Laboratory \\
\hline PASS & Performance Assessment Scientific Support \\
\hline PSD & particle-size distribution \\
\hline PWR & pressurized-water reactor \\
\hline SEM & scanning electron microscope (or microscopy) \\
\hline TIC & total inorganic carbon \\
\hline TOC & total organic carbon \\
\hline XRD & $\mathrm{X}$-ray powder diffraction \\
\hline YMP & Yucca Mountain Site Characterization Project \\
\hline
\end{tabular}




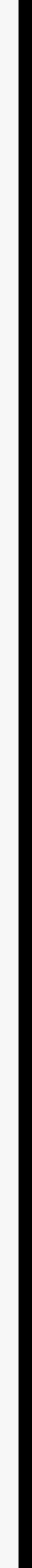




\section{Contents}

Abstract $\quad \ldots \ldots \ldots \ldots \ldots \ldots \ldots \ldots \ldots \ldots \ldots \ldots \ldots \ldots \ldots \ldots \ldots$

Summary and Conclusions $\ldots \ldots \ldots \ldots \ldots \ldots \ldots \ldots \ldots \ldots$

Acknowledgments $\ldots \ldots \ldots \ldots \ldots \ldots \ldots \ldots \ldots \ldots \ldots \ldots \ldots \ldots$ ix

Acronyms $\ldots \ldots \ldots \ldots \ldots \ldots \ldots \ldots \ldots \ldots \ldots \ldots \ldots \ldots \ldots \ldots \ldots \ldots$

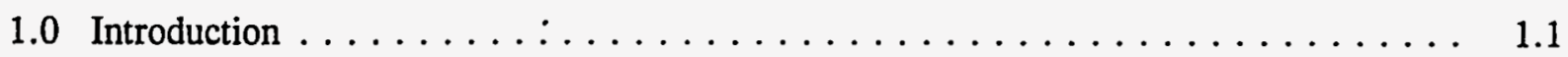

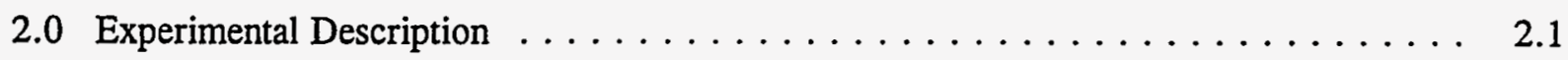

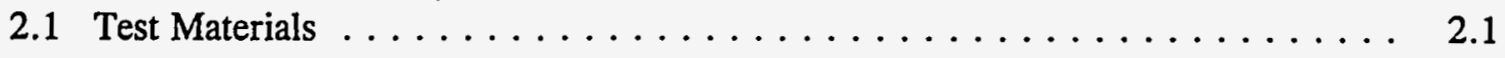

2.1 .1 Spent Fuel $\ldots \ldots \ldots \ldots \ldots \ldots \ldots \ldots \ldots \ldots \ldots \ldots \ldots \ldots \ldots$

2.1.2 Unirradiated Uranium Oxides $\ldots \ldots \ldots \ldots \ldots \ldots \ldots \ldots \ldots$

2.1.3 Surface Area Measurements $\ldots \ldots \ldots \ldots \ldots \ldots \ldots \ldots \ldots$

2.2 Flow-Through Equipment $\ldots \ldots \ldots \ldots \ldots \ldots \ldots \ldots \ldots \ldots \ldots$

2.3 Dissolution Tests $\ldots \ldots \ldots \ldots \ldots \ldots \ldots \ldots \ldots \ldots \ldots \ldots \ldots \ldots$

2.3.1 Dissolution Kinetics. of Spent Fuel $\mathrm{UO}_{2}$ Matrix $\ldots \ldots \ldots \ldots \ldots$

2.3.2 Tests with Oxidized Spent Fuel $\ldots \ldots \ldots \ldots \ldots \ldots \ldots \ldots \ldots$

2.3.3 Supplemental Spent Fuel Tests $\ldots \ldots \ldots \ldots \ldots \ldots \ldots \ldots \ldots$

2.3.4 Supplemental Tests with Unirradiated Uranium Oxide Powders . . . . . . 2.13

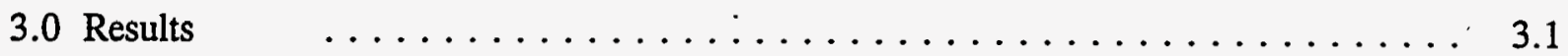

$3.1 \mathrm{UO}_{2}$ Matrix Phase Dissolution Kinetics $\ldots \ldots \ldots \ldots \ldots \ldots \ldots \ldots \ldots$

3.2 Tests with Oxidized Spent Fuel $\ldots \ldots \ldots \ldots \ldots \ldots \ldots \ldots \ldots \ldots \ldots \ldots$

3.3 Supplemental Spent Fuel Tests $\ldots \ldots \ldots \ldots \ldots \ldots \ldots \ldots \ldots \ldots \ldots$

3.3.1 Gap and Grain-Boundary Inventories $\ldots \ldots \ldots \ldots \ldots \ldots . \ldots \ldots$ 
3.3.2 Grain-Boundary Dissolution Rates $\ldots \ldots \ldots \ldots \ldots \ldots \ldots . \ldots . \ldots$

3.3.3 Series-3 Archive Specimen . . . . . . . . . . . . . 3.9

3.3.4 SEM Examination of Spent Fuel $\ldots \ldots \ldots \ldots \ldots \ldots$

3.3.5 Tests with Solution Semi-Saturated with Uranium $\ldots \ldots \ldots \ldots \ldots . . .13$

3.4 Supplemental Tests with Unirradiated Uranium Oxide Powders $\ldots \ldots \ldots \ldots$. . . 3.13

3.4.1 Flow-Through Tests with $\mathrm{UO}_{2}$ at Atmospheric $\mathrm{O}_{2}$ Overpressure $\ldots \ldots \ldots 3.13$

3.4.2 Flow-Through Tests with $\mathrm{UO}_{2}$ at Low $\mathrm{O}_{2}$ Overpressure $\ldots \ldots \ldots \ldots .13$

3.4.3 Flow-Through Tests with $\mathrm{U}_{3} \mathrm{O}_{7}$ and $\mathrm{U}_{3} \mathrm{O}_{8} \ldots \ldots \ldots \ldots . \ldots \ldots$

3.4.4 SEM Examination of Leached $\mathrm{UO}_{2} \ldots \ldots \ldots \ldots \ldots \ldots \ldots$

3.4.5 $\mathrm{UO}_{2}$ Dissolution/Streaming Potential $\ldots \ldots \ldots \ldots \ldots \ldots \ldots$

4.0 Discussion $\ldots \ldots \ldots \ldots \ldots \ldots \ldots \ldots \ldots \ldots \ldots \ldots \ldots \ldots \ldots \ldots \ldots$

4.1 Review of Data Presented in this Report $\ldots \ldots \ldots \ldots \ldots \ldots \ldots$

4.1.1 $\mathrm{UO}_{2}$ Matrix Phase Dissolution Kinetics $\ldots \ldots \ldots \ldots \ldots \ldots \ldots$

4.1 .2 Gap and Grain-Boundary Inventories . . . . . . . . . . . . 4.4

4.1.3. Dissolution Rates of Oxidized Spent Fuel and Unirradiated

Uranium Oxides . . . . . . . . . . . . . . . . 4.5

4.1 .4 SEM Examination of Spent Fuel $\ldots \ldots \ldots \ldots \ldots \ldots \ldots \ldots$

4.1.5 Summary Comparison of Dissolution Rates for Different Types

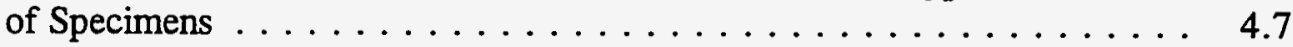

4.1.6 Grain Boundary Penetration by Water $\ldots \ldots \ldots \ldots \ldots \ldots . \ldots$

4.1 .7 Series-3 Archive Specimen $\ldots \ldots \ldots \ldots \ldots \ldots \ldots \ldots \ldots . \ldots \ldots$

$4.1 .8 \mathrm{UO}_{2}$ Dissolution/Streaming Potential $\ldots \ldots \ldots \ldots \ldots \ldots \ldots \ldots$

4.2 Spent Fuel Dissolution Issues Related to Geologic Disposal . . . . . . . . . . 4.11

4.2.1 Gap and Grain-Boundary Inventories . . . . . . . . . . . 4.11

4.2 .2 Fuel Matrix Dissolution Rates $\ldots \ldots \ldots \ldots \ldots \ldots \ldots \ldots . \ldots \ldots$ 
4.2.3 Effective Surface Areas

4.14

5.0 References

5.1

Appendix A - Figures

A. 1 


\section{Tables}

2.1 Characteristics of Spent Fuel and Test Identifications $\ldots \ldots \ldots \ldots \ldots \ldots \ldots$

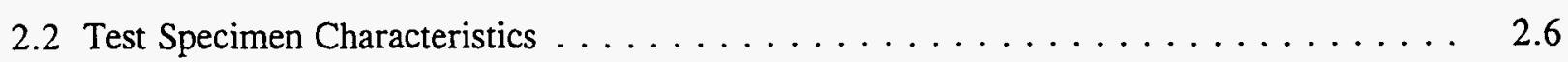

2.3 Record of Specimens used in Tests Listed in Table 3.1 (Section 3.1) $\ldots \ldots \ldots \ldots$

2.4 Analysis of $\mathrm{J}-13$ Well Water, Barrel $\mathrm{G} \ldots \ldots \ldots \ldots \ldots \ldots \ldots \ldots$

3.1 Test Matrix and Results for Spent Fuel Dissolution Tests $\ldots \ldots \ldots \ldots \ldots \ldots$

3.2 Dissolution/Streaming Potential Test Solution Compositions $\ldots \ldots \ldots \ldots \ldots$

4.1 Dependence of Dissolution Rates on $\mathrm{O}_{2}$ Overpressure $\ldots \ldots \ldots \ldots \ldots$ 


\subsection{Introduction}

This report was prepared for the Waste Package Task of the Yucca Mountain Site Characterization Project (YMP), which is part of the U.S. Department of Energy's (DOEs) Office of Civilian Radioactive Waste Management. The Waste Package Task is managed by Lawrence Livermore National Laboratory (LLNL). This document reports FY 1991 through 1994 progress and results for continuing studies of the dissolution behavior of spent fuel, which is being conducted at the Pacific Northwest National Laboratory (PNNL) ${ }^{(a)}$ for the YMP Waste Package Task.

Dissolution and transport as a result of groundwater flow are generally accepted as the primary mechanisms by which radionuclides could be released from a geological repository to the biosphere (National Research Council 1990). Most of the long-lived radioactivity in spent fuel results from low-solubility radionuclides (primarily actinides), for which release from a geologic repository will likely be controlled by solubilities if transport by colloids can be ruled out (Wilson 1990a and 1990b). Whether controlled by solubilities or colloids, release of low-solubility radionuclides would not be dependent on the characteristics of the waste form itself. However, release rates for more soluble radionuclides may depend both on the heterogeneous distribution of these radionuclides within the fuel and the durability of the fuel in a potential repository. In relatively young fuel, which is all that is currently available for testing, ${ }^{137} \mathrm{Cs}$ and ${ }^{90} \mathrm{Sr}$ are the predominant soluble radionuclides. Longer-lived soluble radionuclides of interest during the repository postcontainment period (listed in order of decreasing activity at 1000 years) include ${ }^{99} \mathrm{Tc},{ }^{14} \mathrm{C},{ }^{135} \mathrm{Cs}$, and ${ }^{129} \mathrm{I}$.

Conceptually, it is generally agreed that the dissolution of soluble radionuclides from spent fuel can be divided into components that originate from three regions: 1) the fuel/cladding gap, which includes the spaces between fuel pellets and the open porosity and cracks within the pellets, 2) the grain boundaries of the fuel pellets, and 3) the $\mathrm{UO}_{2}$ matrix (Johnson et al. 1985; O'Connell and Drach 1986; Apted et al. 1987). Experimentally, it has been common to measure the inventories of radionuclides within the gap using short-term dissolution experiments. More recently, methods were developed for measuring the inventories of radionuclides within the grain boundaries and for measuring the dissolution rate of the $\mathrm{UO}_{2}$ matrix (Gray and Strachan 1991). The.latter methods allow unambiguous parametric studies of $\mathrm{UO}_{2}$ matrix dissolution rates without the simultaneous dissolution of radionuclides from the gap and grain-boundary regions.

A primary part of the work reported here included flow-through tests to investigate the effects of four parameters (temperature, $\mathrm{pH}, \mathrm{O}_{2}$ overpressure, and total carbonate/bicarbonate concentrations) on the dissolution kinetics of the spent fuel matrix phase. A statistically designed test matrix allowed a limited number of tests to cover the entire parametric space. A duplicate test matrix was conducted at LLNL with unirradiated $\mathrm{UO}_{2}$ (Steward and Gray 1994).

During the latter part of the FY 1991 to 1994 time period, the emphasis of the flow-through testing changed from the 4-parameter test matrix (because it was nearing completion) to one of testing spent fuel specimens that had been pre-oxidized in air. The incentive for this was that the potential

(a) Pacific Northwest National Laboratory is operated by Battelle Memorial Institute for the U.S. Department of Energy. 
repository site at Yucca Mountain, which is in the unsaturated zone above the water table, is relatively dry and in equilibrium with atmospheric air. If spent fuel were placed in this site, it would not be contacted by water during the first several hundred years after disposal while waste package tempera tures exceeded $95^{\circ} \mathrm{C}$, the boiling temperature of water at the repository elevation. However, if a waste container and fuel cladding both failed, the fuel could be contacted and oxidized by moist air at a rate and extent dependent upon the fuel temperature following the container and cladding failures. At temperatures below about $200^{\circ} \mathrm{C}$, the oxidation would probably be limited to the formation of $\mathrm{U}_{4} \mathrm{O}_{9+\mathrm{x}} \cdot{ }^{\text {(a) }}$ At higher temperatures, more extensive oxidation to produce $\mathrm{U}_{3} \mathrm{O}_{8}$ or even $\mathrm{UO}_{3} \bullet \mathrm{xH}_{2} \mathrm{O}$ could occur. Therefore, this testing was initiated to investigate the stability toward dissolution of each of these more highly oxidized phases of spent fuel.

In addition to the parametric test matrix and the tests with oxidized fuels, four types of supplemental tests were conducted with spent fuel specimens: 1) measurements of gap and grain-boundary inventories of ${ }^{137} \mathrm{Cs},{ }^{90} \mathrm{Sr}$, and ${ }^{99} \mathrm{Tc}$; 2) a flow-through test with fuel fragments to determine grainboundary dissolution rates; 3 ) flow-through testing with an archive specimen previously tested in the Series-3 semistatic tests (Wilson 1990b); and 4) measurement of the ${ }^{137}$ Cs dissolution rate in a solution with high $\mathrm{U}$ concentration. The rationale for the four types of supplemental tests follows.

The need for determination of gap and grain-boundary inventories is based on the expectation that both the gap and grain-boundary inventories would be rapidly dissolved if the container failed and the fuel were contacted by water in a repository. The quantities of radionuclides concentrated within the gap and grain boundaries that are potentially available for transport beyond the waste package are important source terms in any migration model.

Modification of the assumption regarding rapid dissolution of grain-boundary inventories is possible if a means of measuring grain-boundary dissolution rates were developed, which was the objective of the second type of supplemental test. The grain-boundary dissolution rate for ${ }^{137} \mathrm{Cs}$ was derived for one type of spent fuel (ATM-103) using the following method. The rate of dissolution of ${ }^{137} \mathrm{Cs}$ from the $\mathrm{UO}_{2}$ matrix of ATM-103 fuel grains was measured as part of the parametric test matrix described above, and it was shown to be congruent with the $U$ dissolution rate. The excess dissolution rate of ${ }^{137}$ Cs measured for ATM-103 spent fuel fragments, compared to that from the fuel grains, must have come from the grain boundaries. The difference corresponded to the grain-boundary dissolution rate.

Flow-through testing with an archive specimen from the previous semistatic testing program (Wilson 1990a and 1990b) provided information useful for estimating dissolution rates for the $\mathrm{UO}_{2}$ matrix phase in the semistatic tests. This enhances the value of the extensive radionuclide release database provided by the semistatic tests. Although near steady-state release rates were measured for ${ }^{137} \mathrm{Cs},{ }^{90} \mathrm{Sr}$, ${ }^{99} \mathrm{Tc}$, and ${ }^{129} \mathrm{I}$ after a few months in the semistatic tests, the portions of those releases originating from congruent dissolution of the $\mathrm{UO}_{2}$ fuel matrix phase was not known. It is likely that some preferential release originated from the grain boundaries. Therefore, it was not possible to estimate the dissolution rate of the $\mathrm{UO}_{2}$ matrix phase using results from the semistatic tests alone. However, by testing an archive fuel specimen from the Series- 3 test using the flow-through method, information was obtained that provided a means to estimate the dissolution rate of the $\mathrm{UO}_{2}$ matrix phase in the semistatic tests. This was done by measuring the fractional dissolution rates of $\mathrm{U},{ }^{137} \mathrm{Cs}$,

(a) LWR spent fuel oxidized in air at 110 to $200^{\circ} \mathrm{C}$ approaches a stoichiometry of $\sim \mathrm{UO}_{2.4}$, but has the cubic crystal structure of $\mathrm{U}_{4} \mathrm{O}_{9}$ (Einziger et al. 1992). 
${ }^{90} \mathrm{Sr}$, and ${ }^{99} \mathrm{Tc}$ from the archive specimen in the flow-through test (where all dissolved $\mathrm{U}$ remained in solution) and using those results to estimate the $\mathrm{UO}_{2}$ matrix dissolution rate that occurred during the semistatic test. A secondary purpose for the flow-through test with the Series-3 archive specimen was to determine if dissolution rates were similar to those measured in the semistatic test. If so, this would indicate that the contact mode between water and the spent fuel, static or flow-through, is relatively unimportant.

It is sometimes argued that the limited supply of water in a repository will saturate with $U$ thereby reducing, perhaps substantially, the subsequent rate of dissolution of the spent fuel, including the soluble elements within the fuel (Grambow et al. 1990). However, it is clear that ${ }^{137} \mathrm{Cs}$ and ${ }^{90} \mathrm{Sr}$, for example, continue to dissolve from spent fuel in static and semistatic tests (Wilson 1990a and 1990b; Forsyth and Werme 1992) despite the steady-state U concentrations in the test solutions. It cannot be determined from semistatic tests, however, whether the ${ }^{137} \mathrm{Cs}$ and ${ }^{90} \mathrm{Sr}$ dissolution rates were the same as they would have been if the solutions had not been saturated with $U$. Therefore, to determine whether the ${ }^{137} \mathrm{Cs}$ dissolution rate is affected by high $U$ concentrations, a flow-through test was conducted wherein ${ }^{137} \mathrm{Cs}$ dissolution rates were measured under conditions of both low and high $U$ concentration in the water flowing through the test column.

In addition to the supplemental tests with spent fuel, several supplemental tests with unirradiated uranium oxides $\left(\mathrm{UO}_{2}, \mathrm{U}_{3} \mathrm{O}_{7}\right.$, and $\left.\mathrm{U}_{3} \mathrm{O}_{8}\right)$ were also conducted. The original source of all three materials was unirradiated $\mathrm{UO}_{2}$ powder, which was prepared from sintered pellets at PNNL. A portion of the $\mathrm{UO}_{2}$ powder was shipped to LLNL so the same material could be tested by both laboratories. Different test apparatus designs were used for spent fuel at PNNL and unirradiated $\mathrm{UO}_{2}$ at LLNL, so tests with the same material at both laboratories were needed to identify any differences in results caused by different test apparatus and procedures.

Flow-through tests with unirradiated $\mathrm{U}_{3} \mathrm{O}_{7}$ were conducted for comparison with $\mathrm{UO}_{2}$ because of evidence that the oxidation/dissolution mechanism first involves oxidation of the $\mathrm{UO}_{2}$ surface to a stoichiometry of $\sim 2.33$ (Johnson and Shoesmith 1988). Therefore, it was assumed that $\mathrm{U}_{3} \mathrm{O}_{7}$ would dissolve faster than $\mathrm{UO}_{2}$ because the preliminary oxidation step had already occurred. Since U.S. light water reactor (LWR) fuel does not exhibit a $\mathrm{U}_{3} \mathrm{O}_{7}$ phase (Einziger et al. 1992), it was decided to use unirradiated material. It was a logical extension, therefore, to extend the tests to unirradiated $\mathrm{U}_{3} \mathrm{O}_{8}$ for comparison to unirradiated $\mathrm{UO}_{2}$ and $\mathrm{U}_{3} \mathrm{O}_{7}$, and for comparison with $\mathrm{U}_{3} \mathrm{O}_{8}$ spent fuel.

Another type of test with unirradiated $\mathrm{UO}_{2}$ was conducted at PNNL to develop a method for correlation of dissolution rates and zeta potential in tests where dissolution rate changed in response to changes in solution composition. Previous dissolution tests with unirradiated $\mathrm{UO}_{2}$ (Wilson and Gray 1990a) showed that dissolution rates in dilute $\mathrm{NaHCO}_{3}$ solution were greatly depressed when $\mathrm{Si}$ was added as dissolved silicic acid. Dissolved $\mathrm{Ca}$ also depressed the dissolution rate, but appeared to have less effect than $\mathrm{Si}$. The $\mathrm{NaHCO}_{3}, \mathrm{Si}$, and $\mathrm{Ca}$ concentrations used were approximately equal to those contained in J-13 well water. The mechanism by which $\mathrm{Si}$ and $\mathrm{Ca}$ affect dissolution rates may involve adsorption of $\mathrm{Ca}$ and $\mathrm{Si}$ species at the $\mathrm{UO}_{2}$ surface. Such adsorption may change the zeta potential of the $\mathrm{UO}_{2}$ surface and could potentially be monitored during a flow-through dissolution test by measurement of the streaming potential. A brief description of zeta and streaming potential follows.

At the solid-liquid interface; a "double layer" exists consisting of the surface potential determining layer at the solid surface and an adjacent bound layer of adsorbed water and charged electrolyte species called the-Stern layer. Counter ions with charges opposite to that presented by the double layer 
preferentially concentrate in the "diffuse layer" in the liquid adjacent to the double layer, effectively cancelling the surface charge. When the diffuse layer is sheared as a result of laminar flow of the liquid parallel to the surface, a charge separation occurs giving rise to the "streaming potential." The zeta potential is the potential at the first shear plane in the liquid phase adjacent to the bound surface layer. For laminar flow through a cylindrical capillary, streaming potential is proportional to the zeta potential and to the pressure drop across the capillary, and is inversely proportional to the electrolyte conductivity and viscosity. This relationship is expressed by the Helmholtz-Smoluchowski Equation (1.1):

$$
\mathrm{E}_{\mathrm{S}}=\frac{\mathrm{PDZ}}{4 \pi \eta \lambda}
$$

where $E_{\mathrm{S}}=$ streaming potential

$P=$ pressure drop

$\mathrm{D}=$ dielectric constant of liquid

$\mathrm{Z}=$ zeta potential

$\eta \quad=$ viscosity of liquid

$\lambda=$ conductivity of liquid

The same proportional relationships are generally expected to apply to laminar flow through a packed column of particles (Kruyt 1952).

This report contains four sections. The experimental description is presented in Section 2 , which is divided into subsections that describe 1) the test materials used in the various tests, 2) the flow-through test equipment, and 3) the conduct of the respective tests. Section 3 presents the results of the different tests and is also divided into appropriate subsections. Section 4 provides a review and discussion of the data presented in Section 3 and ends with the authors' opinions regarding spent fuel dissolution issues that remain to be resolved. 


\subsection{Experimental Description}

This section describes 1) the preparation of test materials, 2) flow-through test equipment, and 3) several types of dissolution experiments that were performed to satisfy the different test objectives.

\subsection{Test Materials}

This section is divided into subsections that describe the various types of spent fuel test specimens, unirradiated uranium oxide test specimens, and the surface area measurements performed for each type of test specimen.

\subsubsection{Spent Fuel}

Table 2.1 lists some of the characteristics of the spent fuel tested in this work. Descriptions for most of the individual specimen preparations are given for the different tests in the following subsections. However, the test specimens used for grain-boundary inventory measurements are described in Section 2.3.3 along with the test description because the specimen preparations were an integral part of the test. Surface area measurements for the different test specimens are described in Section 2.1.3.

\section{$\mathrm{UO}_{2}$ Matrix Phase Dissolution Kinetics}

The spent fuel specimens used in these tests were prepared from ATM-103 fuel (Table 2.1). The fuel was discharged from the cladding and crushed until most of it passed through a screen with $30-\mu \mathrm{m}$ openings. Since the grain size of this fuel ranged from 14 to $22 \mu \mathrm{m}$, screening eliminated most of the particles larger than a single grain. The very fine subgrain particles produced by the crushing were removed by washing, first with $2 \times 10^{-4} \underline{\mathrm{M} \mathrm{Na}} \mathrm{CO}_{3}$ solution $(\mathrm{pH} \sim 10)$ and then with deionized water (DIW). To wash the fuel, the screened fuel grains were placed in a $100-\mathrm{mL}$ beaker along with 30 to $50 \mathrm{~mL}$ of the $\mathrm{Na}_{2} \mathrm{CO}_{3}$ solution. The solution was agitated ultrasonically for a minute or two followed by vigorous stirring with a magnetic stir bar. After allowing the coarser particles to settle for a few seconds, the fine particles, which remained in suspension, were decanted along with the solution. This was repeated three or four times followed by three repeats using DIW to rinse off the $\mathrm{Na}_{2} \mathrm{CO}_{3}$. The fuel grains were then allowed to air dry at ambient hot-cell temperature. Figure A.1 is a scanning electron microscope (SEM) photograph of the screened and washed fuel grains. It shows that the particles consisted predominantly of single fuel grains with only a few multigrain or fine subgrain particles remaining.

In addition to the removal of fines, the washing procedure removed much of the ${ }^{137} \mathrm{Cs}$ and other soluble radionuclides associated with the gap and grain-boundaries. This was of no consequence since the purpose in testing these fuel grains was to measure the dissolution kinetics of the $\mathrm{UO}_{2}$ matrix and the radionuclides contained in the $\mathrm{UO}_{2}$ matrix phase, independent of dissolution from the gap and grain-boundary regions. 
Table 2.1. Characteristics of Spent Fuel and Test Identifications

\begin{tabular}{|c|c|c|c|c|c|c|c|c|c|c|c|}
\hline \multirow[b]{2}{*}{$\begin{array}{l}\text { Reactor } \\
\text { Type }\end{array}$} & \multirow[b]{2}{*}{ Fuel } & \multirow[b]{2}{*}{ Rod } & \multirow[b]{2}{*}{$\begin{array}{l}\text { Peak Burnup } \\
\text { (MWd/kgM) }\end{array}$} & \multirow[b]{2}{*}{$\begin{array}{c}\text { Grain } \\
\text { Size }^{(\mathrm{b})} \\
(\mu \mathrm{m})\end{array}$} & \multirow[b]{2}{*}{$\begin{array}{c}\mathrm{FGR}^{(\mathrm{c})} \\
(\%)\end{array}$} & \multicolumn{4}{|c|}{ Inventories ${ }^{(a)}$} & \multirow[b]{2}{*}{ Test } & \multirow[b]{2}{*}{ Reference } \\
\hline & & & & & & $\begin{array}{c}\mathrm{U} \\
\text { (fraction) }\end{array}$ & $\begin{array}{c}{ }^{137} \mathrm{Cs} \\
(\mathrm{mCi} / \mathrm{g})\end{array}$ & $\begin{array}{c}{ }^{99} \mathrm{Tc} \\
(\mathrm{mCi} / \mathrm{g})\end{array}$ & $\begin{array}{c}{ }^{90} \mathrm{Sr} \\
(\mathrm{mCi} / \mathrm{g})\end{array}$ & & \\
\hline PWR & ATM-101 & Several & 32 & $6-10$ & 0.21 & 0.845 & 57.5 & 0.0105 & 37.5 & $(\mathrm{~d}, \mathrm{e})$ & (i) \\
\hline PWR & ATM-103 & MLA-098 & 30 & $14-22$ & 0.25 & 0.842 & 72.1 & 0.0114 & 47.2 & $(\mathrm{~d}, \mathrm{f}, \mathrm{g})$ & (j) \\
\hline PWR & ATM-104 & MKP-109 & 44 & $9-14$ & 1.1 & 0.831 & 97.7 & 0.0146 & 61.3 & (d) & (k) \\
\hline BWR & ATM-105 & ADD-2974 & 31 & $11-15$ & 0.59 & 0.845 & 65.5 & 0.0110 & 44.9 & $(\mathrm{~d}, \mathrm{~h})$ & (l) \\
\hline BWR & ATM-105 & ADD-2966 & 34 & $15-28$ & 7.9 & 0.842 & 68.8 & 0.0114 & 46.5 & (d) & (l) \\
\hline PWR & ATM-106 & NBD-095 & 43 & NM & 7.4 & 0.832 & 90.7 & 0.0140 & 52.8 & (d) & (m) \\
\hline PWR & ATM-106 & NBD-107 & 46 & $7-16$ & 11 & 0.829 & 98.1 & 0.0149 & 55.7 & (d) & (m) \\
\hline PWR & ATM-106 & NBD-131 & 50 & NM & 18 & 0.825 & 105.6 & 0.0157 & 58.6 & $(\mathrm{~d}, \mathrm{~h})$ & (n) \\
\hline
\end{tabular}

(a) Radionuclide inventories of the specimens used in these experiments were taken from ORIGEN2 calculations listed in the cited references. The results of analytical measurements of radionuclide inventories are also given in the cited references. Because the ORIGEN2 values and analytical measurements were generally in good agreement, the ORIGEN2 inventories were used throughout for the sake of consistency. The inventories listed for ${ }^{137} \mathrm{Cs}$ and ${ }^{90} \mathrm{Sr}$ have been adjusted for radioactive decay to October 1990 . The inventories of ${ }^{137} \mathrm{Cs}$ and ${ }^{90} \mathrm{Sr}$ used in the fractional dissolution calculations were adjusted for radioactive decay to the time of the particular analysis involved.

(b) $\mathrm{NM}=$ not measured.

(i) Barner 1985

(c) Fission Gas Release.

(j) Guenther et al. 1988a.

(d) Gap and Grain Boundary Inventories.

(k) Guenther et al. 1991a.

(e) Series-3 Archive.

(l) Guenther et al. 1991b.

(f) $\mathrm{UO}_{2}$ Matrix Dissolution.

(m) Guenther et al. 1988b.

(g) Grain Boundary Dissolution Rate.

(h) Oxidized Spent Fuel Test.

(n) Guenther, R.J. Unpublished data obtained by the Materials Characterization Center (MCC) at PNNL. 
The above procedure yielded $3.6 \mathrm{~g}$ of fuel grains, which were placed in a glass vial for use in the flow-through dissolution tests. This provided enough fuel grains to complete the test matrix shown in Table 3.1 in Section 3.1. since each flow-through test utilized $\sim 0.2 \mathrm{~g}$ of fuel grains.

\section{ATM-103 Fragment Specimen}

This ATM-103 specimen was a portion of the same material used to prepare the ATM-103 fuel grain specimen described in the preceding section. The fragment specimen was used for the grainboundary dissolution rate experiment described in Section 2.3.3. It consisted of fuel fragments in essentially the same condition as they were discharged from the cladding. Only the biggest fragments were broken into small enough pieces to fit into the test column. The column was completely filled with $7.3 \mathrm{~g}$ of these fragments, which were $\sim 0.5$ to $4 \mathrm{~mm}$ in size.

\section{Series-3 Archive Specimen}

The Series-3 archive fuel specimen, C5C-I, had been stored under air atmosphere in a glass vial with a plastic screw cap for 4 years following termination of the Series-3 tests (Wilson 1990b). During that time, the polymer seal in the cap degraded and integrity of the seal is assumed to have been lost. The only significance of the failed seal is that an unlimited supply of air would have been available to the specimen. The fuel originally came from the H. B. Robinson reactor and was designated ATM-101 (Barner 1985). The original specimen consisted of untreated fragments in the same condition as they were discharged from the cladding.

Following the 4 years of archive storage, the Series-3 fuel specimen (C5C-I) was spread out in a pan and stirred to provide a uniform distribution of fuel fragment sizes across the pan surface. Portions of the fragments were knifed to one side and loaded into a flow-through column to provide a specimen that was representative of the original Series-3 specimen. The test column was completely filled using $7.6 \mathrm{~g}$ of the fuel fragments.

\section{Oxidized Spent Fuel}

These spent fuel specimens were prepared from a single batch each of ATM-105 and ATM-106 fuels (Table 2.1). That is, a few centimeters of fuel from a single rod of each fuel was discharged from the cladding. Four types of test specimens, oxidized and unoxidized "particles" and "grains" were prepared from each batch of discharged fuel as described in the following paragraphs.

The "particle" specimens were prepared by crushing and screening $(-10 /+24$ Tyler mesh, 700 to $1700 \mu \mathrm{m}$ ) spent fuel fragments and oxidizing a portion of the particles at $175^{\circ} \mathrm{C}$ to $\sim \mathrm{UO}_{2.4}$ as determined by weight gain measurements (Einziger et al. 1992). Ceramographic and x-ray diffraction analyses showed that the material was $\mathrm{U}_{4} \mathrm{O}_{9+\mathrm{x}}$ containing small $\mathrm{UO}_{2}$ remnants $(-1$ to 5 vol\%) at the grain centers, and no detectable $\mathrm{U}_{3} \mathrm{O}_{8}$ or other oxidation products.

The "grain" specimens were prepared by crushing portions of both the oxidized and unoxidized particles, causing them to fracture predominantly along grain boundaries. The crushed fuel was screened (screen openings were 20 to $30 \mu \mathrm{m}$, depending on the grain size of the fuel being screened) to eliminate coarse multi-grain particles. 
All four of the specimen materials (oxidized and unoxidized particles and grains) were washed to remove the fines and thus reduce uncertainties in the measured surface areas. Throughout this report, "particles" refers to specimens consisting of hundreds $(\sim 1 \mathrm{~g})$ of $\sim 700$ - to $1700-\mu \mathrm{m}$ particles, each particle containing several thousand grains. "Grains" refers to specimens consisting of many thousands $(\sim 0.1 \mathrm{~g})$ of separated grains from 7 to $20 \mu \mathrm{m}$ in size.

One test specimen consisted of ATM-106 spent fuel oxidized to $\mathrm{U}_{3} \mathrm{O}_{8}$. It was prepared by heating previously unoxidized particles $\sim 1 \mathrm{~mm}$ in size at $430^{\circ} \mathrm{C}$ in air for 18 hours. Prior to oxidation, the particles had been washed to remove fines. After oxidation, a portion of the particles were pulverized for X-ray powder diffraction (XRD) measurements, which confirmed that the specimen was essentially $100 \% \mathrm{U}_{3} \mathrm{O}_{8}$ with no extra lines observed in the XRD pattern. Figure A.2 is a SEM photograph of the as-oxidized $\mathrm{U}_{3} \mathrm{O}_{8}$ test specimen. Note the extensive cracking and associated increase in surface area that resulted from the decreased density caused by the oxidation.

\subsubsection{Unirradiated Uranium Oxides}

The following subsections describe the preparation of the unirradiated $\mathrm{UO}_{2}, \mathrm{U}_{3} \mathrm{O}_{7}$, and $\mathrm{U}_{3} \mathrm{O}_{8}$ test specimens. Surface area measurements on each of these specimens are described in Section 2.1.3.

$\mathrm{UO}_{2}$

The unirradiated, depleted $\left(0.21 \%{ }^{235} \mathrm{U}\right) \mathrm{UO}_{2}$ used in this work came from pellet lot $388-2$ produced by Exxon Nuclear Company, Inc. of Richland, Washington, in 1985. The pellets were procured by Westinghouse Hanford Company for use in blanket assemblies for the Fast Flux Test Facility (FFTF) reactor, and a portion of those was subsequently transferred to PNNL. Finally, a portion of the pellets that was transferred to PNNL was consigned to the Geological Repository Support Program at PNNL.

Powdered $\mathrm{UO}_{2}$ specimens were prepared by crushing the pellets and grinding the resulting pellet fragments with mortar and pestle until the powder passed through a 140-mesh screen. Those particles retained on a 325-mesh screen were then washed as described below to eliminate the very fine powder that adhered to the coarser particles. Both screens were U.S. Standard Series; thus the particles, after elimination of fines, were in the size range $44 \mu \mathrm{m}$ to $105 \mu \mathrm{m}$.

After screening, the $-140 /+325$ mesh fraction was placed in a beaker with about $100 \mathrm{~mL}$ of $2 \times 10^{-4} \underline{\mathrm{M} \mathrm{Na}} \mathrm{CO}_{3}(\mathrm{pH} \sim 10)$. The powder and solution were agitated ultrasonically for about I minute and then stirred vigorously with a magnetic stir bar. After allowing the particles to settle for a few seconds, the water was rapidly decanted along with the fine particles that remained in suspension. This was repeated 8 to 10 times, and then the particles were washed (with vigorous stirring, no ultrasonic agitation) 3 times with DIW to rinse off the $\mathrm{Na}_{2} \mathrm{CO}_{3}$. After decanting the water the last time, the washed particles were allowed to dry at room temperature overnight. This procedure was essentially the same as that used to wash the spent fuel grain specimens (Section 2.1.1).

The washed powder was heat treated at $950^{\circ} \mathrm{C}$ overnight in a flowing $\mathrm{Ar} / 8 \% \mathrm{H}_{2}$ atmosphere equilibrated with $0^{\circ} \mathrm{C}$ water vapor to adjust the oxygen-to-metal $(\mathrm{O} / \mathrm{M})$ ratio to 2.000 , and then cooled in dry He. A SEM photograph of the screened and washed powder is shown in Figure A.3. The particles appear clean and free of adhering fines following the cleaning procedure. 
$\mathrm{U}_{3} \mathrm{O}_{7}$

A portion of the $\mathrm{UO}_{2}$ described above was subsequently oxidized in air at $225^{\circ} \mathrm{C}$ for $94 \mathrm{~h}$, resulting in an average $\mathrm{O} / \mathrm{M}$ ratio of 2.047 as determined by weight-gain measurements. $\mathrm{X}$-ray diffraction (XRD) measurements of the as-prepared particles indicated the presence of $\mathrm{U}_{3} \mathrm{O}_{7}$ and no detectable $\mathrm{U}_{3} \mathrm{O}_{8}$. In this case, a low-symmetry $\mathrm{U}_{3} \mathrm{O}_{7}$ variant similar to $\delta-\mathrm{U}_{3} \mathrm{O}_{7}\left(\mathrm{U}_{8} \mathrm{O}_{19}\right)$ (Westrum and Grønvold 1962) was produced instead of the more common $\beta-\mathrm{U}_{3} \mathrm{O}_{7}$. A SEM photograph in Figure A.4 shows the $\mathrm{U}_{3} \mathrm{O}_{7}$ phase was only a surface layer around the periphery of the particles and indicates that the thickness of the oxidized layer was $\sim 1 \mu \mathrm{m}$.

Attempts to convert a larger portion of each $\mathrm{UO}_{2}$ particle to $\mathrm{U}_{3} \mathrm{O}_{7}$, either by raising the temperature or by increasing the time at temperature, always resulted in the formation of some $\mathrm{U}_{3} \mathrm{O}_{8}$ on the outer surfaces as determined by XRD measurements. To avoid this, the particles described above were accepted for testing. For relatively short-term dissolution rate tests, oxidizing the particle surface to $\mathrm{U}_{3} \mathrm{O}_{7}$ is just as good as oxidizing the entire particle, since the test solution contacts only (or at least predominantly) the outside surface of the particle.

\section{$\mathrm{U}_{3} \mathrm{O}_{8}$}

A second portion of the $\mathrm{UO}_{2}$ powder described above was oxidized in air at $340^{\circ} \mathrm{C}$ for $18 \mathrm{~h}$. The resulting $\mathrm{O} / \mathrm{M}$ ratio averaged 2.68 (based on weight gain measurements), which compares favorably with the stoichiometric $\mathrm{U}_{3} \mathrm{O}_{8}$ ratio of 2.67. X-ray diffraction analysis, which was performed on a pulverized portion of the specimen, indicated that the resulting material was 100 per cent $\mathrm{U}_{3} \mathrm{O}_{8}$ to within the detection limits of the method $(\sim 1 \%)$. Figure A.5 is a SEM photograph of the as-oxidized material. Note the more extensive cracking than in the spent fuel $\mathrm{U}_{3} \mathrm{O}_{8}$ (Figure A.2).

\subsubsection{Surface Area Measurements}

The various types of specimens tested in this work are listed in Table 2.2 together with their measured surface areas and the method used to measure the surface areas. Two different basic methods were used, the Brunauer, Emmett, and Teller (1938) (BET) method and a particle-size distribution (PSD) method developed for use in this work. Descriptions of the methods and discussions of their relative merits for different types of test specimens are given in the following paragraphs.

The BET method is well recognized and generally accepted for measuring the surface areas of specimens consisting of small particles. However, at the beginning of this work, no one had adapted the BET method for use in measuring the surface areas of spent fuel specimens. This was partly due to the perceived difficulty of installing and using the BET apparatus in a hot-cell, which was required for handling spent fuel specimens. It was also thought by some researchers that the radioactive decay heat of spent fuel specimens would raise the specimen temperature above that of the liquid $\mathrm{N}_{2}$ bath surrounding the specimen thereby reducing the amount of measuring gas that would be adsorbed. This fear would seem to be unfounded when it is considered that the radioactive decay heat amounts to only about 1 milliwatt per gram of fuel and that test specimen sizes can be considerably less than $1 \mathrm{~g}$. To further discount this concern, $\sim 1 \mathrm{~g}$ of spent fuel powder was placed in a glass test tube that was immersed in liquid $\mathrm{N}_{2}$. No measurable temperature difference $\left(<0.5^{\circ} \mathrm{C}\right)$ was observed when a ther-mocouple was placed in the spent fuel powder and subsequently immersed directly in the liquid N2 bath. 
Table 2.2. Test Specimen Characteristics

\begin{tabular}{|c|c|c|c|c|c|}
\hline \multirow[b]{2}{*}{ Material } & \multirow[b]{2}{*}{ Type } & \multirow{2}{*}{$\begin{array}{c}\text { Oxidation } \\
\text { State }\end{array}$} & \multirow{2}{*}{$\begin{array}{c}\text { Specimen } \\
\text { Size }(\mathrm{g})\end{array}$} & \multicolumn{2}{|c|}{ Surface Area $\left(\mathrm{cm}^{2} / \mathrm{g}\right)^{(\mathrm{a})}$} \\
\hline & & & & BET & PSD \\
\hline ATM 103 & Grains & $\mathrm{UO}_{2}$ & -0.2 & & 860 \\
\hline ATM-103 & Fragments & $\mathrm{UO}_{2}^{2}$ & 7.3 & & 6.4 \\
\hline $\begin{array}{l}\text { Series-3 } \\
\text { Archive }\end{array}$ & Fragments & $\mathrm{UO}_{2}$ & 7.6 & & 7.2 \\
\hline ATM-105 & Grains & $\begin{array}{l}\mathrm{UO}_{2} \\
\mathrm{U}_{4} \mathrm{O}_{9+\mathrm{x}}\end{array}$ & $\begin{array}{l}0.15 \\
0.15\end{array}$ & & $\begin{array}{l}980 \\
910\end{array}$ \\
\hline & Particles & $\mathrm{UO}_{2}$ & $\begin{array}{l}1.3 \\
1.1 \\
0.064\end{array}$ & 2.770 & $\begin{array}{l}17 \\
15\end{array}$ \\
\hline ATM-106 & Grains & $\begin{array}{l}\mathrm{UO}_{4} \mathrm{O}_{9+\mathrm{x}}\end{array}$ & $\begin{array}{l}0.064 \\
0.22\end{array}$ & 1,150 & 860 \\
\hline & Particles & $\begin{array}{l}\mathrm{UO}_{2} \\
\mathrm{U}_{4} \mathrm{O}_{9+\mathrm{x}}\end{array}$ & $\begin{array}{l}1.2 \\
0.94\end{array}$ & $\begin{array}{l}120 \\
450\end{array}$ & $\begin{array}{l}19 \\
22\end{array}$ \\
\hline Unirrad. & $\begin{array}{l}\text { Powder } \\
\text { Powder }\end{array}$ & $\begin{array}{l}\mathrm{U}_{3} \mathrm{O}_{8} \\
\mathrm{UO}_{2} \\
\mathrm{U}_{3} \mathrm{O}_{7} \\
\mathrm{U}_{3} \mathrm{O}_{8}\end{array}$ & 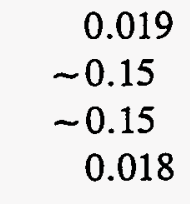 & $\begin{array}{c}4,900 \\
267^{(b)} \\
267^{(d)} \\
12,200\end{array}$ & $264^{(c)}$ \\
\hline
\end{tabular}

(a) Where values are given for both the BET and PSD methods, the BET result was used for normalizing the dissolution data except for the ATM-106 particles where the PSD results were used.

BET - Measured by the BET method.

PSD - Calculated from particle-size distribution measurements and then multiplied by a surface roughness factor of three.

(b) BET values of $267 \mathrm{~cm}^{2} / \mathrm{g}$ and 243 to $258 \mathrm{~cm}^{2} / \mathrm{g}$ were measured at LLNL and PNNL, respectively. The LLNL value was measured first and was the value used throughout this work.

(c) The surface area calculated from the particle-size distribution measurement was $88 \mathrm{~cm}^{2} / \mathrm{g}$. Since this was almost exactly a factor of three less than the BET measurement, a surface roughness factor of three was adopted for adjusting all of the PSD measurements.

(d) Assumed to be the same as the $\mathrm{UO}_{2}$ because the light oxidation to produce the $\mathrm{U}_{3} \mathrm{O}_{7}$ surface layer was expected to have a negligible effect on the surface area.

A much more intractable problem with using the BET method to measure the surface areas of spent fuel specimens that are used for dissolution tests is that the method overestimates the effective surface areas of multi-grain specimens. This happens because some of the internal grain boundary surfaces measured by the BET method are inaccessible to water. This situation is illustrated by the BET and 
PSD data shown in Table 2.2 for ATM-106 grains and particles: The PSD method described below gave a surface area for oxidized ATM-106 grains $\left(\mathrm{U}_{4} \mathrm{O}_{9+\mathrm{x}}\right)$ in reasonably good agreement with the BET method because the grain specimens contained few small cracks or pores that would be inaccessible to water. However, the BET surface area of the ATM-106 particle specimen was much larger than the PSD value because the measuring gas $(\mathrm{Kr})$ was able to penetrate into the internal grain boundaries. Therefore, even after the BET apparatus was installed in the hot-cell, the BET results for particle specimens, where measured, were not used to normalize the dissolution data. Additional aspects of the surface areas measured by the two methods are discussed in Section 4.1.6.

Particle-size distribution (PSD) measurements, from which surface areas were calculated, were made in two ways. For specimens consisting of particles smaller than $150 \mu \mathrm{m}$, which included spent fuel grains and $\mathrm{U}_{3} \mathrm{O}_{8}$ powder plus all the unirradiated uranium oxide powders, measurements were made by a Brinkman Model 2010 particle size analyzer. This instrument measures the fraction of particles found within size increments that are $0.5 \mu \mathrm{m}$ in width and range from $0.5 \mu \mathrm{m}$ to $150 \mu \mathrm{m}$. Specific surface areas, assuming spherical particles, were calculated for each of these increments and multiplied by the fraction of particles within each increment. Summing these data over the entire size range resulted in specific surface areas for the specimens as a whole.

For particles larger than $150 \mu \mathrm{m}$ (referred to as fragments), PSD measurements were made by weighing a representative number $(\sim 50)$ of individual fragments. Surface areas of the individual fragments were calculated from the weight and density $\left(10.1 \mathrm{~g} / \mathrm{cm}^{3}\right)$ assuming a reasonable geometry such as cubical, ${ }^{(a)}$ and averaging over the total number of fragments.

The surface area calculated from the PSD measurement made on the unirradiated $\mathrm{UO}_{2}$ powder specimen was $88 \mathrm{~cm}^{2} / \mathrm{g}$ (Table 2.2). This was almost exactly three times less than the BET measurement. In contrast to BET measurements on spent fuel particle specimens where the $\mathrm{Kr}$ measuring gas can penetrate the grain boundaries, the grain boundaries of the unirradiated $\mathrm{UO}_{2}$ specimens appear to be tight enough to exclude the Kr. Therefore, the difference in the BET and PSD measurements on the $\mathrm{UO}_{2}$ can be attributed entirely to the fact that the particles were irregular in shape rather than spherical, as was assumed in the calculation, and that the particle surfaces were rather rough. This seemingly reasonable surface roughness factor of three was subsequently chosen for application to all of the surface areas measured by the PSD method..

Wilson (1990b) also used a PSD method to estimate the geometric surface area of the C5C-I Series 3 specimen. He weighed a representative number of individual fuel fragments and calculated their surface areas assuming a wedge shape and a density of $10.1 \mathrm{~g} / \mathrm{cm}^{3}$. Depending on the shape assumed for the wedge, specific surface areas between 2.3 and $2.6 \mathrm{~cm}^{2} / \mathrm{g}$ were calculated. The specific surface area of the specimen used in the current flow-through test was taken to be $7.2 \mathrm{~cm}^{2} / \mathrm{g}$, which was obtained by multiplying a geometric surface area of $2.4 \mathrm{~cm}^{2} / \mathrm{g}$ (approximately mid-way between the values cited above) by a surface roughness factor of three.

(a) The particular geometry assumed is relatively unimportant for these calculations where surface area uncertainties of $\pm 50 \%$ are considered acceptable. For example, the surface area of a cube is only $26 \%$ less than that of a $4 \times 4 \times 1$ parallelpiped or $24 \%$ larger than that of a sphere, all of the same mass. 


\subsection{Flow-Through Equipment}

The flow-through apparatus used for both unirradiated $\mathrm{UO}_{2}$ and spent fuel testing is shown schematically in Figure A.6. The pumps were Milton Roy metering pumps, which are reciprocating plunger, positive displacement pumps. They are capable of generating pulsed-flow average flow

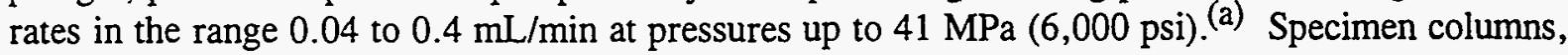
$6.4 \mathrm{~mm}$ ID $\times 51 \mathrm{~mm}$ long, were made of stainless steel and were capped at both ends by stainless steel

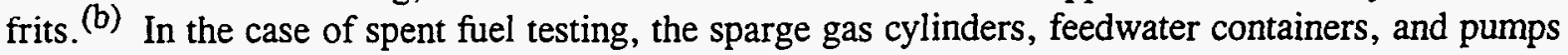
were located outside the hot-cell and the specimen columns and sample collection vials were located inside the hot-cell. Stainless steel tubing $(1.6 \mathrm{~mm}$ OD) connected the pumps to the columns, passing through the hot-cell wall for the spent fuel tests, and also extended from the columns to the sample collection vials. Tygon tubing was used between the feedwater containers and pumps for tests conducted at atmospheric $\mathrm{O}_{2}$ overpressure. For tests conducted at lower $\mathrm{O}_{2}$ overpressure, stainless steel tubing was used between the feedwater containers and pumps. Copper or stainless steel tubing extended from the gas cylinders to the feedwater containers.

\subsection{Dissolution Tests}

The experimental description of the dissolution tests is divided into subsections that discuss 1) the flow-through test matrix conducted with spent fuel grains to measure dissolution kinetics of the $\mathrm{UO}_{2}$ matrix phase; 2) flow-through tests with oxidized spent fuel; 3 ) four types of supplementary spent fuel tests; and 4) four sets of flow-through tests with unirradiated uranium oxides.

In addition to these tests, one additional flow-through test with unirradiated $\mathrm{UO}_{2}$ was performed by each of three laboratories (PNNL, LLNL, and AECL) using a common saline test solution. The results of those tests have been reported (Gray et al. 1994) and are not described here.

\subsubsection{Dissolution Kinetics of Spent Fuel $\mathrm{UO}_{2}$ Matrix}

The test specimens used in these experiments are described in Section 2.1, and the test conditions for the experiments are listed in Table 3.1 in Section 3.1. Several of the spent fuel specimens were used for more than one test as illustrated in Table 2.3. For example, in Table 2.3, Specimen No. 2 was first used in Test No. 2 and then in Test No. 6 before it was discarded.

The flow-through test equipment is described in Section 2.2, and the compositions of the solutions pumped through the columns are defined by Table 3.1 (Section 3.1). It was found during early testing that the solutions were unstable with regard to $\mathrm{pH}$ because of exchange of $\mathrm{CO}_{2}$ with the atmosphere. Therefore, to provide the appropriate $\mathrm{CO}_{2}$ partial pressure, the solutions in the feedwater containers were slowly and continuously sparged with nitrogen/oxygen mixtures (the $\mathrm{O}_{2}$ content is defined by the

(a) Generally the back pressure was far less than $41 \mathrm{MPa}$ since the primary resistance to flow was friction in the tubing and the stainless steel frits at the ends of the column.

(b) Openings in the frits were $0.5 \mu \mathrm{m}$ with fuel grain, $\mathrm{U}_{3} \mathrm{O}_{8}$ spent fuel, and unirradiated uranium oxide specimens; $2 \mu \mathrm{m}$ with spent fuel fragment and particle specimens. 
Table 2.3. Record of Specimens used in Tests Listed in Table 3.1 (Section 3.1)

Specimen

No.

Test Numbers

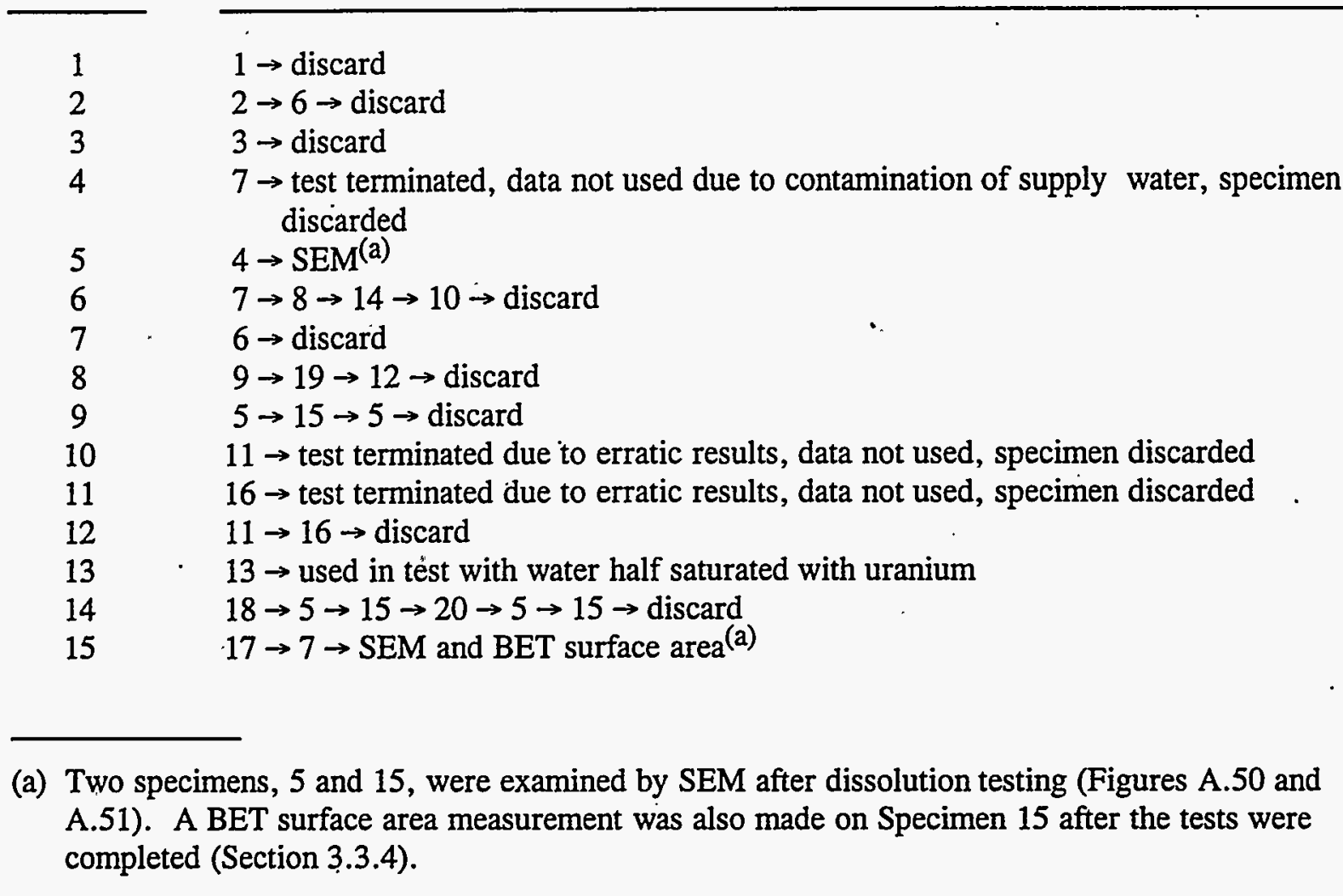

fifth column in Table 3.1) containing small amounts of $\mathrm{CO}_{2}$ gas (the concentration of $\mathrm{CO}_{2}$ is defined by the seventh column in Table 3.1 ) to stabilize the $\mathrm{pH}$.

A weighed amount of test specimen (typically $\sim 200 \mathrm{mg}$ ) was placed in each column. This amount of test specimen was chosen so that $U$ concentrations in the column effluent would be well below the solubility limit yet high enough to be easily measured. The amount of test specimen was small compared to the column volume, and it was found that best results were obtained when the water flow was downward through the column. Prior to connecting the tubing from the pump to the column, the pump was run for sufficient time to purge all air from the system. Then the tubing was connected to the column and water was pumped through the column in the upward direction for sufficient time to purge all air from the column. The column was then turned, without disconnecting the inlet and outlet tubing, so that the water traveled in the downward direction. After that, the system was expected to remain relatively free of air bubbles, but any small amount of air that passed through the pump and tubing should have been trapped in the upper part of the column and never contact the test specimen. 
There was some concern that dissolved gases $\left(\mathrm{O}_{2}\right.$ and $\left.\mathrm{CO}_{2}\right)$ in the test solutions might evolve from solution in the elevated temperature tests thereby lowering the concentrations below their nominal values. In addition, if this were to happen, gases would build up in the upper part of the test column (under conditions of downward flow) eventually filling the entire column. If that happened, the test specimens would not be completely submerged as was intended. Instead, the test specimen would experience a dripping flow situation.

To evaluate this possibility, some of the test columns were carefully opened at the end of a given test, and the approximate amount of water remaining in the column was determined. In all cases, at least $6 \mathrm{~mm}$ of water remained above the top of the test specimen. This demonstrated that the test column constituted a closed system and, as a result, the gas concentrations in water leaving the column must have equalled the concentrations in the incoming water. In other words, the fact that water remained in the column above the top of the test specimens proves that the gas concentrations were equal to the nominal values listed in Table 3.1 (Section 3.1).

Water was pumped through the columns at flow rates in the range 0.04 to $0.4 \mathrm{~mL} / \mathrm{min}$. Most of the column effluent was allowed to drain into a waste system. Periodically (typically two to five times per week) a few milliliters of effluent was collected in a sample vial, which contained a small amount of nitric acid ${ }^{(a)}$ to ensure that $U$ and other slightly soluble elements remained in solution rather than precipitating or depositing on the walls of the vial.

\subsubsection{Tests with Oxidized Spent Fuel}

Both oxidized and unoxidized portions of the spent fuel specimens described in Section 2.1 were tested in the flow-through columns described in Section 2.2. Table 2.2 (Section 2.3.1) lists the amount of test specimen used in each case. The amounts varied approximately inversely with surface area so that the $U$ concentrations in the column effluents were in the same range for all the tests. The test conditions are given in Section 3.2 along with a summary of results.

\subsubsection{Supplemental Spent Fuel Tests}

Supplemental spent fuel tests are divided into those designed to 1) measure gap and grain-boundary inventories, 2) determine the dissolution rates of spent fuel grain boundaries, 3) determine the dissolution rate of an archive specimen from an earlier semistatic test, and 4) measure the effect of using water with high $U$ concentrations on the dissolution rate of ${ }^{137} \mathrm{Cs}$ from spent fuel. The first type of test used a semistatic dissolution testing procedure with frequent changes of leachant. The last three tests were performed using the same type of flow-through dissolution experiments used for the

(a) Nitric acid was used only in the spent fuel tests. Repeated checking demonstrated that nitric acid was required in the spent fuel tests but not in tests with unirradiated uranium oxides. The difference was apparently due to the use of glass sample collection vials in the spent fuel tests and polyethylene vials in the tests with unirradiated uranium oxides. 
dissolution kinetics tests described in Section 2.3.1 (see Section 2.2 for a description of the apparatus). Each of these four types of tests is described in detail below.

\section{Gap and Grain-Boundary Inventory Measurements}

The fuel specimens used in this study were prepared from 12- to 25-mm-long segments cut from the ATM-104, ATM-105, and ATM-106 rods identified in Table 2.1. Measurements were also made by the same method described below on ATM-101 and ATM-103 fuels and the results were reported earlier (Gray and Strachan 1991; Gray, Strachan, and Wilson 1992).

To ensure that the measured grain-boundary inventories of ${ }^{137} \mathrm{Cs},{ }^{99} \mathrm{Tc}$, and ${ }^{90} \mathrm{Sr}$ did not include portions of the gap inventories, it was first necessary to dissolve the ${ }^{137} \mathrm{Cs},{ }^{99} \mathrm{Tc}$, and ${ }^{90} \mathrm{Sr}$ located within the gap region and separate it from the residual fuel specimen. In the process, the quantities of ${ }^{137} \mathrm{Cs},{ }^{99} \mathrm{Tc}$, and ${ }^{90} \mathrm{Sr}$ dissolved from the gap (i.e., the gap inventories) were measured. To do this, the fuel was discharged from the cladding and placed in a glass vessel along with the empty cladding segment. A measured volume $(200$ to $250 \mathrm{~mL}$ ) of DIW was added to the vessel and allowed to stand for 1 week at hot-cell temperature. At the end of that time, an aliquot of water was removed, filtered, acidified, and analyzed for $\mathrm{U},{ }^{137} \mathrm{Cs},{ }^{99} \mathrm{Tc}$, and ${ }^{90} \mathrm{Sr}$. The inventory fractions of dissolved $\mathrm{U}$ were subtracted from the inventory fractions of dissolved ${ }^{99} \mathrm{Tc}$ and ${ }^{90} \mathrm{Sr}$ (typically $\sim 10 \%$ correction) to obtain the gap inventories for those radionuclides. The inventory fractions of dissolved $U$ were negligible compared to the inventory fractions of dissolved ${ }^{137} \mathrm{Cs}$, so no correction was applied to obtain the ${ }^{137} \mathrm{Cs}$ gap inventories.

Grain-boundary inventory measurements were performed on the fuel specimens after completion of the gap inventory measurements. Following their 1-week exposure to water, the fuel fragments were dried, crushed, and screened using screens with $20-$ to $30-\mu \mathrm{m}$ openings, depending on the grain size of the fuel being prepared (see Table 2.1 for grain sizes). Figure A.7 shows SEM photographs of ATM-104, ATM-105, and ATM-106 fuel specimens prepared in this manner. Very few multigrain particles are visible in these photographs indicating that virtually all of the grain-boundary surfaces were exposed as was intended. The ATM-106 fuel specimens (Figures A.7c and A.7d) exhibited more transgranular fracturing than has typically been the case with this method of preparation. However, despite the exposure of non-grain-boundary surfaces, this was not expected to adversely affect the measurements of the grain-boundary inventories for the following reason. Dissolution of ${ }^{137} \mathrm{Cs},{ }^{99} \mathrm{Tc}$, and ${ }^{90} \mathrm{Sr}$ from the $\mathrm{UO}_{2}$ matrix has previously been shown to be congruent with the dissolution of $U$ (Gray and Strachan 1991). Further, grain-boundary inventories were derived by subtracting the inveritory fractions of dissolved $U$ from the inventory fractions of dissolved ${ }^{137} \mathrm{Cs},{ }^{99} \mathrm{Tc}$, and ${ }^{90} \mathrm{Sr}$. Therefore, any ${ }^{137} \mathrm{Cs},{ }^{99} \mathrm{Tc}$, and ${ }^{90} \mathrm{Sr}$, that dissolved congruently along with $\mathrm{U}$ from transgranular fracture surfaces present in the specimens would not be included as part of the grain-boundary inventories.

The grain-boundary inventory measurements consisted of placing $\sim 0.5 \mathrm{~g}$ of the screened fuel grains and subgrains described above in a $50-\mathrm{mL}$ beaker along with $20 \mathrm{~mL}$ of $0.1 \mathrm{M} \mathrm{HCl}$. Periodically over $3 \mathrm{~h}$ the acid was removed, filtered, and replaced with fresh acid. The filtered samples were. analyzed for $\mathrm{U}^{\prime}{ }^{137} \mathrm{Cs},{ }^{99} \mathrm{Tc}$, and ${ }^{90} \mathrm{Sr}$, and the data were treated as described above. 
Some of the solutions resulting from both the gap inventory and the grain-boundary inventory tests were analyzed for ${ }^{129} \mathrm{I}$ concentrations. However, there is some question about the validity of the data, so they are not being reported here. Plans have been formulated to repeat some of the measurements for ${ }^{129}$ I using a technique used by Canadian researchers (Stroes-Gascoyne et al. 1994).

\section{Grain-Boundary Dissolution Rates}

To provide information on grain-boundary dissolution rates, a test using ATM-103 fuel fragments instead of fuel grains was performed under the same conditions as Test 4 in Table 3.1 (Section 3.1). A test column was completely filled with fuel fragments as described in Section 2.1.1. Water from the same feedwater container that was used for the parallel experiment with fuel grains was pumped through the column of fuel fragments. Unlike the flow-through tests with spent fuel grains, the water passed through the column in the upward direction. The entire volume of column effluent was collected, in two separate batches, for the first four days to allow measurement of the total amount of radionuclides dissolved during the first part of the test. The first batch, which consisted of effluent for the first day, was collected in one container and the second batch consisted of effluent collected over the weekend in a second container. Thereafter, a few milliliters of column effiuent were collected on a periodic basis, typically one to three times per week. The method used to extract the grain-boundary dissolution rates from analysis of the solution samples is described in Section 3.3.2.

\section{Series-3 Archive Specimen}

A test column was completely filled with fuel fragments as described in Section 2.1.1, and J-13 water described below was pumped through the column. Water flow was in the upward direction, which was preferred for columns using fuel fragments, versus downward flow for columns with powdered specimens. The flow rate for the initial portion of the test was approximately $0.2 \mathrm{~mL} / \mathrm{min}$. All effluent from the first and second days was collected as two large samples, and periodic effiuent samples were taken thereafter.

The J-13 well water used for the flow-through test came from a full barrel (designated barrel G) that was acquired from the Nevada Test Site in 1985. Barrel F, which was acquired at the same time, was used for the semistatic testing program that included the Series-3 tests (Wilson 1990b). Two samples of the J-13 water from barrel G were analyzed by Inductively Coupled Plasma Emission Spectroscopy (ICP) for cations, Ion Chromatography (IC) for anions, total inorganic carbon (TIC), total organic carbon (TOC), and $\mathrm{pH}$. Results of these analyses are given in Table 2.4. The $\mathrm{HCO}_{3}$ results were obtained by multiplying the TIC results (not shown in the table) by $61 / 12$ to adjust for molecular weight.

\section{Test with Semi-Saturated Uranium Solution}

The purpose of this test was to determine whether the presence of $U$ (at about half saturation) in the supply water had any effect on the dissolved ${ }^{137} \mathrm{Cs}$ concentrations. Following Test 13 (Section 3.1), the water was changed to a solution that contained $2 \times 10^{-3} \mathrm{M} \mathrm{NaHCO}$ equilibrated with air at ambient temperature. The $\mathrm{pH}$ stabilized at about 9 . After 47 days, 6 to $8 \mu \mathrm{g} / \mathrm{mL}$ of dissolved $\mathrm{U}$ was added to the $\mathrm{NaHCO}_{3}$ solution. This $\mathrm{U}$ concentration is apparently equal to about half the $\mathrm{U}$ solubility limit under these water chemistry conditions, as indicated by the data in Figure A.8, which indicate that the $\mathrm{U}$ concentration will eventually stabilize near $15 \mu \mathrm{g} / \mathrm{mL}$. No other changes were made in the water 
Table 2.4. Analysis of $\mathrm{J}-13$ Well Water, Barrel $\mathrm{G}(\mathrm{mg} / \mathrm{L})^{(\mathrm{a})}$

\begin{tabular}{lcc} 
Component & Sample 1 & Sample 2 \\
\cline { 3 - 3 } $\mathrm{Ca}$ & 13.0 & 12.9 \\
$\mathrm{~K}$ & 4.6 & 5.2 \\
$\mathrm{Mg}$ & 2.0 & 2.0 \\
$\mathrm{Na}$ & 44.4 & 44.5 \\
$\mathrm{Si}$ & 29.9 & 30.4 \\
$\mathrm{Cl}$ & 6.6 & 6.9 \\
$\mathrm{~F}$ & 2.3 & 2.3 \\
$\mathrm{NO}_{3}$ & 8.9 & 9.1 \\
$\mathrm{SO}_{4}$ & 18.6 & 18.8 \\
$\mathrm{HCO}_{3}$ & 126 & 126 \\
$\mathrm{TOC}^{3}$ & 1.0 & 2.6 \\
$\mathrm{pH}$ & 8.39 & 8.35
\end{tabular}

(a) Sample 1 was taken directly from barrel $\mathrm{G}$ and Sample 2 was taken from a plastic jug filled from barrel $G$ for the flow-through test.

chemistry. Uranium was added to the water used in the flow-through test by placing $\sim 1 \mathrm{~g}$ of unirradiated $\mathrm{UO}_{2}$ (same $\mathrm{UO}_{2}$ described in Section 2.1.2.1) in $20 \mathrm{~L}$ of $2 \times 10^{-3} \mathrm{M} \mathrm{NaHCO}$ solution exposed to air and letting it stand for $\sim 2$ months. The water was then filtered $(0.45 \mu \mathrm{m})$ to remove particulate $\mathrm{UO}_{2}$ before pumping it through the test column.

\subsubsection{Supplemental Tests with Unirradiated Uranium Oxide Powders}

The following subsections describe tests conducted with various unirradiated uranium oxide powders:

- Flow-through tests with unirradiated $\mathrm{UO}_{2}$ powder for comparison with similar tests at LLNL.

- Flow-through tests with unirradiated $\mathrm{UO}_{2}$ powder to evaluate test results obtained under conditions of low $\mathrm{O}_{2}$ overpressure. These tests were motivated by some unexpected results obtained with spent fuel under conditions of low $\mathrm{O}_{2}$ overpressure. There was a need to determine whether or not the test equipment was operating properly.

- Flow-through tests with unirradiated $\mathrm{U}_{3} \mathrm{O}_{7}$ and $\mathrm{U}_{3} \mathrm{O}_{8}$ powders.

- Flow-through tests with unirradiated $\mathrm{UO}_{2}$ powder with simultaneous measurement of streaming potential. 
Tests with $\mathrm{UO}_{2}$ for Comparison with LLNL

Unirradiated $\mathrm{UO}_{2}$ powder ( $200 \mathrm{mg}$ ) prepared as described in Section 2.1 .2 was placed in a flowthrough column and tested under the same conditions as Test 4 in Table 3.1 (Section 3.1). As with the spent fuel grains, the water flowed downward through the column after first flowing upwards to purge air from the column.

\section{Tests with $\mathrm{UO}_{2}$ at Low $\mathrm{O}_{2}$ Overpressure}

Unirradiated $\mathrm{UO}_{2}$ powder ( $200 \mathrm{mg}$ ) prepared as described in Section 2.1 .2 was placed in a flowthrough column and initially tested under the same conditions as Test 7 in Table 3.1 (Section 3.1). Periodically thereafter, the $\mathrm{O}_{2}$ overpressure was changed while all other test parameters remained constant. As with the spent fuel grains, the water flowed downward through the column after first flowing upwards to purge air from the column.

\section{Tests with $\mathrm{U}_{3} \mathrm{O}_{7}$ and $\mathrm{U}_{3} \mathrm{O}_{8}$}

Test specimens of unirradiated $\mathrm{U}_{3} \mathrm{O}_{7}$ and $\mathrm{U}_{3} \mathrm{O}_{8}$ prepared as described in Section 2.1.2 were placed in flow-through columns and tested under conditions defined (along with the test results) in Section 3.4.3. The $\mathrm{U}_{3} \mathrm{O}_{7}$ specimens were 100 to $200 \mathrm{mg}$ in size while the $\mathrm{U}_{3} \mathrm{O}_{8}$ specimen was only $18 \mathrm{mg}$ because of its large specific surface area. As with the spent fuel grains and all the uranium oxide powder specimens, the water flowed downward through the column after first flowing upwards to purge air from the column.

\section{$\mathrm{UO}_{2}$ Dissolution/Streaming Potential}

Nonconducting acrylic plastic specimen columns and interfacing fittings were designed and fabricated to accommodate tubing connections and $\mathrm{Ag} / \mathrm{AgCl}$ electrodes. Ethylene propylene O-rings and 325-mesh stainless steel screen disks were used at the ends of the specimen columns to provide watertight seals and retain the $\mathrm{UO}_{2}$ particles within the specimen columns. $\mathrm{Ag} / \mathrm{AgCl}$ electrodes were made by threading silver wires through rubber stoppers and coating the portion of the wire extending through the stopper with $\mathrm{AgCl}$. The $\mathrm{AgCl}$ coating was formed by applying a positive 3-V d.c. potential to the wire in $0.1 \mathrm{~N} \mathrm{HCl}$ for about $20 \mathrm{~s}$. Electrodes were periodically recoated during the tests.

Two dissolution/streaming potential tests were conducted with unirradiated $\mathrm{UO}_{2}$ powder specimens prepared as described in Section 2.1.2. Approximately $1.4 \mathrm{~g}$ of $\mathrm{UO}_{2}$ powder was packed into each of the $5.06-\mathrm{cm}$-long by $2.38-\mathrm{mm}$ ID plastic columns. Test solutions were pumped through the columns by a peristaltic pump at a flow rate of about $0.3 \mathrm{~mL} / \mathrm{min}$. A Reynold's number ${ }^{(a)}$ of about 0.1 was calculated for flow through the specimen assuming cylindrical capillary geometry, indicating that flow through the packed particle columns should be laminar.

(a) Reynold's number is a dimensionless value with significance relative to fluid flow conditions. Transition from laminar flow to turbulent flow is expected to occur for Reynold's numbers above 0.1 to 75 , depending on factors such as surface roughness (Scheidegger 1974). 


\subsection{Results}

The test results are divided into subsections that discuss 1 ) the flow-through test matrix conducted with spent fuel grains to measure dissolution kinetics of the $\mathrm{UO}_{2}$ matrix phase; 2) flow-through tests with oxidized spent fuel; 3 ) four types of supplementary spent fuel tests; and 4) four sets of flowthrough tests with unirradiated uranium oxides.

Dissolution rates reported here were normalized according to the following equation (3.1):

$$
R=\frac{C_{\mathrm{i}} \mathrm{F}}{\mathrm{MAf}_{\mathrm{i}}}
$$

where $\quad R=$ dissolution rate of the spent fuel matrix based on the data for component $\mathrm{i}\left(\mathrm{U},{ }^{137} \mathrm{Cs}\right.$, ${ }^{99} \mathrm{Tc}$, or $\left.{ }^{90} \mathrm{Sr}\right)\left(\mathrm{mg} \cdot \mathrm{m}^{-2} \bullet \mathrm{d}^{-1}\right)$

$\mathrm{C}_{\mathrm{i}}=$ concentration of component $\mathrm{i}$ in column effluent $(\mathrm{mg} / \mathrm{mL}$ or $\mathrm{Bq} / \mathrm{mL})$

$\mathrm{F}=$ flow rate of test solution through column $(\mathrm{mL} / \mathrm{d})$

$\mathrm{M}=$ mass of test specimen (mg)

$A=$ specific surface area of test specimen $\left(\mathrm{m}^{2} / \mathrm{mg}\right)$

$f_{i}=$ concentration of component $i\left(U,{ }^{137} \mathrm{Cs},{ }^{99} \mathrm{Tc}\right.$, or $\left.{ }^{90} \mathrm{Sr}\right)$ in test specimen $(\mathrm{mg} / \mathrm{mg}$ or $\mathrm{Bq} / \mathrm{mg}$ ).

It is important to understand the implications of this equation. It has the very distinct advantage that spent fuel dissolution rates calculated from data for different components are equal if the specimen dissolves congruently. However, the calculated rate must not be interpreted to mean that $\mathrm{R}$ milligrams of component $i$ are dissolving per unit surface area per day. Rather, the correct interpretation is that $\mathrm{R}$ milligrams of spent fuel are dissolving per unit surface area per day, based upon the data for . component $i$.

It is also important to point out that an alternate Equation (3.2) has often been used.

$$
R_{i}=\frac{C_{i} F}{M A}
$$

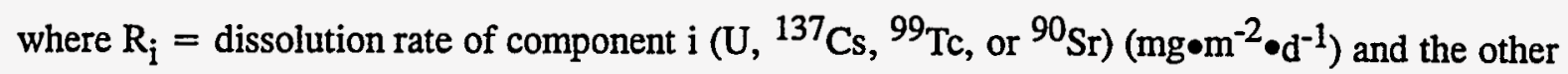
symbols have the same meaning as in Equation (3.1). 
The correct interpretation of Equation (3.2) is that $\mathrm{R}_{\mathrm{i}}$ milligrams of component $i$ are dissolving per unit surface area per day. This is quite different from the amount of spent fuel that is dissolving, particularly when the component being considered has a low concentration in the fuel, e.g., ${ }^{137} \mathrm{Cs}$. Equation (3.2) may seem like a more sensible way to present the data than equation (3.1) because it gives a direct and unambiguous value for the dissolution rates for the different components. However, it has the problem that the rates for the different components will be very different simply because their concentrations in the fuel are very different. Therefore, they are difficult to present on a single graph. Furthermore, the data do not indicate whether the spent fuel specimen is dissolving congruently.

The difference between Equations (3.1) and (3.2) is small for $U$ because the concentration, $f_{i}$, of $U$ is 0.88 in $\mathrm{UO}_{2}$ and about 0.84 in spent fuel. Equation (3.2) was used in a prior publication of results from the $\mathrm{UO}_{2}$ matrix phase dissolution kinetics (Steward and Gray 1994). Therefore, dissolution rates in that publication differ from the ones reported here by these factors, 0.88 for $\mathrm{UO}_{2}$ and 0.84 for spent fuel.

\section{1 $\mathrm{UO}_{2}$ Matrix Phase Dissolution Kinetics}

In this section, results are reported for all of the tests listed in Table 3.1, which gives some of the test parameters and summarizes the results. The temperatures listed are measured averages; in each case, the temperature varied \pm 2 to $3^{\circ} \mathrm{C}$ from the average during the test. Actual carbonate concentrations were within $1 \%$ of the nominal values listed, obtained through accurate weighing of the components. The $\mathrm{O}_{2}$ overpressures represent nominal concentrations in the sparge gas except for the $0.3 \%$ listings which were obtained using a dissolved $\mathrm{O}_{2}$ meter. Nominal room temperature values are listed for $\mathrm{pH}$; measured values typically agreed within 0.1 unit. The as-analyzed concentrations of $\mathrm{CO}_{2}$ in the sparge gas were within $10 \%$ of the nominal values listed.

Tests 1 through 3 (Figure A.9) in Table 3.1 were triplicates performed to investigate repeatability. The data were averaged for each test, omitting the initial transient period of 15 days, and the results are listed in Table 3.1. Two times the sample standard deviations are also listed in the table and the results indicate that the tests are indistinguishable. Replicates of other tests $(5,6,7$, and 15 in Table 3.1$)$ are described later in this section and in Section 4.1.1.

After Tests 2 and 3 were terminated, Test 1 was continued to allow for testing at a variety of flow rates as shown in Figure A.10. Perhaps because $U$ concentrations in the test column were partially constrained by the solubility limit, the dissolution rate dropped when the fiow was decreased to $-0.05 \mathrm{~mL} / \mathrm{min}$. However, the rate only partially recovered when the flow rate was increased again. The average dissolution rate for days 56 to 105 was $5.02 \mathrm{mg}^{-2} \bullet \mathrm{d}^{-1}$ compared to $7.58 \mathrm{mg}^{-2} \mathrm{~m}^{-2} \bullet \mathrm{d}^{-1}$ for days 4 to 37 . This difference seems somewhat outside the scatter for this particular test, but within the context of all the data presented in this report, the difference was not large. Perhaps data from the earlier time period should be considered part of the transient that was commonly observed in these tests. 
Table 3.1. Test Matrix and Results for Spent Fuel Dissolution Tests

\begin{tabular}{|c|c|c|c|c|}
\hline $\begin{array}{l}\text { Test } \\
\text { No. }\end{array}$ & $\begin{array}{c}\text { Specimen } \\
\text { No. }\end{array}$ & $\begin{array}{c}\text { Temp. } \\
\left({ }^{\circ} \mathrm{C}\right)\end{array}$ & $\begin{array}{l}\text { Carbonate } \\
\text { (millimolar) }\end{array}$ & $\begin{array}{c}\left(\mathrm{P}_{\mathrm{O}_{2}}\right)^{(\mathrm{b})} \\
(\%)\end{array}$ \\
\hline 1 & 1 & 50 & 2 & 20 \\
\hline 2 & 2 & 50 & 2 & 20 \\
\hline 3 & 3 & 50 & 2 & 20 \\
\hline 4 & 5 & 22 & 20 & 20 \\
\hline 5 & 9 & .74 & 20 & 20 \\
\hline 5 & 14 & 74 & 20 & 20 \\
\hline $6(d)$ & 2 & 74 & 0.2 & 20 \\
\hline $6(e)$ & 7 & 74 & 0.2 & 20 \\
\hline 7 & 6 & 21 & 0.2 & 20 \\
\hline 7 & 15 & 21 & 0.2 & 20 \\
\hline 8 & 6 & 22 & 20 & 20 \\
\hline 9 & 8 & 22 & 2 & 20 \\
\hline 0 & 6 & 27 & 0.2 & 2 \\
\hline 11 & 12 & 78 & 0.2 & 2 \\
\hline 12 & 8 & 25 & 20 & 2 \\
\hline 13 & 13 & 77 & 20 & 2 \\
\hline 20 & 14 & 75 & 20 & 2 \\
\hline 14 & 6 & 23 & 20 & 0.3 \\
\hline 15 & 9 & 75 & 20 & 0.3 \\
\hline 15 & 14 & 74 & 20 & 0.3 \\
\hline 16 & 12 & 78 & 0.2 & 0.3 \\
\hline 17 & 15 & 19 & 0.2 & 0.3 \\
\hline 18 & 14 & 50 & 20 & 0.3 \\
\hline 19 & 8 & 21 & 2 & 0.3 \\
\hline
\end{tabular}

(a) Made up using appropriate amounts of $\mathrm{Na}_{2} \mathrm{CO}_{3}$ and $\mathrm{NaHCO}_{3}$.

(b) Feed solutions were slowly and continuously sparged with gas containing these concentrations of $\mathrm{O}_{2}$ and $\mathrm{CO}_{2}$, balance $\mathrm{N}_{2}$ to stabilize the pH and control the $\mathrm{O}_{2}$ overpressure.

\begin{tabular}{|c|c|c|c|c|}
\hline \multirow[b]{2}{*}{$\mathrm{pH}$} & \multirow{2}{*}{$\begin{array}{c}\left(\mathrm{P}_{\mathrm{O}_{2}}\right)^{(\mathrm{b})} \\
(\mathrm{ppm})\end{array}$} & \multirow[b]{2}{*}{ Days $^{(c)}$} & \multicolumn{2}{|c|}{ 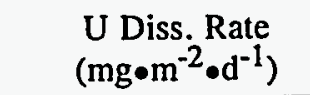 } \\
\hline & & & Avg & $2 \sigma$ \\
\hline 9 & 117 & $16-37$ & 7.53 & 0.65 \\
\hline 9 & 117 & $16-37$ & 8.37 & 1.71 \\
\hline 9 & 117 & $16-37$ & 6.02 & 1.60 \\
\hline 8 & 11000 & $83-105,116-130$ & 4.10 & 0.61 \\
\hline 10 & 55 & $38-114$ & 13.8 & 2.7 \\
\hline 10 & 55 & $2-23,142-161$ & 19.8 & $5 . \dot{0}$ \\
\hline 8 & 125 & $22-81$ & 9.99 & 1.58 \\
\hline 8 & 125 & $22-75$ & 10.4 & 2.07 \\
\hline 10 & 0.9 & $37-78$ & 0.490 & 0.164 \\
\hline 10 & 0.9 & $109-169$ & 1.00 & 0.302 \\
\hline 9 & 1030 & $22-59$ & 3.36 & 0.36 \\
\hline 10 & 7.7 & $5-32$ & 2.42 & 0.67 \\
\hline 8 & 125 & $7-51$ & 2.13 & 0.31 \\
\hline 10 & 0.9 & $5-52$ & 1.77 & 0.30 \\
\hline 10 & 55 & $67-130$ & 2.43 & 0.39 \\
\hline 8 & 11000 & $60-114$ & 3.43 & 0.51 \\
\hline 10 & 55 & $107-140$ & 5.65 & 2.10 \\
\hline 8 & 11000 & $91-154,185-224$ & 3.36 & 0.53 \\
\hline 10 & 55 & $122-149$ & $0.0678(f)$ & 0.0340 \\
\hline 10 & 55 & $63-88$ & 0.823 & 0.20 \\
\hline 8 & 125 & $60-106$ & 2.35 & 0.44 \\
\hline 10 & 0.9 & $70-98$ & 0.602 & 0.012 \\
\hline 10 & 55 & $30-72$ & 1.24 & 0.29 \\
\hline 9 & 117 & $6-57,90-154$ & 2.22 & 0.67 \\
\hline
\end{tabular}

(c) Time period over which the dissolution rate was averaged.

(d) Same spent fuel specimen used in Test 2.

(e) Fresh spent fuel specimen used.

(f) This value was not repeated and was, therefore, discounted (see Section 4.1.1). 
The variable flow-rate testing, which was performed with Test 1 and a few other tests, was required to demonstrate that the specimen sizes and flow-rate parameters were in the proper range to allow the true forward kinetic rate constant to be determined. To demonstrate this, a plot of $U$ concentration versus reciprocal flow must yield a straight line that passes through the origin indicating that the dissolution rate is independent of flow rate over the range tested. This condition shows that the concentrations are well below the $U$ solubility limit and ensures that the true rate-limiting step in the test is the dissolution rate of the specimen, i.e., that the observed dissolution rate is not significantly influenced by solubility constraints. In tests conducted at sufficiently low flow rates (high reciprocal flow rates), the $U$ concentrations fall below a straight line relationship (e.g., Figures A.11 and A.13). If the data were extended to even lower flow rates that approached static conditions, the $U$ concentrations would eventually approach a constant value equal to the solubility limit. Flow-rate dependence tests were performed for different types of specimens (fuel grains, fuel fragments, and $\mathrm{UO}_{2}$ powder) and for some of the different test conditions listed in Table 3.1. In each case, a regression line passing through the origin was fit to the data to test for flow-rate independence of the dissolution rate.

Data for Test 1 beyond 45 days are plotted in Figure A.11, and the regression line was fit to data below reciprocal flows of $15 \mathrm{~min} / \mathrm{mL}$. There is a good deal of scatter in the data above reciprocal flows of $5 \mathrm{~min} / \mathrm{mL}$, and most data above reciprocal flows of $15 \mathrm{~min} / \mathrm{mL}$ fall well below the regression line suggesting that the concentrations were partially limited by solubility constraints. However, the data below $15 \mathrm{~min} / \mathrm{mL}$ were judged to be acceptable in the sense that the necessary conditions (noted above) seemed to be reasonably well satisfied, and the test was terminated.

Figure A. 12 shows the dissolution rates for Test 4 . The ${ }^{137} \mathrm{Cs},{ }^{99} \mathrm{Tc}$, and ${ }^{90} \mathrm{Sr}$ dissolved nearly congruently with $U$ after the first day or two although, after a few days, the ${ }^{99} \mathrm{Tc}$ data tended to fall a little below the $U$ data. Some of the ${ }^{99} \mathrm{Tc}$ may have been present in the form of very fine metallic particles (Thomas and Guenther 1988), which are relatively insoluble, and this may have resulted in a lower overall dissolution rate for the ${ }^{99} \mathrm{Tc}$. Also, the ${ }^{99} \mathrm{Tc}$ concentrations were not far above detection

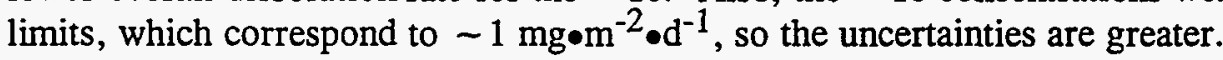

Figure A.12 also indicates that the flow rates were varied for times beyond 81 days. Uranium data for days 83 through 144 are plotted in Figure A.13. At the higher reciprocal flows, the U concentrations appear to fall a little below the regression line, perhaps indicating that the concentrations were partially limited by solubility constraints. Otherwise the fit is good. Therefore, data for reciprocal flows below $15 \mathrm{~min} / \mathrm{mL}$ were averaged, and the result is listed in Table 3.1 .

Data for Test 5, representing two different specimens, are shown in Figures A.14 and A.15, respectively. Figure A.14 shows that, after 114 days, the $\mathrm{O}_{2}$ overpressure in the test solution was reduced to $0.003 \mathrm{~atm}$, i.e., Test 15 conditions. ${ }^{\text {(a) }}$ This 70 -fold drop in $\mathrm{O}_{2}$ overpressure resulted in a rapid decrease in dissolution rate by a factor of more than 100 . Returning the $\mathrm{O}_{2}$ overpressure to $0.2 \mathrm{~atm}$ after 149 days restored the dissolution rate to its original Test- 5 condition value. Finally, after 170 days, the $\mathrm{O}_{2}$ overpressure was again reduced to $0.003 \mathrm{~atm}$ and the dissolution rate again dropped markedly. At this point the test was terminated because it was decided to repeat the test using a different specimen to determine whether the unexpectedly large dependence on $\mathrm{O}_{2}$ overpressure could be repeated.

(a) Test conditions 5 and 15 were identical except for $\mathrm{O}_{2}$ overpressure. Thus, changing the $\mathrm{O}_{2}$ overpressure in the test allowed for a direct comparison between those two test conditions. 
Figure A.14 shows that a few samples were analyzed for ${ }^{137} \mathrm{Cs}$. The dissolution rate of ${ }^{137} \mathrm{Cs}$ was nearly congruent with $\mathrm{U}$ before the $\mathrm{O}_{2}$ overpressure was dropped. Reducing the $\mathrm{O}_{2}$ overpressure caused a large decrease in the ${ }^{137} \mathrm{Cs}$ dissolution rate just as it did the $U$ dissolution rate, although the difference between ${ }^{137} \mathrm{Cs}$ and $U$ was a little larger than at the higher $\mathrm{O}_{2}$ overpressure. This shows that the ${ }^{137} \mathrm{Cs}$ dissolution rate was controlled by the dissolution rate of the $\mathrm{UO}_{2}$ matrix, as was expected.

Figure A.15 shows results obtained using a different specimen from that used to generate the data in Figure A.14. Oxygen overpressures were varied between $0.2 \mathrm{~atm}, 0.02 \mathrm{~atm}$, and $0.003 \mathrm{~atm}$ (Tests 5,20 , and 15, respectively). At 0.2 atm $\mathrm{O}_{2}$ overpressure, the observed dissolution rate was similar to that shown in Figure A.14. At 0.003 atm $\mathrm{O}_{2}$ overpressure, the observed rate was rather erratic but seemed to stabilize at a value more than 10 times higher than that shown in Figure A.14. Average dissolution rates for Tests 5, 15, and 20 from both Figures A.14 and A.15 are listed in Table 3.1 along with the time periods over which the data were averaged. The dependence of spent fuel dissolution rates on $\mathrm{O}_{2}$ overpressure is further discussed in Section 4.1.1.

Test 6 (Figure A.16) was performed in duplicate to help resolve an uncertainty about the possible influence of prior testing upon the results of subsequent dissolution tests. In one of the duplicate tests, a fresh specimen of spent fuel was placed in the flow-through column. In the other test, one of the columns was simply switched from Test 2 conditions to Test 6 conditions, i.e., the carbonate/ bicarbonate solution being pumped through the column was changed from $2 \times 10^{-3} \mathrm{M}, \mathrm{pH}=9$ to $2 \times 10^{-4} \underline{\mathrm{M}}, \mathrm{pH}=8$, and the column temperature was increased from $50^{\circ} \mathrm{C}$ to $75^{\circ} \mathrm{C}$. Figure A.16 shows little difference between the two tests after about 10 days, and Table 3.1 shows that the average dissolution rates were indistinguishable. Because the results of these tests indicated that there was no difference between a fresh specimen and a previously tested specimen, some of the other specimens were used for more than one test condition as is shown in Table 2.3.

Data for Test 7 are shown in Figures A.17 and A.18. Figure A.17 shows that the dissolution rate was relatively stable after about 30 days and that flow-rate variations were started after 47 days. A few samples were analyzed for ${ }^{137} \mathrm{Cs},{ }^{99} \mathrm{Tc}$, and ${ }^{90} \mathrm{Sr}$, and the results show nearly congruent dissolution. The data for ${ }^{99} \mathrm{Tc}$ are essentially equal to the detection limit, which corresponds to $\sim 1 \mathrm{mg} \bullet \mathrm{m}^{-2} \cdot \mathrm{d}^{-1}$. Data for day 37 and beyond were plotted in Figure A.18, which shows a straight line relationship up through the highest reciprocal flow rates. Therefore, all data for day 37 and beyond were included in the average dissolution rate listed in Table 3.1. Test 7 was terminated and the test conditions were changed to those for Test 8 while retaining the same specimen because the duplicate runs of Test 6 indicated that it was not necessary to change test specimens.

Note that a second specimen was also tested under Test 7 conditions. Results from that test are shown in Figure A.27 and discussed along with the results from Test 17. The average dissolution rate from the second Test 7 are also listed in Table 3.1.

Figures A.19 to A.23 show results for Tests 8 through 12, respectively. In each case, the dissolution rate reached an approximately steady-state value after a few days. As indicated in the figures, the steady-state data were averaged and the results are listed in Table 3.1.

Figure A.24 indicates that the dissolution rate in Test 13 reached an approximately steady state value after 60 days. Therefore, data for day 60 and beyond were averaged-and the result is listed in 
Table 3.1. Following this test, water containing dissolved $U$ was pumped through the column to determine any effect this would have on the ${ }^{137} \mathrm{Cs}$ dissolution rate. Results from this follow-on test are described in Section 3.3.5.

Figure A.25 shows results from Test 14. Data were averaged for day 91 to 154 plus day 185 to 224 and the result is listed in Table 3.1. In the interim period from day 154 to 185 , the $\mathrm{O}_{2}$ overpressure was increased to $0.2 \mathrm{~atm}$, which is the same as Test 4 conditions. The effect on dissolution rates of changing the $\mathrm{O}_{2}$ overpressure is further discussed in Section 4.1.1.

Data for Test 15 were presented in Figures A.14 and A.15 and were discussed earlier. The lower of the two averages listed for Test 15 in Table 3.1 was discounted for reasons discussed in Section 4.1.1.

Figure A.26 indicates that the dissolution rate in Test 16 reached an approximately steady state value after 60 days. Therefore, data for day 60 and beyond were averaged and the result is listed in Table 3.1.

Figure A.27 indicates that the dissolution rate in Test 17 reached an approximately steady state value after 70 days. Therefore, data for days 70 to 98 were averaged and the result is listed in Table 3.1. After day 100, the $\mathrm{O}_{2}$ overpressure was increased to $0.2 \mathrm{~atm}$ (Test 7 conditions). This had little effect on the dissolution rate (see Section 4.1.1 for further discussion of the dependence of dissolution rates on $\mathrm{O}_{2}$ overpressure). Data for days 109 to 169 were averaged and the result is listed for Test 7 in Table 3.1 .

Figure A.28 indicates that the dissolution rate in Test 18 reached an approximately steady state value after 30 days. Therefore, data for day 30 and beyond were averaged and the result is listed in Table 3.1.

Data for Test 19 are shown in Figure A.29. Data for days 6 to 57 and 90 to 154 were averaged and the result is listed in Table 3.1. During the interim period between days 57 and 90 , the low flow rate may have been the cause of the low dissolution rates that were observed (due to $U$ solubility constraints). Therefore, these interim data were not included in the average:

\subsection{Tests with Oxidized Spent Fuel}

Figures A.30 and A.31 show results obtained with oxidized $\left(\mathrm{U}_{4} \mathrm{O}_{9+\mathrm{x}}\right)$ and unoxidized $\left(\mathrm{UO}_{2}\right)$ specimens of ATM-105 and ATM-106 spent fuels, respectively. Note that the test conditions were not the same for the two fuels. The ATM-105 specimens (Figure A.30) were tested under the conditions of Test 1 in Table 3.1. The ATM-106 specimens (Figure A.31) were tested under the conditions of Test 4 in Table 3.1. Therefore, direct comparison between results for the two types of fuel is not possible. However, the purpose of the tests was to compare oxidized fuel with unoxidized fuel, not to make direct comparisons between fuel types.

Figure A.32 shows results for ATM-106 oxidized to $\mathrm{U}_{3} \mathrm{O}_{8}$ as described in Section 2.1.1. The test conditions were the same as in Figure A.31, i.e., the same as Test 4 in Table 3.1. 
The slow dissolution rate of ${ }^{99} \mathrm{Tc}$ shown in Figure A.32 was unexpected. After the first few days, the ${ }^{99} \mathrm{Tc} / \mathrm{U}$ dissolution ratio was only 0.1 to 0.2 . It was first thought that the higher temperatures needed to generate $\mathrm{U}_{3} \mathrm{O}_{8}$ during the short-time laboratory exposure to air may have vaporized a large fraction of the ${ }^{99} \mathrm{Tc}$, perhaps as the volatile compound $\mathrm{Tc}_{2} \mathrm{O}_{7}$ (Migge 1989). To evaluate that possibility, a portion of the $\mathrm{U}_{3} \mathrm{O}_{8}$ was completely dissolved and analyzed for $\mathrm{U},{ }^{137} \mathrm{Cs},{ }^{99} \mathrm{Tc}$, and ${ }^{90} \mathrm{Sr}$. The dissolution involved exposing the $\mathrm{U}_{3} \mathrm{O}_{8}$ to $12 \mathrm{M} \mathrm{HNO}_{3}$ for several days. However, even with some heating during that time, there was residue left undissolved. Therefore, the entire solution was evaporated to dryness, fused with $\mathrm{Na}_{2} \mathrm{O}_{2}$ in a $\mathrm{Zr}$ crucible and redissolved in $6 \mathrm{M} \mathrm{HCl}$. Analysis of this solution indicated that $93 \%$ of the $U$ was recovered, which was considered acceptable. The analyzed ratio of ${ }^{137} \mathrm{Cs},{ }^{99} \mathrm{Tc}$, and ${ }^{90} \mathrm{Sr}$ to the ORIGEN2 inventories of these elements in the $\mathrm{U}_{3} \mathrm{O}_{8}$ specimen was as follows: $\mathrm{Cs} / \mathrm{Cs}_{\mathrm{inv}}=1.46 ; \mathrm{Tc} / \mathrm{Tc}_{\mathrm{inv}}=0.85 ; \mathrm{Sr} / \mathrm{Sr}_{\mathrm{inv}}=1.13$. None of these ratios correct for the $93 \% \mathrm{U}$ recovery cited above. The $\mathrm{Cs}$ ratio seems a bit high but both the $\mathrm{Tc}$ and $\mathrm{Sr}$ ratios are within analytical experimental error for a single sample. Clearly, there was no large loss of ${ }^{99} \mathrm{Tc}$ during oxidation of the spent fuel to $\mathrm{U}_{3} \mathrm{O}_{8}$ as was first suspected. Therefore, the low dissolution rate of ${ }^{99} \mathrm{Tc}$ cannot be attributed to a reduced amount of ${ }^{99} \mathrm{Tc}$ in the fuel. Rather, the relatively large 5metal particles, which contain at least some of the ${ }^{99} \mathrm{Tc}$, in this fuel are probably responsible for the low ${ }^{99}$ Tc dissolution rate (Gray and Thomas 1994).

\subsection{Supplemental Spent Fuel Tests}

This section is divided into subsections that describe 1) gap and grain-boundary inventories, 2) grain-boundary dissolution rates, 3) flow-through dissolution rates for an archive specimen from the Series-3 semistatic tests, 4) SEM examination of spent fuel specimens, and 5) flow-through tests with water containing high $U$ concentrations.

\subsubsection{Gap and Grain-Boundary Inventories}

Figures A.33 and A.34 show the cumulative fractions of $U,{ }^{137} \mathrm{Cs},{ }^{99} \mathrm{Tc}$, and ${ }^{90} \mathrm{Sr}$ dissolved from the two highest fission gas release (FGR) ATM-106 fuels listed in Table 2.1. Similar results were obtained for all fuels that have been tested. As described in Section 2.3.3, grain-boundary inventories were obtained from these data by subtracting the dissolved $U$ fraction from the dissolved fractions of each of the other elements. For ${ }^{99} \mathrm{Tc}$ and ${ }^{90} \mathrm{Sr}$, this led to values that were nearly constant after the first 10 to $30 \mathrm{~min}$. However, the derived ${ }^{137} \mathrm{Cs}$ values continued to increase slowly with time after 30 to $60 \mathrm{~min}$. Somewhat arbitrarily, therefore, the grain-boundary inventories of all three were taken to be the values obtained at $60 \mathrm{~min}$.

Figure A.35 summarizes results for both the ${ }^{137} \mathrm{Cs}$ gap inventories (see Section 2.3 .3 for measurement method) and the ${ }^{137} \mathrm{Cs}$ grain-boundary inventories, derived as described above, for all the fuels listed in Table 2.1. The grain-boundary inventories for the first two fuels listed in Table 2.1 were published previously (Gray and Strachan 1991; Gray et al. 1991); the gap inventories for those same two fuels came from unpublished data obtained earlier by W. J. Gray as part of the Performance Assessment Scientific Support (PASS) and Materials Characterization Center (MCC) programs at PNNL. Figure A.35 shows that the ${ }^{137} \mathrm{Cs}$ gap inventory was roughly equal to the FGR only for the lower FGR fuels. At higher FGR, the ${ }^{137} \mathrm{Cs}$ gap inventories were about one fourth the FGR. The grain-boundary 
inventories obtained for ${ }^{137} \mathrm{Cs}$ are shown to be generally about $1 \%$, or less, of the total ${ }^{137} \mathrm{Cs}$ inventory and not strongly correlated with FGR. Except at the lowest FGR where they were roughly equal, the ${ }^{137} \mathrm{Cs}$ grain-boundary inventories are shown to be generally less than the gap inventories.

Figure A.36 shows that the gap and grain-boundary inventories of ${ }^{99} \mathrm{Tc}$ and ${ }^{90} \mathrm{Sr}$ were considerably smaller than those shown for ${ }^{137} \mathrm{Cs}$ in Figure A.35. In fact, they were near or below the detection limits $(\sim 0.1 \%)$ for the methods used. In some cases, the derived inventories were essentially zero or, in the case of ${ }^{99} \mathrm{Tc}$, even negative. Negative inventories were derived when the fractional amounts that dissolved during the inventory measurements were less than the fractional amounts of $U$ that dissolved. A possible reason for dissolved ${ }^{99} \mathrm{Tc}$ fractions being smaller than dissolved $U$ fractions in these experiments could be that some of the ${ }^{99} \mathrm{Tc}$ was present in the form of relatively insoluble metallic particles (Thomas and Guenther 1988) as already mentioned in Section 3.1.

Gap and grain-boundary inventories measured for ${ }^{129} \mathrm{I}$ remain questionable and are not published here. Further testing for those inventories are planned using a method developed by Canadian researchers (Stroes-Gascoyne et al. 1994).

\subsubsection{Grain-Boundary Dissolution Rates}

Figures A.37 and A.38 show dissolution rate results for spent fuel fragments tested under the same conditions as spent fuel grains in Test 4 (see Figure A.12 for the fuel grain results). Some of the column effluent samples were also analyzed for ${ }^{137} \mathrm{Cs},{ }^{99} \mathrm{Tc}$, and ${ }^{90} \mathrm{Sr}$, and those results are also shown in Figure A.38. The ${ }^{137} \mathrm{Cs}$ continued to dissolve at a faster rate than $U$ for 4 months (samples collected after longer times have not been analyzed for ${ }^{137} \mathrm{Cs}$ ). Most of the ${ }^{137} \mathrm{Cs}$ that dissolved during the first day $\left(0.13 \%\right.$ of the total ${ }^{137} \mathrm{Cs}$ inventory) probably represents ${ }^{137} \mathrm{Cs}$ associated with the gap since the specimen was not pretreated to dissolve the gap components. After the first day, the excess ${ }^{137} \mathrm{Cs}$ (compared to $\mathrm{U}$ ) can be attributed to ${ }^{137} \mathrm{Cs}$ being leached from the grain boundaries.

Figure A.38 also shows that $\mathrm{U},{ }^{99} \mathrm{Tc}$, and ${ }^{90} \mathrm{Sr}$ dissolved approximately congruently from the fuel fragments. This is consistent with the data in Section 3.3 .1 , which indicate that the ${ }^{99} \mathrm{Tc}$ and ${ }^{90} \mathrm{Sr}$ grain-boundary inventories are quite small. Therefore, the ${ }^{99} \mathrm{Tc}$ and ${ }^{90} \mathrm{Sr}$ that dissolved from the fuel fragments must have come from the $\mathrm{UO}_{2}$ matrix, not the grain boundaries.

Figure A.38 also shows that the flow rates were varied for times between 74 and 130 days.

Because the dissolution rate didn't reach an approximately steady-state value until after about 85 days, only data from 85 to 130 days are replotted in Figure A.39. The regression line fits all the data in that

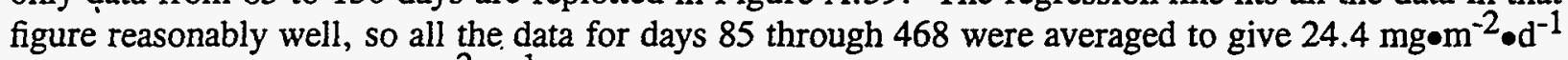
with a $2 \sigma$ value of $7.4 \mathrm{mg}^{-2} \bullet \mathrm{d}^{-1}$.

The U and ${ }^{137} \mathrm{Cs}$ data from Figure A.38 are also plotted in Figure A.40 to show the cumulative fractions dissolved over time. The ${ }^{137} \mathrm{Cs}$ data include ${ }^{137} \mathrm{Cs}$ dissolved from three sources, gap, grain boundaries, and $\mathrm{UO}_{2}$ matrix. The contribution from the grain boundaries was obtained by subtracting the $0.13 \%$ dissolved the first day (the amount attributed to ${ }^{137} \mathrm{Cs}$ from the gap) and by subtracting the dissolved $U$ fraction (equal to the fraction of ${ }^{137} \mathrm{Cs}$ dissolved congruently with the $U$ from the $\mathrm{UO}_{2}$ matrix). These derived ${ }^{137} \mathrm{Cs}$ results are plotted in Figure A.41 and can be compared to the total grain-boundary inventory of ${ }^{137} \mathrm{Cs}$, which is indicated by the line in the figure positioned at $0.48 \%$ of the total ${ }^{137} \mathrm{Cs}$ inventory (see Section 3.3.1 for the grain-boundary inventory of ATM-103 fuel). Less 
than half the grain-boundary inventory of ${ }^{137} \mathrm{Cs}$ is shown to have been leached from the fuel fragments in 4 months. Eventually the curve must become asymptotic to the line at $0.48 \%$. However, if the argument in Section 4.2.3 regarding lack of grain boundary penetration by water deeper than a few grain diameters is correct, leaching of almost $100 \%$ of the grain-boundary inventory will not happen until almost the entire fuel fragment has dissolved.

\subsubsection{Series-3 Archive Specimen}

Dissolution rates of $\mathrm{U},{ }^{137} \mathrm{Cs},{ }^{90} \mathrm{Sr}$, and ${ }^{99} \mathrm{Tc}$ measured for the Series-3 archive specimen are plotted in Figure A.42. Approximately $0.02 \%$ to $0.04 \%$ of each of the four components was dissolved

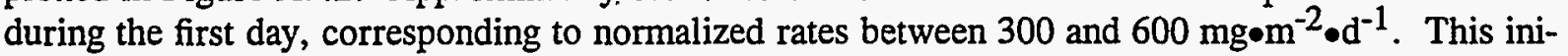
tial pulse may be a result of reaction of the fuel with the air atmosphere during the 4-year storage period. (a) The dissolution rates of ${ }^{137} \mathrm{Cs},{ }^{90} \mathrm{Sr}$, and $\mathrm{U}$ decreased by more than an order of magnitude the second day $\left({ }^{99} \mathrm{Tc}\right.$ was not measured again until day 6$)$. After the initial rapid dissolution period, ${ }^{90} \mathrm{Sr}$ dissolution appeared to be approximately congruent with that of the $\mathrm{UO}_{2}$ matrix; ${ }^{137} \mathrm{Cs}$ and ${ }^{99} \mathrm{Tc}$ continued to dissolve at rates approximately twice that of the matrix.

Results between 40 and 122 days are plotted with an expanded y-axis scale in Figure A.43. Flow rates were varied over the range 0.05 to $0.4 \mathrm{~mL} / \mathrm{min}$ during the time periods indicated in the figure. Uranium concentration is plotted versus reciprocal flow in Figure A.44 for times between 45 and 111 days. All the data fit the regression line reasonably well, which indicates that $U$ concentrations were well below saturation in the $\mathrm{J}-13$ water.

\subsubsection{SEM Examination of Spent Fuel}

Figures A.45 to A.51 are SEM photographs of various ATM-103 spent fuel specimens. Figure A.45 shows an unleached fuel fragment, while Figures A.46 to A.50 show specimens after leaching under Test 4 (Table 3.1) conditions. Figures A.46 through A.48 show fuel fragments after 137 days of leaching and Figure A.49 shows a fuel fragment after 468 days of leaching (see Figure A.37 for leaching results); Figure A.50 shows fuel grains after 144 days of leaching (see Figure A.12 for leaching results). Figure A.51 shows ATM-103 fuel grains after leaching for 100 days under Test 17 (Table 3.1) conditions plus 69 days under Test 7 (Table 3.1) conditions (see Figure A.27 for leaching results).

Note in Figure A.45 the different nature of the fracture for the different areas of the fracture surface. In some places, the fracture was intergranular and in others it was transgranular. This mixture of intergranular and transgranular fracture seems to be fairly typical of the -6 fracture surfaces examined. In some cases, the intergranular and transgranular fracture areas were intimately mixed as shown in Figure A.45. In other cases, some areas of a fracture surface were almost entirely intergranular, while other areas were almost entirely transgranular. Sometimes, one fracture surface of a fuel fragment appeared to be mostly transgranular while a different fracture surface of the same fuel fragment was predominantly intergranular.

(a) The fuel specimen was stored under air atmosphere in a glass vial with a plastic screw cap for 4 years between the termination of the Series-3 tests and the start of the flow-through test. During that time, the polymer seal in the cap degraded and integrity of the seal is assumed to have been lost. 
Figures A.46 through A.48 show the surfaces of fuel fragments that were removed from a flowthrough column ${ }^{(a)}$ after 137 days of testing under the conditions listed for Test 4 in Table 3.1 (see Section 3.1). Different areas of the top surface of the fragment shown in Figure A.46a appear quite different. A few areas were quite smooth while others were quite pitted (they have a "worm-eaten" or "sponge-like" appearance). Based on examinations of $\sim 6$ surfaces of leached fragments, a similar number of unleached fragments, as well as leached grains (Figures A.50 and A.51), it appears that the difference between the smooth grain surfaces and the worm-eaten grain surfaces depends on whether the surface prior to leaching was an intergranular fracture surface or a transgranular fracture surface. That is, the worm-eaten surfaces, whether looking at a fragment (Figures A.46 through A.49) or at grains (Figures A.50 and A.51), appear to have been grain-boundary surfaces. The smooth surfaces all appear to be transgranular fracture surfaces. The grains in Figure A.50 were removed from a flowthrough column after 144 days of testing under the Test 4 conditions in Table 3.1 (see Section 3.1), i.e., the same conditions that apply to the fragments shown in Figures A.46 through A.49.

Figure A.47 is an edge fracture surface of the same fragment shown in Figure A.46a. It has a different appearance than the other leached fragment surfaces that have been examined. The overall surface appears to be a fracture surface, but it is difficult to tell by looking at the different grains whether the fracture was intergranular or transgranular. The entire surface looks worm-eaten. A possible explanation is that the fracture occurred early in the irradiation history of the fuel pellet, and that the resulting free surface acted like a grain-boundary surface even in areas where the fracture was transgranular. In contrast, the other fracture surfaces examined are believed to have fractured after irradiation but before leaching. In support of the belief that the fractures did not occur after leaching, some surfaces have just a few grains (10\% or less) in the middle of the fracture surface that appear worm-eaten (e.g., Figure A.48). If the fracture had occurred after leaching, this would mean that the worm-eaten grain surfaces in the middle of the fragment would have to be the result of grain-boundary leaching that extended all the way to the center of the fragment. However, there is good reason to believe that water does not penetrate grain boundaries completely through the fuel fragments (Section 4.1.6). If that is true, the fracture must have occurred before leaching.

Figure A.48 shows two different areas of a fragment different from the one shown in Figures A.46 and A.47. This figure shows examples of both the worm-eaten surfaces and the smooth surfaces noted above, but it also shows clearer evidence of grain-boundary attack than the other figures. All the grain boundaries in this figure appear quite pitted. One gets the impression that a grain plucked from the surface of the fragment would expose additional surfaces with worm-eaten appearance. Figure A.48c and d show "smooth" grain surfaces that are much more pitted within the interior of the grains than the surface in Figure A.48a and b or in Figures A.46 and A.47. This seems to be an uncommon feature and is probably from a low-density region of a fuel pellet.

Figure A.49 shows a surface of a fuel fragment after 468 days of leaching under Test 4 (Table 3.1) conditions. Most of the grain surfaces show evidence of greater attack than was apparent after only 137 days (Figures A.46 to A.48). Nevertheless, some of the grain surfaces, which appear to be transgranular fracture surfaces, remain smooth just as they did after the shorter leaching period (Figures A.46 to A.48).

(a) The leached fuel fragments from this column and the unleached fragment shown in Figure A.45 came from adjacent segments of the same fuel rod. 
Figure A.51 shows the surfaces of an ATM-103 fuel grain after 100 days of leaching under Test 17 (Table 3.1) conditions plus 69 days under Test 7 (Table 3.1) conditions. The surfaces are similar in appearance to many of those in Figures A.46 to A.50. Thus, the different conditions of Tests 4 and Test 17 plus 7 both appear to have caused similar worm-eaten looking surfaces.

A BET surface area of $4,440 \mathrm{~cm}^{2} / \mathrm{g}$ was measured for the specimen shown in Figure A.51. This is much higher than the $860 \mathrm{~cm}^{2} / \mathrm{g}$ measured by the PSD method on the unleached specimen. Since the two measurement methods are expected to give similar results for this type of specimen (grain specimen), the difference apparently represents a real increase that occurred during leaching. The increased surface area following the leaching test is not surprising in view of the very rough worm-eaten appearance of the surface. However, this was not accompanied by any increase in dissolution rate (Figure A.27) as might have been expected. Why the conspicuously increased surface areas did not manifest themselves with increased dissolution rates, either in Figure A.27 or Figures A.37 and A.38, cannot be explained without further investigation.

Figure A.52 shows both unoxidized $\left(\mathrm{UO}_{2}\right)$ and oxidized $\left(\mathrm{U}_{4} \mathrm{O}_{9+\mathrm{x}}\right)$ particles of ATM-105 fuel prior to the start of dissolution testing. Figure A.53 shows the oxidized and unoxidized particles after 69 days of leaching under Test 1 (Table 3.1) conditions. The surfaces after leaching have the same sort of rough, worm-eaten, appearance as shown in Figures A.46 to A.51. There are no discernable differences between the unoxidized (Figures A.53a and A.53b) and oxidized (Figures A.53c and A.53d) particles. Smooth transgranular fracture surfaces are evident on the oxidized particle, just as was observed in many of the photographs shown in Figures A.46 to A.51. No such smooth transgranular fracture surfaces are evident for the unoxidized particle in Figures A.53a and A.53b. However, without examination of other particles, or even other areas of this same particle, it cannot be unequivocally stated that the leached unoxidized particles do not exhibit smooth transgranular fracture surfaces.

Figure A.54 shows cross-sectioned views of oxidized and unoxidized particles from the same test specimen shown in Figure A.53. The grain boundaries within two or three grain diameters of the particle surfaces appear to be somewhat more open than those closer to the interiors of the particles. This is believed to be due to penetration by water during the dissolution testing. The grain boundaries throughout the oxidized particle are more open than those of the unoxidized particle, but this difference was caused by the oxidation itself and is always observed. The apparent penetration by water to a depth of two to three grains appears to be no different between oxidized and unoxidized particles, but it is less obvious in the oxidized particle because of the generally more open grain boundaries resulting from the oxidation.

Figures A.55 and A.56 show surfaces of unoxidized and oxidized particles of ATM-106 fuel, respectively, before the start of dissolution testing. It is interesting that the surface of the oxidized particle (Figure A.56) looks more like a transgranular (as opposed to intergranular) fracture surface than expected. Several regions of this particle, as well as a second particle that is not shown, were examined and they all looked like this. This is in contrast to the oxidized ATM-105 particle shown in Figures A.52c and A.52d. It also differs from the unoxidized particle surface shown in Figure A.55. However, without examination of several more oxidized particle surfaces, it is impossible to make any generalized statements regarding the differences noted above.

No SEM surface images of the ATM-106 particles described above were taken after dissolution testing. However, several particles were cross-sectioned following 171 days of testing under Test 4 (Table 3.1) conditions. A few optical and over 30 SEM photos were taken of both the oxidized and 
unoxidized particles. Examples of the SEM images of these particles are shown in Figure A.57, but examination of all the photos was required to arrive at the impressions described below. However, before describing impressions from the current micrographs, it is necessary to digress and describe some aspects of the microstructure of this fuel, which is known from previous examinations to vary considerably (Thomas, Beyer, and Charlot 1992).

Restructuring, which is characterized by small grain sizes $(\sim 1 \mu \mathrm{m}$ down to a few 10's of nanometers) and more open grain boundaries, is evident near the outer rim of the fuel. Closer to the center of the fuel pellets, larger grains occur as a result of grain-growth, and large 5-metal particles are observed. The grain boundaries appear to be much tighter. At intermediate distances between center and edge of the pellets, little grain growth is observed, but the grain boundaries still appear to be relatively tight. As a result of this, there is considerable variation in the microstructure shown in the numerous micrographs for both oxidized and unoxidized fuel. The overall impression one gets from examination of the current set of micrographs follows:

- Water appears to have penetrated to a depth of several (at least a dozen) grain diameters in some cases where the particle appears to have originated near the pellet rim. This is more obvious for the unoxidized particle (Figure A.57b) than in the oxidized particle (Figure A.57d) because, as is typical, all the grain boundaries have been partially cracked open in the oxidized particles. As a result, the additional grain boundary opening caused by the water penetration is less obvious in the oxidized particle.

- In other cases, water apparently penetrated only one or two grain diameters (Figures A.57a and A.57c).

- On average, the water penetration depth may have been greater than for the ATM-105 fuel, described above, but this impression is not unequivocal and cannot be demonstrated by showing one or two micrographs of each fuel. Water penetration depths in the oxidized fuel may have been somewhat greater than in the unoxidized fuel. Again, this impression is impossible to quantify.

SEM photographs of the Series-3 archive specimen before testing and after 148 days of flowthrough testing are shown in Figure A.58. Figures A.58a and A.58b, which were taken 3 years after termination of the Series-3 tests but about 1 year before the start of flow-through testing, showed areas of significant alteration (compared with fuel specimens with fresh fracture surfaces or even freshly leached surfaces, examples of which are shown in Figures A.45 to A.53 and A.55 to A.56). Areas of altered appearance were still present on fragment surfaces shown in Figure A.58c and A.58d after nearly 5 months of flow-through testing.

Figures A.59 and A.60 show SEM photographs of Series-3 archive fragments after 281 days of leaching in J-13 well water. These photographs appear much different from those in Figure A.58c and A.58d, which were taken after 148 days. Figure A.58 shows no evidence of fuel grains either before or after flow-through testing. There appears to be something on the surface, perhaps left from the semistatic testing or the 4 years of storage after the semistatic tests were terminated. In contrast, Figures A.59 and A.60 clearly show fuel grains. Its as if the material covering the surfaces in Figure A.58 has been washed off. However, not much additional material was removed during the flow-through testing period between 148 and 281 days; the total fraction dissolved from the specimen represented in Figure A.58 was $8.6 \times 10^{-4}$ compared with $1.1 \times 10^{-3}$ for the specimen represented in 
Figures A.59 and A.60. Note that the worm-eaten appearance similar to that shown in Figures A.46 to A.51 may be starting to develop in Figure A.60 but not in Figure A.59.

\subsubsection{Tests with Solution Semi-Saturated with Uranium}

Figure A.61 shows that the ${ }^{137} \mathrm{Cs}$ dissolution rate was not affected by water containing a high concentration of $U$. For the first 47 days, the water pumped through the column was free of $U$. The column effluent during that period stabilized at a $U$ concentration near $0.15 \mathrm{mg} / \mathrm{L}$ from dissolution of the spent fuel. Then water containing $U$ concentrations of 6 to $8 \mathrm{mg} / \mathrm{L}$ (about half the saturation value of $\sim 15 \mathrm{mg} / \mathrm{L}$ ) was pumped through the column. No significant change in the ${ }^{137} \mathrm{Cs}$ dissolution rate was observed at this point. When water containing no $U$ was again pumped through the column starting at 85 days, an increase in both $\mathrm{U}$ and ${ }^{137} \mathrm{Cs}$ dissolution rates of $\sim 50 \%$ was observed. The reason for the increase at this point is not understood. However, the data imply that the ${ }^{137} \mathrm{Cs}$ and $\mathrm{U}$ dissolved congruently with or without a high concentration of $U$ in the feedwater. More importantly, the ${ }^{137} \mathrm{Cs}$ dissolution rate did not decrease when a high $U$ concentration was introduced.

\subsection{Supplemental Tests with Unirradiated Uranium Oxide Powders}

This section is divided into subsections that describe results for 1 ) flow-through tests with $\mathrm{UO}_{2}$ at atmospheric $\mathrm{O}_{2}$ overpressure, 2) flow-through tests with $\mathrm{UO}_{2}$ at low $\mathrm{O}_{2}$ overpressure, 3) flow-through tests with $\mathrm{U}_{3} \mathrm{O}_{7}$ and $\mathrm{U}_{3} \mathrm{O}_{8}$, and 4) SEM examination of leached $\mathrm{UO}_{2}$.

\subsubsection{Flow-Through Tests with $\mathrm{UO}_{2}$ at Atmospheric $\mathrm{O}_{2}$ Overpressure}

Figure A.62 shows data for unirradiated $\mathrm{UO}_{2}$ (see Section 2.1.2 for specimen description) tested under the same conditions as Test 4 listed in Table 3.1. The dissolution rate averaged $1.15 \pm 0.25 \mathrm{mg}^{-2} \bullet \mathrm{d}^{-1}$ after steady state was achieved for times beyond about 137 days. Only data for day 137 and beyond are plotted in Figure A.63 where the regression line is shown to pass through all the data indicating that the $U$ concentrations were well below solubility limits at all flow rates.

\subsubsection{Flow-Through Tests with $\mathrm{UO}_{2}$ at Low $\mathrm{O}_{2}$ Overpressure}

Figure A.64 shows $\mathrm{UO}_{2}$ dissolution rates at a variety of $\mathrm{O}_{2}$ overpressures. The initial conditions were the same as for Test 7 (Table 3.1). Later, the $\mathrm{O}_{2}$ overpressure was changed while all other parameters were kept the same as they were initially. For overpressures listed as $0.003 \mathrm{~atm}$, the sparge gas actually contained $0.2 \%(0.002 \mathrm{~atm}) \mathrm{O}_{2}$. However, measurement with a dissolved-oxygen analyzer indicated that the actual overpressure was closer to $0.003 \mathrm{~atm}$. The higher-than-nominal $\mathrm{O}_{2}$ overpressure is believed to have resulted from $\mathrm{O}_{2}$ diffusion into the polyethylene feedwater container from the room atmosphere. Dissolved-oxygen measurements indicated that $\mathrm{O}_{2}$ overpressures at 0.2 and $0.02 \mathrm{~atm}$ were within $5 \%$ of the nominal values listed. The highest $\mathrm{O}_{2}$ overpressure, for times beyond 280 days, was achieved by sparging the feedwater with pure $\mathrm{O}_{2}$.

The $\mathrm{O}_{2}$ overpressure listed as $2 \times 10^{-6}$ atm is an estimated value based on the following information. The feedwater was sparged with high-purity $\mathrm{N}_{2}$. The polyethylene feedwater container was placed inside a second polyethylene container, and the annulus between the two containers was continuously purged with the same high-purity $\mathrm{N}_{2}$. The purpose of the outer container was to eliminate, or 
markedly reduce, the potential for $\mathrm{O}_{2}$ from the room to diffuse into the feedwater container. The $\mathrm{O}_{2}$ concentration in the high-purity $\mathrm{N}_{2}$ was not measured, but this grade of $\mathrm{N}_{2}$ typically contains $1 \mathrm{ppm}$ (or less) of $\mathrm{O}_{2}$. Based on this fact together with the precautions described above to minimize diffusion of $\mathrm{O}_{2}$ from the atmosphere, the $\mathrm{O}_{2}$ overpressure in the feedwater was expected to be no greater than $-2 \mathrm{ppm}\left(2 \times 10^{-6} \mathrm{~atm}\right)$.

During the time that the $\mathrm{O}_{2}$ overpressure was nominally $2 \times 10^{-6} \mathrm{~atm}$, the dissolution rate continued to decrease and never stabilized. Despite never approaching a steady state dissolution rate, the $\mathrm{O}_{2}$ over-pressure was increased again after about 2 weeks. This was done because the $2 \times 10^{-6}$ atm $\mathrm{O}_{2}$ over-pressure was experimentally more difficult to maintain and because this low $\mathrm{O}_{2}$ overpressure, while of academic interest, was not of particular interest to the Yucca Mountain Project.

The observed dissolution rates at each of the listed $\mathrm{O}_{2}$ overpressures following the lowest $\mathrm{O}_{2}$ overpressure were never as high as they had been earlier. Nevertheless, the observed dissolution rates were quite reproducible at the different $\mathrm{O}_{2}$ overpressures, i.e., there was no noticeable trend with time back toward the values observed before the $2 \times 10^{-6}$ atm $\mathrm{O}_{2}$ time period.

Figures A.65 to A.67 show linear regressions for different portions of the data shown in Figure A.64. Figure A.65 includes much of the early data plus the last three points during the $2 \times 10^{-6} \mathrm{~atm} \mathrm{O} \mathrm{O}_{2}$ time period. Figure A.66 includes the last three points during the $2 \times 10^{-6} \mathrm{~atm} \mathrm{O}$ time period plus all the data after that. Figure A.67 includes only the data beyond 179 days and specifically does not include any data from the $2 \times 10^{-6}$ atm $\mathrm{O}_{2}$ time period. Despite the different portions of the data plotted in Figures A.65 to A.67, the slopes of the regression lines of all three plots are approximately the same. This is true whether or not data from the $2 \times 10^{-6}$ atm $\mathrm{O}_{2}$ time period is included and despite the fact that the absolute dissolution rates were higher before the $2 \times 10^{-6}$ atm $\mathrm{O}_{2}$ time period than they were afterward. The fact that data from the $2 \times 10^{-6}$ atm $\mathrm{O}_{2}$ time period fits the regression line reasonably well lends credibility to the estimated value $\left(2 \times 10^{-6} \mathrm{~atm}\right)$ of the $\mathrm{O}_{2}$ overpressure.

\subsubsection{Flow-Through Tests with $\mathrm{U}_{3} \mathrm{O}_{7}$ and $\mathrm{U}_{3} \mathrm{O}_{8}$}

Figure A.68 shows dissolution rates for $\mathrm{UO}_{2}, \mathrm{U}_{3} \mathrm{O}_{7}$, and $\mathrm{U}_{3} \mathrm{O}_{8}$, all under Test 4 conditions (Table 3.1). See Section 2.1.2 for a description of these materials. The dissolution rate of $\mathrm{U}_{3} \mathrm{O}_{7}$ was less than twice that of $\mathrm{UO}_{2}$ and the difference decreased near the end. The convergence of the $\mathrm{U}_{3} \mathrm{O}_{7}$ and $\mathrm{UO}_{2}$ data raise a question about whether the entire layer of $\mathrm{U}_{3} \mathrm{O}_{7}$ (Figure A.4) may have dissolved during the test so that the latter part of the curve actually represents dissolution of the underlying $\mathrm{UO}_{2}$ rather than $\mathrm{U}_{3} \mathrm{O}_{7}$. This question was shown to be unfounded by calculating, from the cumulative amount of $U$ that dissolved, that the thickness of the $\mathrm{U}_{3} \mathrm{O}_{7}$ layer that dissolved was only $\sim 0.1 \mu \mathrm{m}$ thick. This was only a small fraction of the original $\mathrm{U}_{3} \mathrm{O}_{7}$ layer, which was $-1 \mu \mathrm{m}$ thick.

Figure A.68 also shows that $\mathrm{U}_{3} \mathrm{O}_{8}$ dissolved a little faster than $\mathrm{U}_{3} \mathrm{O}_{7}$ but still only about 3 times faster than $\mathrm{UO}_{2}$ when the data are normalized by surface area. On a fractional basis, however, the $\mathrm{U}_{3} \mathrm{O}_{8}$ dissolved about 200 times faster that the $\mathrm{UO}_{2}$ (see the right-hand scales in Figure A.68). This was due to the very large surface area that was generated when the $\mathrm{UO}_{2}$ was oxidized to $\mathrm{U}_{3} \mathrm{O}_{8}$ (see Sections 2.1.2 and 2.1.3 and Figure A.5). The $\mathrm{U}_{3} \mathrm{O}_{8}$ test was terminated after 17 days because $30 \%$ of the specimen had dissolved by that time. 
Figure A.69 compares the dissolution rates of $\mathrm{UO}_{2}$ and $\mathrm{U}_{3} \mathrm{O}_{7}$ when the $\mathrm{O}_{2}$ overpressure in the feedwater was only $0.003 \mathrm{~atm}$ (Test 17 conditions, Table 3.1). Although the difference was somewhat greater than at atmospheric $\mathrm{O}_{2}$ overpressure (Figure A.68), it was still only a factor of about three. Again, the difference grew smaller with passing time.

\subsubsection{SEM Examination of Leached $\mathrm{UO}_{2}$}

Figure A.70 shows SEM photographs of $\mathrm{UO}_{2}$ particle surfaces after 221 days (Figure A.62) of flow-through testing under the same conditions as Test 4 in Table 3.1. Comparison of Figure A.70 with Figure A.3 (unleached particles) shows no notable changes due to leaching. However, the highest magnification in Figure A.3 is not high enough to allow a comparison on a very small scale.

Figure A.70 can also be compared with Figures A.46 to A.51, which show spent fuel after leaching. The worm-eaten surface appearance in many of the spent fuel photographs are absent from the $\mathrm{UO}_{2}$ surfaces.

\subsection{5 $\mathrm{UO}_{2}$ Dissolution/Streaming Potential}

Initial results from a test using the same sequence of solutions used in a previously reported test (Wilson and Gray 1990b) are plotted in Figure A.71. Compositions of the solutions (designated B, $\mathrm{BC}$, and $\mathrm{BCS}$ ) are given in Table 3.2. Measured streaming potential values were normalized to a constant solution conductivity value of $200 \mu \mathrm{mho} / \mathrm{cm}$ so that normalized streaming potential would remain proportional to zeta potential when solution composition was changed. The plotted streaming potential polarity is the same as the zeta potential, which was negative for all solutions used.

Initial erratic potentials measured in $0.002 \mathrm{M} \mathrm{NaHCO}$ solution (B) were attributed to electrode deterioration caused by the lack of $\mathrm{Cl}$ in the solution. When the solution was switched to the $\mathrm{Ca}-$

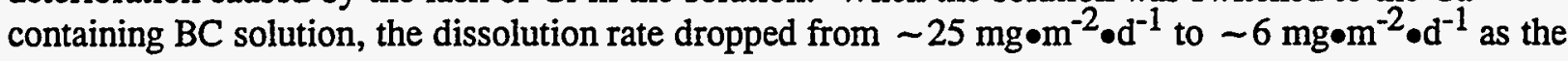
normalized streaming potential increased from about $-40 \mathrm{mV}$ to $-11 \mathrm{mV}$. The implication is that the dissolution rate decreased and zeta potential became more positive as $\mathrm{Ca}^{+2}$ adsorbed into the double layer. When the $\mathrm{BC}$ solution was changed to the $\mathrm{Ca}$ - and Si-containing $\mathrm{BCS}$ solution, a continuously decreasing trend occurred in the dissolution rate. Streaming potential became more negative during this period, first suggesting that the lower dissolution rate was correlated with adsorption of a negatively charged silicic acid species into the double layer. However, after the 30 day sample, solution pressure caused the inlet electrode stopper to pop out. A sample of $\mathrm{UO}_{2}$ particles from the inlet end of the specimen column was then examined by SEM, and a precipitate at the column inlet was found, probably some type of Si gel. Since the streaming potential is theoretically proportional to both zeta potential and pressure drop as described in Section 1.0, and much of the pressure drop likely occurred where Si gel began to plug the $\mathrm{UO}_{2}$ particle column, it is not clear what the zeta potential response to the silicic acid addition was, except that it remained negative. 
Table 3.2. Dissolution/Streaming Potential Test Solution Compositions ${ }^{(a, b, c)}$

\begin{tabular}{lccc}
\multicolumn{1}{c}{ Component } & $\mathrm{B}$ & $\mathrm{BC}$ & $\mathrm{BCS}$ \\
$\mathrm{Ca}$ & & & \\
$\mathrm{Na}$ & 46 & 46 & 10 \\
$\mathrm{Si}$ & & & 46 \\
$\mathrm{Cl}$ & & 12.0 & 32 \\
$\mathrm{NO}_{3}$ & 122 & 15.1 & 13.2 \\
$\mathrm{HCO}_{3}$ & 183 & 255 & 15.0 \\
Conductivity $(\mu \mathrm{mho} / \mathrm{cm})$ & & & 249
\end{tabular}

(a) $\mathrm{Ca}, \mathrm{Na}$ and $\mathrm{Si}$ by ICP; $\mathrm{Cl}$ and $\mathrm{NO}_{3}$ by $\mathrm{IC} ; \mathrm{HCO}_{3}$ is $\mathrm{TIC} \times 61 / 12$.

(b) Units are $\mathrm{mg} / \mathrm{L}$; solution $\mathrm{B}$ values as-prepared, all others are analytical results.

(c) $\mathrm{pH}$ range, $8.4 \pm 0.2$ for all solutions.

A second column was started in $0.002 \underline{\mathrm{M} \mathrm{NaHCO}} 3+0.0002 \underline{\mathrm{M} \mathrm{NaCl}}$ solution, and the results are shown in Figure A.72. With this solution, the conductivity-normalized streaming potential increased from $-21 \mathrm{mV}$ on day 1 to about $-4.5 \mathrm{mV}$ for days 7 through 9 . Besides being less negative than in the initial period of the first column, the streaming potential was also less erratic with $\mathrm{Cl}^{-}$present in the $0.002 \mathrm{M} \mathrm{NaHCO}_{3}$ solution. Silicic acid was added to the initial $\mathrm{NaHCO}_{3}+\mathrm{NaCl}$ solution after the 9-day sample causing the dissolution rate and streaming potential to drop. The solution was changed to $\mathrm{NaHCO}_{3}+$ silicic acid $+\mathrm{CaCl}_{2}+\mathrm{Ca}\left(\mathrm{NO}_{3}\right)_{2}$ (BCS solution) on day 20 , causing a brief increase in both dissolution rate and streaming potential, followed by a continuing decrease in both. The electrode stopper on this column also popped out on day 26. Visual examination of the inlet end of the specimen column did not reveal evidence of gel formation such as was observed in the first column. However, later removal of some of the $\mathrm{UO}_{2}$ from the inlet end of the column resulted in less negative streaming potential, indicating that partial plugging at the column inlet by Si gel may also have occurred in this column. 


\subsection{Discussion}

This section is divided into a review of the data presented in this report followed by a generalized discussion of data needs for the Yucca Mountain Project. Both of these major areas are further divided into subsections that describe specific topics.

\subsection{Review of Data Presented in this Report}

This section is divided into seven subsections that discuss results from the different types of dissolution tests conducted with spent fuel and unirradiated $U$ oxides.

\subsection{1 $\mathrm{UO}_{2}$ Matrix Phase Dissolution Kinetics}

These tests involved the use of a flow-through test method combined with spent fuel test specimens that had been ground and screened to a fine powder, which consisted predominantly of separated fuel grains. The combination of this test method and test specimen configuration allowed the intrinsic dissolution rate of the $\mathrm{UO}_{2}$ matrix of spent fuel to be accurately and unambiguously measured for the first time. It is important to understand why this test method/test specimen combination is unique in this regard.

First, the test method featured a column, or bed, of test particles through which the test solution passed at a continuous rate such that the concentration of $U$ remained well below its solubility limit. This allowed the dissolution rate of the $\mathrm{UO}_{2}$ matrix to be measured directly because the dissolution was not inhibited by solubility constraints. In contrast, test methods that involve limited water must infer the $\mathrm{UO}_{2}$ matrix dissolution rate from the measured dissolution rate of a "marker," such as $\mathrm{Sr}$, because $\mathrm{U}$ concentrations quickly reach a steady-state value in such tests due to solubility limitations. Not only does the flow-through method give a direct measure of the intrinsic $\mathrm{UO}_{2}$ matrix dissolution rate, but the results also appear to be in reasonable agreement with those obtained in semistatic tests (Section 4.1.7). This is a very important characteristic and indicates that the flow-through results are, indeed, applicable to repository conditions.

Second, the importance of the powdered test specimen cannot be overemphasized. The surface area of this type of specimen was unambiguously measured with either a BET method or a particle-size distribution method as described in Section 2.1.3. The reason this is such an important attribute is because surface area measurements made on multigrain spent fuel fragments where the internal grain boundaries are not completely exposed, for example, are inherently wrong. The problem is that no surface area measurement method can properly account for the effective surface area contribution of the.grain boundaries that are partially penetrated by water during the dissolution testing. As a result, any attempt to normalize the measured dissolution rate by the surface area of the test specimen is inherently incorrect. This problem was avoided in the current test series by the use of properly prepared powdered test specimens, which allowed the surface area to be reliably measured.

The specially prepared powdered test specimens provided another advantage. Because all the grain boundaries of such test specimens were openly exposed to the test solution, all soluble elements, such as Cs, that may have been somewhat concentrated along the grain boundaries were quickly dissolved 
and carried away by the test solution. Thereafter, all components that dissolved from the test specimen were known to have originated from within the $\mathrm{UO}_{2}$ matrix. This is in sharp contrast to the results obtained from spent fuel test specimens that consist of multigrain fragments. With multigrain specimens, it is known that Cs (and perhaps one or two other soluble elements) dissolves from two sources, preferentially from the grain boundaries and congruently from the $\mathrm{UO}_{2}$ matrix. Depending on the test method, the source of the Cs may not be determinable. This problem was avoided in the current test series by use of the test method/test specimen combination referred to above.

Two papers that describe this work have been published (Gray, Leider, and Steward 1992; Steward and Gray 1994). Therefore, the discussion here will be limited to a summary of results plus the description of some details that were not included in the publications.

Data in Table 3.1 show that the ATM-103 spent fuel dissolution rates varied from 0.5 to $20 \mathrm{mg} \bullet \mathrm{m}^{-2} \bullet \mathrm{d}^{-1}$ over the range of conditions tested. To use data such as this in performance assessment calculations (for example, Apted et al. 1990; Engel et al. 1994), one must multiply these intrinsic dissolution rates by an applicable spent fuel surface area in order to project the absolute, or fractional, rate to be used as a source term in radionuclide migration calculations. A reasonable minimum surface area to use might be the original pellet surface area plus the surface area that results from cracks that form during reactor operation. Barner (1985) measured a surface area of this nature for ATM-101 fuel to be $150 \mathrm{~mm}^{2}$ per millimeter of fuel rod length, which is equivalent to $2.2 \times 10^{-4} \mathrm{~m}^{2} / \mathrm{g}$. A similar surface area can probably be assumed for the ATM-103 fuel. This geometric area must be multiplied by a surface roughness factor, say three, as has been used throughout this report. Also, to account for some penetration of the grain boundaries by water, an additional surface area multiplication factor of six (see Section 4.1.6) is needed. Thus, the above surface area must be multiplied by a factor of 18 to give $3.9 \times 10^{-3} \mathrm{~m}^{2} / \mathrm{g}$. This leads to fractional dissolution rates in the range $7.2 \times 10^{-4}$ to $2.9 \times 10^{-2}$ per year when multiplied by the measured intrinsic dissolution rates cited above.

The maximum surface area that might reasonably be applied to the range of intrinsic dissolution rates would be sum of the individual grain surface areas. Measured BET surface areas listed for spent fuel grain specimens in Table 2.2 ranged from 860 to $2,800 \mathrm{~cm}^{2} / \mathrm{g}$. However, the latter may include a relatively large fraction of subgrain particles caused by transgranular fracturing. Therefore, a more realistic value for the total grain surface of a typical LWR spent fuel might be about $1,000 \mathrm{~cm}^{2} / \mathrm{g}$ $\left(0.1 \mathrm{~m}^{2} / \mathrm{g}\right)$. Multiplying this by the dissolution rates cited above yields fractional rates of $1.8 \times 10^{-2}$ to $7.3 \times 10^{-1}$ per year.

All of the fractional dissolution rates calculated in the two preceding paragraphs exceed the limit of $10^{-5}$ per year established by the U.S. Nuclear Regulatory Commission in 10 CFR 60 (1985), some by a large margin. Therefore, it is clear that other factors, such as a limited distribution of container failures or lower dissolution rates in more realistic groundwaters, are needed to comply with the regulations.

A notable feature of the data presented in Table 3.1 is the complex dependence of spent fuel dissolution rate on $\mathrm{O}_{2}$ overpressure. The data show that the dissolution rate depends on a combination of $\mathrm{O}_{2}$ and other variables, primarily temperature. As a result, Steward and Gray (1994) found that the data were best represented by the following Equation (4.1); 


$$
\begin{aligned}
\log (\mathrm{R})= & 9.310+0.142 \log \left[\mathrm{CO}_{3}\right]-16.7 \log \left(\mathrm{P}_{\mathrm{O}_{2}}\right)+0.140 \log [\mathrm{H}]-2130 / \mathrm{T} \\
& +6.81 \log (\mathrm{T}) \cdot \log \left(\mathrm{P}_{\mathrm{O}_{2}}\right)
\end{aligned}
$$

where the concentrations in brackets ( e.g., $\left[\mathrm{CO}_{3}\right]$ ) are in moles $/ \mathrm{L}, \mathrm{P}_{\mathrm{O}}$ is $\mathrm{O}_{2}$ overpressure in atm, and $T$ is in kelvins. The last term in Equation (4.1) is required to satisfy the complex dependence on $\mathrm{O}_{2}$ and temperature mentioned above. Note that first term in Equation (4.1) differs from the one published by Steward and Gray (1994) by the addition of $-\log (0.84)=0.076$ due to the different way in which the data were normalized (see Section 3.0).

The complex dependence on both $\mathrm{O}_{2}$ and temperature represented by the last term in Equation (4.1) is better illustrated by Figures A.15, A.27, and A.73 and by Table 4.1. Figure A.73 shows the effect of $\mathrm{O}_{2}$ overpressure on spent fuel dissolution rates at $75^{\circ} \mathrm{C}$, which was obtained from Tests 5 , 15, and 20. As indicated, data for days 2 to 23 and 63 to 161 from Figure A.15 are plotted in this figure. The slope of the regression line is shown to be 0.79 . There is still considerable scatter in the data at the lowest $\mathrm{O}_{2}$ overpressure despite elimination of the data from days 23 to 63 . One might suspect that this scatter could have been caused by variations in the $\mathrm{O}_{2}$ overpressure in the feedwater. However, given the slope of the regression line (0.79) in Figure A.73, the $\mathrm{O}_{2}$ overpressure would have had to vary by over a factor of 10 to cause the observed scatter, which seems unlikely. In fact, the two times that the $\mathrm{O}_{2}$ overpressures were directly measured with a dissolved $\mathrm{O}_{2}$ meter (at 93 and 100 days), values of 0.004 atm were found, i.e., not far from the nominal value of $0.003 \mathrm{~atm}$.

In contrast.to the strong $\mathrm{O}_{2}$ dependence shown by Figures A.15 and A.73, Figure A.27, which represents Test pairs 7 and 17, shows little or no dependence on $\mathrm{O}_{2}$ overpressure. Other test pairs where $\mathrm{O}_{2}$ overpressure was the only parameter that changed are $4 / 14$ and $6 / 16$. The $\mathrm{O}_{2}$ dependence observed for the various test pairs is summarized in Table 4.1. The data in Table 4.1 show that the rate is almost independent of $\mathrm{O}_{2}$ at $25^{\circ} \mathrm{C}$, as was also illustrated by Figure A.27. At $75^{\circ} \mathrm{C}$, reaction orders with respect to $\mathrm{O}_{2}$ of 0.79 and 0.35 were found. Although Equation (4.1) accounts only for an interaction between $\mathrm{O}_{2}$ and temperature, the data in Table 4.1 suggest that there may also be an interaction between $\mathrm{O}_{2}$ and total carbonate concentration. This is indicated by the difference between test

Table 4:1. Dependence of Dissolution Rates on $\mathrm{O}_{2}$ Overpressure

$\begin{array}{lcc}\text { Test Pairs } & \text { Temperature }\left({ }^{\circ} \mathrm{C}\right) & \mathrm{O}_{2} \text { Dependency }(\mathrm{a}) \\ 4 / 14 & 25 & \\ 5 / 15 / 20 & 75 & 0.047 \\ 6 / 16 & 75 & 0.79 \\ 7 / 17 & 25 & 0.35 \\ & & 0.051\end{array}$

(a) This is the reaction order with respect to $\mathrm{O}_{2}$, and is given by the slope of a $\log$ (dissolution rate) versus $\log \left(\mathrm{P}_{\mathrm{O}_{2}}\right)$ plot such as Figure A.73. 
pairs $5 / 15 / 20$ and $6 / 16$. Temperatures of both pairs were $75^{\circ} \mathrm{C}$ but there was a 100 -fold difference in carbonate concentrations, and the $\mathrm{O}_{2}$ dependency differed by a factor of two. Nevertheless, Steward and Gray (1994) found that Equation (4.1) represented the data about as well as an even more complex equation. And without further evidence to support the dependence of dissolution rate on a combination of $\mathrm{O}_{2}$, temperature, and carbonate concentration, the simplest equation that adequately represented the data was preferred.

The initial purpose of conducting tests with unirradiated $\mathrm{UO}_{2}$ at reduced $\mathrm{O}_{2}$ overpressures was to evaluate the performance of the test equipment, which was inspired by the unexpected results that were being obtained at low $\mathrm{O}_{2}$ overpressures with spent fuel. No problems were found and repeatable data were obtained with both $\mathrm{UO}_{2}$ and spent fuel. The inescapable conclusion was that the spent fuel exhibits unusual dependence on $\mathrm{O}_{2}$ overpressure, as discussed above, and is distinctly different from $\mathrm{UO}_{2}$ in that regard.

In addition to the complex dependence of spent fuel dissolution rate on $\mathrm{O}_{2}$ overpressure described above, Steward and Gray (1994) found that the next most important parameter was temperature followed by carbonate/bicarbonate concentration. When tested at atmospheric $\mathrm{O}_{2}$ overpressure, the data show that the dissolution rate was nearly independent of $\mathrm{pH}$ over the range tested, 8 to 10 .

Table 3.1 summarizes results from the entire matrix of spent fuel tests in this series, which included several sets of replicate tests. Tests 1,2 , and 3 were planned replicates of the same test condition. Tests 5,7 , and 15 were each duplicated to determine whether the unexpected dependence of spent fuel dissolution rates on $\mathrm{O}_{2}$ overpressures could be repeated. Test 6 was duplicated, as was described in Section 3.1, to determine whether prior testing had any influence on subsequent results when the test parameters were changed. Good repeatability was achieved in all cases except for Test 15. Table 3.1 shows that the first dissolution rate obtained for Test 15 was more than ten times lower than found the second time. Because the second value was repeated two times (Figure A.15), and because it fell more in line with the data presented in Figure A.73, a decision was made to discount the first (lower) value.

\subsubsection{Gap and Grain-Boundary Inventories}

Data reported here indicate that ${ }^{137} \mathrm{Cs}$ gap inventories (the percentage of the total ${ }^{137} \mathrm{Cs}$ inventories located within the gaps) were only about one fourth the FGR percentages for the fuel rods that were tested. In contrast, it has generally been assumed that ${ }^{137} \mathrm{Cs}$ and ${ }^{129} \mathrm{I}$ gap inventories would be approximately equal to FGR percentages. This assumption is based on 1) diffusion models where calculations indicate that $\mathrm{Cs}, \mathrm{I}$, and inert gases should diffuse out of the $\mathrm{UO}_{2}$ matrix at comparable rates under the influence of temperature gradients (Ritzman 1979);2) measurement of the Cs and I gap inventories for one Boiling Water Reactor (BWR) fuel with high FGR (Lorenz et al. 1980) and one Pressurized Water Reactor (PWR) fuel with low FGR (Lorenz et al. 1981); and 3) Canadian measurements of ${ }^{137} \mathrm{Cs}$ and ${ }^{129} \mathrm{I}$ gap inventories made on a variety of Canadian natural-uranium, heavy-water-moderated and-cooled power reactor (CANDU) fuels (Stroes-Gascoyne et al. 1987; Garisto et al. 1989). The applicability of item 2 above is somewhat doubtful because the measurements by Lorenz et al. $(1980 ; 1981)$ were made by a high-temperature vaporization method, which may give results that are different from, and inapplicable to, those obtained by aqueous dissolution. Regarding the applicability of item 3 above, the CANDU fuels tend to be operated at higher temperatures than U.S. LWR fuels and, therefore, might be expected to have generally higher FGR percentages. Despite 
the temperature difference, it is not apparent that the relationship between FGR and gap inventories of ${ }^{137} \mathrm{Cs}$ and ${ }^{129}$ I should be significantly different for the CANDU and LWR fuels because both depend upon diffusion out of the $\mathrm{UO}_{2}$ matrix. Thus, based on available information, there seems to be good reason to believe that ${ }^{137} \mathrm{Cs}$ and ${ }^{129} \mathrm{I}$ gap inventories should be about equal to FGR percentages.

However, the data presented here do not support that contention. Additional measurements on a few additional U.S. LWR fuels are needed to resolve this issue.

It has also been commonly assumed that ${ }^{99} \mathrm{Tc}$ and, perhaps, ${ }^{90} \mathrm{Sr}$ could be important components of the gap inventory although no strong evidence has been presented to support that possibility. The concept appears to be based on the fact that neither ${ }^{99} \mathrm{Tc}$ nor ${ }^{90} \mathrm{Sr}$ are particularly compatible with the $\mathrm{UO}_{2}$ matrix and potentially could migrate to the gap under the influence of temperature gradients during reactor operation, just like Cs. However, the data presented here show that very little $(<0.2 \%)$ of the ${ }^{99} \mathrm{Tc}$ and ${ }^{90} \mathrm{Sr}$ inventories were located within the gap region.

Another assumption regarding the inhomogeneous distribution of elements like $\mathrm{Cs}, \mathrm{I}, \mathrm{Tc}$, and $\mathrm{Sr}$ in spent fuel is that there should be some enrichment within the grain boundaries. The same mechanisms that drive these elements, particularly $\mathrm{Cs}$ and $\mathrm{I}$, out of the $\mathrm{UO}_{2}$ matrix into the gap should also increase their concentrations within the grain boundaries. Computer calculations have been made indicating that high concentrations might be expected in the grain boundaries of CANDU fuels (Garisto, Johnson, and Hocking 1990). However, recent experimental measurements (Stroes-Gascoyne et al. 1993) indicate that the calculations may over predict the concentrations in some cases. Data for a few U.S. LWR fuels described in the present report show that the grain-boundary inventories of ${ }^{137} \mathrm{Cs}$ are no more than about $1 \%$, even for fuels with up to $18 \%$ FGR. This is consistent with microanalysis of spent fuel grain-boundary surfaces where very little ${ }^{137} \mathrm{Cs}$ was found (Thomas and Charlot 1990). Data on ${ }^{99} \mathrm{Tc}$ and ${ }^{90} \mathrm{Sr}$ reported here show that $<0.2 \%$ of the inventories of these elements were located in soluble form at the grain boundaries.

\subsubsection{Dissolution Rates of Oxidized Spent Fuel and Unirradiated Uranium Oxides}

Results from flow-through dissolution tests with oxidized specimens of spent fuel and unirradiated $\mathrm{U}_{3} \mathrm{O}_{7}$ and $\mathrm{U}_{3} \mathrm{O}_{8}$ have been published (Gray and Thomas 1992; Gray, Thomas, and Einziger 1993; Gray and Thomas 1994). Therefore, only highlights will be discussed here together with some details that were not included in these publications.

Dissolution rates of spent fuels oxidized to $\mathrm{U}_{4} \mathrm{O}_{9+\mathrm{x}}$ have been measured for only two fuels so far, ATM-105 and ATM-106. The surface area normalized dissolution rate of oxidized fuel grains was little or no higher than unoxidized $\left(\mathrm{UO}_{2}\right)$ grains for ATM-105. Oxidized ATM-106 fuel grains dissolved somewhat faster than unoxidized grains, but still the difference was a factor of only about five.

When ATM-106 fuel was oxidized to $\mathrm{U}_{3} \mathrm{O}_{8}$, its surface area normalized dissolution rate was about 10 times faster than unoxidized ATM-106 fuel grains and about twice as fast as ATM-106 fuel grains oxidized to $\mathrm{U}_{4} \mathrm{O}_{9+\mathrm{x}}$ (compare Figures A.31a and A.32). A more important effect of oxidation to $\mathrm{U}_{3} \mathrm{O}_{8}$ was the very large increase in surface area compared to the particles used to prepare the $\mathrm{U}_{3} \mathrm{O}_{8}$ (Table 2.2). This resulted in a fractional dissolution rate (rate per unit specimen weight) of $\mathrm{U}_{3} \mathrm{O}_{8}$ equal to 150 times that of the unoxidized particles. 
At atmospheric $\mathrm{O}_{2}$ overpressure, the intrinsic dissolution rate of unirradiated $\mathrm{U}_{3} \mathrm{O}_{7}$ was less than twice that of $\mathrm{UO}_{2}$ (Figure A.68) and the intrinsic dissolution rate of unirradiated $\mathrm{U}_{3} \mathrm{O}_{8}$ was about three times that of $\mathrm{UO}_{2}$ (Figure A.68). At an $\mathrm{O}_{2}$ overpressure of $0.003 \mathrm{~atm}$, the intrinsic dissolution rate of the $\mathrm{U}_{3} \mathrm{O}_{7}$ was about three times that of $\mathrm{UO}_{2}$ (Figure A.69).

In summary, for each test conducted with oxidized spent fuel or unirradiated $\mathrm{U}_{3} \mathrm{O}_{7}$ or $\mathrm{U}_{3} \mathrm{O}_{8}$, the intrinsic dissolution rate of the oxidized material was only moderately higher than the unoxidized $\left(\mathrm{UO}_{2}\right)$ material. The largest difference was a factor of 10 with spent fuel $\mathrm{U}_{3} \mathrm{O}_{8}$. This difference seems relatively small when it is considered that the surface of $\mathrm{UO}_{2}$ must first oxidize to a stoichiometry equivalent to approximately $\mathrm{UO}_{2.33}$ before significant dissolution of $U$, as $U(V I)$ species, can occur (Johnson and Shoesmith 1988). These observations suggest that initial surface oxidation is not involved in a rate-limiting step of the $\mathrm{UO}_{2}$ oxidation/dissolution mechanism.

A major reason for conducting dissolution tests with spent fuel oxidized to $\mathrm{U}_{3} \mathrm{O}_{8}$ was to determine whether the inter- and intra-granular cracks produced by the oxidation would lead to high initial dissolution rates of soluble radionuclides. Therefore, $100 \%$ of the test-column effluent was collected and analyzed for each of the first two days. During the first day $(29 \mathrm{~h}), 16.2 \%$ of the total ${ }^{137} \mathrm{Cs}$ inventory dissolved compared with $4.5 \%$ of the $U$; thus the excess of ${ }^{137} \mathrm{Cs}$ over $U$ was about $12 \%$, which represents the amount exposed by oxidation-induced cracking and grain-boundary opening. Nearly congruent dissolution of ${ }^{137} \mathrm{Cs}$ and $\mathrm{U}$ was observed during the second and subsequent days. The origin of the excess ${ }^{137} \mathrm{Cs}$ over $U$ is further discussed below:

Because the fuel particles were washed before they were oxidized to $\mathrm{U}_{3} \mathrm{O}_{8}$, the ${ }^{137} \mathrm{Cs}$ associated with the gap inventory would have been removed. Also, the ${ }^{137} \mathrm{Cs}$ inventory associated with grain boundaries of this fuel was only about $1 \%$ of the total ${ }^{137} \mathrm{Cs}$ inventory, as described in Section 4.2. Therefore, of the $12 \%$ excess of ${ }^{137} \mathrm{Cs}$ over $U$ cited above, only $1 \%$ could have come from oxidationinduced opening of the grain boundaries. The remaining $11 \%$ had to originate from oxidation-induced cracking of the grain interiors. This confirms speculation that oxidation to $\mathrm{U}_{3} \mathrm{O}_{8}$ might expose a relatively large fraction of the ${ }^{137} \mathrm{Cs}$ inventory to water where it could be readily dissolved, at least for this one type of spent fuel (ATM-106).

\subsubsection{SEM Examination of Spent Fuel}

The SEM photographs of leached spent fuel specimens (Figures A.46 to A.51, and A.53) illustrate an interesting feature (see Section 3.3.4 for description) that apparently represents a difference in the way exposed grain-boundary surfaces and transgranular fracture surfaces were corroded. It is not possible at this time to say what effect this might have on long-term leaching. In fact, SEM photographs of the Series-3 archive spent fuel specimens that were previously leached under semistatic conditions (Figure A.58), which more closely represent expected conditions in a repository, do not show this feature. However, one of the two archive fragments examined after 284 days of flowthrough testing (Figure A.60) does have rough surfaces similar to the grain-boundary surfaces shown in Figures A.46 to A.51, and A.53. Thus, the primary implications of the worm-eaten surfaces may be any effect that these surfaces may have on these particular tests. One would expect the surface areas to change as this feature develops and, in fact, a large BET surface area was measured for the one specimen that was examined after leaching (see Figure A.51 and Section 3.3.4). Also, since an unchanging surface area was assumed in the normalized dissolution rate calculations, one would expect these "apparent" dissolution rates to increase as the true surface area apparently increased. However, this 
was not observed. Thus, despite surface roughening during leaching that appears to be a common feature in these tests, the dissolution rates did not increase as a result.

\subsubsection{Summary Comparison of Dissolution Rates for Different Types of Specimens}

Figure A.62 shows that the Test 4 (Table 3.1) dissolution rate of unirradiated $\mathrm{UO}_{2}$ stabilized at $1.2 \mathrm{mg} \bullet \mathrm{m}^{-2} \cdot \mathrm{d}^{-1}$ after $\sim 140$ days. A portion of the same batch of $\mathrm{UO}_{2}$ powder tested under the same conditions at LLNL stabilized at a rate near $4 \mathrm{mg} \bullet \mathrm{m}^{-2} \bullet \mathrm{d}^{-1}$ after $\sim 250$ days. A similar difference was measured by the two laboratories when portions of the same batch of unirradiated $\mathrm{UO}_{2}$ was tested under the same flow-through conditions using a saline test solution (Gray et al. 1994). This factor of three or four difference between laboratories is far better than the 1 to 2 orders of magnitude comparisons that were possible using previous testing methods.

A test matrix similar to that shown in Table 3.1 was completed at LLNL using unirradiated $\mathrm{UO}_{2}$ (Steward and Gray 1994). This allowed a direct comparison between $\mathrm{UO}_{2}$ and ATM-103 spent fuel. Under atmospheric $\mathrm{O}_{2}$ conditions (note the complex dependence of spent fuel dissolution rates on $\mathrm{O}_{2}$ overpressures discussed in Section 4.1.1), the average dissolution rates of $\mathrm{UO}_{2}$ were about three times higher than those for the spent fuel. However, since this difference was about the same as that cited above using portions of the same batch of $\mathrm{UO}_{2}$, there appears to be no discernable difference between the ATM-103 spent fuel and $\mathrm{UO}_{2}$.

The test with unirradiated $\mathrm{UO}_{2}$ at $\mathrm{PNNL}$ that was conducted under the conditions of Test 4 in Table 3.1 allow a direct comparison, by the same laboratory, with spent fuel tested under those conditions. As shown by Figure A.62, the average dissolution rate of the $\mathrm{UO}_{2}$ was $1.2 \mathrm{mg} \bullet \mathrm{m}^{-2} \bullet \mathrm{d}^{-1}$ after $\sim 140$ days compared with $4.1 \mathrm{mg}^{-2} \mathrm{~m}^{-2} \bullet \mathrm{d}^{-1}$ for the spent fuel. While this difference is the reverse of that cited in the paragraph above, it should be noted that the comparison here was for a single condition whereas the one above was an average over several test conditions. Data presented by Steward and Gray (1994) indicated that apparent differences between spent fuel and $\mathrm{UO}_{2}$ varied from test to test. These apparent differences, as well as the one cited above, can most likely be attributed to random variations. Thus, it must be concluded, on the basis of the data presented here and by Steward and Gray (1994), that there is no significant difference between the dissolution rates of ATM-103 spent fuel and $\mathrm{UO}_{2}$ under the conditions tested.

Data presented in Table 3.1 and Figures A.30 and A.31 allow comparisons between ATM-103, ATM-105, and ATM-106 fuels. Figure A.30 shows that the unoxidized ATM-105 fuel grain specimen dissolved at $\sim 7 \mathrm{mg}^{-2} \mathrm{~m}^{-2} \bullet \mathrm{d}^{-1}$ under Test 1 conditions. Table 3.1 shows that the three ATM-103 specimens tested under Test 1 conditions dissolved at an average rate of $7.3 \mathrm{mg}^{\prime} \mathrm{m}^{-2} \bullet \mathrm{d}^{-1}$, which is very good agreement. Figure A.31 shows that the unoxidized ATM-106 fuel grain specimen dissolved at $-1.5 \mathrm{mg}^{-2} \mathrm{~m}^{-2} \mathrm{~d}^{-1}$ under Test 4 conditions. Table 3.1 shows that the ATM-103 specimen tested under

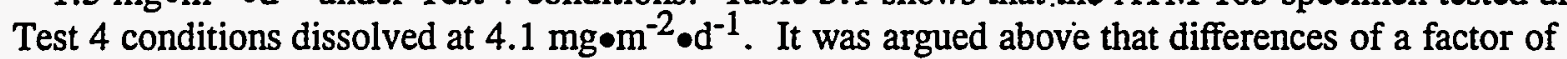
three or less are insignificant when based on a single test. Thus, these test results do not distinguish any significant differences between the ATM-103, ATM-105, and ATM-106 fuels. Nor was there any difference between unirradiated $\mathrm{UO}_{2}$ and ATM-103 spent fuel, as was noted above.

Despite the similarity between spent fuel and unirradiated $\mathrm{UO}_{2}$, there was a difference in the way spent fuel and $\mathrm{UO}_{2}$ responded to changes in $\mathrm{O}_{2}$ overpressure. Steward and Gray (1994) noted that the reaction order with respect to $\mathrm{O}_{2}$ was approximately 0.5 for $\mathrm{UO}_{2}$ over the $\mathrm{O}_{2}$ overpressure range 
0.002 to 0.2 atm. A similar result was obtained here over the $\mathrm{O}_{2}$ overpressure range $2 \times 10^{-6}$ to 1.0 atm (Figures A.65 to A.67). However, the response of spent fuel to changes in $\mathrm{O}_{2}$ overpressure were much more complex as was discussed in Section 4.1. The reason for the difference between spent fuel and $\mathrm{UO}_{2}$ in this regard is not known, but it is possible that radiolysis, which may play a role in the spent fuel tests but not $\mathrm{UO}_{2}$ tests, could be responsible for at least part of the difference.

\subsubsection{Grain Boundary Penetration by Water}

Figures A.30 and A.31 show data for both grains and particles of ATM-105 and ATM-106 fuels. Comparison of the $U$ dissolution rates from particles versus grains for both oxidized and unoxidized test specimens shows that particles apparently dissolved faster than grains. As described in the following paragraphs, this apparent difference was used to estimate the depth to which the water penetrated the grain boundaries of the particle specimens during those tests. The estimated penetration was based on the idea that intrinsic dissolution rates must be independent of specimen morphology and that the apparent difference in dissolution rates occurred only because of the different methods used to measure the surface areas of the grain and particle specimens.

Surface-area measurements of multi-grain spent fuel particles are inherently ambivalent. The BET method may overestimate the effective surface area by including some of the internal grain boundary surfaces that are not open to penetration by water. In contrast, the PSD method used to estimate the surface areas of the particle specimens assumes that none of the grain boundaries are exposed to water. In reality, a small portion of the grain boundaries clearly are penetrated by water. ${ }^{\text {(a) }}$ Thus, the PSD method actually underestimates the effective surface area of the particle specimens somewhat even though the calculated areas included a surface roughness factor of three.

Grain specimen surface areas measured by the BET method are thought to be reasonable representations of the surfaces actually exposed to water, as discussed in Section 2.1.3. Therefore, the dissolution rates shown in Figures A.30 and A.31 for the grain specimens are expected to be true intrinsic rates.

Since true intrinsic dissolution rates of particles and grains must be equal, the apparent difference between particles and grains shown in Figures A.30 and A.31 must be due to the exposed grainboundary surfaces of the particles that were not accounted for by the PSD surface-area measurement method. This apparent difference between particles and grains can be used to estimate the depth of grain boundary penetration by the water as follows.

If the grain boundaries for just the outer layer of grains on each particle were penetrated by the water, the exposed surface area would be increased by a factor of roughly five ${ }^{(b)}$ over the calculated value. This is enough to account for the observed difference in dissolution rates between the ATM-105

(a) In this view, essentially $100 \%$ of the grain boundaries that intersect the surfaces of a particle are penetrated by water to a depth of one, or a few, grain diameters. However, grain boundaries in the interior of the particle are not penetrated. Thus, only a "small portion" of the total volume of grain boundaries in a particle are penetrated by the water.

(b) The increased surface area would be exactly a factor of five if the grains were cubes and the exposed surface increased from just the outer surface to the outer surface plus the four side surfaces. 
grains and particles (Figure A.30). However, dissolution from the confines of grain boundaries is likely to be slower than from free surfaces due to limited movement of the test solution within the grain boundaries. The limited movement might allow the $U$ concentrations to approach saturation, and transport of reacting species in and out of grain boundary regions may depend upon diffusion. Therefore, the actual depth of water penetration could reasonably be expected to be at least 2 or 3 grain layers.

By similar argument, the 15-fold faster dissolution rate of unoxidized ATM-106 fuel particles, compared to grains (Figure A.31), should correlate with three times the grain-boundary exposure of the ATM-105 fuel particles. That is, the outer six to nine layers of grain boundaries of the unoxidized ATM-106 fuel particle specimen were apparently exposed to water. Also by similar argument, the 30-fold faster dissolution rate of oxidized ATM-106 fuel particles, compared to grains (Figure A.31), should correlate with a dozen or more layers of grain boundaries exposed to water.

The above estimate of grain boundary penetration is consistent with the ceramographic examinations of particles described in Section 3.3.4. However, the ceramographic impressions are not unequivocal as might be expected from the following calculations of grain boundary widening. To start, the thickness of exposed surfaces that dissolve can be determined by integrating the measured dissolution rate for grains over time and dividing by the density. If grain-boundary surfaces dissolve at the same rate as exposed surfaces, this implies grain boundary widening of $0.04 \mu \mathrm{m}$ to $0.2 \mu \mathrm{m}$ in 100 days for unoxidized and oxidized ATM-106 fuel particles, respectively. However, SEM ceramography would not readily resolve the grain-boundary widening until it exceeded $-0.1 \mu \mathrm{m}$. This suggests that tests of much longer duration would be required before grain-boundary attack becomes more manifest using SEM ceramography.

An estimate of grain boundary penetration by water can also be made for the ATM-103 fuel fragments described in Section 3.3.2. The dissolution rate of these fragments for times beyond 85 days was shown to be $24.4 \mathrm{mg}^{-2} \bullet \mathrm{d}^{-1}$ under Test 4 conditions. This is six times higher than the Test 4 value listed in Table 3.1 for ATM-103 grains. By the same argument offered above for ATM-105 fuel, the 6-fold higher dissolution rate of the ATM-103 fragments implies grain boundary penetration by water to a depth of 2 to 3 grain layers.

The above estimates of grain boundary penetration were based on the relative rates of $U$ dissolution from the grains and particles or fragments. A second method of estimating grain boundary penetration makes use of the ${ }^{137} \mathrm{Cs}$ grain-boundary inventory and the grain boundary dissolution rate estimates described in Sections 3.3.1 and 3.3.2. Figure A.41 shows that $42 \%(0.2 / 0.48)$ of the grain boundary inventory of ${ }^{137} \mathrm{Cs}$ dissolved in 120 days. This indicates that water penetrated and dissolved ${ }^{137} \mathrm{Cs}$ from $42 \%$ of the volume of the fragments. The fragments averaged $2.5 \mathrm{~mm}$ in size; thus a layer $250 \mu \mathrm{m}$ thick around each fragment represents $42 \%$ of the fragment volume. Since the grains in ATM-103 fuel average $18 \mu \mathrm{m}$ (Table 2.1), the $250 \mu \mathrm{m}$ layer represents a thickness equal to 14 grain diameters.

The two different estimates of water penetration into the grain boundaries of ATM-103 fuel given in the preceding two paragraphs may result from solubility limitations for the U-based estimate that would not similarly limit the ${ }^{137} \mathrm{Cs}$-based estimate. That is, water may very well penetrate 14 grain layers and dissolve away ${ }^{137} \mathrm{Cs}$. However, $U$ concentrations within the confines of the grain boundaries may approach saturation and limit the amount of $U$ that is removed from those regions. This would simply be manifested in the argument presented here as a smaller penetration depth when the estimate is based on the $U$ data. 


\subsubsection{Series-3 Archive Specimen}

Following the initial rapid dissolution period in the flow-through test with the Series-3 archive specimen (originally tested at $25^{\circ} \mathrm{C}$ ), the subsequent dissolution of ${ }^{90} \mathrm{Sr}$ appeared to be approximately congruent with that of the $\mathrm{UO}_{2}$ matrix (see Figures A.42 and A.43). This shows that there was no preferential dissolution of ${ }^{90} \mathrm{Sr}$ from grain boundaries or other sources. Because $\mathrm{U}$ and ${ }^{90} \mathrm{Sr}$ dissolved congruently in the flow-through test, the implication is that they also dissolved congruently in the semistatic test. This further implies that the ${ }^{90} \mathrm{Sr}$ fractional dissolution rates in the $25^{\circ} \mathrm{C}$ semistatic tests were indicative of matrix dissolution rates. In the $85^{\circ} \mathrm{C}$ semistatic tests, ${ }^{90} \mathrm{Sr}$ appeared to have precipitated from solution and would not be a good indicator of matrix dissolution rates. Measurement of the relative $\mathrm{U},{ }^{137} \mathrm{Cs}$, and ${ }^{99} \mathrm{Tc}$ fractional dissolution rates from a Series-3 specimen previously tested at $85^{\circ} \mathrm{C}$ in a flow-through test at $85^{\circ} \mathrm{C}$ is recommended. By measuring the ratio of $\mathrm{U}$ to ${ }^{137} \mathrm{Cs}$ or $\mathrm{U}$ to ${ }^{99} \mathrm{Tc}$ dissolution rates in a flow-through test, one might apply these same ratios to the $85^{\circ} \mathrm{C}$ Series-3 test thereby allowing the matrix dissolution rate in that test to be estimated.

The fractional rates observed in the Series-3 test were $6.1,6.9$, and $3.9 \times 10^{-7}$ per day for ${ }^{137} \mathrm{Cs}$, ${ }^{99} \mathrm{Tc}$, and ${ }^{90} \mathrm{Sr}$, respectively (Wilson $1990 \mathrm{~b}$ ). These can be converted to normalized rates by dividing by the estimated surface area, $7.2 \mathrm{~cm}^{2} / \mathrm{g}$ (see Table 2.2 ). This calculation gives normalized values of $0.85,0.96$, and $0.54 \mathrm{mg} \bullet \mathrm{m}^{-2} \cdot \mathrm{d}^{-1}$ for ${ }^{137} \mathrm{Cs},{ }^{99} \mathrm{Tc}$, and ${ }^{90} \mathrm{Sr}$, respectively. These values are less than 10 times lower than those shown for the respective elements in Figure A.43. In particular, the ${ }^{90} \mathrm{Sr}$ rate in the flow-through test was approximately congruent with $U$ and was about 6 times greater than in the semistatic test. This indicates that the $\mathrm{UO}_{2}$ matrix dissolution rate in the flow-through test was only about 6 times greater than in the semistatic test, a relatively small difference considering the different nature of the tests. Moreover, the greater dissolution rates measured in the flow-though test may have been at least partially the result of alteration of the fuel during the 4-year storage time between the end of the Series-3 test and the start of the flow-through test.

An important aspect of the flow-through test with the Series-3 archive specimen is that the results from the two tests on the same specimen suggest that the water contact mode, flow-through or static, was relatively unimportant. This would imply that results from flow-through tests can be applied with reasonable confidence to project upper bound dissolution rate behavior under repository conditions. However, unsaturated tests that were recently started by Finn et al. (1994) involve still a different type of water contact mode, and future results from those tests may require a reassessment of the above conclusion.

\subsection{8 $\mathrm{UO}_{2}$ Dissolution/Streaming Potential}

Correlating dissolution rate to zeta potential by measuring streaming potential during a flowthrough dissolution test appears to be a sound approach only for solutions that do not precipitate and increase flow resistance through the column during the test. Indications of Si-gel precipitation were observed in the current developmental tests several days to a few weeks after switching the columns to solutions containing dissolved silicic acid. Measurement of solution pressure at some point between the peristaltic pump and specimen column is recommended to indicate such precipitation in future tests using this method. For small pressure changes, it may be valid to normalize measured streaming potential to both pressure and conductivity to roughly correlate streaming potential to zeta potential. 
For measurement of zeta potential in solutions that result in localized plugging of the specimen column, such as the silicic-acid-containing solutions used here, the electrophoretic method would be recommended. Zeta meters based on the electrophoretic method measure the migration velocity of finely suspended particles through a solution in an applied electric field. Another approach initially considered for this study was measurement of surface charge by the potentiometric titration method. The streaming potential method was chosen because it is a simple on-line measurement that could be made during flow-through dissolution tests.

Correlation between surface charge and dissolution rate was recently reviewed by Bruno et al. (1991). The surface charge of $\mathrm{UO}_{2}$ tends to be negative at high $\mathrm{pH}$ values, becoming more positive as the amphoteric surface is protonated at lower $\mathrm{pH}$ values. A correlation discussed in the review was that the rates of dissolution of $\mathrm{UO}_{2}$ and $\mathrm{U}_{3} \mathrm{O}_{7}$ are at their minimum at near-neutral $\mathrm{pH}$ values, which correspond to the zero point of charge. In the current study, the most negative streaming potentials (in the absence of $\mathrm{Si}$ gel formation) were measured in $\mathrm{NaHCO}_{3}$ solution which also produced the highest dissolution rates. The observation that dissolution rate and zeta potential both decreased when $\mathrm{Ca}+2$ was added may be analogous to the reported $\mathrm{pH}$ effects if $\mathrm{Ca}^{+2}$ adsorbs into the potential-determining layer reducing the magnitude of the negative surface potential. A mechanism by which Si may act to depress dissolution rates may be adsorption or reaction of dissolved $\mathrm{Si}$ species at the $\mathrm{UO}_{2}$ surface forming a stable surface layer phase that acts as a kinetic barrier to dissolution processes.

\subsection{Spent Fuel Dissolution Issues Related to Geologic Disposal}

As described in Section 1.0, radionuclides in spent fuel can be divided into two groups based on solubility. Although most of the radioactivity occurs in the form of low-solubility nuclides, they are not the subject of this report because their potential for release from the repository is not likely to depend on the characteristics of the fuel nor on the dissolution rate of the $\mathrm{UO}_{2}$ matrix. In contrast, the potential for release of high solubility nuclides will be partially dependent on their distribution in the fuel, on the characteristics of the fuel, and on the response of the fuel to interactions with groundwater. Of the soluble nuclides, ${ }^{14} \mathrm{C}$ is not addressed in this report in part because of the prospect that the regulations regarding its release may change (Van Konynenburg 1991; 1994). Some issues involving the potential for release of other soluble radionuclides from spent fuel in a geologic repository are enumerated and defined below.

\subsubsection{Gap and Grain-Boundary Inventories}

The most prominent elements in this category are ${ }^{137} \mathrm{Cs}$ and ${ }^{129} \mathrm{I}$. Although ${ }^{99} \mathrm{Tc}$ and ${ }^{90} \mathrm{Sr}$ are sometimes also included, the results of this study suggest that the amounts of ${ }^{99} \mathrm{Tc}$ and ${ }^{90} \mathrm{Sr}$ located, in soluble form, in the gap and grain boundaries are quite small.

Solubilities could influence the invientory measurements. For example, ${ }^{99} \mathrm{Tc}$ occurs at least partially as part of a 5-metal phase (Thomas and Charlot 1990) that is not very soluble. Some of the 5-metal particles lie within the grain boundaries and could be considered part of the grain-boundary inventory. However, this would be misleading because it is only the soluble gap and grain-boundary inventories that are meaningful. Similarly, although most of the ${ }^{137} \mathrm{Cs}$ in the gap and grain boundaries is expected to occur as soluble compounds such as CsI, some could occur as relatively insoluble compounds, such as Cs urinates. Although sparingly soluble Cs compounds may not dissolve in short-term 
laboratory experiments, they could contribute to the rapid release term in a repository since "rapid", in this case, could be a few years. This issue has not been addressed.

Data reported here indicate that ${ }^{137} \mathrm{Cs}$ gap inventories are less than expected, only about one fourth the FGR percentage. Grain-boundary inventories of ${ }^{137} \mathrm{Cs}$ were generally about $1 \%$ or less. Gap and grain-boundary inventories of ${ }^{99} \mathrm{Tc}$ and ${ }^{90} \mathrm{Sr}$ were essentially unmeasurable, i.e., less than about $0.2 \%$. Although the data reported here cover FGR percentages from near zero to $18 \%$, they cover only the five fuels (total of 8 rods) listed in Table 2.1. A generalized statement regarding relatively low inventories would be more convincing if a few additional fuels were tested.

One measurement of the dissolution rate of ${ }^{137} \mathrm{Cs}$ from grain boundaries of ATM-103 fuel was made for 120 days (Figure A.41). There is the potential to extend this time to 468 days simply by performing ${ }^{137} \mathrm{Cs}$ analyses on additional existing samples from the test with ATM-103 fragments (Section 3.3.2). However, the measurement of grain boundary dissolution rates could become relatively less important if low grain boundary inventories of ${ }^{137} \mathrm{Cs}$ and other elements is confirmed.

\subsubsection{Fuel Matrix Dissolution Rates}

This topic has been one of much research by several countries for a number of years. Much has been learned. However, until the advent of flow-through dissolution tests using finely powdered spent fuel specimens of the sort reported herein, it was never certain that true $\mathrm{UO}_{2}$ matrix dissolution rates were being measured. It is comforting, therefore, to find that the data reported here are in reasonable agreement with other published reports of spent fuel dissolution rates. It is also reassuring to find that the dissolution rates reported here under high-flow-rate conditions, which guarantee maximum rates, are not much higher (factor of 10 or less) than those reported for near-static conditions, which are more representative of expected repository conditions.

Given the existing data base on spent fuel dissolution rates resulting from this and previously published reports, it is important to consider what additional information is required to bring reasonable closure to this issue. The following discussion addresses some important parameters.

\section{Effect of Spent Fuel Condition}

The condition, or state of deterioration, of the fuel if and when it is contacted by groundwater will be one of the most important criterion for determining its dissolution rate. Data presented here on two different fuels suggest that oxidation to $\mathrm{U}_{4} \mathrm{O}_{9+\mathrm{x}}$ may have minimal effect. Measurements on one additional fuel oxidized to $\mathrm{U}_{4} \mathrm{O}_{9+x}$ will be made in the near future. If the results are similar to those obtained with the other two fuels, this aspect of potential fuel oxidation will begin to look relatively less important.

However, if the fuel were oxidized to $\mathrm{U}_{3} \mathrm{O}_{8}$, the effect on dissolution rate can be very large due primarily to the large increase in surface area (see Section 4.2 .3 for additional discussion on the importance of surface areas). Based on the one spent fuel tested so far, the intrinsic dissolution rate of fuel oxidized to $\mathrm{U}_{3} \mathrm{O}_{8}$ may be only $\sim 10$ times higher than unoxidized $\left(\mathrm{UO}_{2}\right)$ fuel. However, because of the increased surface area, the dissolution rate per unit mass of fuel was $\sim 150$ times higher. Another important effect of the increased surface area, which results from both inter- and intra-granular cracking, is that it exposes additional ${ }^{137} \mathrm{Cs}$ (and, perhaps, other high-solubility elements) to immediate 
dissolution upon contact by water. In the one test conducted with fuel oxidized to $\mathrm{U}_{3} \mathrm{O}_{8}, 12 \%$ of the ${ }^{137} \mathrm{Cs}$ was made available for immediate dissolution. This was in addition to that already available in the gap region of the fuel.

If spent fuel could oxidize to $\mathrm{U}_{3} \mathrm{O}_{8}$ in a repository, this would have serious consequences. In addition to the increased potential for dissolution described above, the fuel cladding would split because of the density decrease (Einziger and Strain 1986; Einziger 1994) and make the fuel more accessible to any groundwater ingress. To better quantify the potential for increased dissolution should fuel be oxidized to $\mathrm{U}_{3} \mathrm{O}_{8}$, additional fuels must be tested. And to further assess the consequences of fuel oxidation, dissolution tests with even higher oxidation states of spent fuel, e.g., $\mathrm{UO}_{3} \bullet \mathrm{xH}_{2} \mathrm{O}$, are planned.

\section{Effect of Groundwater Chemistry}

This is a subject that has received considerable attention, both in this report and by other researchers. The main question that remains is one of ensuring that the important water chemistry parameters have been bounded. Examples of remaining uncertainties include the following:

- Is further investigation of $\mathrm{pH}<7$ needed? Low $\mathrm{pH}$ could be important if radiation combined with small amounts of water result in radiolytic generation of $\mathrm{HNO}_{3}$. There are two important aspects of this question. One is the potential for low $\mathrm{pH}$ to develop in a repository. The second is the potential for low-pH environments to be produced in tests with fresh spent fuel (none other exists) thereby creating conditions that are not realistic for a repository. To the extent that this could happen, information is required to allow this "unrealistic" effect to be factored out of the data base.

- Should the effect of radiation on dissolution rates be further investigated? This is a separate question from the one above. Radiation has the potential to increase the redox potential, which is expected to increase dissolution rates, of a repository environment. Although this may be relatively unimportant if the repository is in equilibrium with the atmosphere, the effects of radiation on dissolution rates in different environments is not well known.

- How does spent fuel dissolution respond to changes in $\mathrm{O}_{2}$ overpressure? Until the data in this report demonstrated the complexity of this response, the answer was thought to be known at least approximately. If the repository $\mathrm{O}_{2}$ environment is assumed to be approximately atmospheric, then the above question may be academic. However, if a low oxidation potential in a repository were thought to be achievable (either by tailoring the environment or by selecting a different site), the data in this report indicate that a corresponding decrease in dissolution rate, as would have been expected, may not occur. Therefore, if the potential benefit of a repository with low oxidation potential were proposed, then the response of spent fuel dissolution to changes in $\mathrm{O}_{2}$ overpressure should be further explored.

- What effect does the presence of $\mathrm{Si}$ and $\mathrm{Ca}$ in groundwater have on dissolution rates? Wilson and Gray (1990b) showed that the addition of $\mathrm{Si}$ and $\mathrm{Ca}$ to a bicarbonate solution could reduce the dissolution rate of unirradiated $\mathrm{UO}_{2}$ up to at least 100 times. Despite the limited work with streaming-potential measurements (Section 3.4.5), the mechanism of this effect has not been determined. Because most groundwaters contain some $\mathrm{Si}$ and $\mathrm{Ca}$, the potential benefit of these 
elements on spent fuel dissolution rates should be quantified. Additional effort should also be made to understand the mechanism of this effect in order to add credibility to any benefits that may be claimed.

\section{Effect of Fuel Type}

There seems to have been a great deal of emphasis placed by various people and organizations, at least verbally, on measuring the effects of various spent fuel variables, such as burnup, on dissolution rates. However, no evidence has been published to date that would suggest that fuel variables have more than a minor effect on dissolution rates. Data in this report indicate that there is little difference between unirradiated $\mathrm{UO}_{2}$ (zero burnup) and spent fuel with burnup to $50 \mathrm{MWd} / \mathrm{kgM}$ when both were tested at atmospheric $\mathrm{O}_{2}$ overpressure. No measurable difference between PWR and BWR fuel was found (however, only one BWR fuel was tested in the current program). Thus, there does not seem to be a strong argument for testing more than three or four additional types of fuel. One additional high burnup fuel ( $>60$, preferably $>70 \mathrm{MWd} / \mathrm{kgM}$ ) should be tested to determine whether the lack of dependence on burnup extends to very high values. A second type of fuel that should be tested is one that contains a burnable poison, e.g., Gd. Although Gd is not expected to affect dissolution rates, this should be confirmed. Third, a second BWR fuel should be tested to confirm the similarity between BWR and PWR fuels.

\subsubsection{Effective Surface Areas}

This is undoubtedly the largest uncertainty, by far, remaining in the realm of spent fuel dissolution. The question for performance assessment activities is, "To what surface area should the reported dissolution rates be applied?" The answer can vary by several orders of magnitude. The minimum surface area might be the original pellet surface area plus new surfaces resulting from cracks generated during reactor operation. Potentially, the wetted surface area could be even smaller due to limitations in the amount of water. The maximum surface area that might reasonably have to be considered could be the entire grain boundary area if water were able to penetrate to the interior of the entire volume of fuel fragments along grain boundaries. The effect on fractional dissolution rates of these different surface area assumptions was calculated for the dissolution rates measured in this report in Section 4.1.1.

A more likely scenario than total grain boundary penetration is one where water could penetrate each fragment to a depth of only a few grain diameters. Further penetration would then be expected to slow to the same speed at which the exterior grain surfaces dissolve. That is what appears to happen in short-term laboratory tests. The problem comes in trying to prove that this mechanism prevails over hundreds or thousands of years in a repository. Plans have been made by PNNL and AECL to investigate the depth of water penetration along grain boundaries for fuels exposed to water for very long times (up to 20 years). However, it may take a long-term program dedicated specifically to the investigation of grain boundary penetration rates to provide a credible answer to this question. 


\subsection{References}

10 CFR 60. 1985. U.S. Nuclear Regulatory Commission, "Disposal of High-Level Radioactive Wastes in Geologic Repositories." U.S. Code of Federal Regulations.

Apted, M. J., W. J. O'Connell, K. H. Lee, A. T. MacIntyre, T. -S. Ueng, W.W.-L, Lee, and T. H. Pigford. 1990. Preliminary Calculations of Release Rates of Tc-99, 1-129, and Np-237 from Spent Fuel in a Potential Repository in Tuff. LBL-31069, Lawrence Berkeley Laboratory, Berkeley, California.

Apted, M. J., A. M. Liebetrau, and D. W. Engel. 1987. "Spent Fuel as a Waste Form: Analysis with AREST Performance Assessment Code." In Waste Management '87, Vol. 2 High-Level Waste, ed. R. G. Post, pp. 545-554. Proceedings of the Symposium on Waste Management at Tucson, Arizona.

Barner, J. O. 1985. Characterization of LWR Spent Fuel MCC-Approved Testing Material-ATM-101. PNL-5109, Rev. 1, Pacific Northwest Laboratory, Richland, Washington.

Brunauer, S., P. Emmett, and E. Teller. 1938. "Adsorption of Gases in Multimolecular Layers." J. Am. Chem. Soc. 60:309.

Bruno, J., I. Casas, and I. Puigdomenech. 1991. "The Kinetics of Dissolution of $\mathrm{UO}_{2}$ Under Reducing Conditions and the Influence of an Oxidized Surface Layer $\left(\mathrm{UO}_{2+\mathrm{x}}\right)$ : Application of a Continuous Flow-Through Reactor." Geochimica et Cosmochimica Acta 55:647-658.

Einziger, R. E., L. E. Thomas, H. C. Buchanan, and R. B. Stout. 1992. "Oxidation of Spent Fuel in Air at 175 to $195^{\circ} \mathrm{C}: "$ J. Nucl. Mater. 190:53-60.

Einziger, R. E., and R. V. Strain. 1986. "Behavior of Breached Pressurized Water Reactor Spent-Fuel Rods in an Air Atmosphere Between $250^{\circ}$ and $360^{\circ} \mathrm{C}$." Nucl. Tech. 75:82-95.

Einziger, R. E. 1994. "Preliminary Spent Fuel Oxidation Source Term Model." High-Level Radioactive Waste Management: Proceedings of the Fifth International Conference, pp. 554-559. American Nuclear Society, Inc., La Grange Park, Illinois.

Engel, D. W., B. P. McGrail, J. A. Fort, and J. S. Roberts. 1994. "Development and Feasibility of a Waste Package Coupled Reactive Transport Model (AREST-CT)." High-Level Radioactive Waste Management: Proceedings of the Fifth International Conference, pp. 1214-1221. American Nuclear Society, Inc., La Grange Park, Illinois. 
Finn, P. A., M. Gong, J. K. Bates, J. W. Emery, and J. C. Hoh. 1994. "The Effect of Fuel Type in Unsaturated Spent Fuel Tests." High-Level Radioactive Waste Management: Proceedings of the Fifth International Conference, pp. 1080-1087. American Nuclear Society, Inc., La Grange Park, Illinois.

Forsyth, R. S., and L. O. Werme. 1992. "Spent Fuel Corrosion and Dissolution." J. Nucl. Mater. 190, pp. 3-19.

Garisto, N. C., E. R. Vance, S. Stroes-Gascoyne, and L. H. Johnson. 1989. Instant-Release Fractions for the Assessment of Used Nuclear Fuel Disposal. AECL-9892, Whiteshell Nuclear Research Establishment, Pinawa, Manitoba, Canada.

Garisto, N. C., L. H. Johnson, and W. H. Hocking. 1989. "An Instant Release Source Term for the Assessment of Used Nuclear Fuel Disposal." In Second International Conference on CANDU Fuel, Conference Proceedings, pp. 352-368, Pembroke, Ontario, Canada.

Grambow, B. 1989. Spent Fuel Dissolution and Oxidation. An Evaluation of Literature Data. SKB Technical Report 89-13, Swedish Nuclear Fuel and Waste Management Co., Stockholm, Sweden.

Grambow, B., R. S. Forsyth, L. O. Werme, and J. Bruno. 1990. "Fission Product Release from Spent $\mathrm{UO}_{2}$ Fuel Under Uranium-Saturated Oxic Conditions." Nucl. Tech., 92:204-213.

Gray, W. J., and D. M. Strachan. 1991. "UO 2 Matrix Dissolution Rates and Grain Boundary Inventories of Cs, Sr, and Tc in Spent LWR Fuel." Sci. Basis for Nucl. Waste Management. XIV 212:205-212. Eds. T. Abrajano, Jr., and L. H. Johnson, pp. 205-112. Materials Research Society, Pittsburgh, Pennsylvania.

Gray, W. J., D. M. Strachan, and C. N. Wilson. 1991. "Gap and Grain-Boundary Inventories of Cs, Tc, and Sr in Spent LWR Fuel." PNL-SA-19689, Pacific Northwest Laboratory, Richland, Washington.

Gray, W. J., H. R. Leider, and S. A. Steward. 1992. "Parametric Study of LWR Spent Fuel Dissolution Kinetics." J. Nucl. Mater., 190:46-52.

Gray, W. J., D. M. Strachan, and C. N. Wilson. 1992. "Gap and Grain-Boundary Inventories of Cs, Tc, and Sr in Spent LWR Fuel." Sci. Basis for Nucl. Whaste Management XV, Vol. 257, ed. C. G. Sombret, pp. 353-360. Materials Research Society, Pittsburgh, Pennsylvania.

Gray, W. J., and L. E. Thomas. 1992. "Dissolution Rates of As-Received and Partially Oxidized Spent Fuel." High-Level Radioactive Waste Management: Proceedings of the Third International Conference, pp. 1458-1464. American Nuclear Society, Inc., La Grange Park, Illinois. 
Gray, W. J., L. E. Thomas, and R. E. Einziger. 1993. "Effects of Air Oxidation on the Dissolution Rate of LWR Spent Fuel." Sci. Basis for Nucl. Waste Management XVI. Vol. 294, ed.

C. G. Interrante and R. T. Pabalan, pp. 47-54. Materials Research Society, Pittsburgh, Pennsylvania.

Gray, W. J., J. C. Tait, S. A. Steward, and D. W. Shoesmith. 1994. "Interlaboratory Comparison of $\mathrm{UO}_{2}$ Dissolution Rates." High-Level Radioactive Waste Management: Proceedings of the Fifth International Conference, pp. 2597-2601. American Nuclear Society, Inc., La Grange Park, Illinois.

Gray, W. J., and L. E. Thomas. 1994. "Initial Results from Dissolution Testing of Various Air-Oxidized Spent Fuels." Sci. Basis for Nucl. Waste Management XVII. Vol. 333, eds. A. Barkatt, and R. A. Van Konynenburg, pp. 391-398. Materials Research Society, Pittsburgh, Pennsylvania.

Guenther, R. J., et al. 1988a. Characterization of Spent Fuel Approved Testing Material - ATM-103. PNL-5109-103, Pacific Northwest Laboratory, Richland, Washington.

Guenther, R. J., et al. 1988b. Characterization of Spent Fuel Approved Testing Material - ATM-106. PNL-5109-106, Pacific Northwest Laboratory, Richland, Washington.

Guenther, R. J., et al. 1991a. Characterization of Spent Fuel Approved Testing Material - ATM-104. PNL-5109-104, Pacific Northwest Laboratory, Richland, Washington.

Guenther, R. J., et al. 1991b. Characterization of Spent Fuel Approved Testing Material - ATM-105. PNL-5109-105, Pacific Northwest Laboratory, Richland, Washington.

Johnson, L. H., N. C. Garisto, and S. Stroes-Gascoyne. 1985. "Used-Fuel Dissolution Studies in Canada." In Waste Management '85, Vol. 1--High-Level Waste, ed. R. G. Post, pp. 479-482.

Proceedings of the Symposium on Waste Management at Tucson, Arizona.

Johnson, L. H., and D. W. Shoesmith. 1988. "Spent Fuel," Chapter 11 in Radioactive Waste Forms for the Future, eds. W. Lutze, and R. C. Ewing, North-Holland Publishers, New York.

Kruyt, H. R. 1952. Colliod Science, Vol. 1. Elsevier, New York.

Lorenz, R. A., J. L. Collins, and A. P. Malinauskas. 1980. Fission Product Release from Highly Irradiated LWR Fuel. NUREG/CR-0722, prepared by Oak Ridge National Laboratory for the U.S. Nuclear Regulatory Commission, Washington, D.C.

Lorenz, R. A., J. L. Collins, M. F. Osborne, R. L. Towns, and A. P. Malinauskas. 1981. Fission Product Release from BWR Fuel Under LOCA Conditions. NUREG/CR-1773, prepared by Oak Ridge National Laboratory for the U.S. Nuclear Regulatory Commission, Washington, D.C. 
Migge H. 1989. "Thermochemical Comparison of the Systems Re-O and Tc-O." Sci. Basis for Nucl. Waste Management XII, Vol. 127, eds. W. Lutze, and R. C. Ewing, pp. 205-213. Materials Research Society, Pittsburgh, Pennsylvania.

National Research Council. 1990. Rethinking High-Level Radioactive Waste Disposal, A Position Statement of the Board on Radioactive Waste Management. National Academy Press, Washington, D.C.

O'Connell, W. J., and R. S. Drach. 1986. Waste Package Performance Assessment: Deterministic System Model Program Scope and Specification. UंCRL-53761, Lawrence Livermore National Laboratory, Livermore, California.

Ritzman, R. L. 1979. "Fission Gas Release Model II. Iodine, Cesium, and Tellurium at High Temperature." In proceedings of ANS Topical Meeting on LIGHT WATER REACTOR FUEL PERFORMANCE, pp. 328-335. American Nuclear Society, Inc., La Grange Park, Illinois.

Scheidegger, A. E. 1974. The Physics of Flow Through Porous Media, 3rd edition. University of Toronto Press, Toronto, Ontario, Canada.

Steward, S. A., and W. J. Gray. 1994. "Comparison of Uranium Dissolution Rates from Spent Fuel and Uranium Dioxide." High-Level Radioactive Waste Management: Proceedings of the Fifth International Conference, pp. 2602-2608. American Nuclear Society, Inc., La Grange Park, Illinois.

Stroes-Gascoyne, S., L. H. Johnson, and D. M. Sellinger. 1987. "The Relationship Between Gap Inventories of Stable Xenon, ${ }^{137} \mathrm{Cs}$, and ${ }^{129}$ I in Used CANDU Fuel." Nucl. Technol. 77:320-330.

Stroes-Gascoyne, S., J. C. Tait, R. J. Porth, J. L. McConnell, T. R. Barnsdale, and S. Watson. 1993. "Measurements of Grain-Boundary Inventories of ${ }^{137} \mathrm{Cs},{ }^{90} \mathrm{Sr}$, and ${ }^{99} \mathrm{Tc}$ in Used CANDU Fuel." Sci. Basis for Nucl. Waste Management XVI, Vol. 294, eds. C. G. Interrante, and R. T. Pabalan, pp. 41-46. Materials Research Society, Pittsburgh, Pennsylvania.

Stroes-Gascoyne, S., J. C. Tait, R. J. Porth, J. L. McConnell, and W. J. Lincoln. 1994. "Release of ${ }^{14} \mathrm{C}$ from the Gap and Grain-Boundary Regions of Used CANDU Fuels to Aqueous Solutions." Waste Management, 4:385-392.

Thomas, L. E., and R. J. Guenther. 1988. "Characterization of Low-Gas-Release LWR Fuels by Transmission Electron Microscopy." Sci. Basis for Nucl. Waste Management XII, Vol. 127, eds. W. Lutze, and R. C. Ewing, pp. 293-300, Materials Research Society, Pittsburgh, Pennsylvania.

Thomas, L. E., and L. A. Charlot. 1990. "Analytical Electron Microscopy of Light-Water Reactor Fuels." Ceramic Transactions 9:397-407. 
Thomas, L. E., C. E. Beyer, and L. A. Charlot. 1992. "Microstructural Analysis of LWR Spent Fuels at High Burnup." J. Nucl. Mater. 188:80-89.

Van Konynenburg, R. A. 1991. "Gaseous Release of Carbon-14: Why the High Level Waste Regulations Should be Changed." High-Level Radioactive Waste Management: Proceedings of the Second International Conference, pp. 313-319. American Nuclear Society, Inc., La Grange Park, Illinois.

Van Konynenburg, R. A. 1994. "Behavior of Carbon-14 in Waste Packages for Spent Fuel in a Tuff Repository." Waste Management, Vol 14, pp. 363-383.

Westrum, E. F., Jr., and F. Grønvold. 1962. "Triuranium Heptaoxides: Heat Capacities and Thermodynamic Properties of $\alpha$ - and $\beta-\mathrm{U}_{3} \mathrm{O}_{7}$ from 5 to $350^{\circ} \mathrm{K}$." J. Phys. Chem. Solids, 23:39-53.

Wilson, C. N. 1990a. Results from NNWSI Series 2 Bare Fuel Dissolution Tests. PNL-7169, Pacific Northwest Laboratory, Richland, Washington.

Wilson, C. N. 1990b. Results from NNWSI Series 3 Spent Fuel Dissolution Tests. PNL-7170, Pacific Northwest Laboratory, Richland, Washington.

Wilson, C. N. 1991. "Results from Long Term Dissolution Tests Using Oxidized Spent Fuel." Sci. Basis for Nucl. Waste Management XIV, Vol. 212, eds. T. Abrajano, Jr., and L. H. Johnson. pp. 197-204. Materials Research Society, Pittsburgh, Pennsylvania.

Wilson, C. N., and W. J. Gray. 1990a. "Effects of Water Composition on the Dissolution Rate of $\mathrm{UO}_{2}$ Under Oxidizing Conditions." In High Level Radioactive Waste Management, Vbl. 2, pp. 1431-1436. American Nuclear Society, Inc., La Grange Park, Illinois.

Wilson, C. N., and W. J. Gray. 1990b. "Measurement of Soluble Nuclide Dissolution Rates from Spent Fuel." Sci. Basis for Nucl. Waste Management XIV, Vol. 176 eds. V. M. Oversby and P. W. Brown, pp. 489-498. Materials Research Society, Pittsburgh, Pennsylvania. 
Appendix A

Figures 



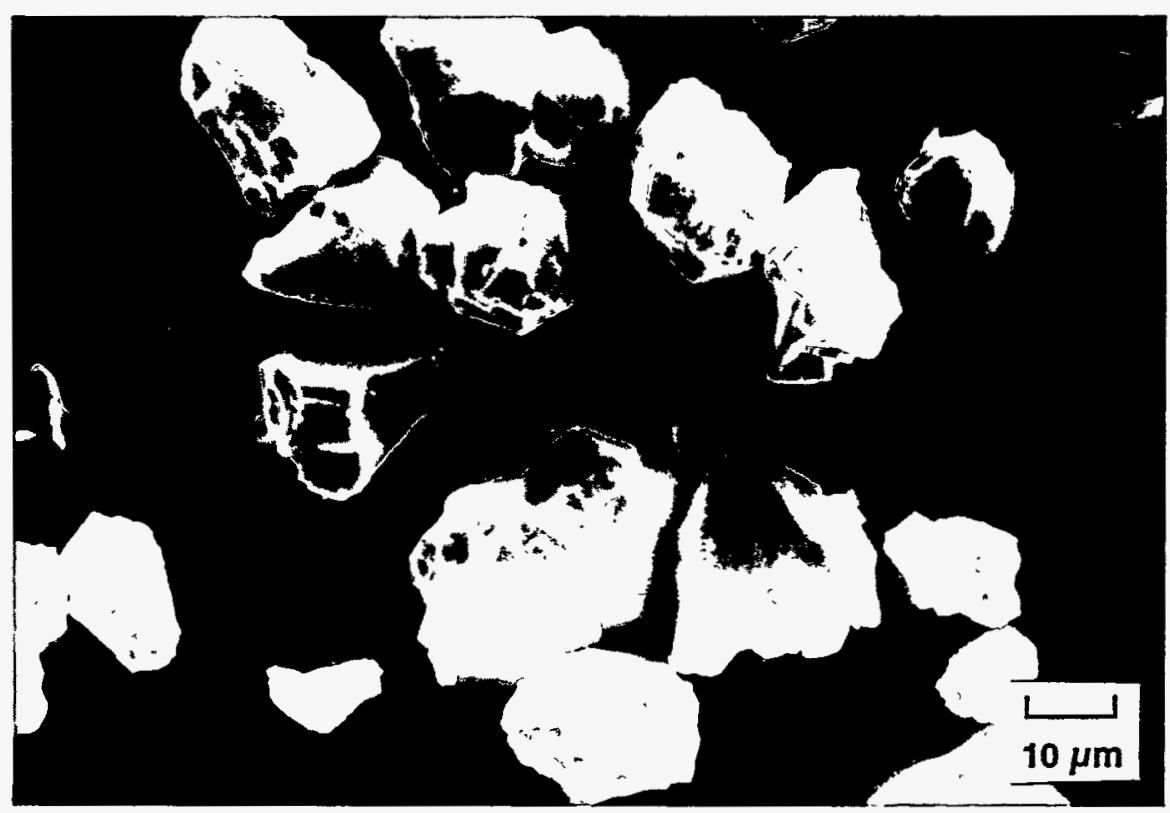

Figure A.1. SEM Photograph of Screened and Washed Grains of ATM-103 Spent Fuel 

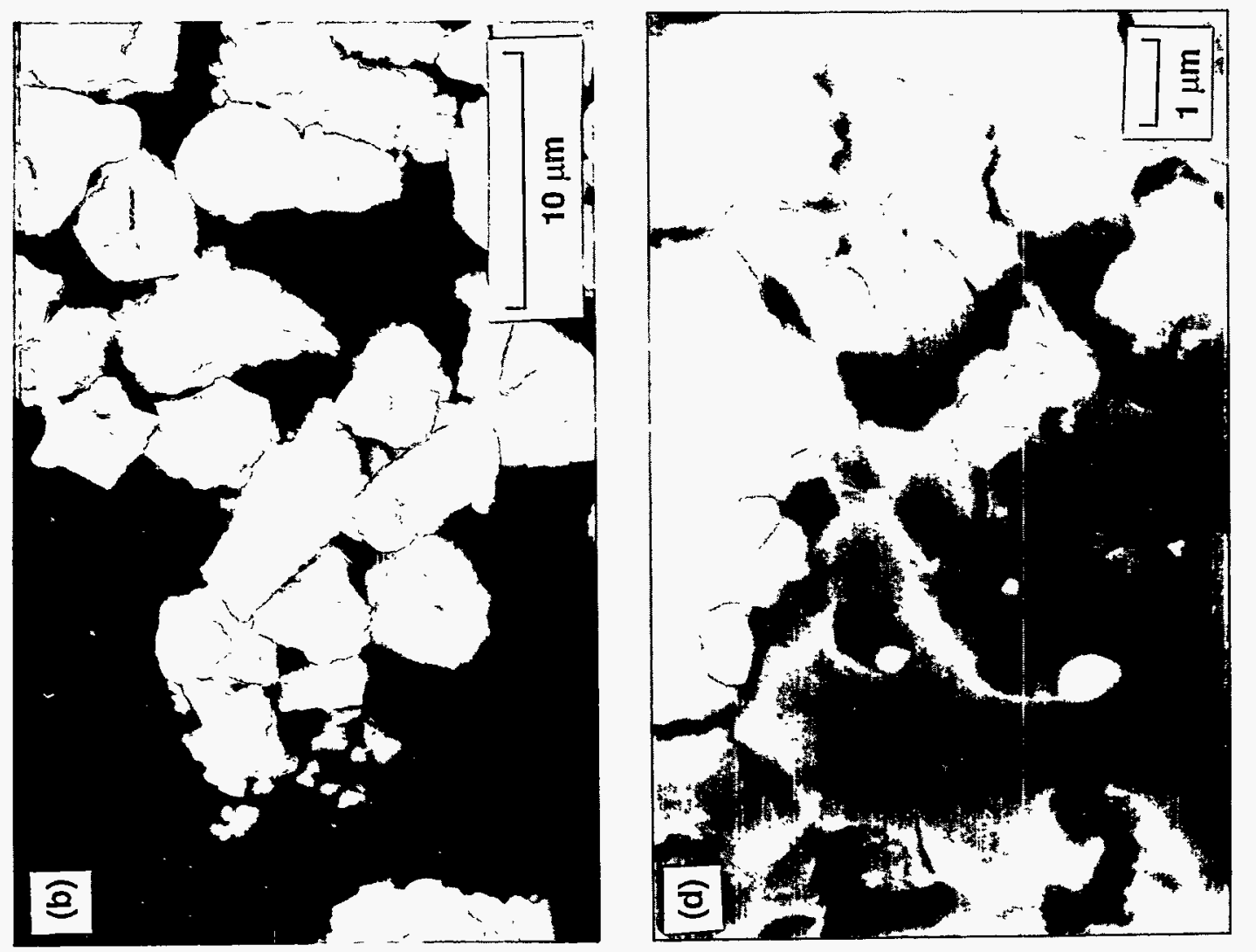


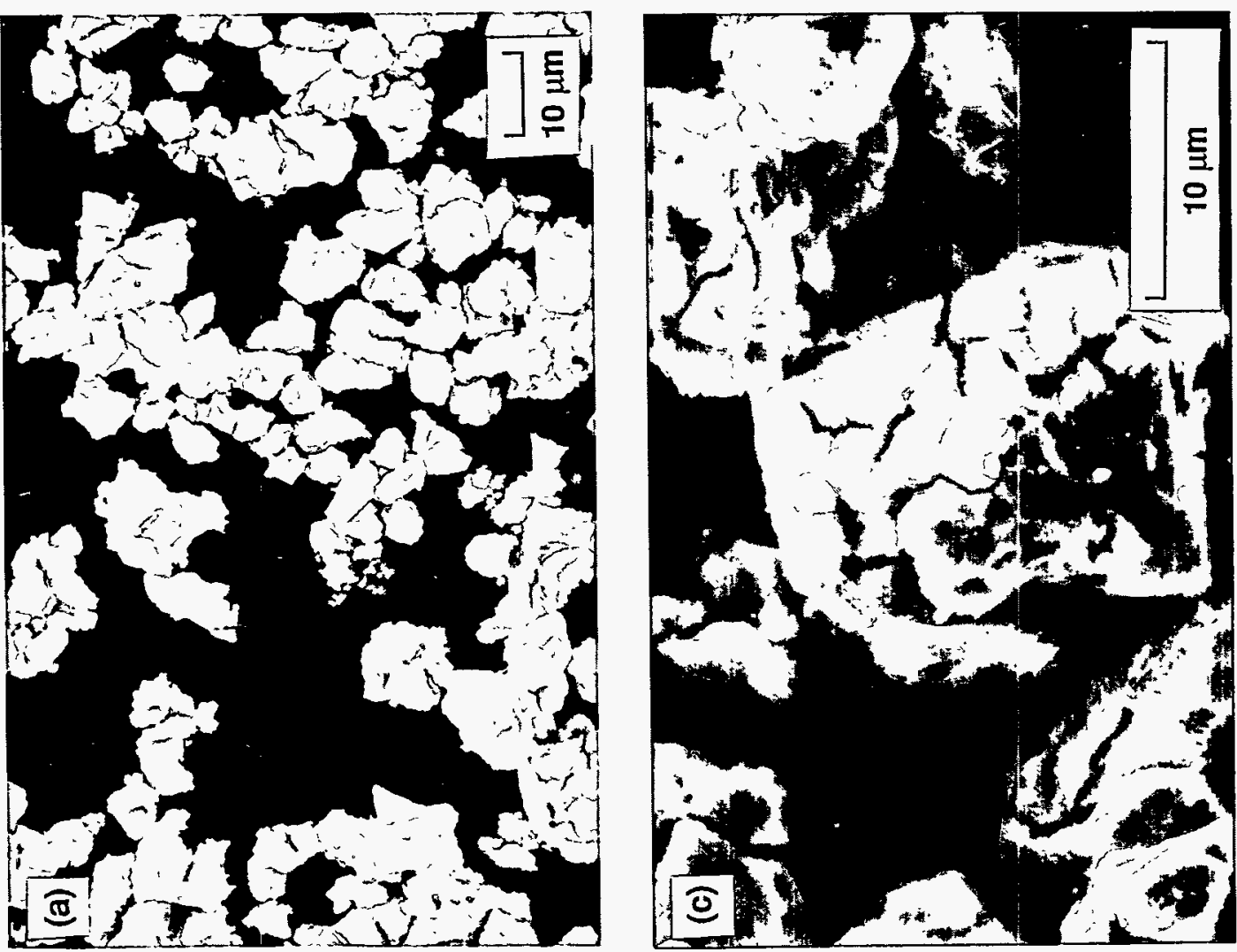

A. 2 

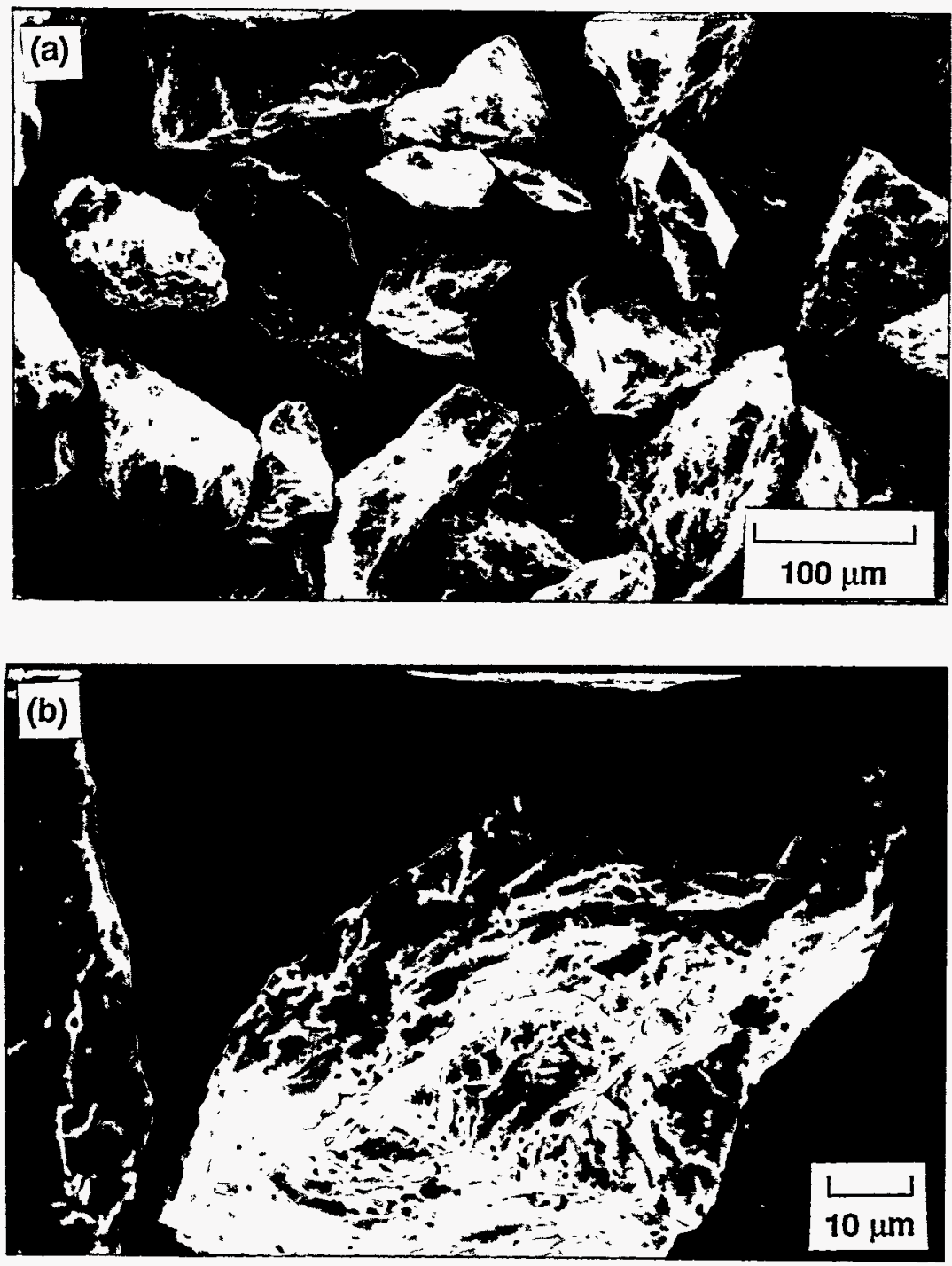

Figure A.3. SEM Photograph of Screened and Washed Powder Prepared from Unirradiated $\mathrm{UO}_{2}$ Pellets: (a) Overall view, (b) Center of a 


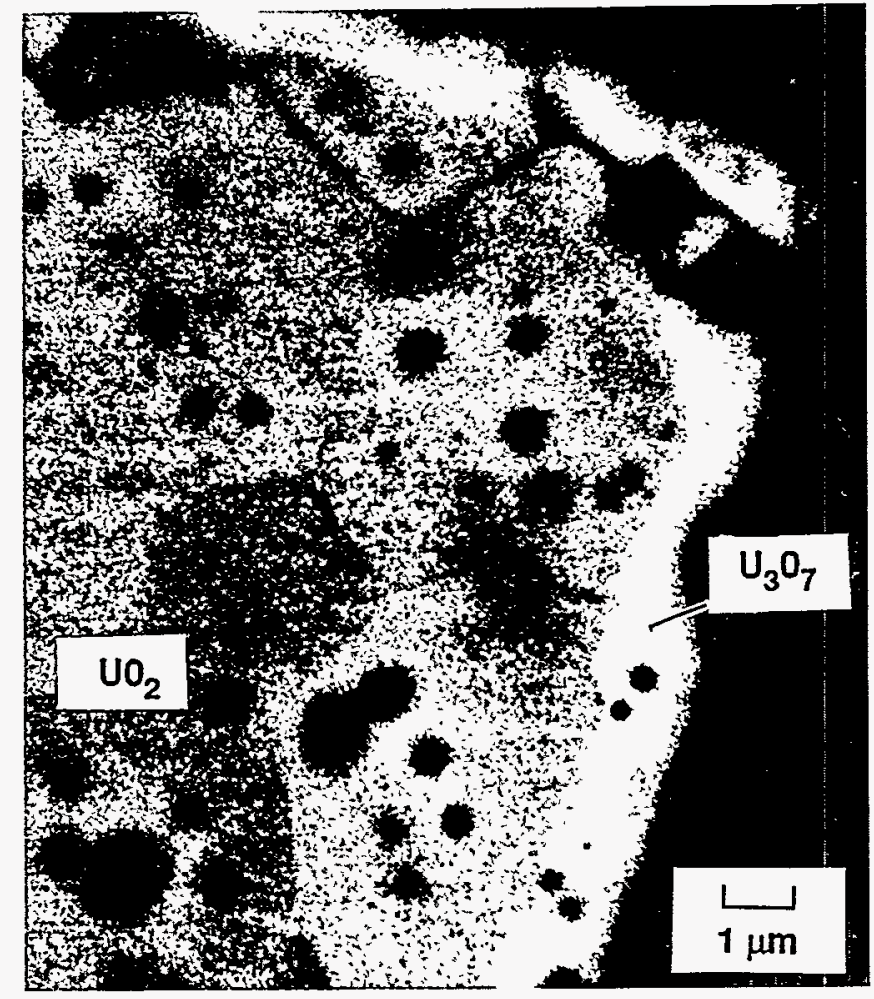

Figure A.4. SEM Photograph of Unirradiated $\mathrm{U}_{3} \mathrm{O}_{7}$ 

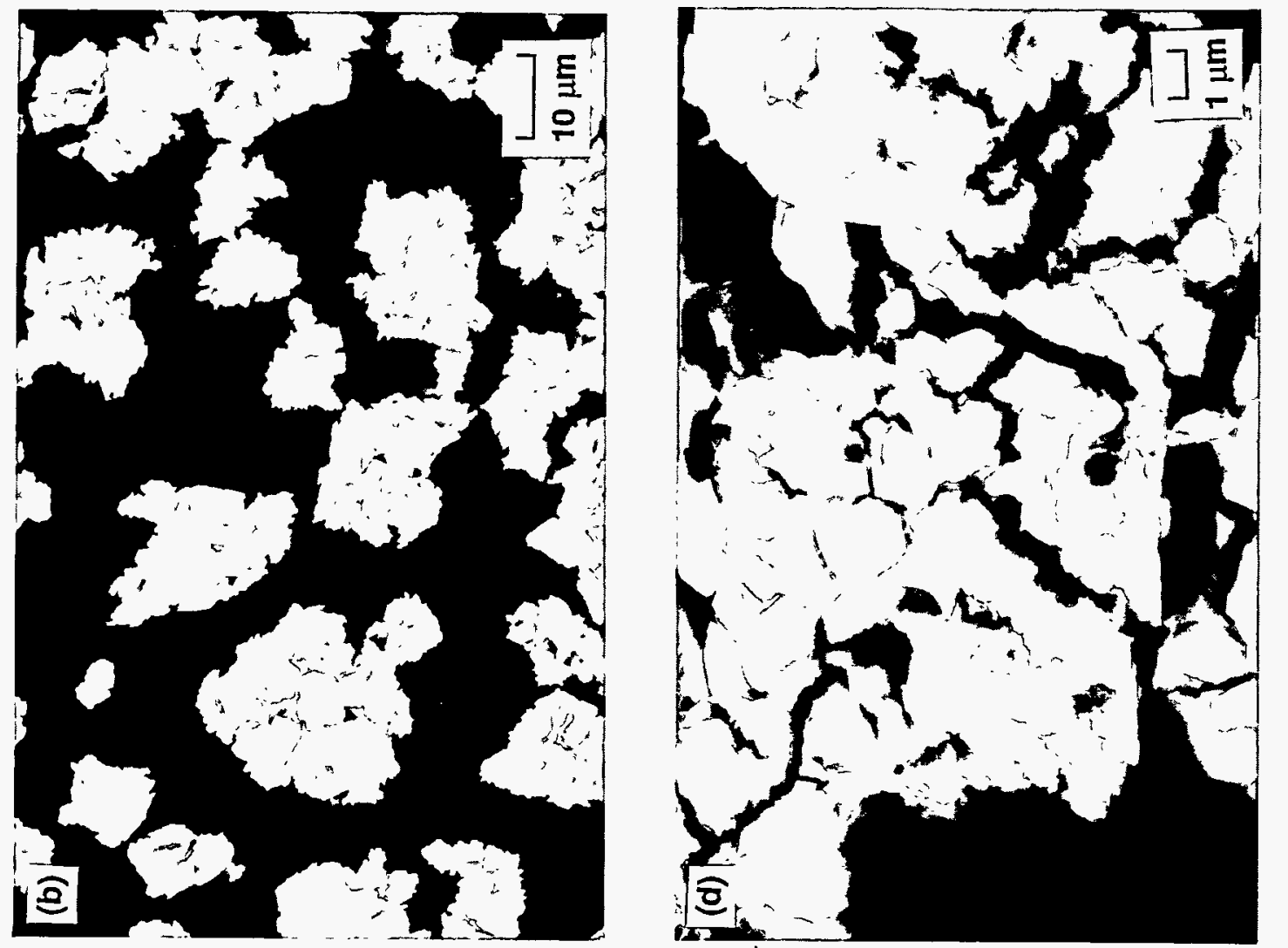

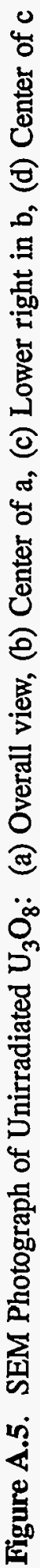
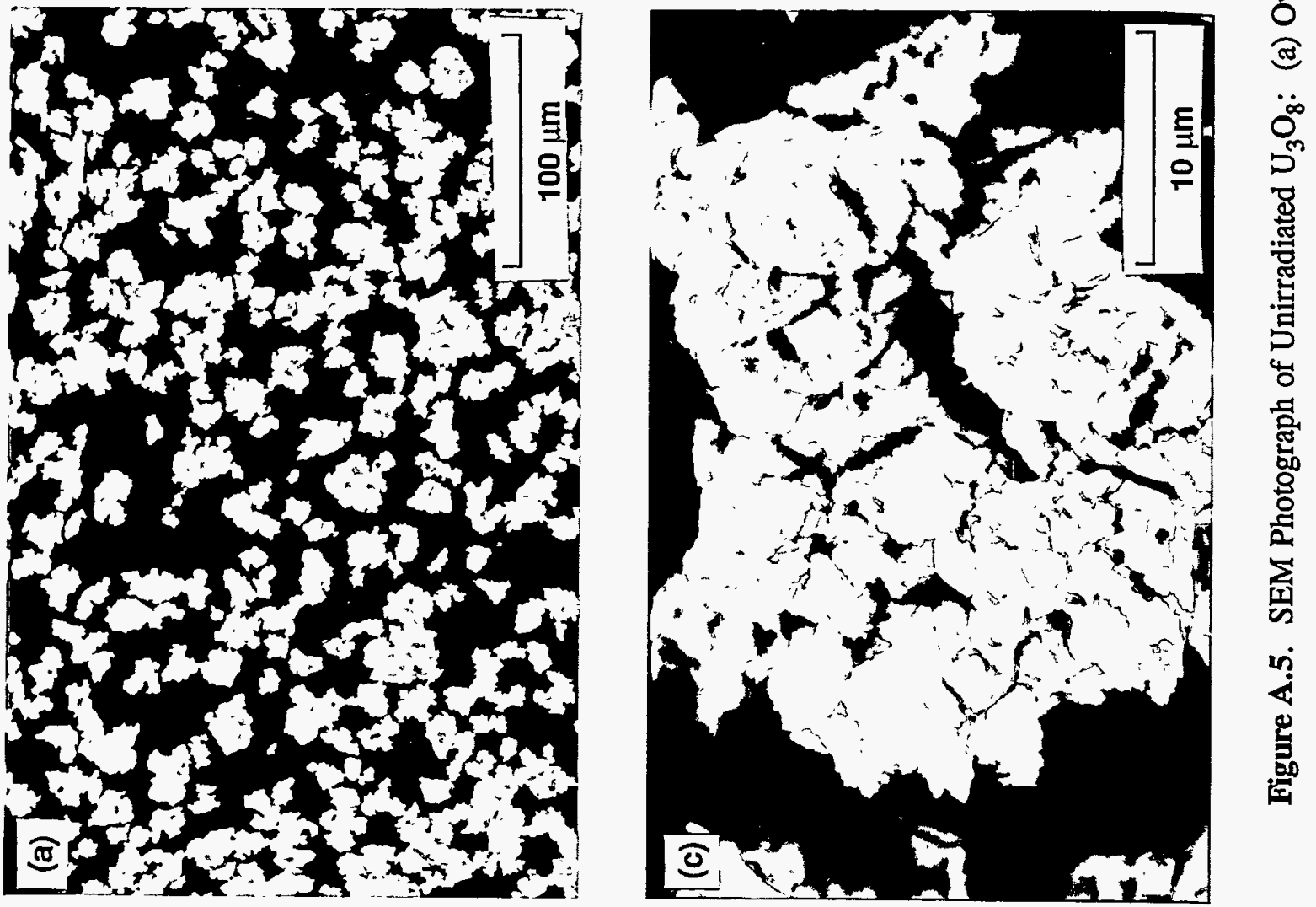

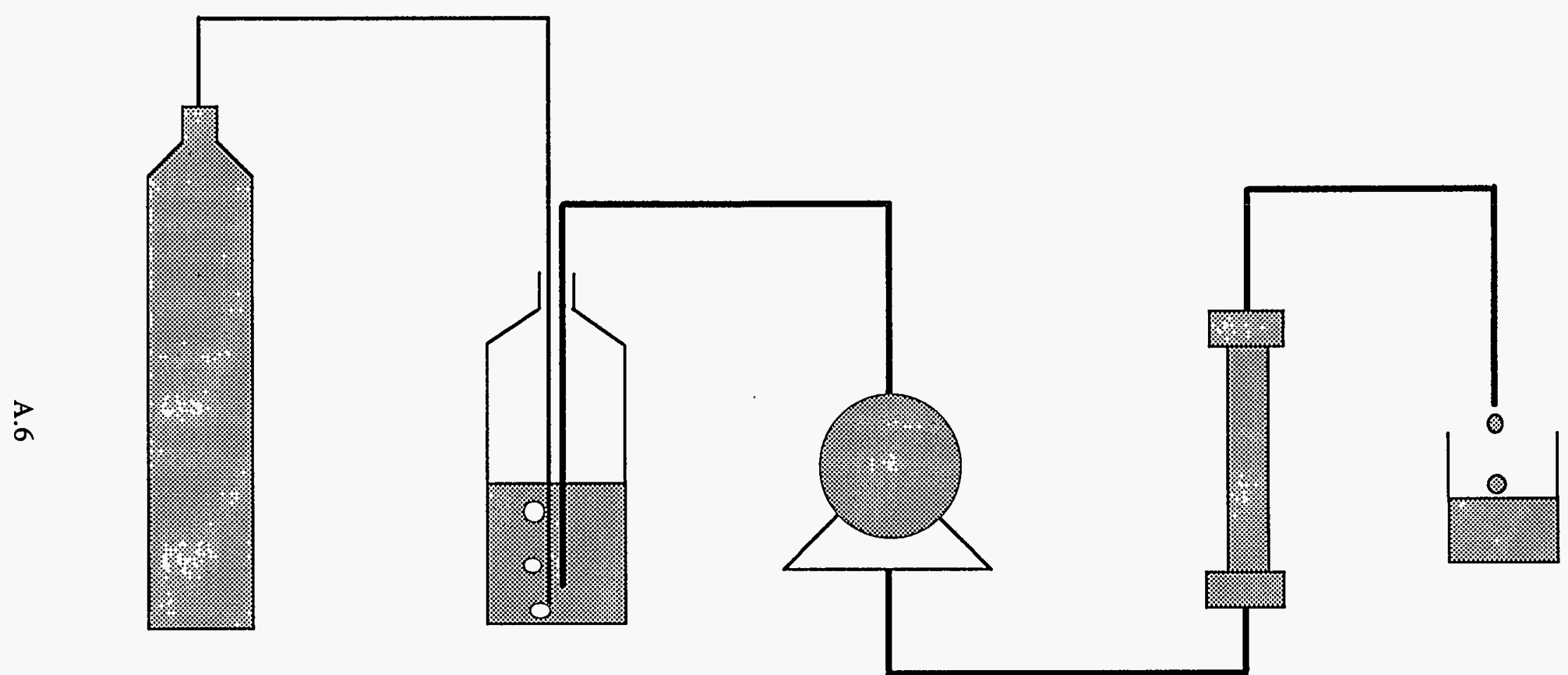

\section{Gas}

Cylinder

\section{Feedwater}

Container

\section{Controlled- \\ Flow Pump}

\section{Specimen \\ Column}
Sample/Waste Container

Figure A.6. Schematic Diagram of Flow-Through Apparatus (Column orientation with upward flow was used on tests with fuel particles and fragments. A downward flow column orientation was used for tests with fuel grains and $\mathrm{UO}_{2}$ powder specimens.) 

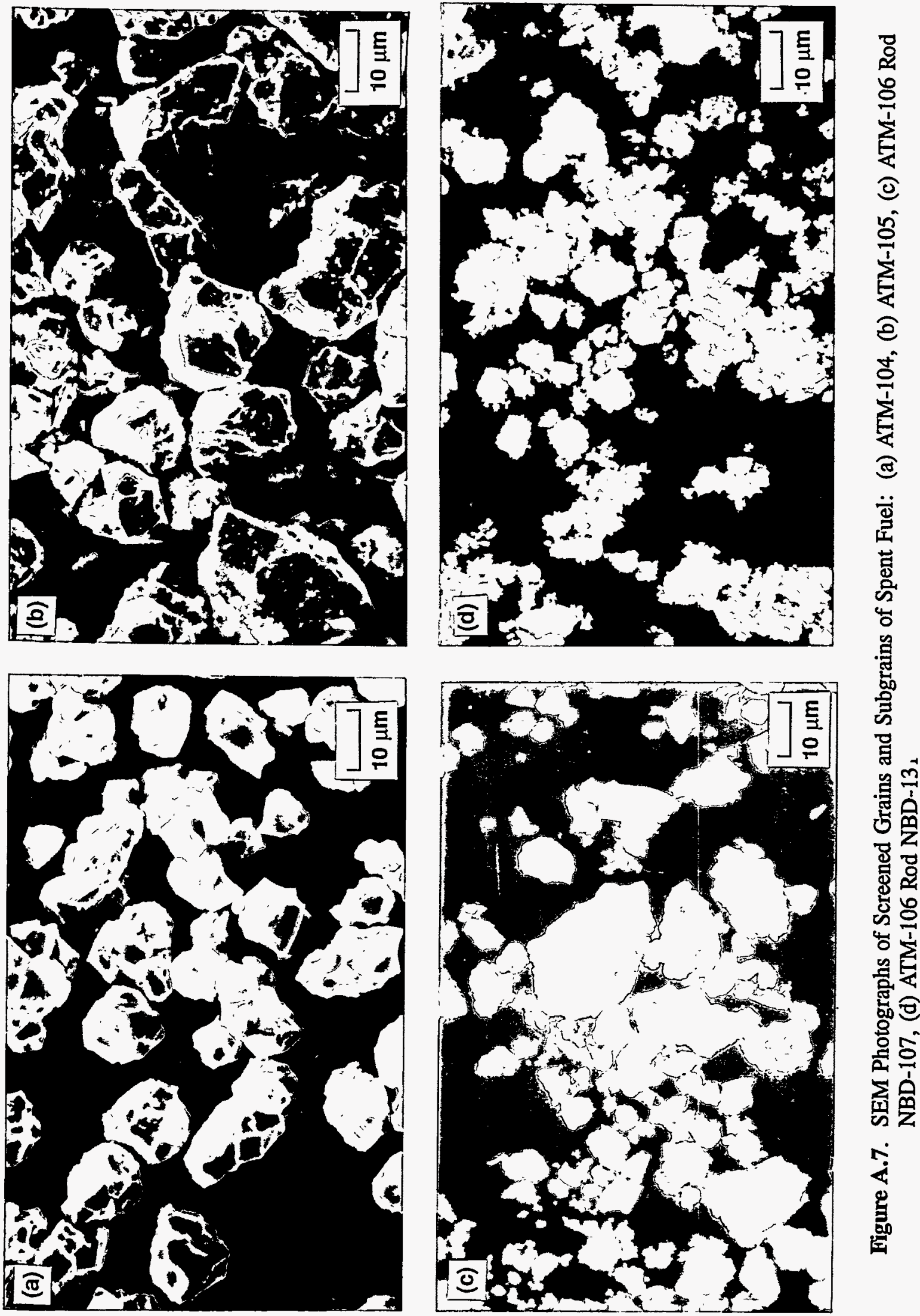

A.7 


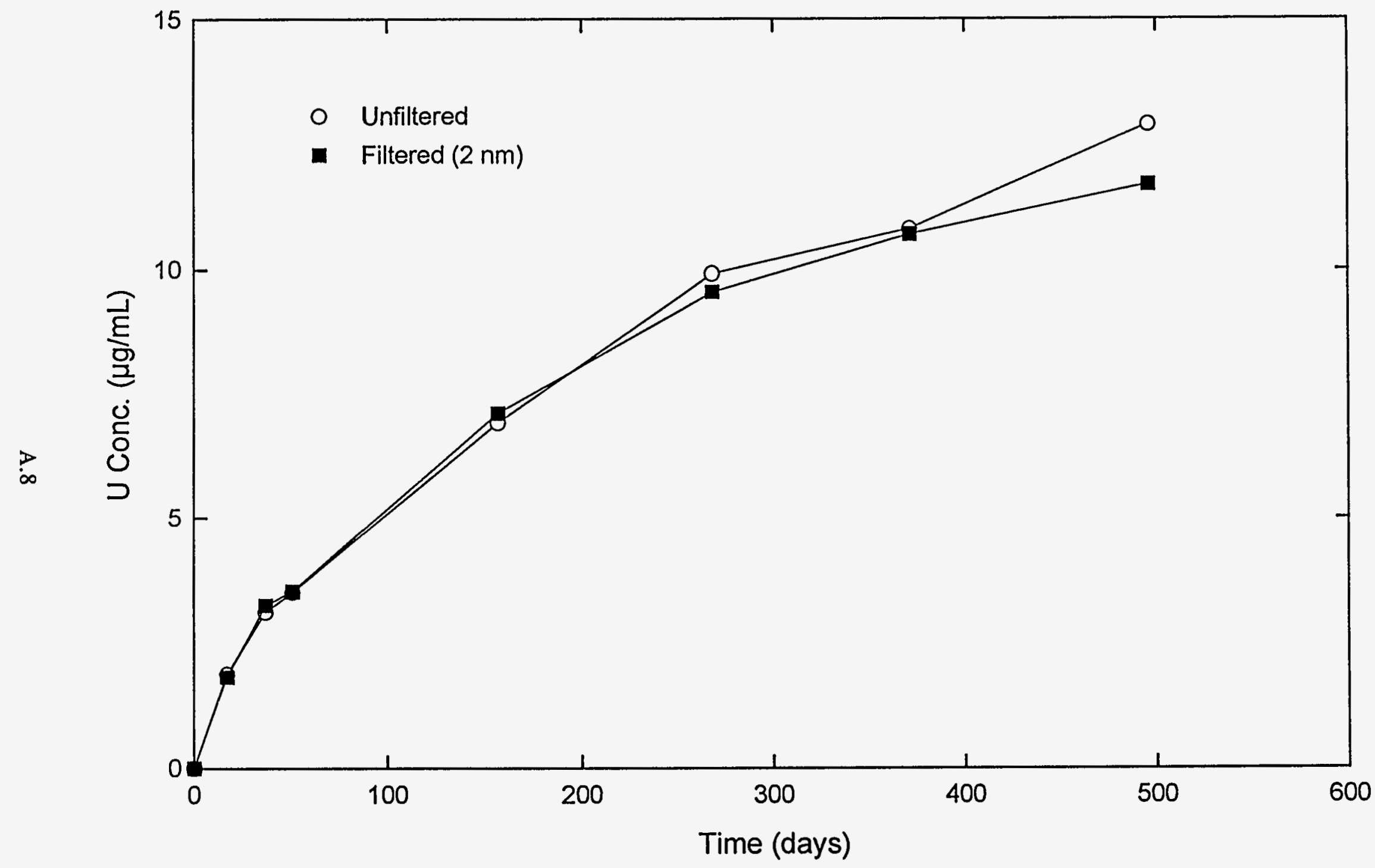

Figure A.8. Uranium Concentration in $2 \times 10^{-3} \mathrm{M} \mathrm{NaHCO}_{3}$ Solution Exposed to Air, $\mathrm{pH} \sim 8.6$ [Data was obtained from $1 \mathrm{~g}$ of $\mathrm{UO}_{2}$ powder placed in $250 \mathrm{~mL}$ of solution, which was allowed to stand at ambient temperature $\left(\sim 25^{\circ} \mathrm{C}\right)$.] 


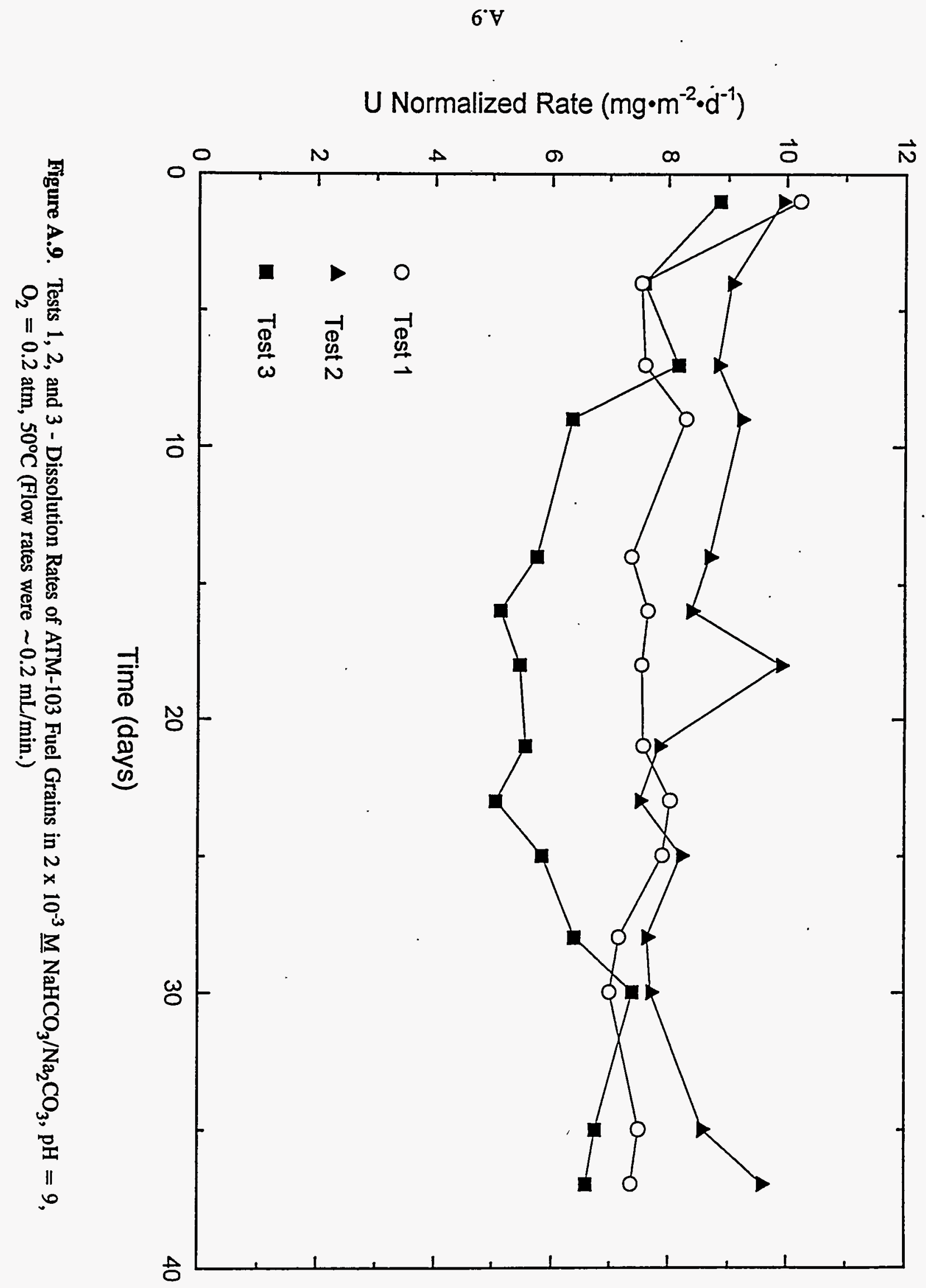




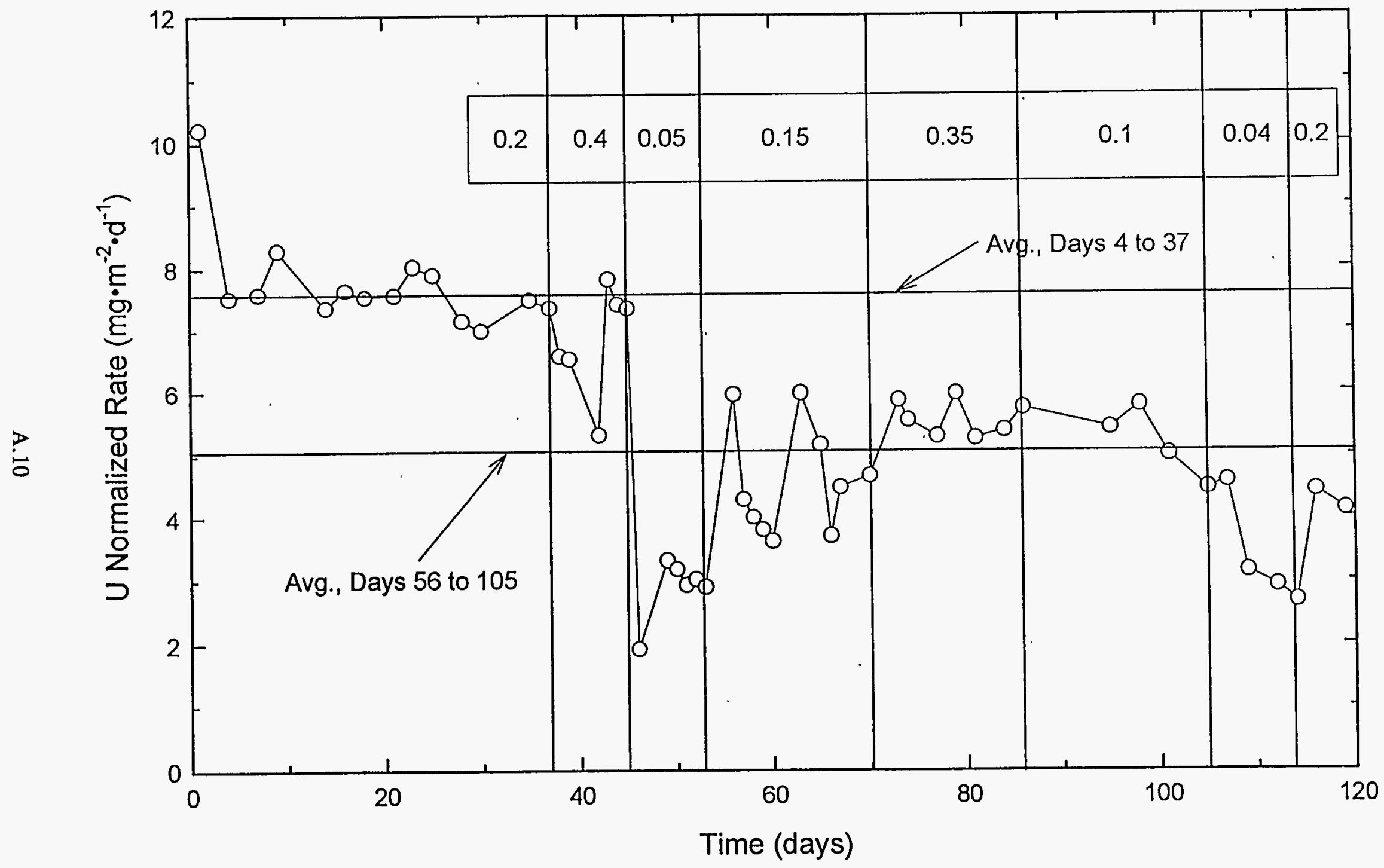

Figure A.10. Test 1 - Dissolution Rate of ATM-103 Fuel Grains in $2 \times 10^{-3} \underline{\mathrm{M} ~} \mathrm{NaHCO}_{3} / \mathrm{Na}_{2} \mathrm{CO}_{3}, \mathrm{pH}=9, \mathrm{O}_{2}=0.2$ atm, $50^{\circ} \mathrm{C}$ (Vertical lines divide regions of different approximate flow rates in $\mathrm{mL} / \mathrm{min}$, which are given by numbers in box.) 


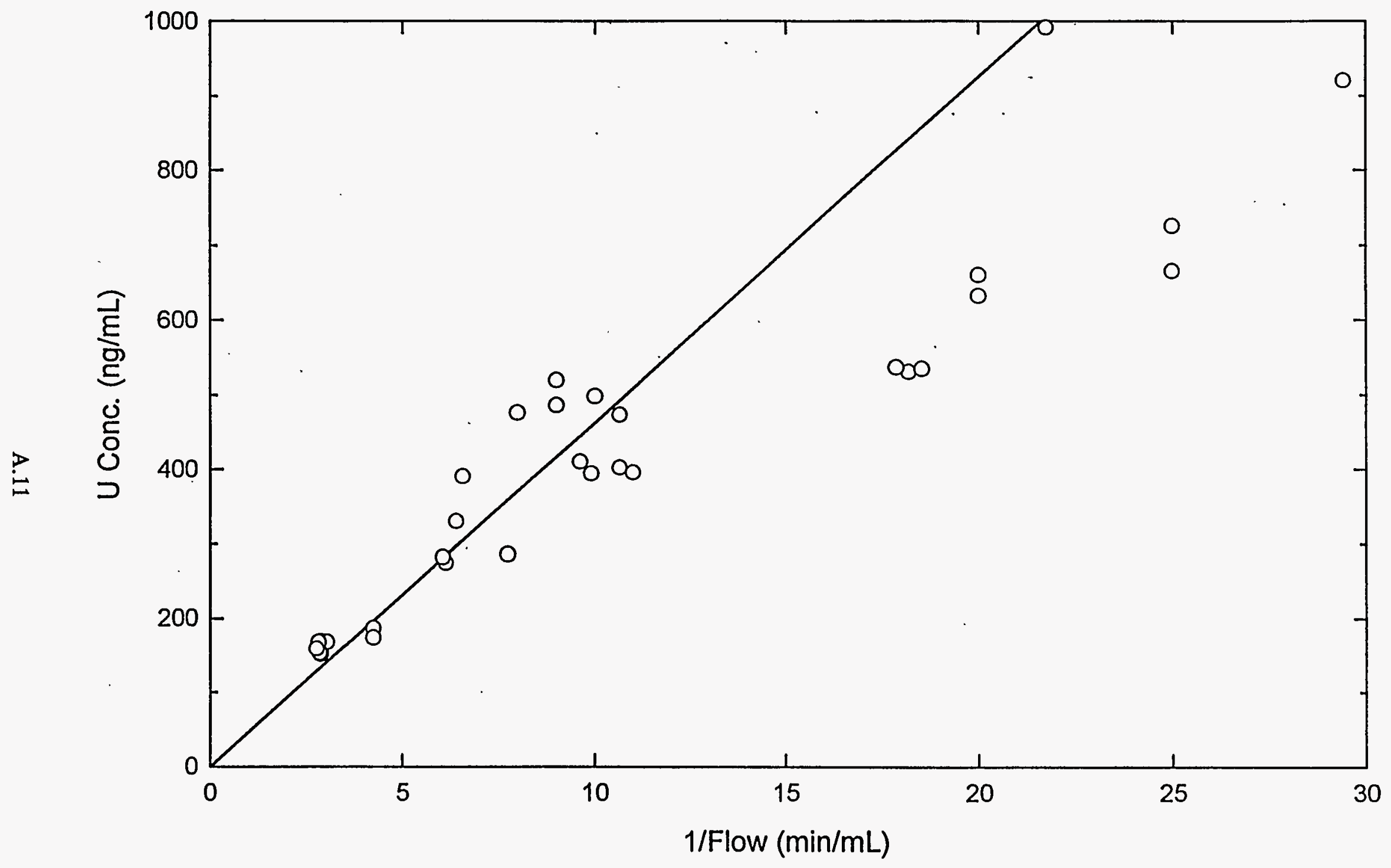

Figure A.11. Test 1 - Dependence of U Concentration on Reciprocal Flow for ATM-103 Fuel Grains in $2 \times 10^{-3} \underline{\mathrm{M}}$ $\mathrm{NaHCO}_{3} / \mathrm{Na}_{2} \mathrm{CO}_{3}, \mathrm{pH}=9, \mathrm{O}_{2}=0.2 \mathrm{~atm}, 50^{\circ} \mathrm{C}$ (Data are plotted for days 46 to 119 ; the regression line does not include data above reciprocal flows of $15 \mathrm{~min} / \mathrm{mL}$.) 


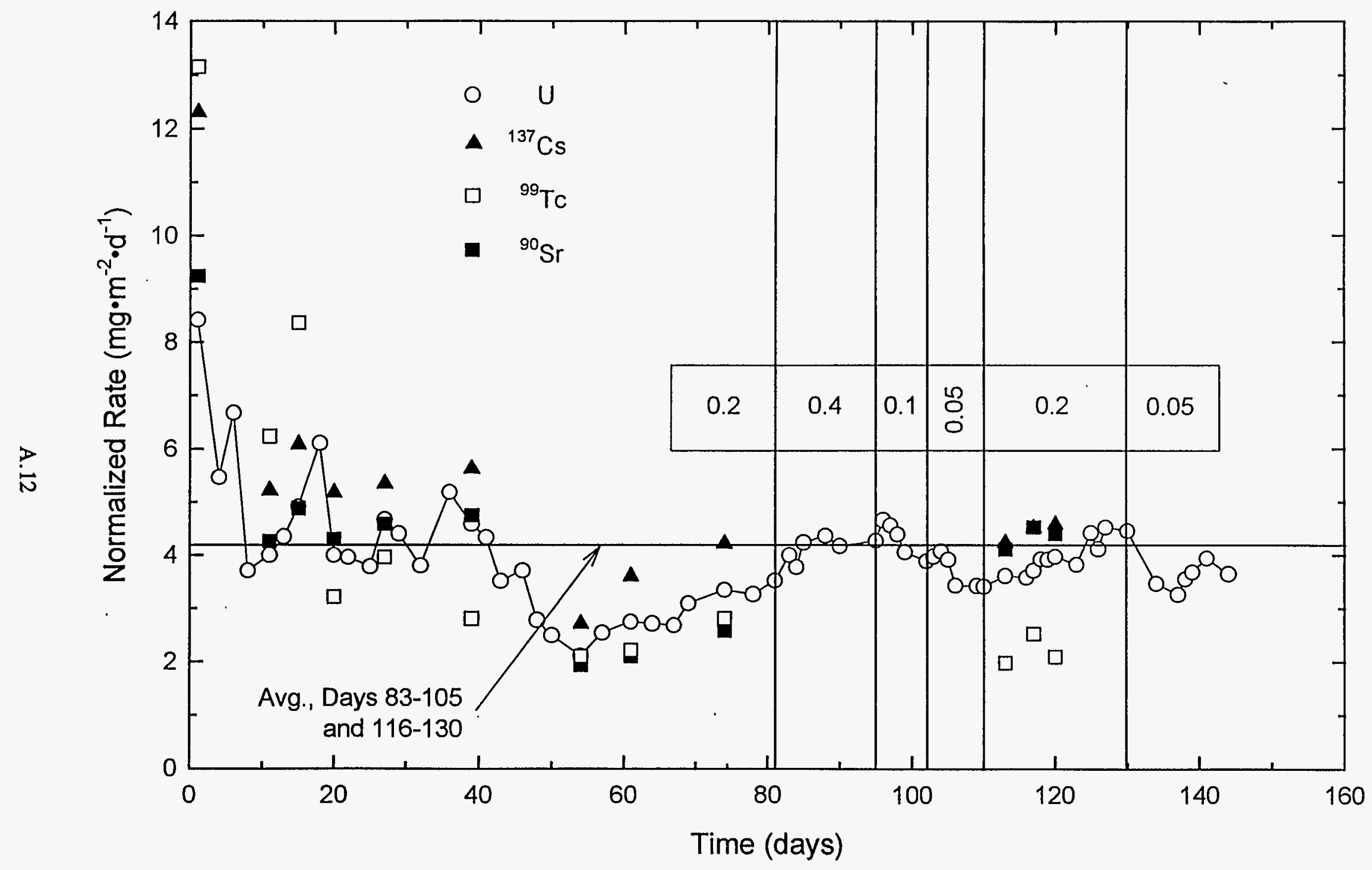

Figure A.12. Test 4 - Dissolution Rate of ATM-103 Fuel Grains in $2 \times 10^{-2} \mathrm{M} \mathrm{NaHCO} / \mathrm{Na}_{2} \mathrm{CO}_{3}, \mathrm{O}_{2}=0.2$ atm, $22^{\circ} \mathrm{C}$ (pH initially $\sim 9$ until stabilized at 8.0 to 8.2 after 55 days. Vertical lines divide regions of different approximate flow rates in $\mathrm{mL} / \mathrm{min}$, which are given by numbers in box.) 


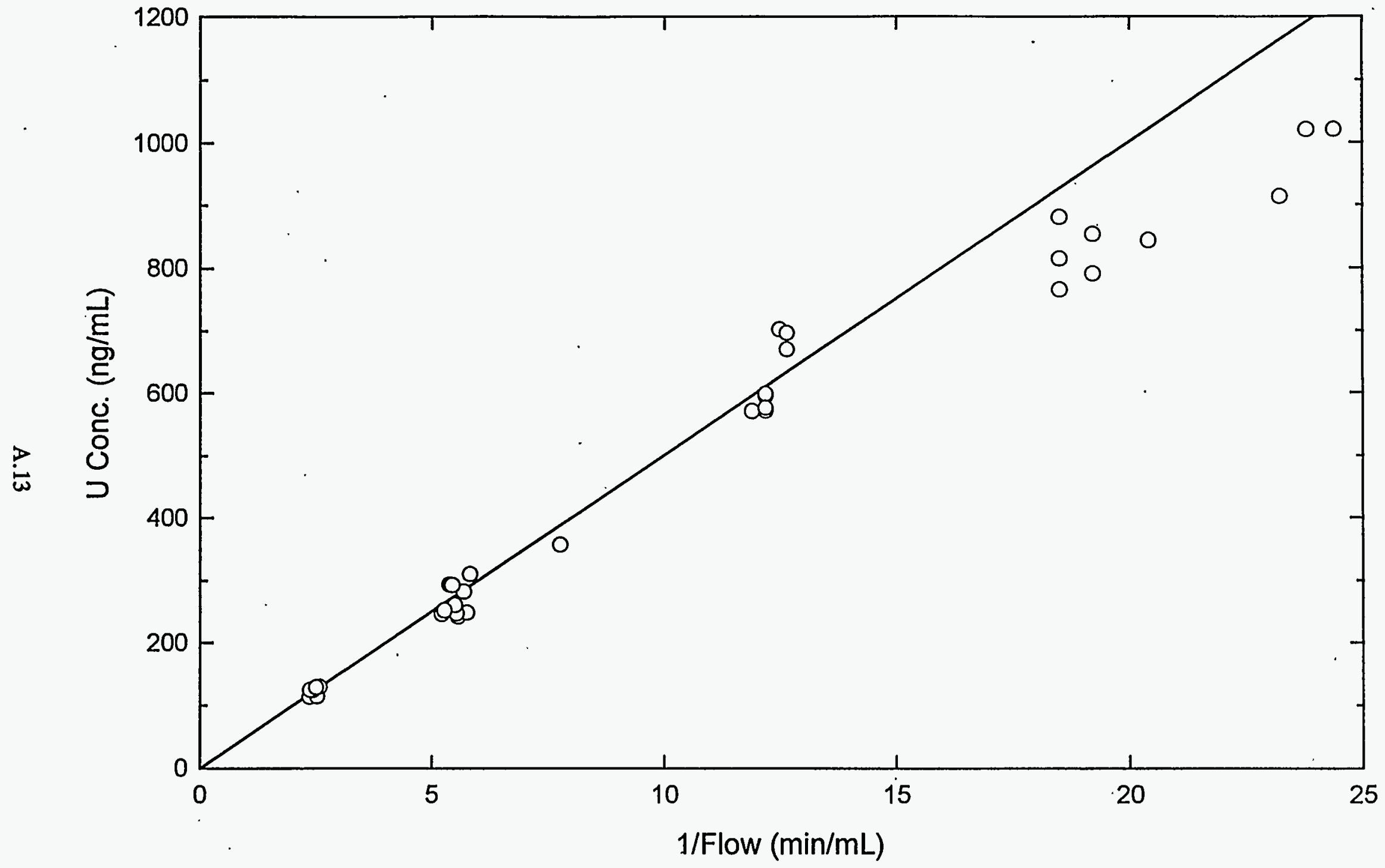

Figure A.13. Test 4 - Dependence of $U$ Concentration on Reciprocal Flow for ATM-103 Fuel Grains in $2 \times 10^{-2} . M$ $\mathrm{NaHCO}_{3} / \mathrm{Na}_{2} \mathrm{CO}_{3}, \mathrm{pH}=8, \mathrm{O}_{2}=0.2 \mathrm{~atm}, 22^{\circ} \mathrm{C}$ (Data are plotted for days 83 to 144 ; the regression line does not include data above reciprocal flows of $15 \mathrm{~min} / \mathrm{mL}$.) 


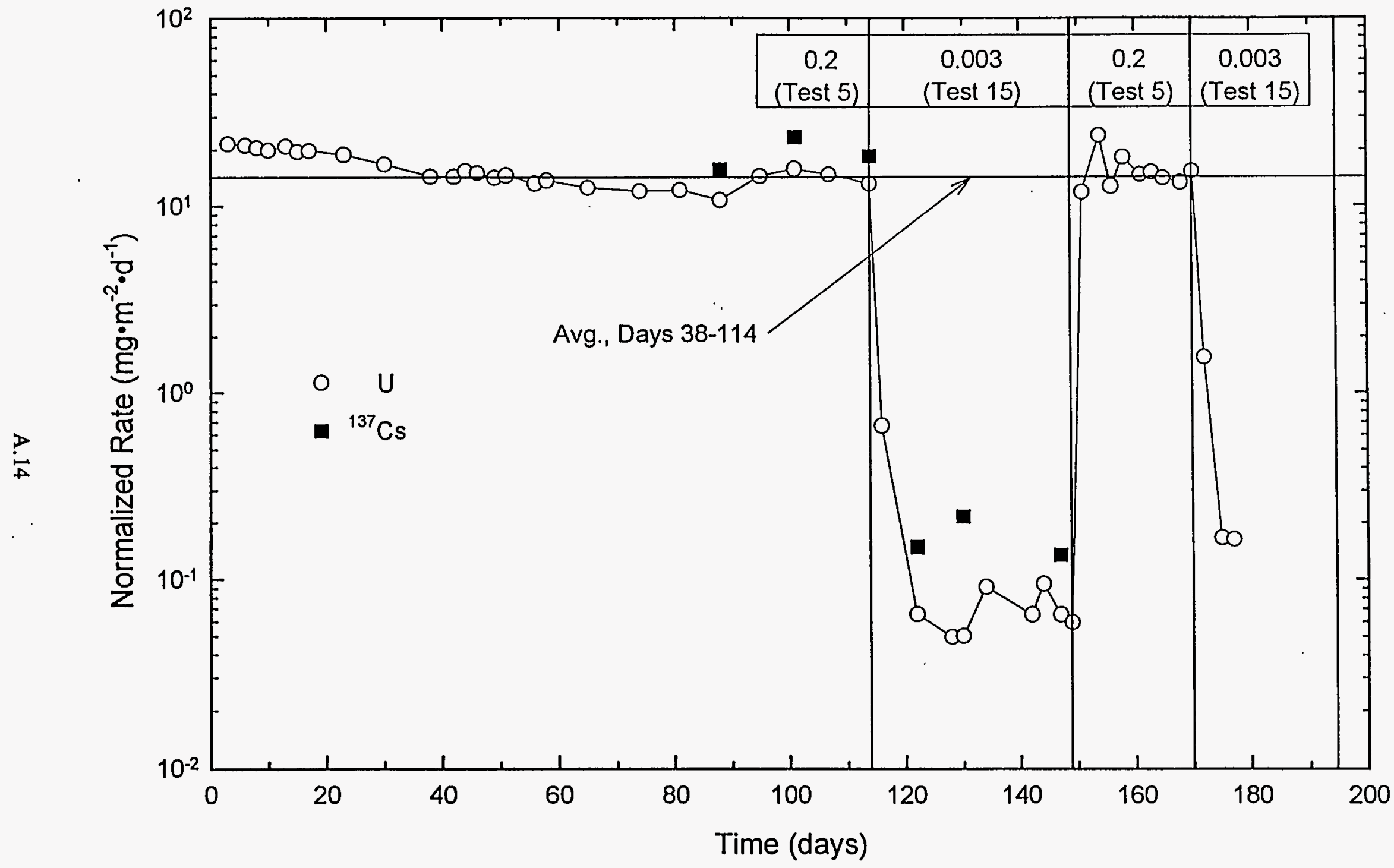

Figure A.14. Tests 5 and 15 - Dissolution Rate of ATM-103 Fuel Grains in $2 \times 10^{-2} \underline{\mathrm{M} \mathrm{NaHCO}} / \mathrm{Na}_{2} \mathrm{CO}_{3}, \mathrm{pH}=10,74^{\circ} \mathrm{C}$ (Vertical lines divide regions of different $\mathrm{O}_{2}$ overpressures (atm), which are given by numbers in box.) 


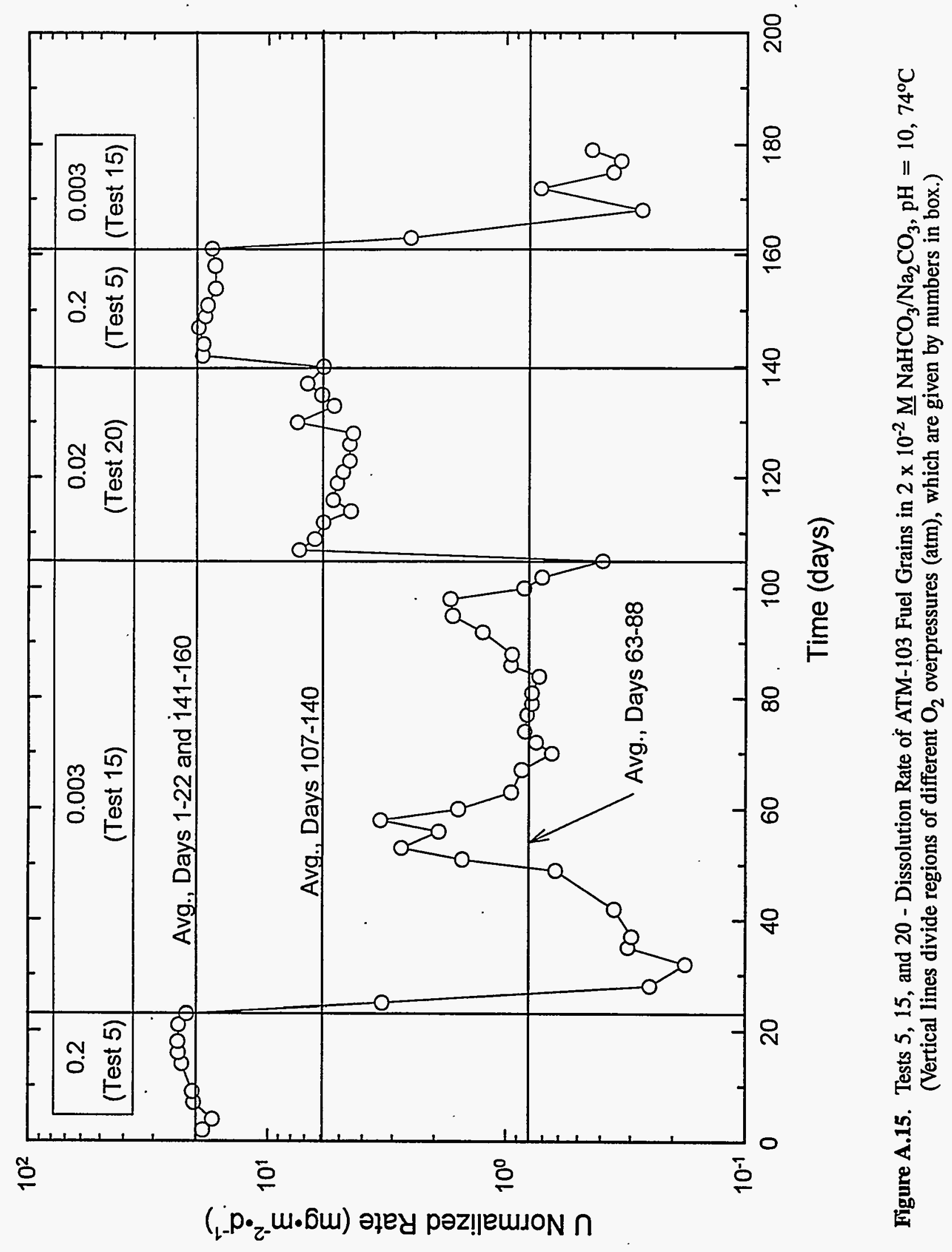




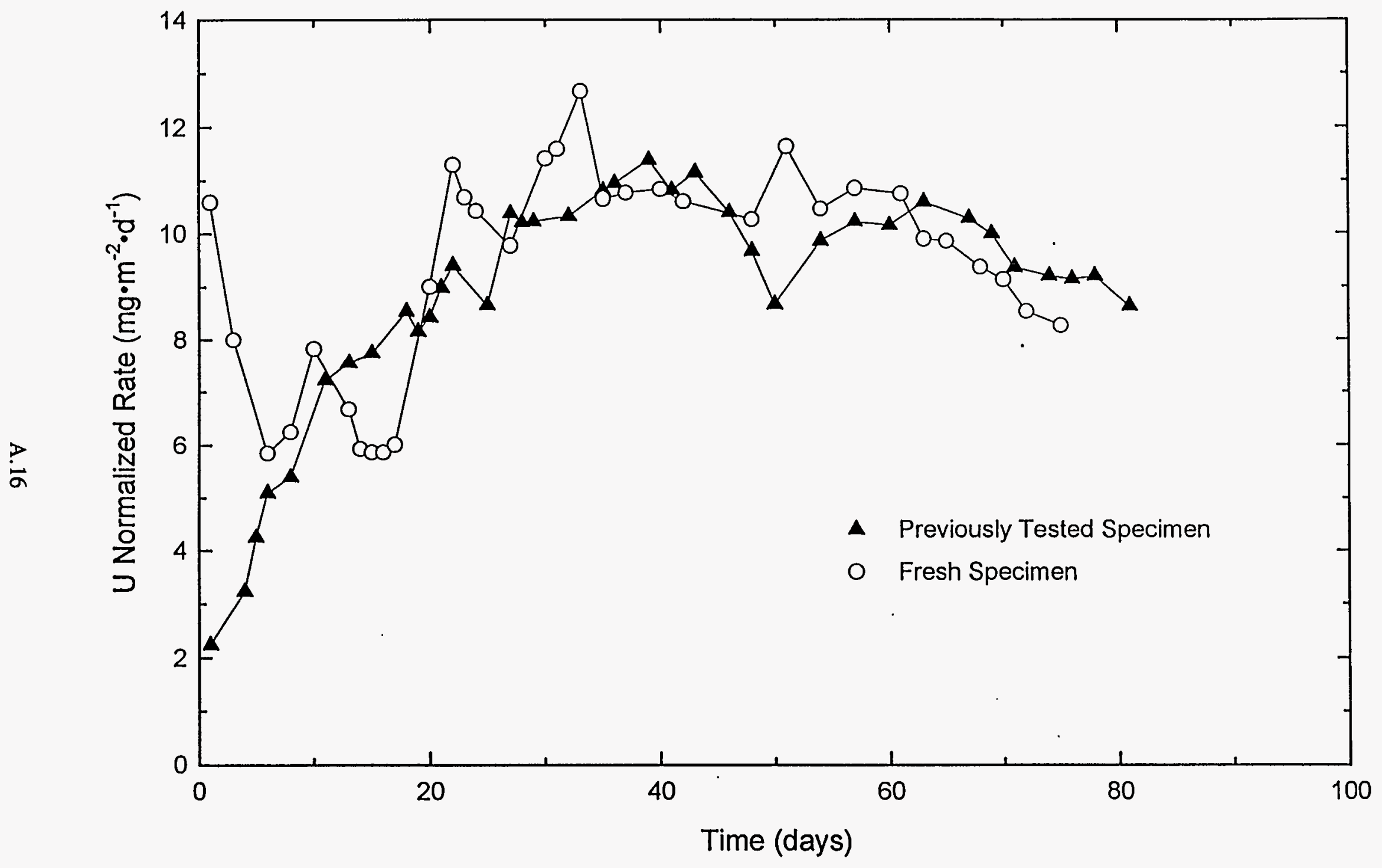

Figure A.16. Test 6 - Dissolution Rate of ATM-103 Fuel Grains in $2 \times 10^{-4} \underline{\mathrm{M} \mathrm{NaHCO}} / \mathrm{Na}_{2} \mathrm{CO}_{3}, \mathrm{pH}=8, \mathrm{O}_{2}=0.2$ atm, $74^{\circ} \mathrm{C}$ (Flow rates were $\sim 0.2 \mathrm{~mL} / \mathrm{min}$.) 


\section{LI' $V$}

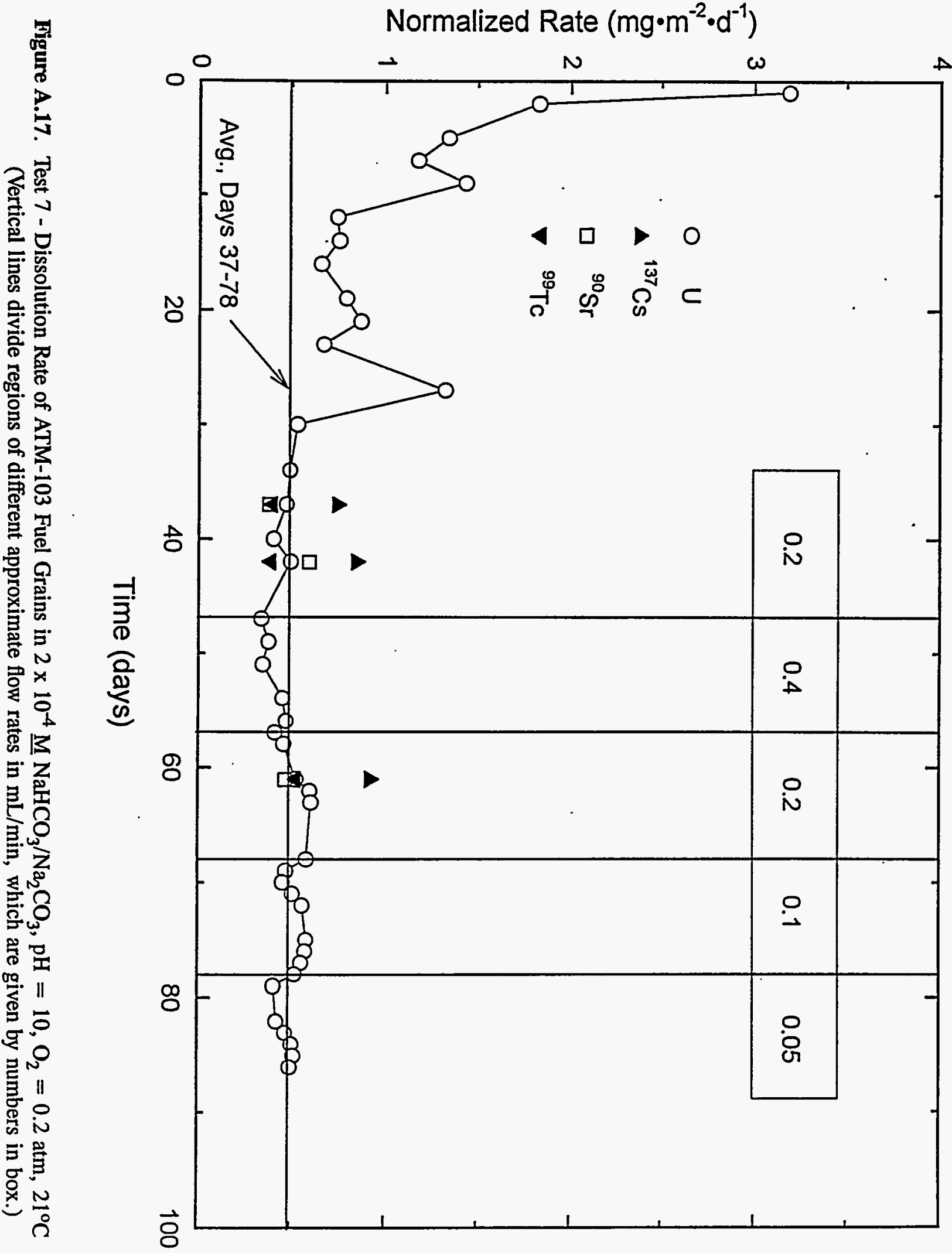




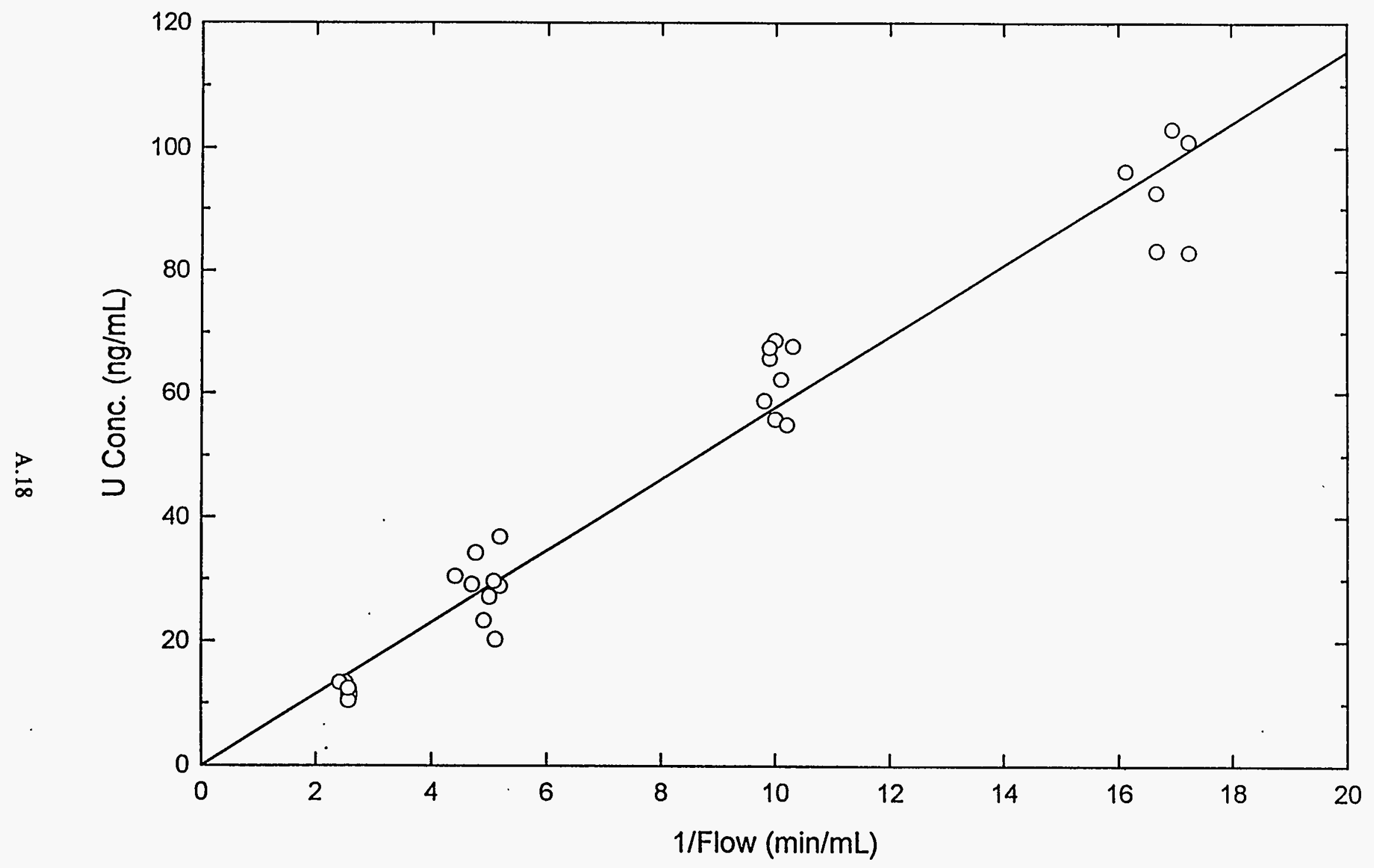

Figure A.18. Test 7 - Dependence of U Concentration on Reciprocal Flow for ATM-103 Fuel Grains in $2 \times 10^{-4} \underline{\mathrm{M}}$ $\mathrm{NaHCO}_{3} / \mathrm{Na}_{2} \mathrm{CO}_{3}, \mathrm{pH}=10, \mathrm{O}_{2}=0.2$ atm, $21^{\circ} \mathrm{C}$ (Data are plotted for days 37 to 86 ; the regression line includes all data shown in this figure.) 


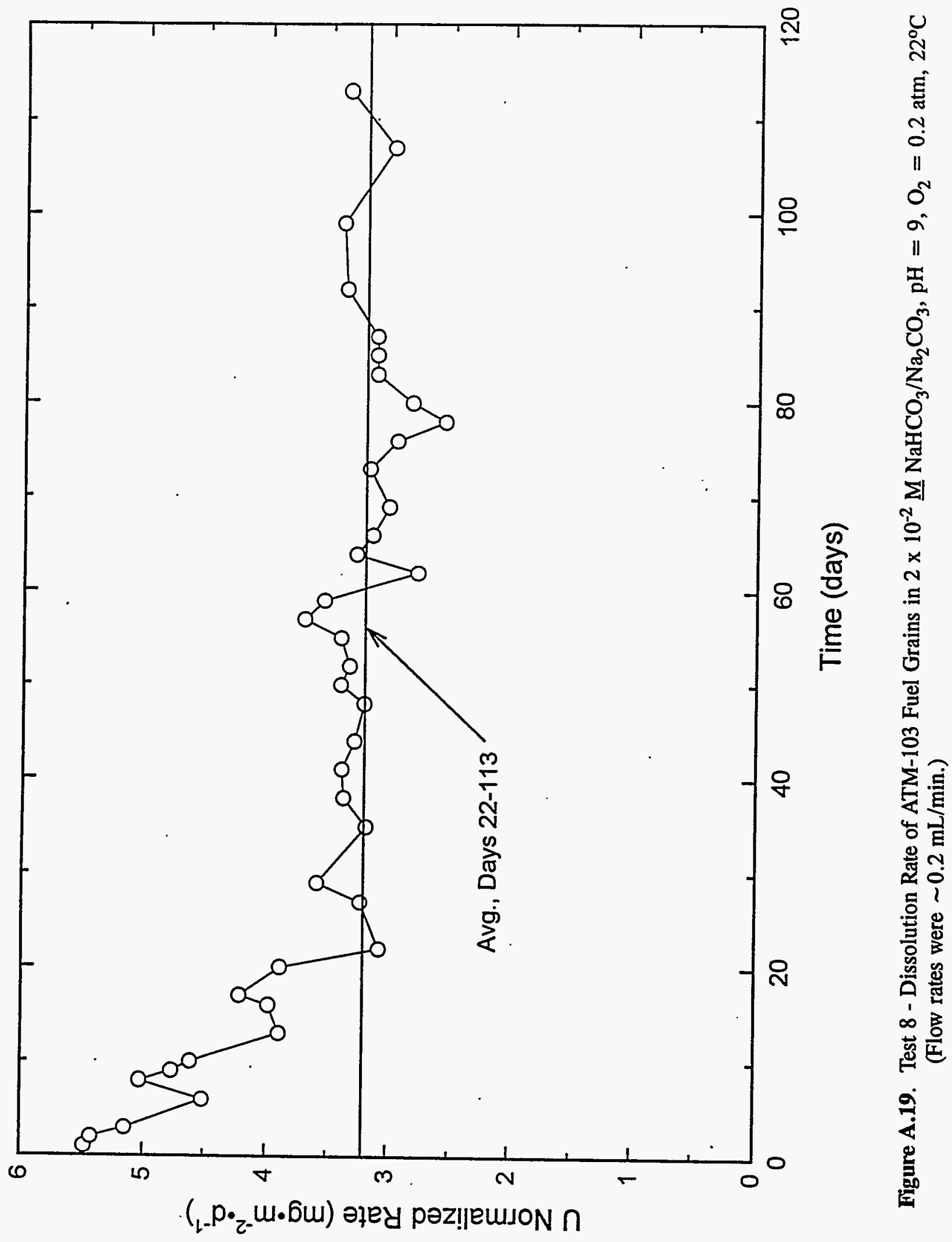

A. 19 


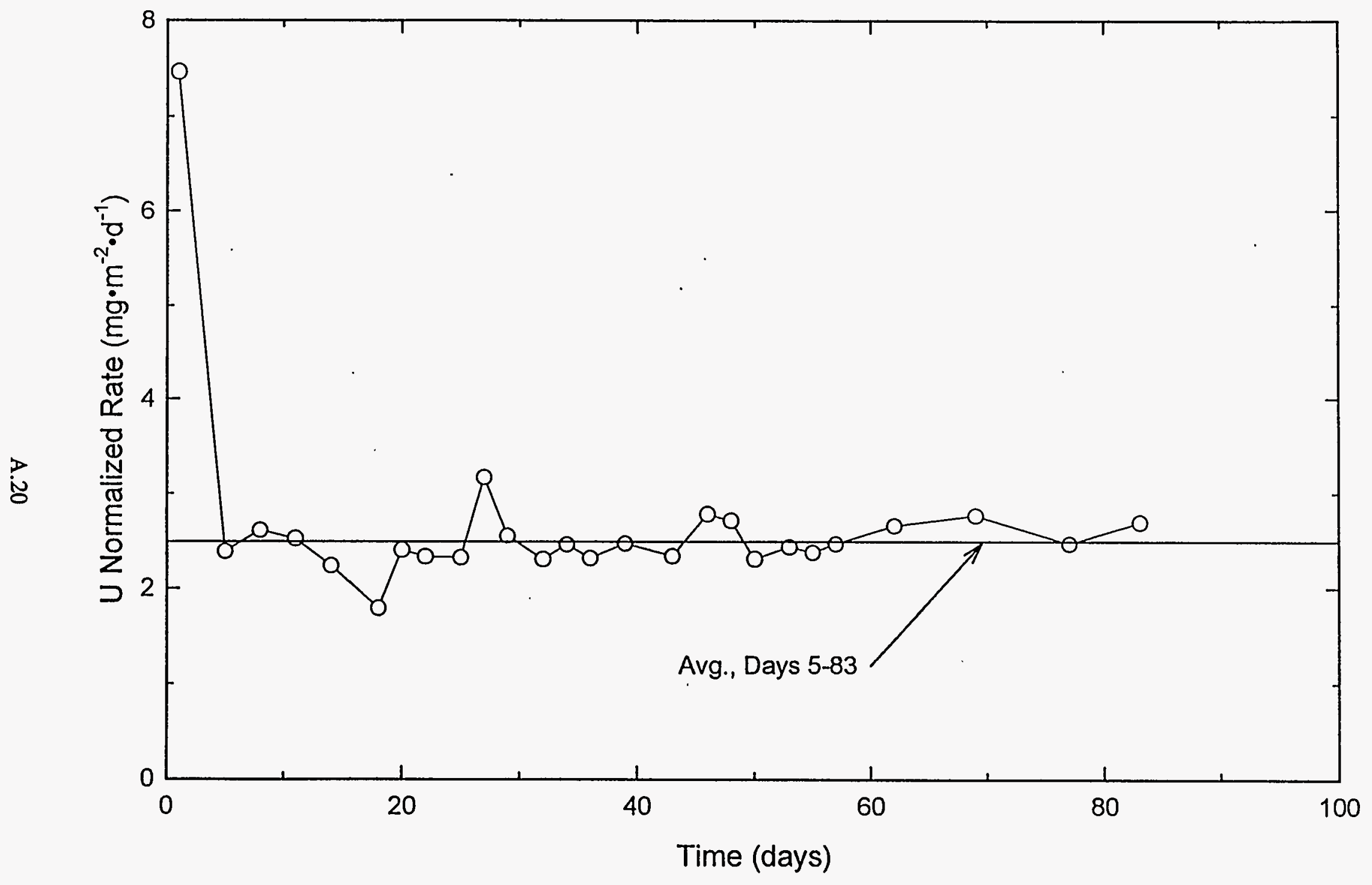

Figure A.20. Test 9 - Dissolution Rate of ATM-103 Fuel Grains in $2 \times 10^{-3} \underline{\mathrm{M} \mathrm{NaHCO}}{ }_{3} / \mathrm{Na}_{2} \mathrm{CO}_{3}, \mathrm{pH}=10, \mathrm{O}_{2}=0.2$ atm, $22^{\circ} \mathrm{C}$ (Flow rates were $\sim 0.2 \mathrm{~mL} / \mathrm{min}$.) 


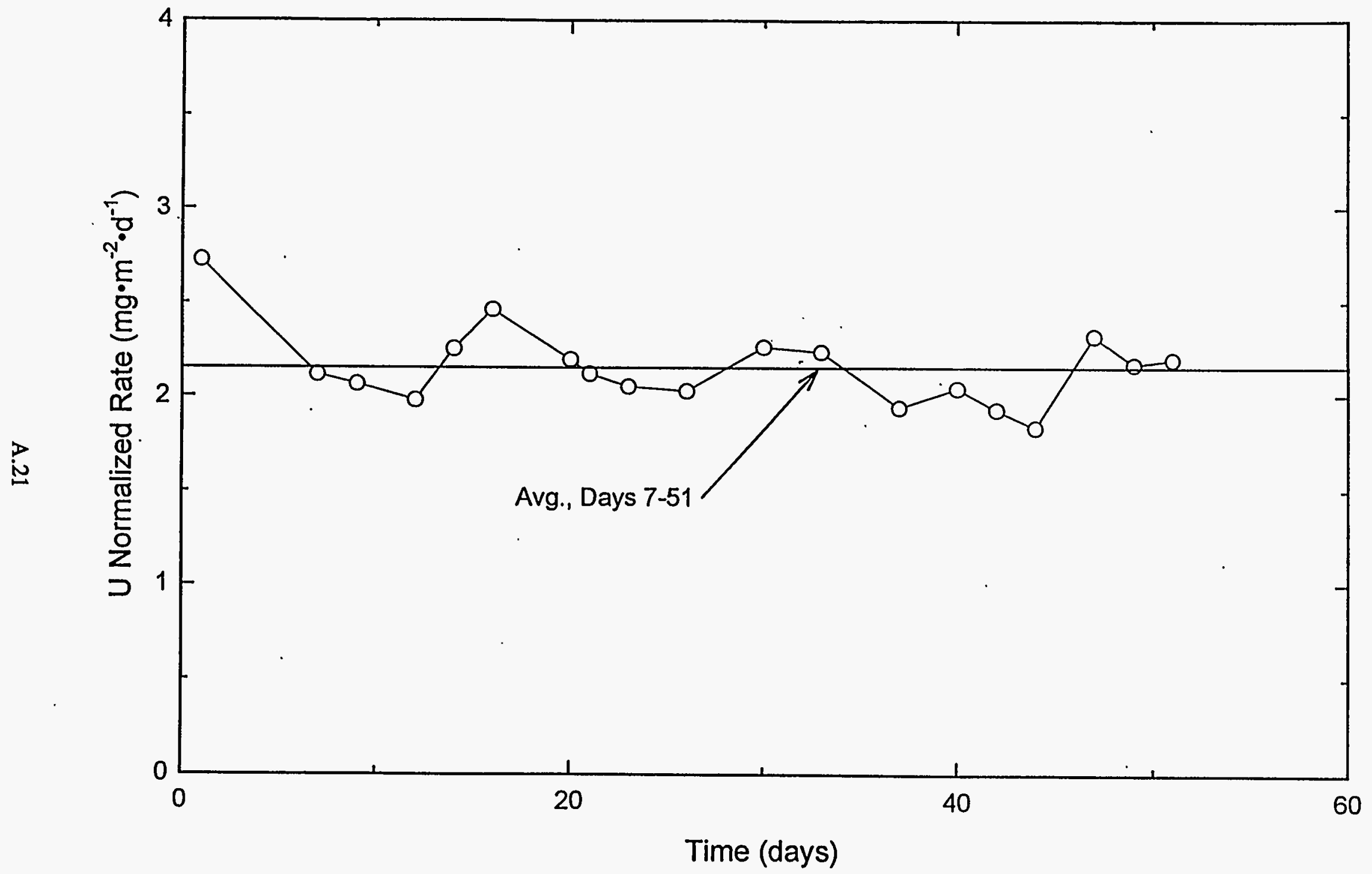

Figure A.21. Test 10 - Dissolution Rate of ATM-103 Fuel Grains in $2 \times 10^{-4} \underline{\mathrm{M} \mathrm{NaHCO}}{ }_{3} / \mathrm{Na}_{2} \mathrm{CO}_{3}, \mathrm{pH}=8, \mathrm{O}_{2}=0.02$ atm, $27^{\circ} \mathrm{C}$ (Flow rates were $\sim 0.2 \mathrm{~mL} / \mathrm{min}$.) 


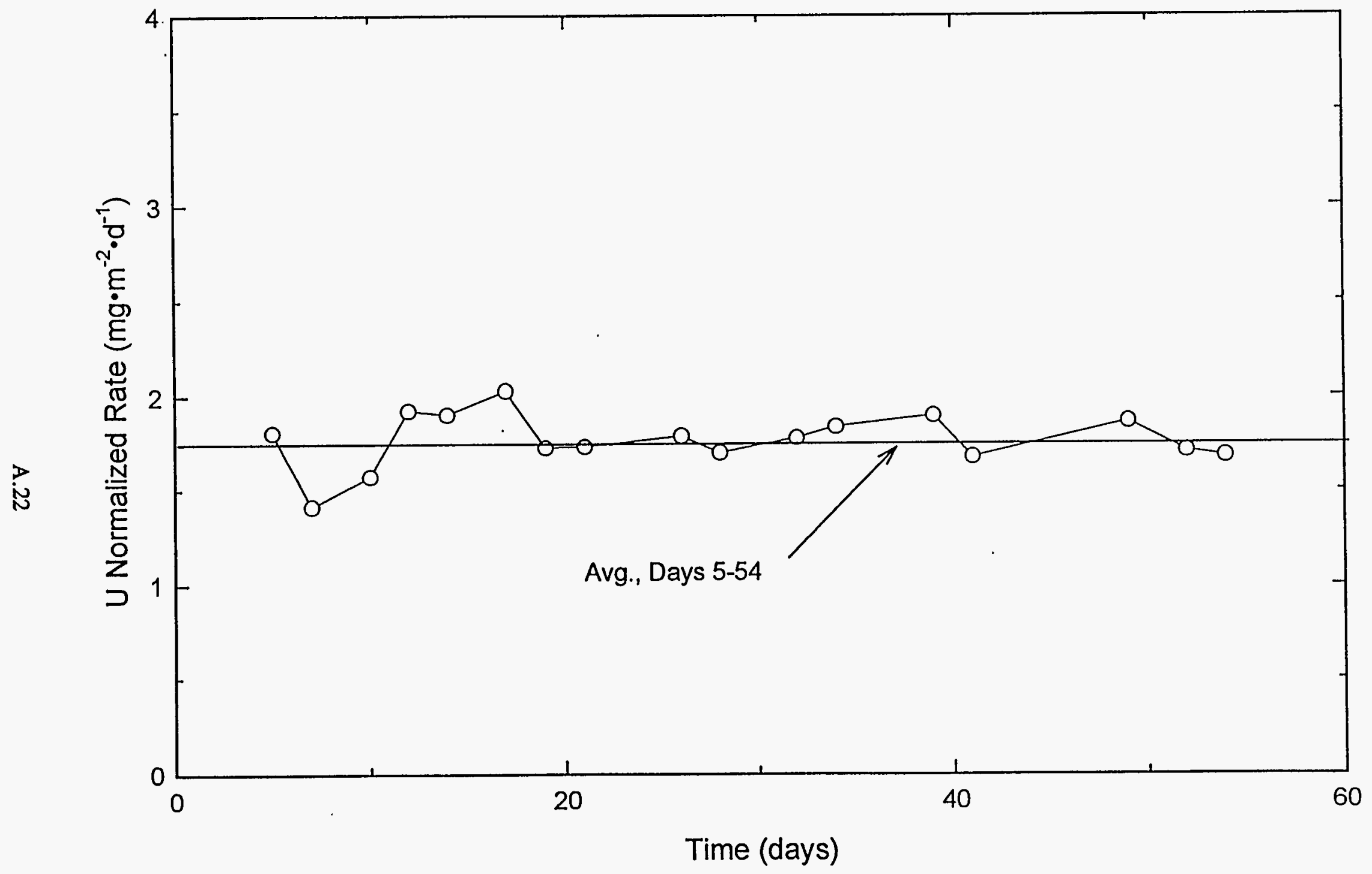

Figure A.22. Test 11 - Dissolution Rate of ATM-103 Fuel Grains in $2 \times 10^{-4} \underline{\mathrm{M} \mathrm{NaHCO}} / \mathrm{Na}_{2} \mathrm{CO}_{3}, \mathrm{pH}=10, \mathrm{O}_{2}=0.02 \mathrm{~atm}$, $78^{\circ} \mathrm{C}$ (Flow rates were $\sim 0.2 \mathrm{~mL} / \mathrm{min}$.) 


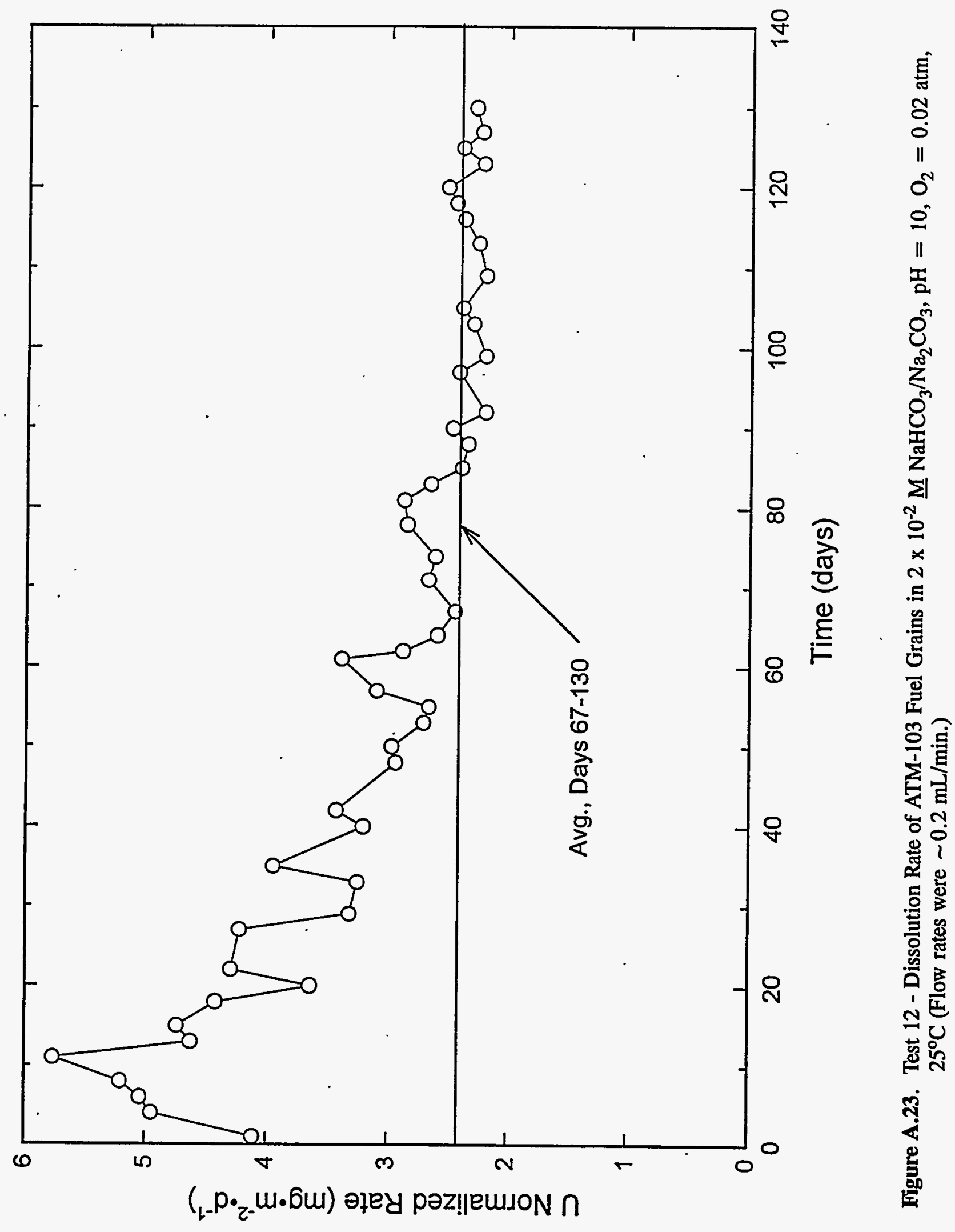




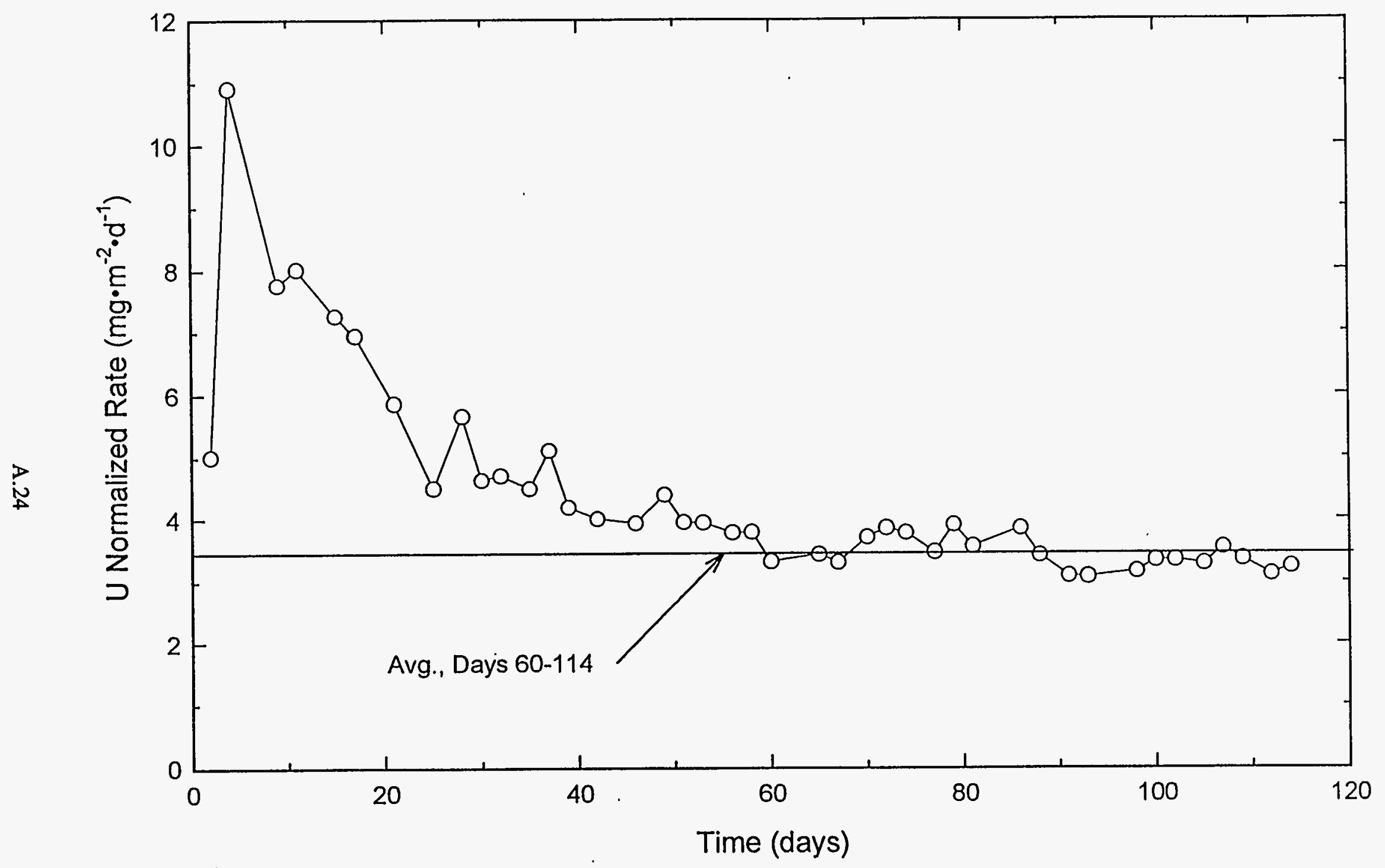

Figure A.24. Test 13 - Dissolution Rate of ATM-103 Fuel Grains in $2 \times 10^{-2} \underline{\mathrm{M} \mathrm{NaHCO}} \mathrm{Na}_{2} \mathrm{CO}_{3}, \mathrm{pH}=8, \mathrm{O}_{2}=0.02$ atm, $77^{\circ} \mathrm{C}$ (Flow rates were $\sim 0.2 \mathrm{~mL} / \mathrm{min}$.) 


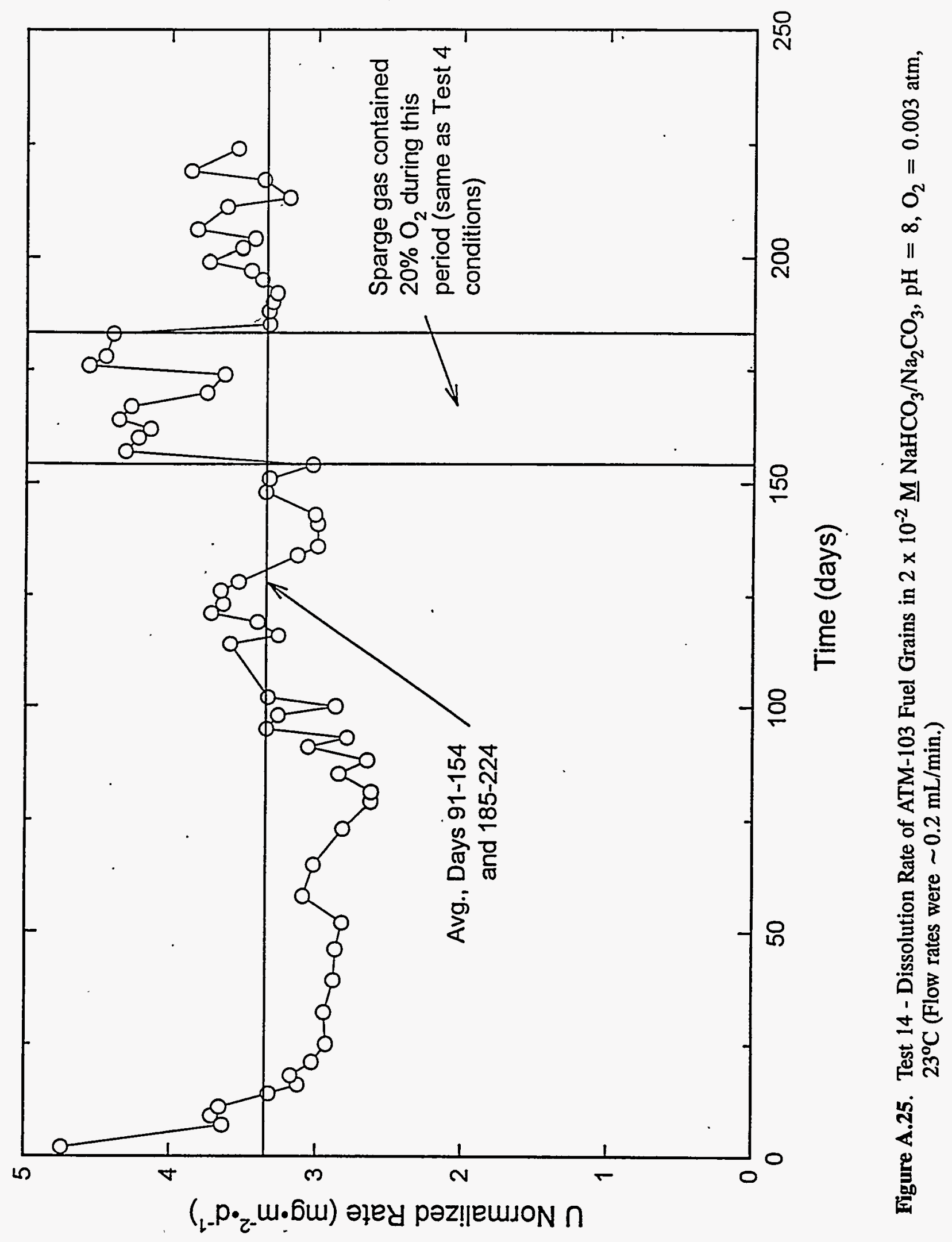




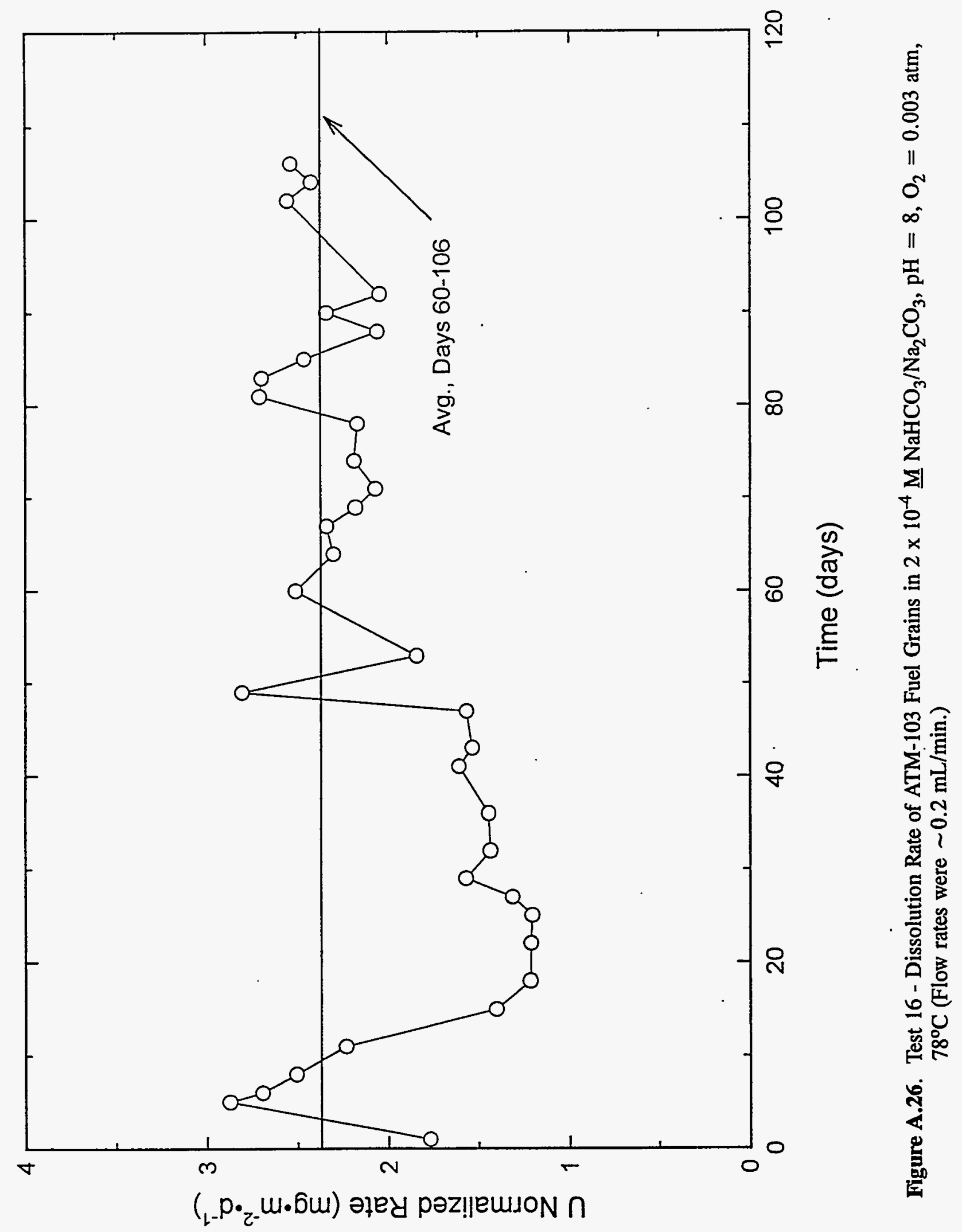

A.26 


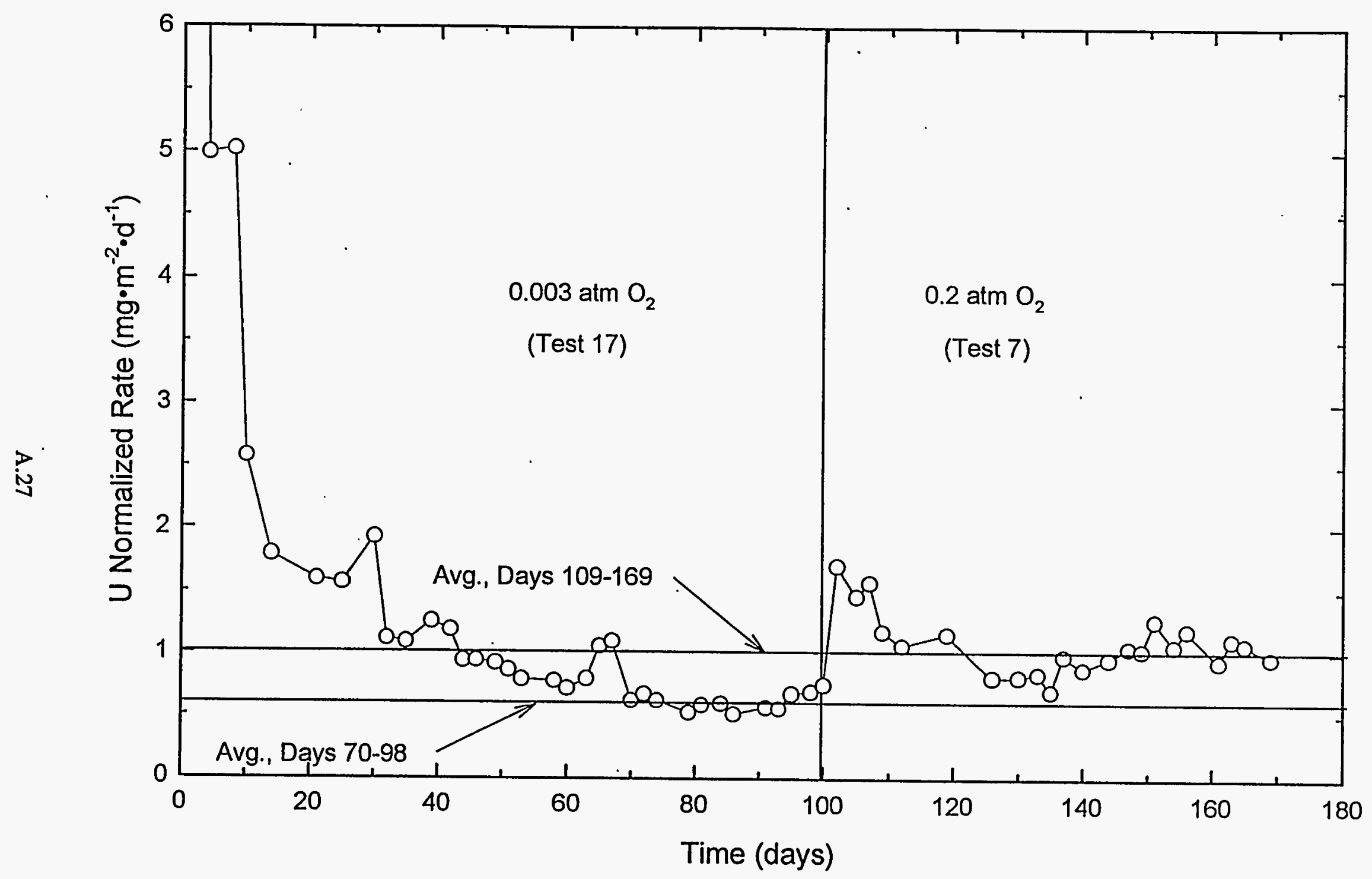

Figure A.27. Tests 7 and 17 - Dissolution Rates of ATM-103 Fuel Grains in $2 \times 10^{-4} \underline{\mathrm{M} ~} \mathrm{NaHCO}_{3} / \mathrm{Na}_{2} \mathrm{CO}_{3}, \mathrm{pH}=10,20^{\circ} \mathrm{C}$ [Flow rates were $\sim 0.2 \mathrm{~mL} / \mathrm{min}$. Vertical line divides regions with different $\mathrm{O}_{2}$ overpressures (atm).] 


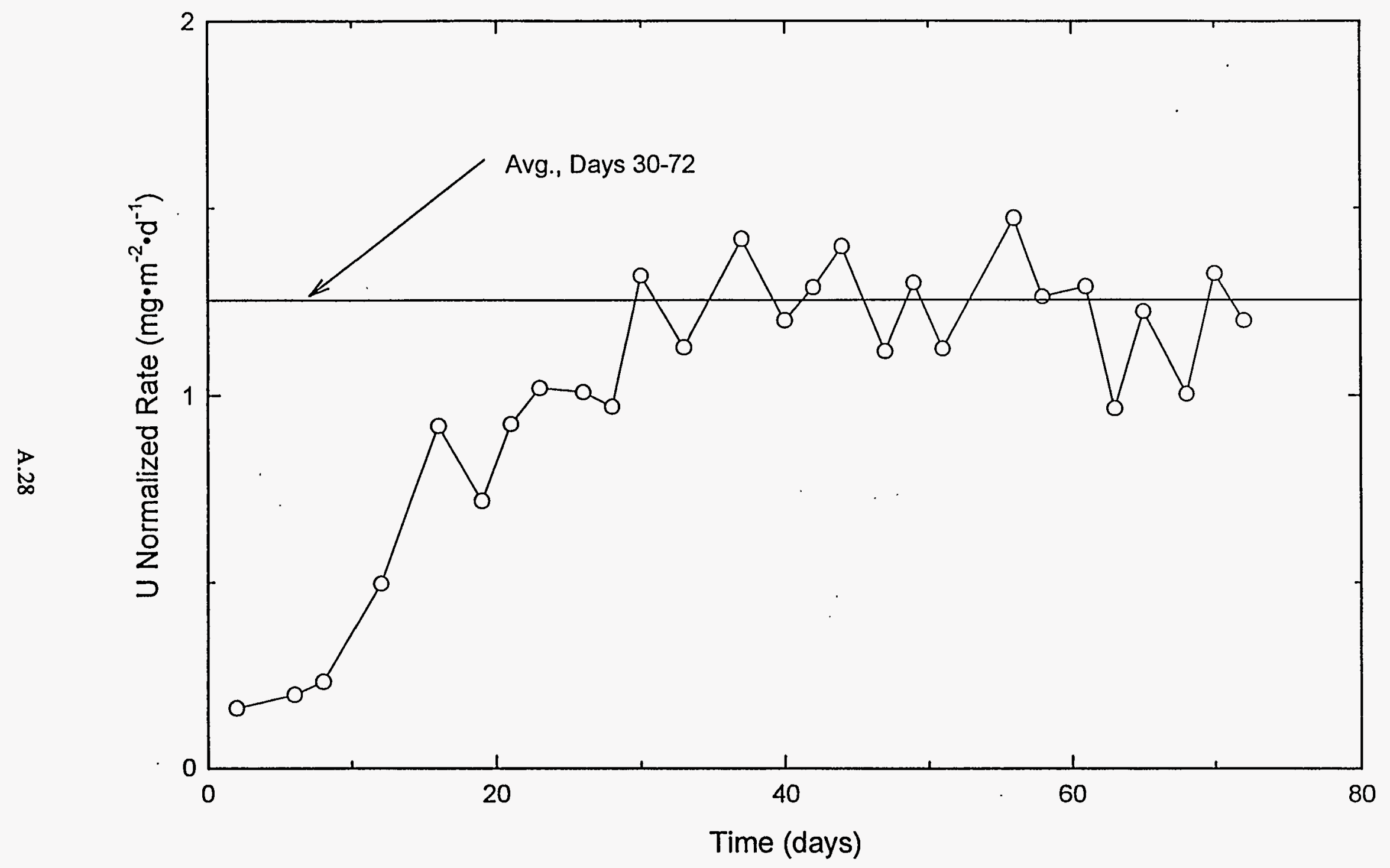

Figure A.28. Test 18 - Dissolution Rate of ATM-103 Fuel Grains in $2 \times 10^{-2} \underline{\mathrm{M} \mathrm{NaHCO}} / \mathrm{Na}_{2} \mathrm{CO}_{3}, \mathrm{pH}=10, \mathrm{O}_{2}=0.003$ atm, $50^{\circ} \mathrm{C}$ (Flow rates were $\sim 0.2 \mathrm{~mL} / \mathrm{min}$.) 


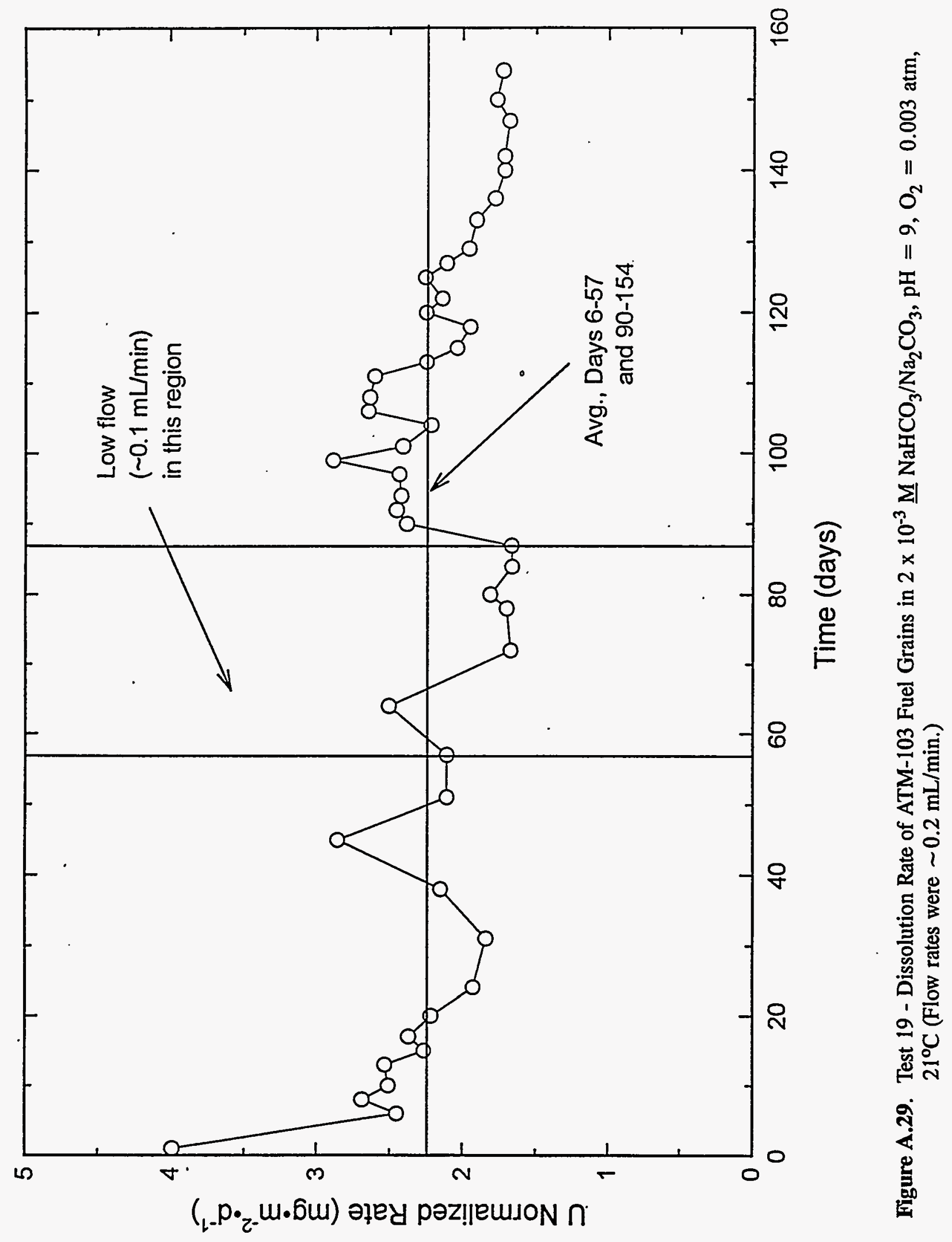



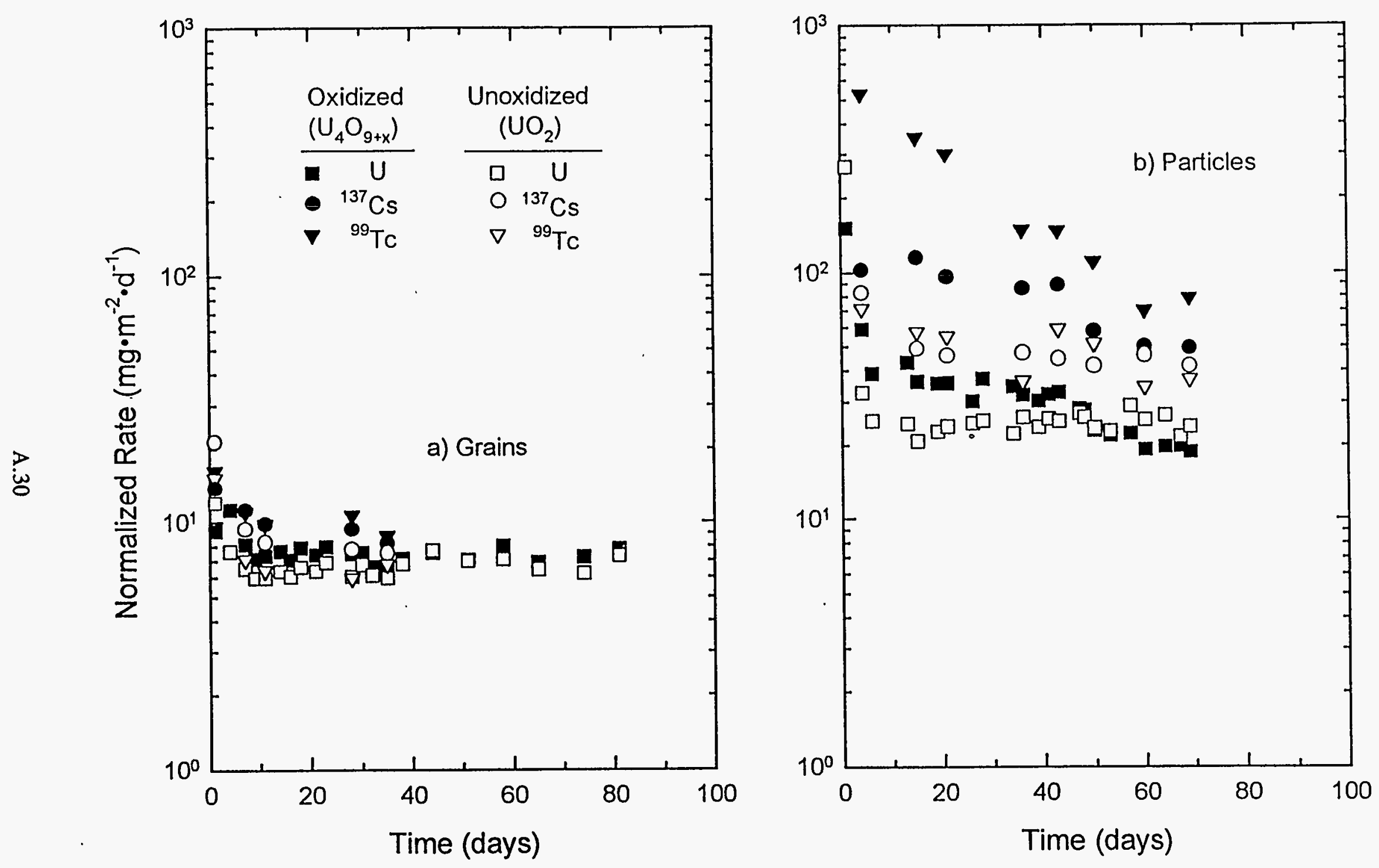

Figure A.30. Dissolution Rate of ATM-105 Spent Fuel in $2 \times 10^{-3} \mathrm{M} \mathrm{NaHCO}_{3} / \mathrm{Na}_{2} \mathrm{CO}_{3}, \mathrm{pH}=9, \mathrm{O}_{2}=0.2 \mathrm{~atm}, 50^{\circ} \mathrm{C}$ (Legend applies to both figures, a) grains and b) particles.) 

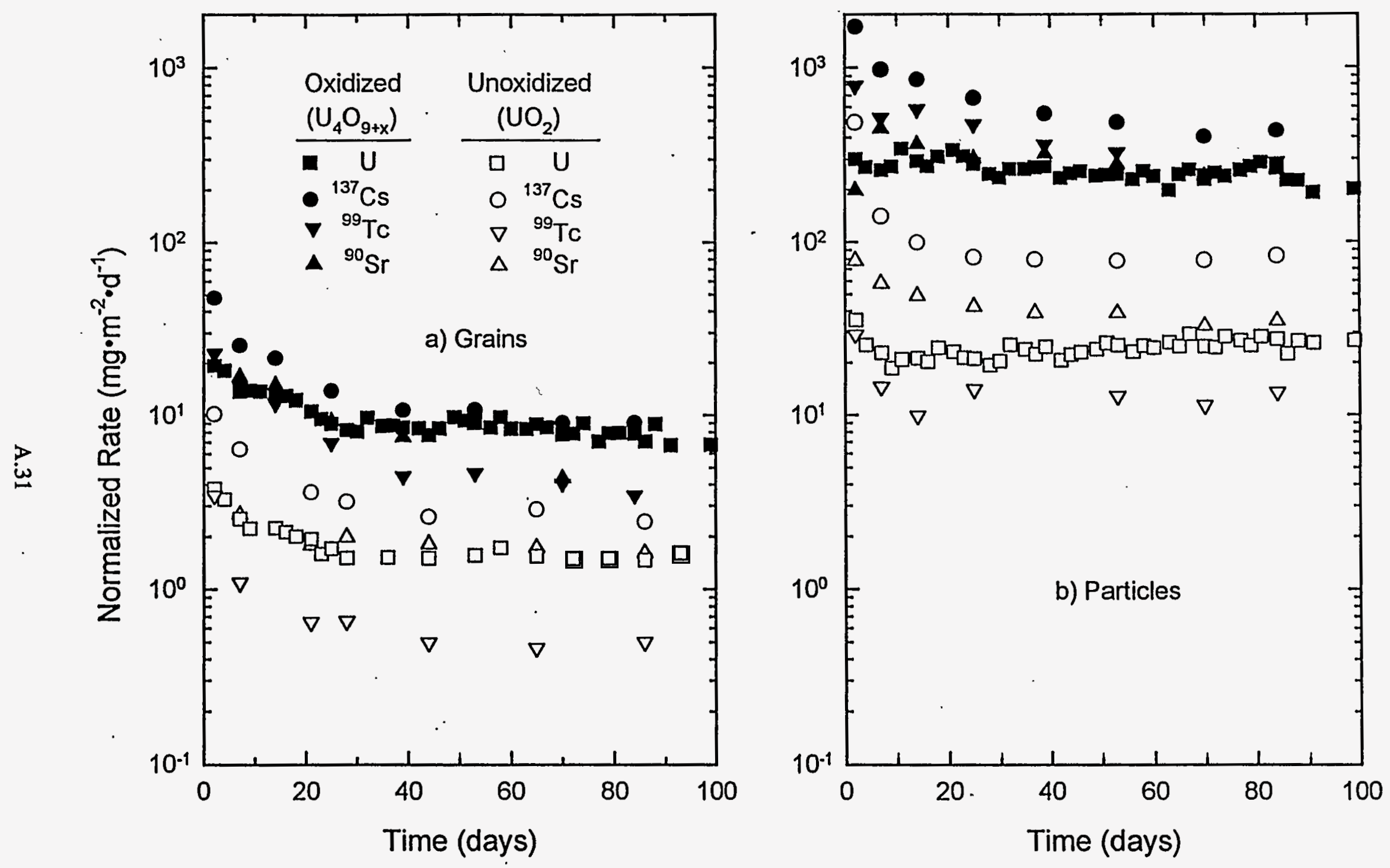

Figure A.31. Dissolution Rate of ATM-106 Spent Fuel in $2 \times 10^{-2} \mathrm{M} \mathrm{NaHCO} / \mathrm{Na}_{2} \mathrm{CO}_{3}, \mathrm{pH}=8, \mathrm{O}_{2}=0.2 \mathrm{~atm}, 22^{\circ} \mathrm{C}$ (Legend applies to both figures, a) grains and b) particles.) 


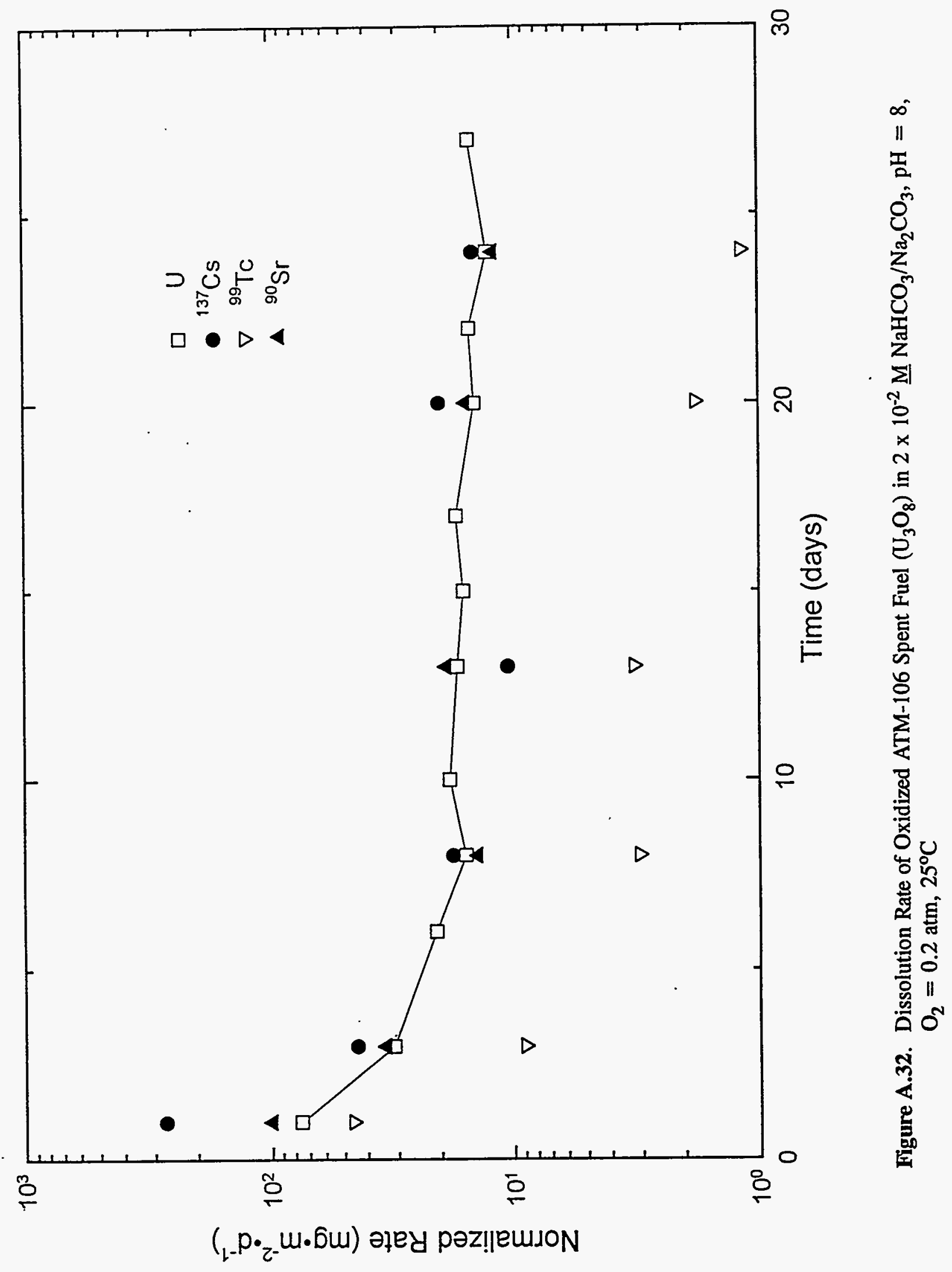

A. 32 


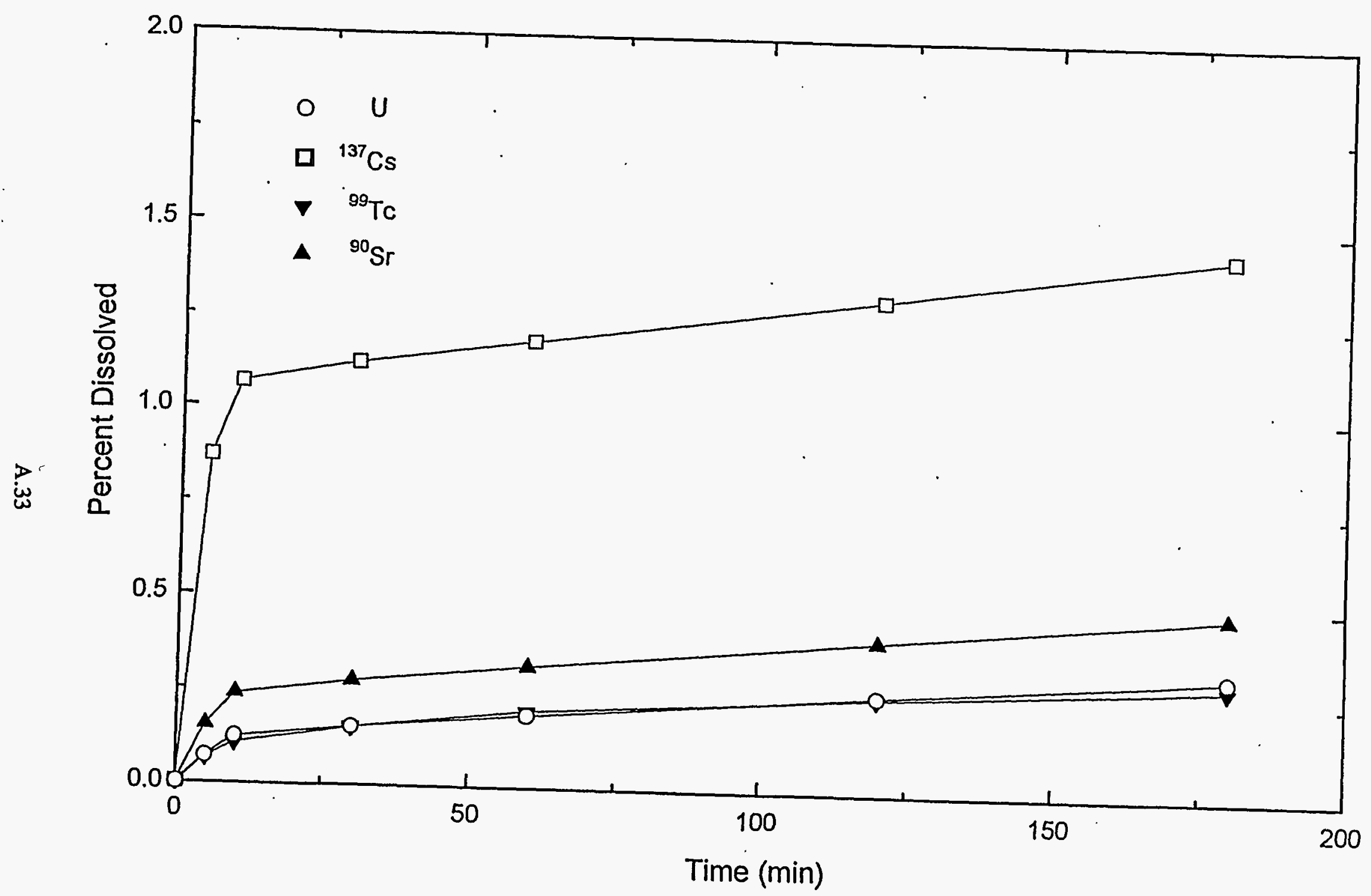

Figure A.33. Cumulative Fraction of Radionuclides Dissolved from ATM-106 Spent Fuel (11\% FGR) in $0.1 \underline{\mathrm{M} \mathrm{HCl}}$ 


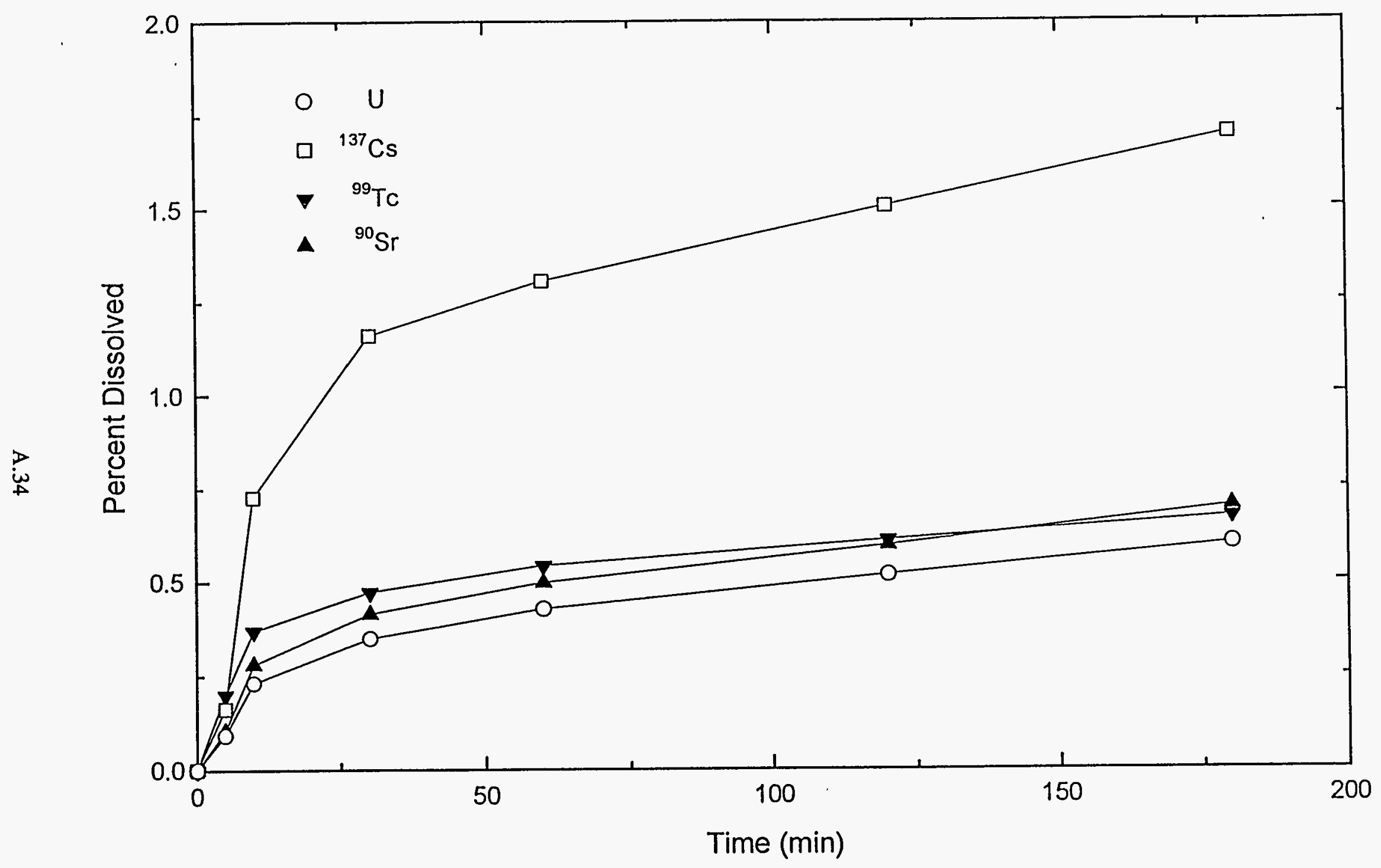

Figure A.34. Cumulative Fraction of Radionuclides Dissolved from ATM-106 Spent Fuel (18\% FGR) in $0.1 \underline{\mathrm{M}} \mathrm{HCl}$ 


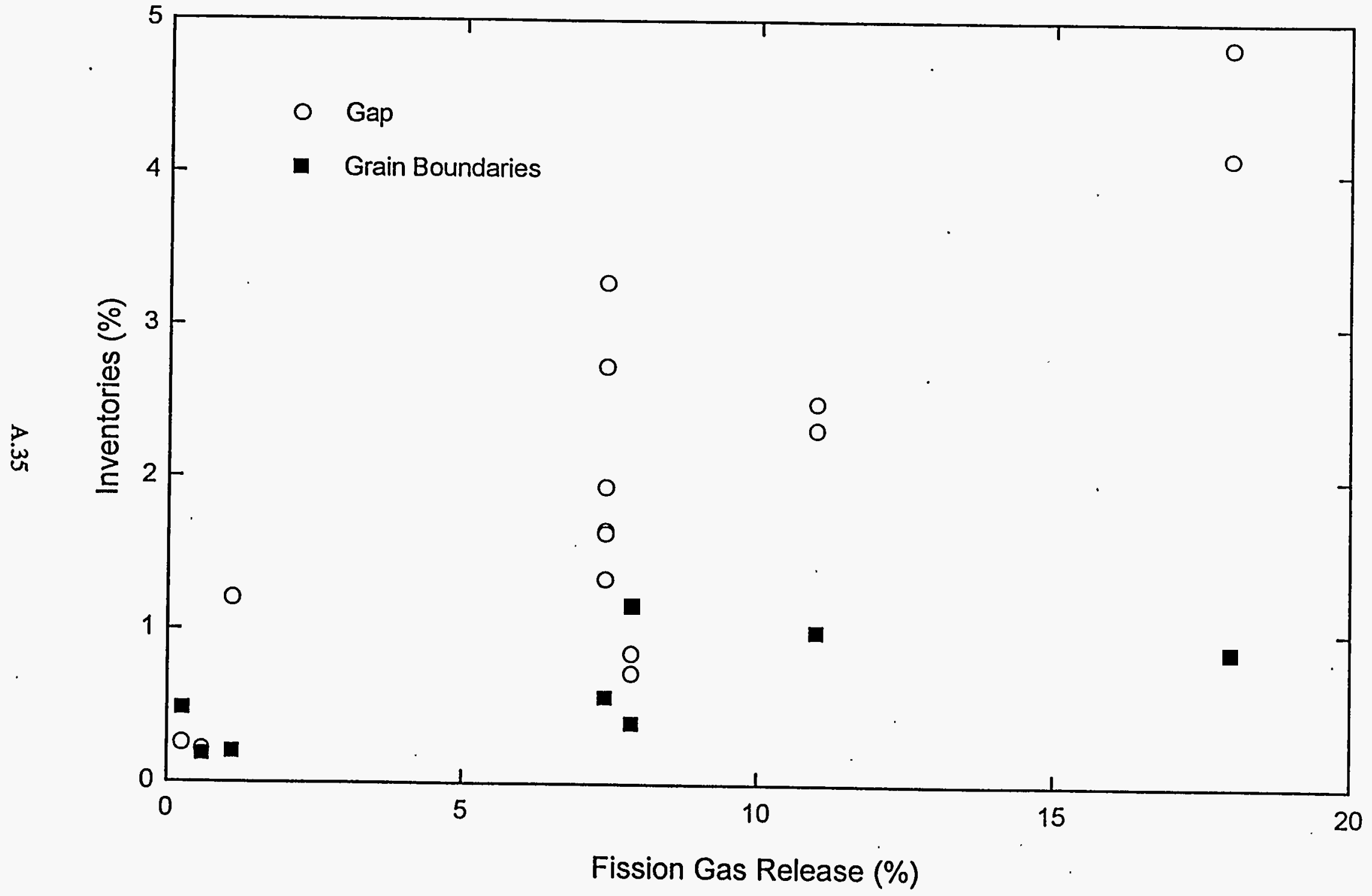

Figure A.35. Gap and Grain-Boundary Inventories of ${ }^{137} \mathrm{Cs}$ for the Fuels Indicated in Table 2.1 


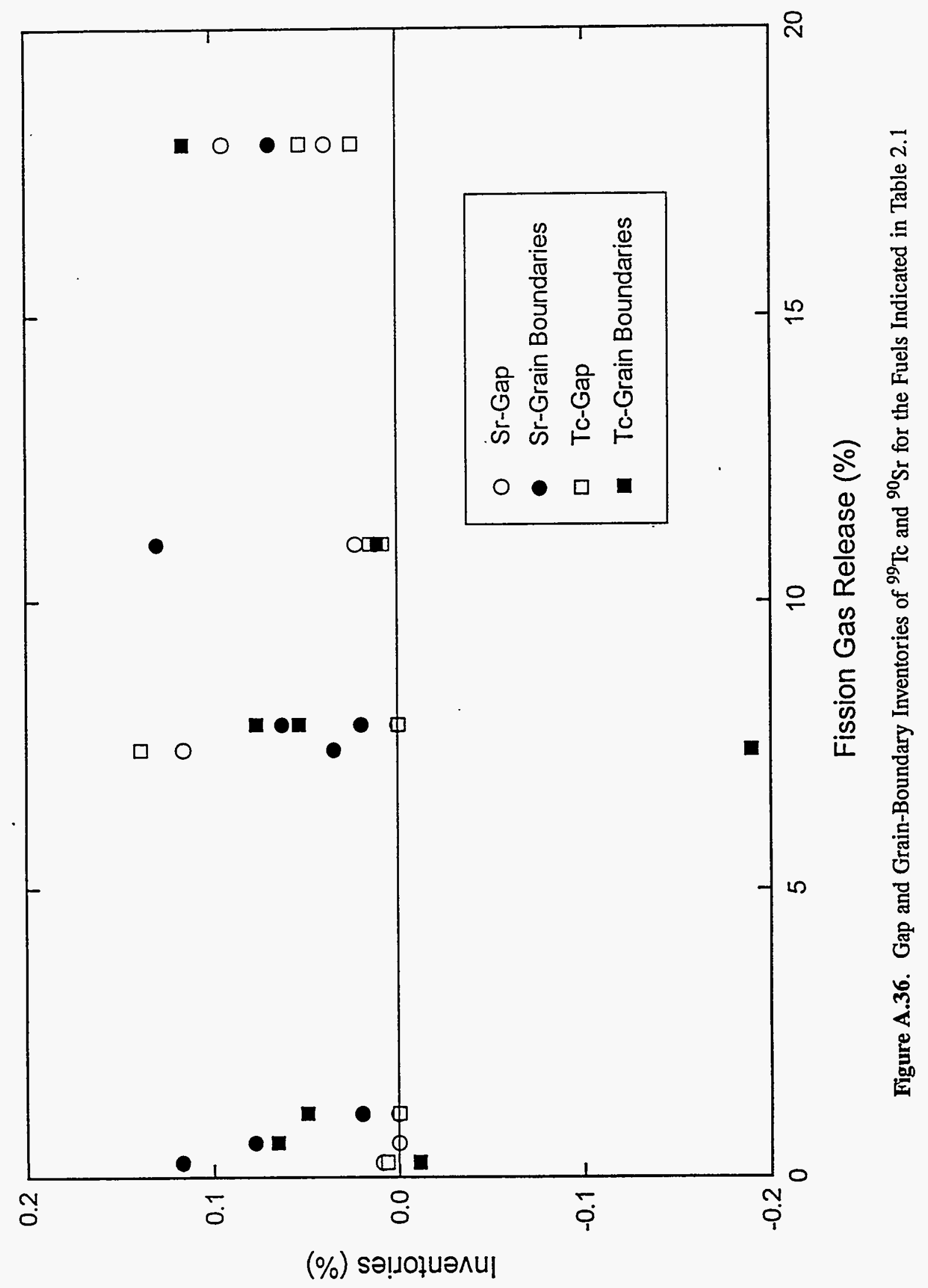

A. 36 


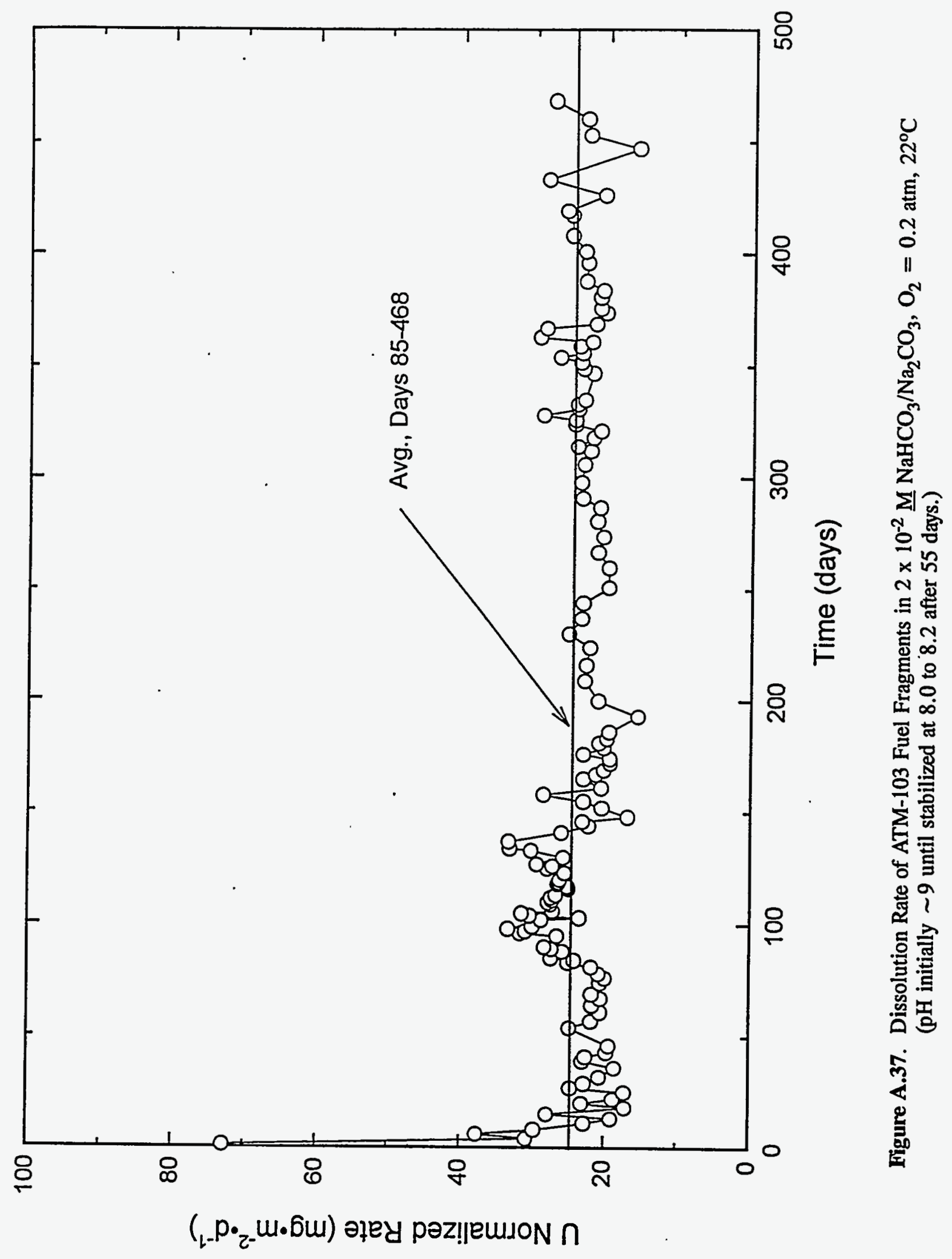




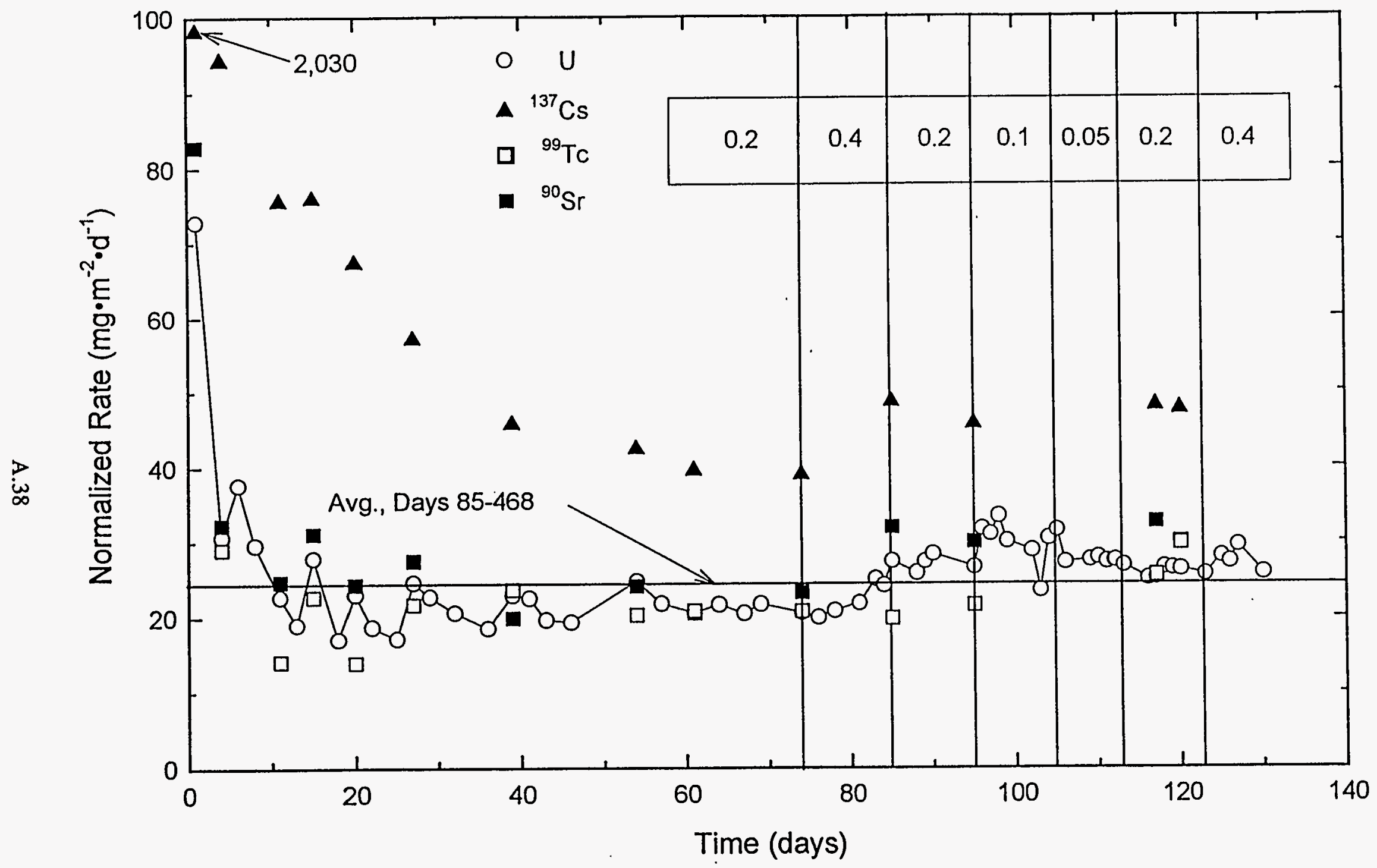

Figure A.38. Dissolution Rate of ATM-103 Fuel Fragments in $2 \times 10^{-2} \underline{\mathrm{M} \mathrm{NaHCO}} / \mathrm{Na}_{2} \mathrm{CO}_{3}, \mathrm{O}_{2}=0.2$ atm, $22^{\circ} \mathrm{C}(\mathrm{pH}$ initially $\sim 9$ until stabilized at 8.0 to 8.2 after 55 days. Vertical lines divide regions of different approximate flow rates in $\mathrm{mL} / \mathrm{min}$, which are given by numbers in box.) 


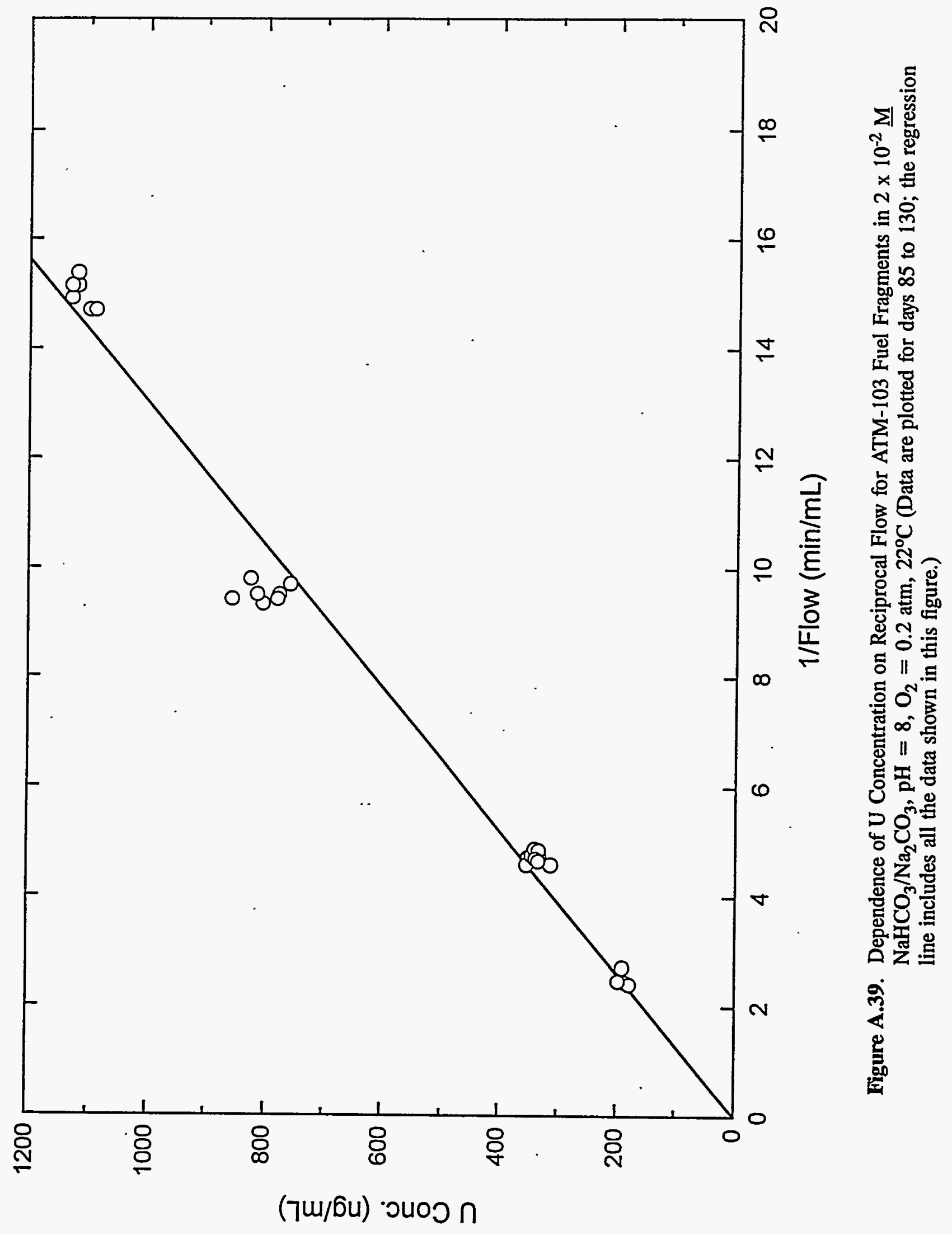

A.39 


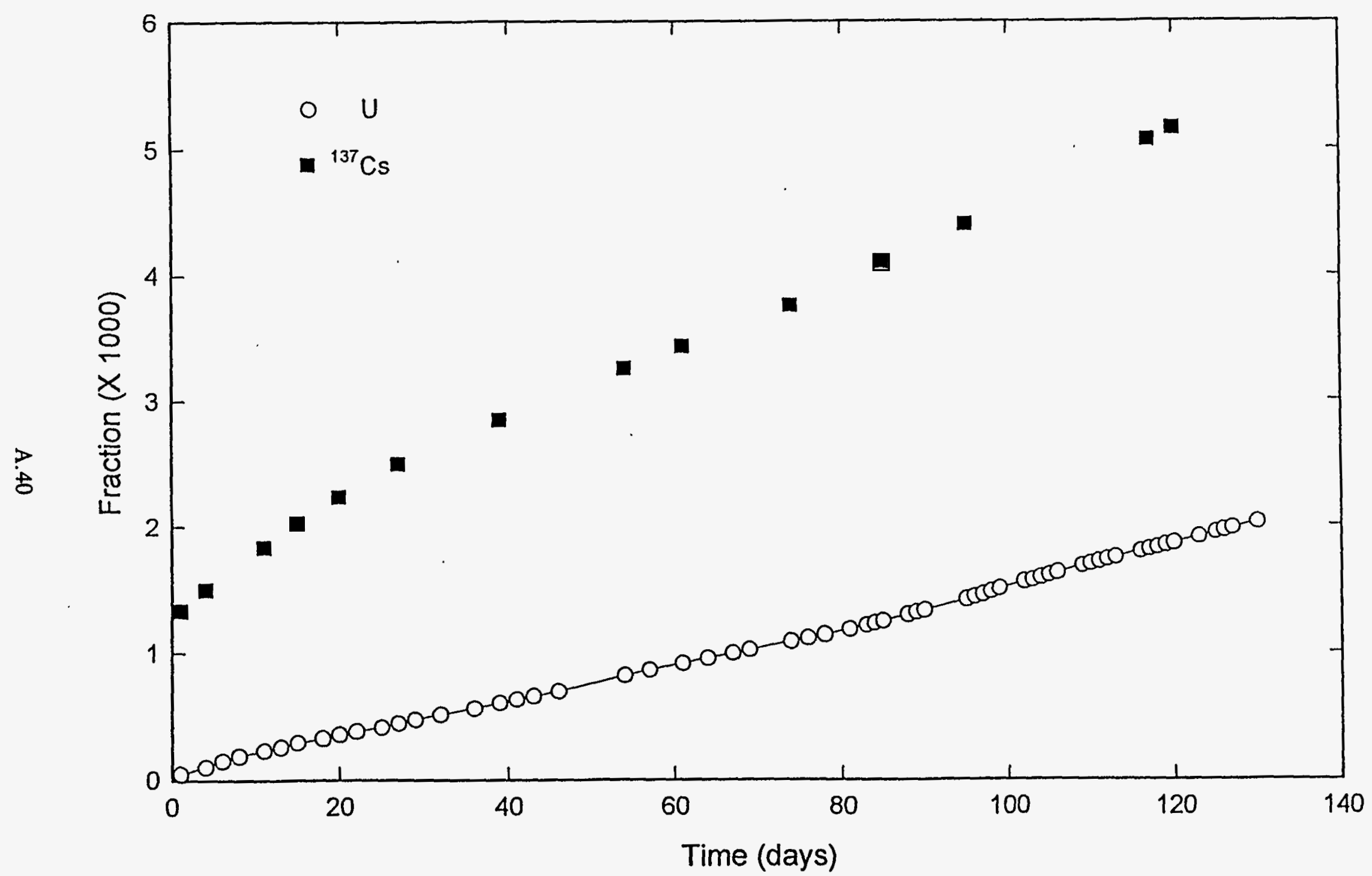

Figure A.40. Cumulative Fractions of $\mathrm{U}$ and ${ }^{137} \mathrm{Cs}$ Dissolved from ATM-103 Fuel Fragments in $2 \times 10^{-2} \mathrm{M} \mathrm{NaHCO}_{3} / \mathrm{Na}_{2} \mathrm{CO}_{3}$, $\mathrm{O}_{2}=0.2 \mathrm{~atm}, 22^{\circ} \mathrm{C}(\mathrm{pH}$ initially $\sim 9$ until stabilized at 8.0 to 8.2 after 55 days.) 


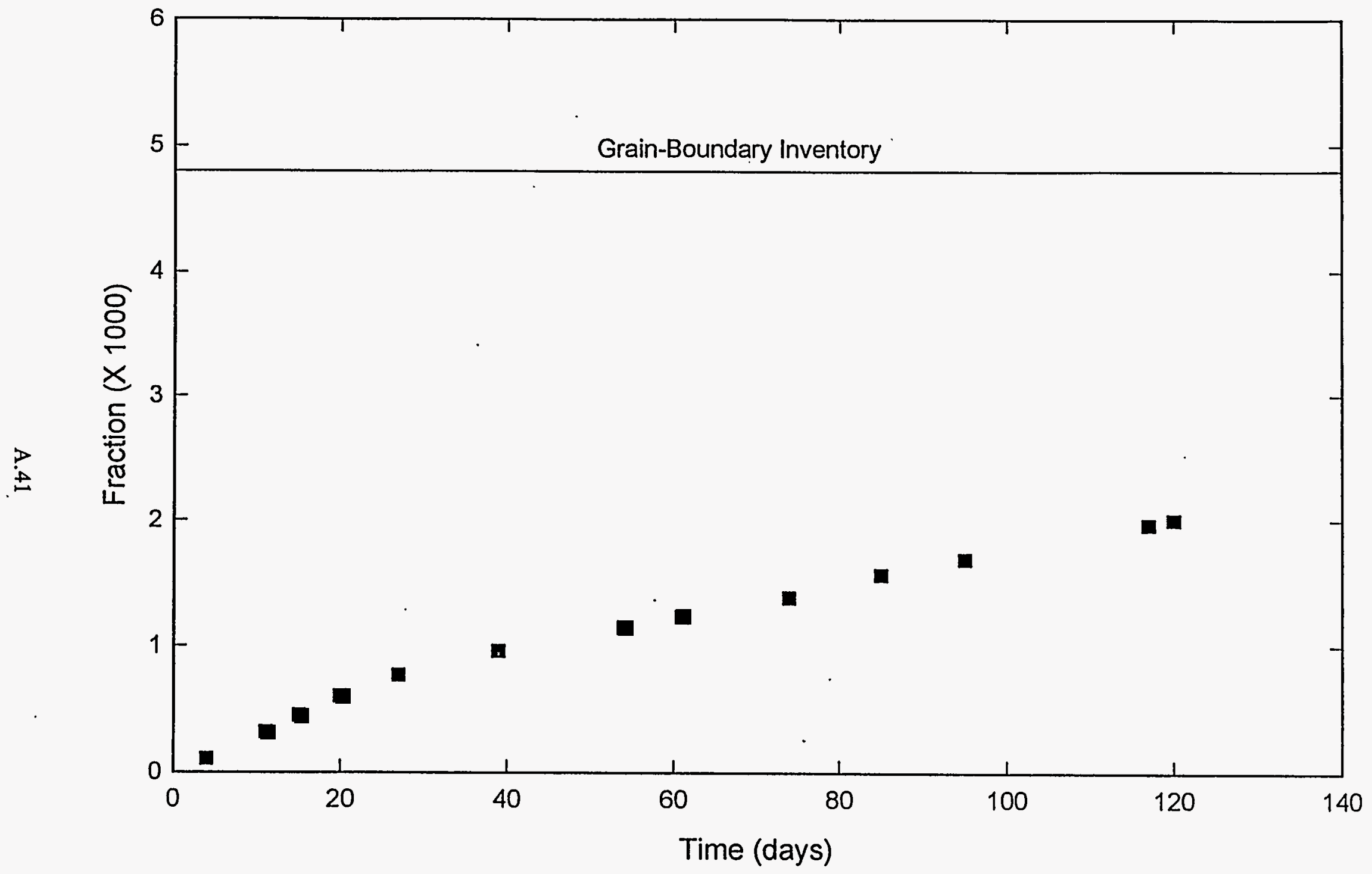

Figure A.41. Cumulative Fraction of ${ }^{137} \mathrm{Cs}$ Dissolved from the Grain Boundaries of ATM-103 Fuel Fragments in $2 \times 10^{-2} \mathrm{M}$ $\mathrm{NaHCO}_{3} / \mathrm{Na}_{2} \mathrm{CO}_{3}, \mathrm{O}_{2}=0.2 \mathrm{~atm}, 22^{\circ} \mathrm{C}$ ( $\mathrm{pH}$ initially $\sim 9$ until stabilized at 8.0 to 8.2 after 55 days.) 


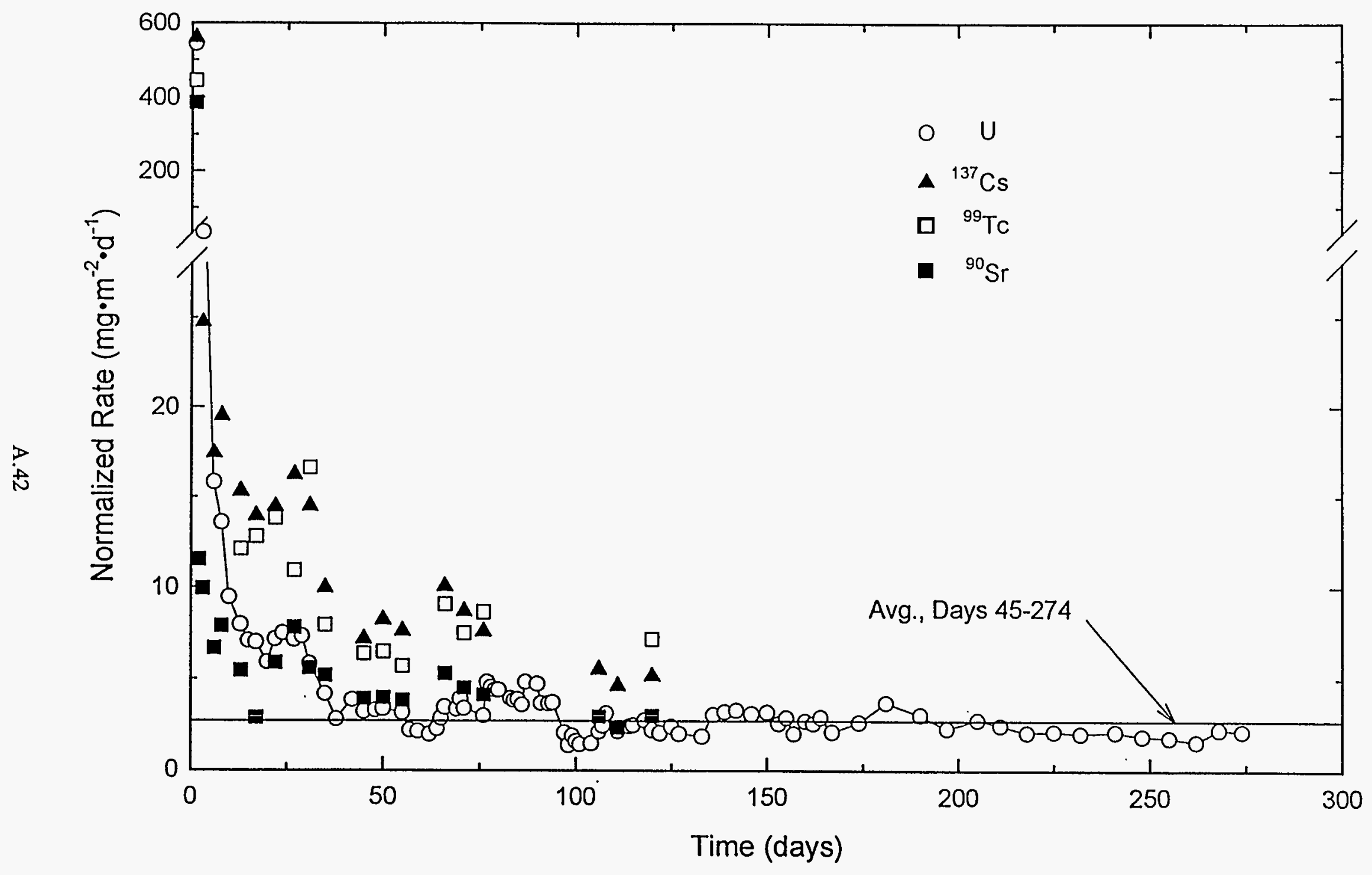

Figure A.42. Dissolution Rate of Series-3 Archive Specimen in J-13 Well Water at $\mathrm{O}_{2}=0.2 \mathrm{~atm}, 22^{\circ} \mathrm{C}$ 


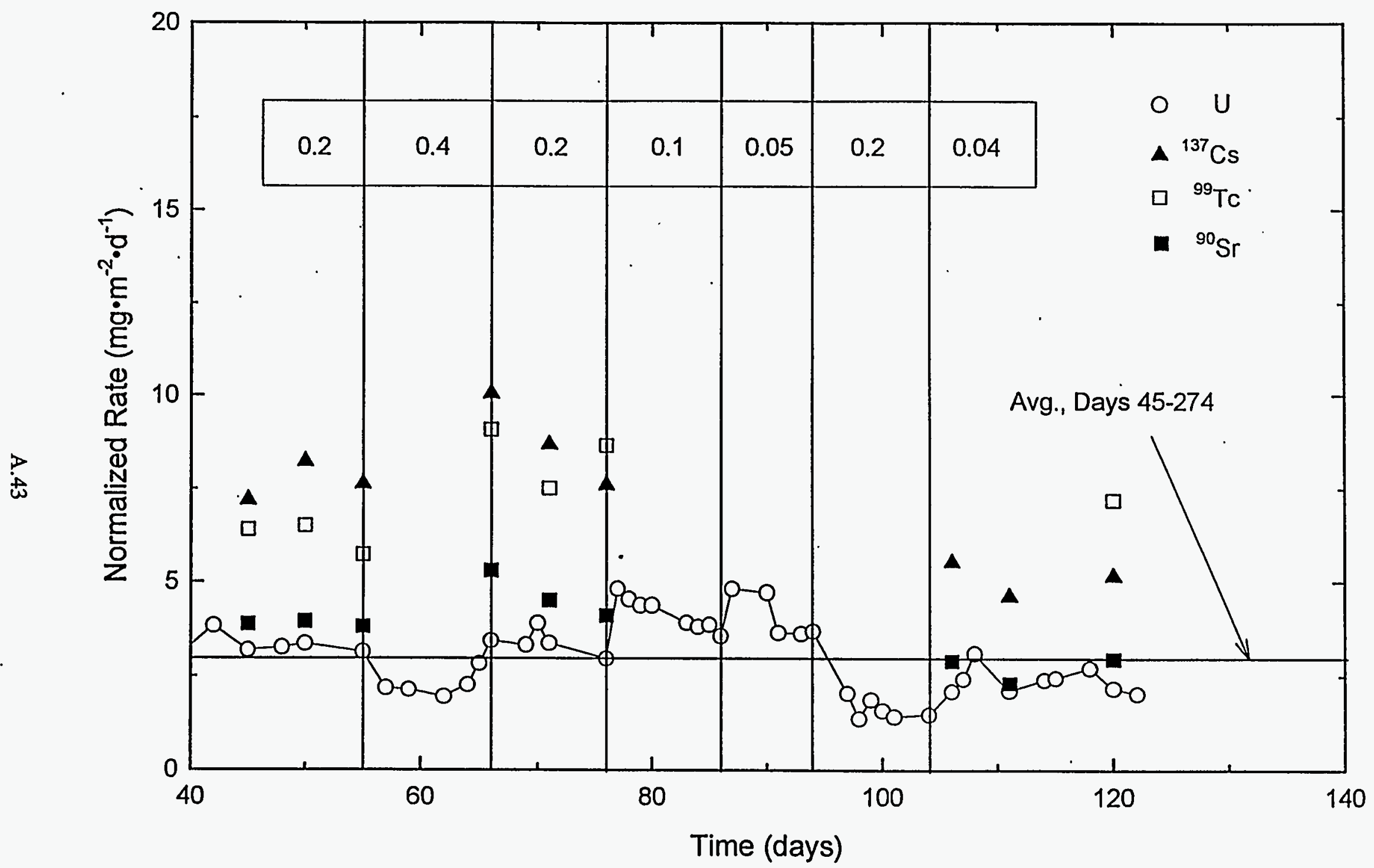

Figure A.43. Dissolution Rate of Series-3 Archive Specimen in J-13 Well Water at $\mathrm{O}_{2}=0.2 \mathrm{~atm}, 22^{\circ} \mathrm{C}$ (Expanded $\mathrm{x}$ - and y-axis scales for a portion of Figure A.42. Vertical lines divide regions of different approximate flow rates in $\mathrm{mL} / \mathrm{min}$, which are given by numbers in box.) 


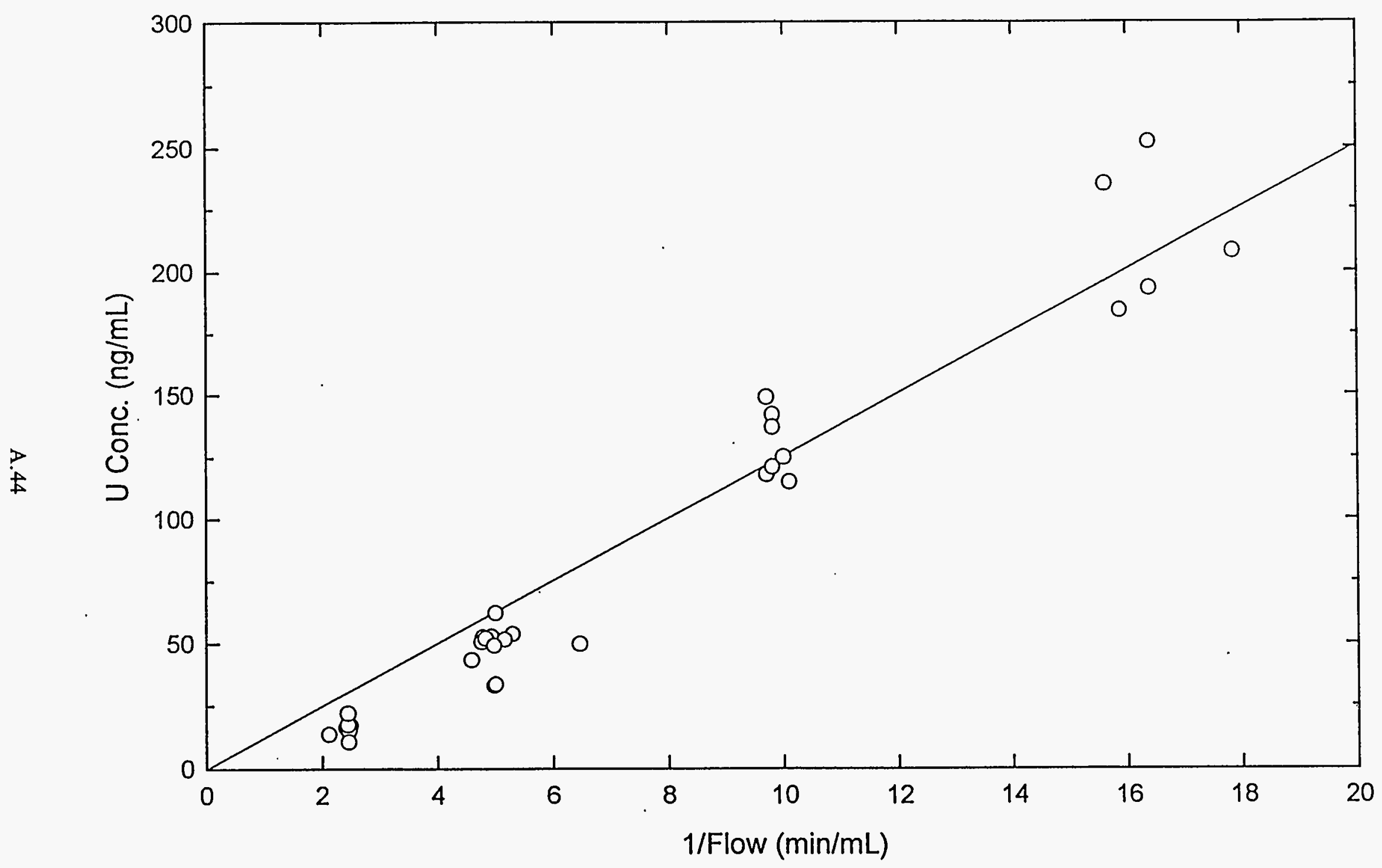

Figure A.44. Dependence of U Concentrations on Reciprocal Flow for Series-3 Archive Specimen in J-13 Well Water at $\mathrm{O}_{2}=0.2 \mathrm{~atm}, 22^{\circ} \mathrm{C}$ (Data are plotted for days 45 to 111 ; the regression line includes all data shown in this figure.) 

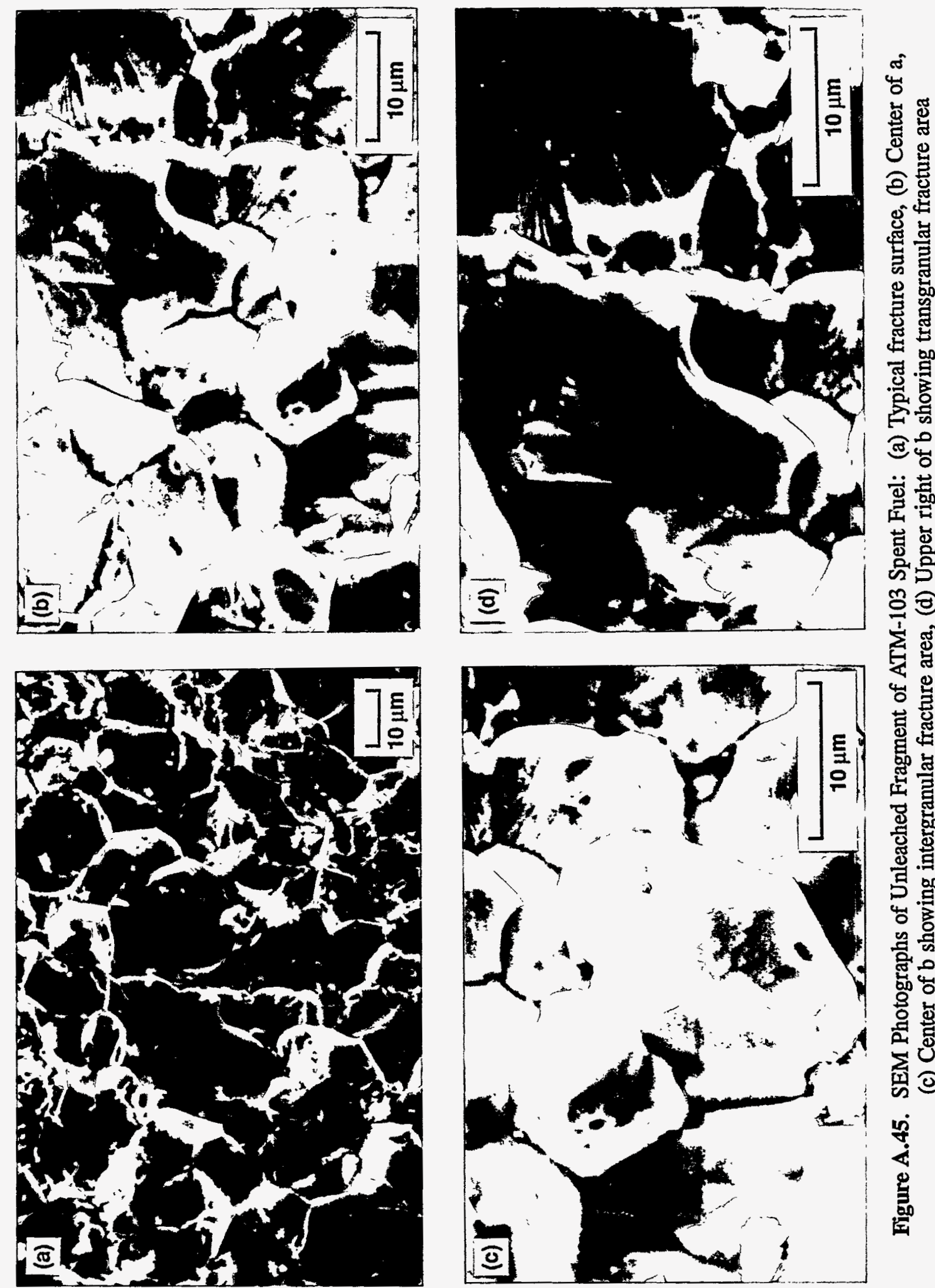


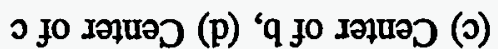

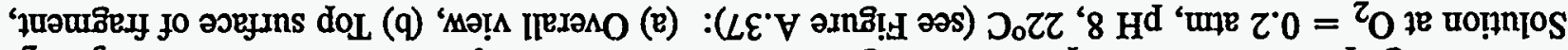

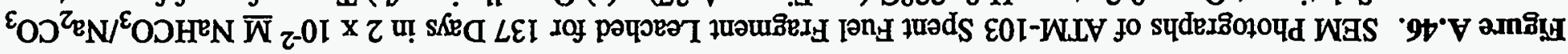
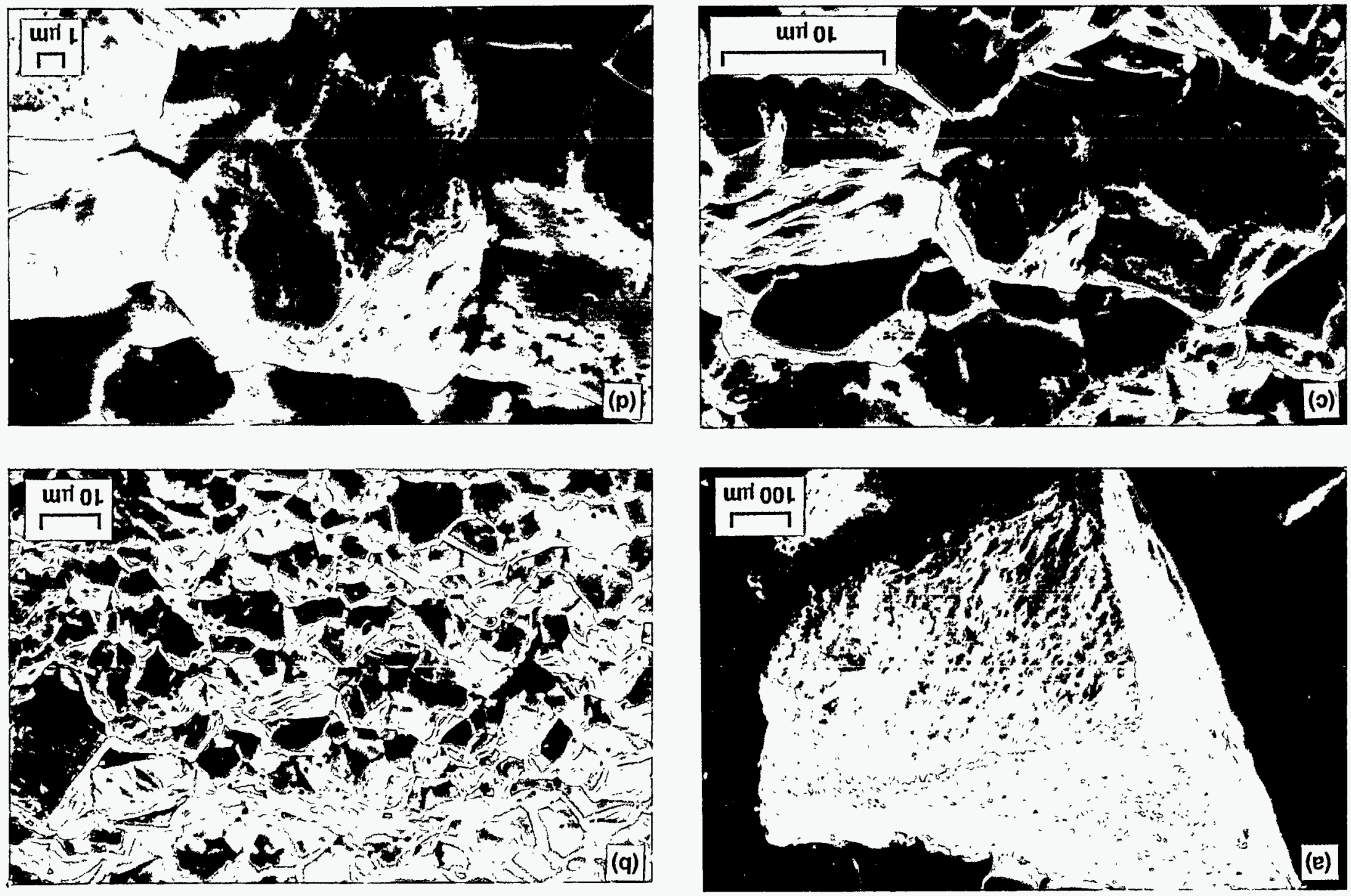

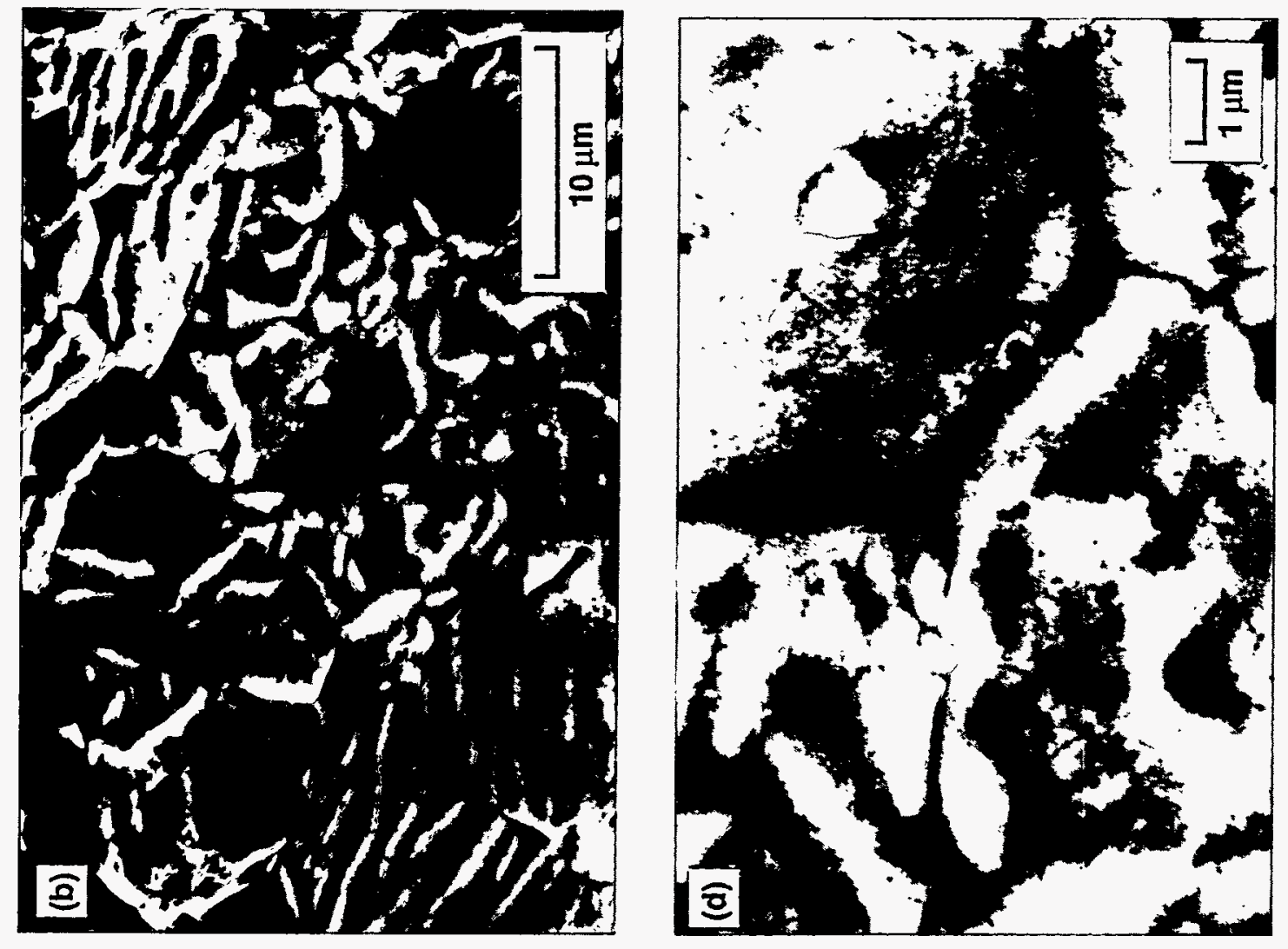

రீச்

䓀

on

돈

穵

네함

주을

品

N

.

50

忍 ญ

กิ

뭉

윰

항

क्ष

$\mapsto 0$

몽이 (4)

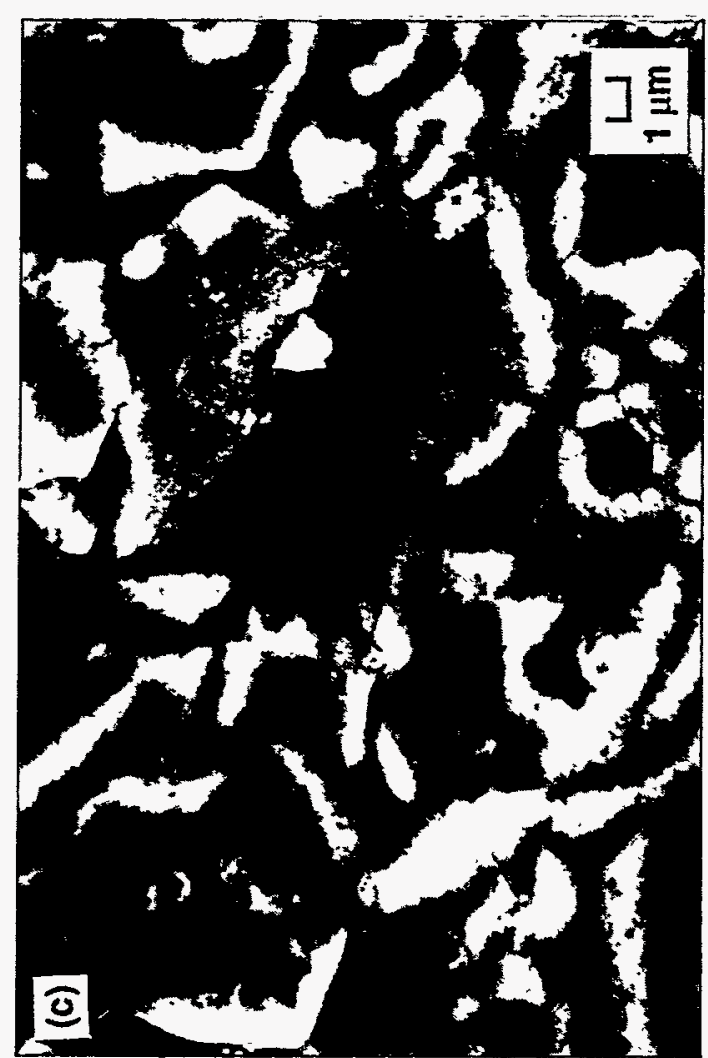

은

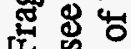

Фบ 농

零

范

की 11

응폼

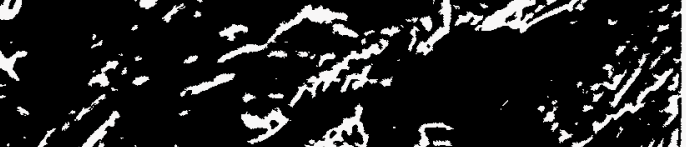

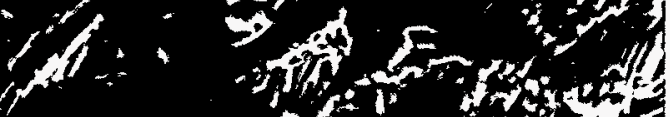

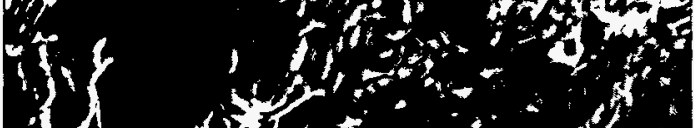
(1)

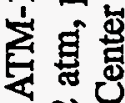

ㄸํㅇㄹㅡ

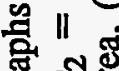

荧

융 즁

究 点

페윯

告 

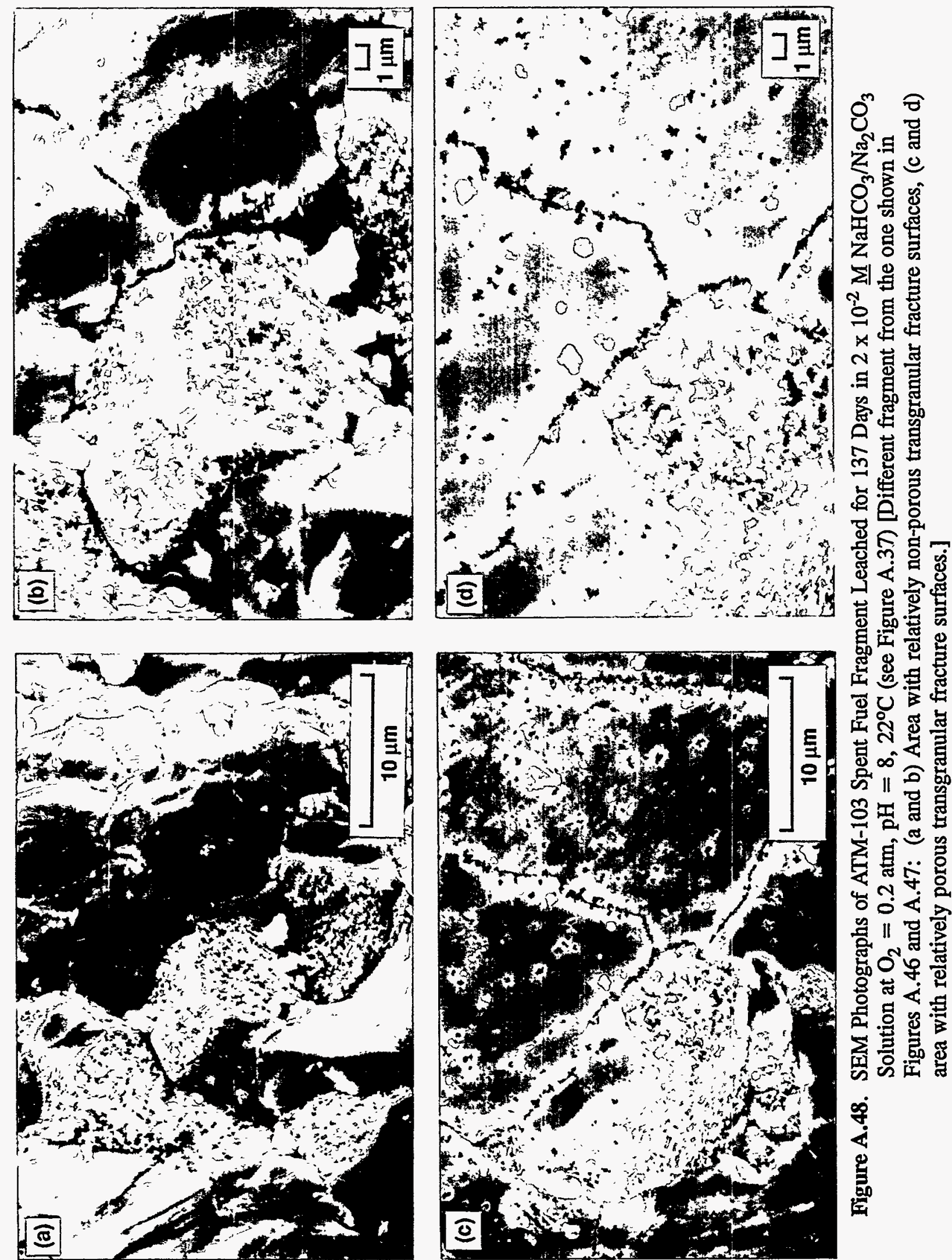

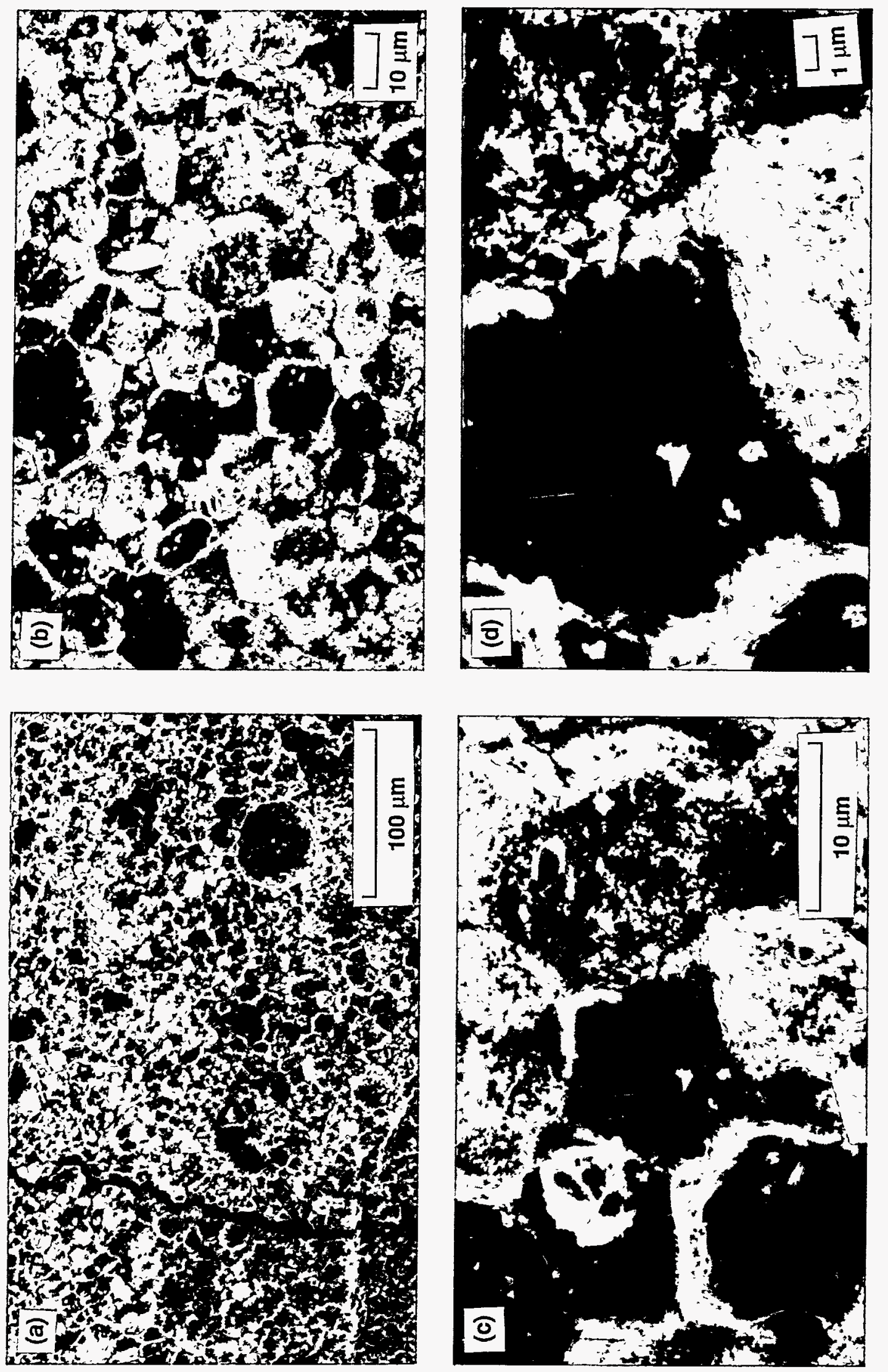

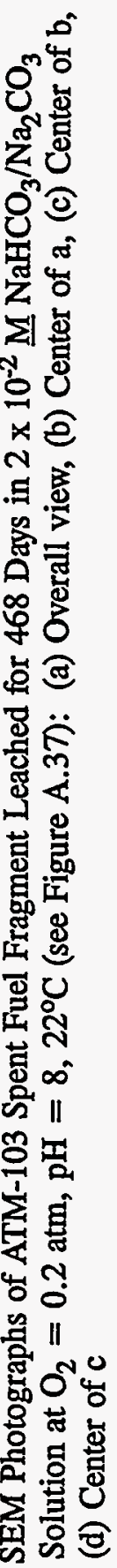

㝵 


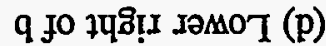

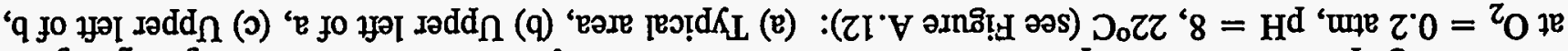

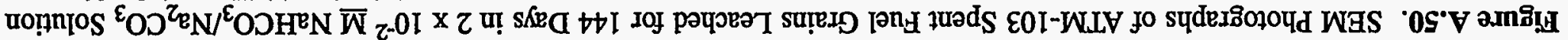
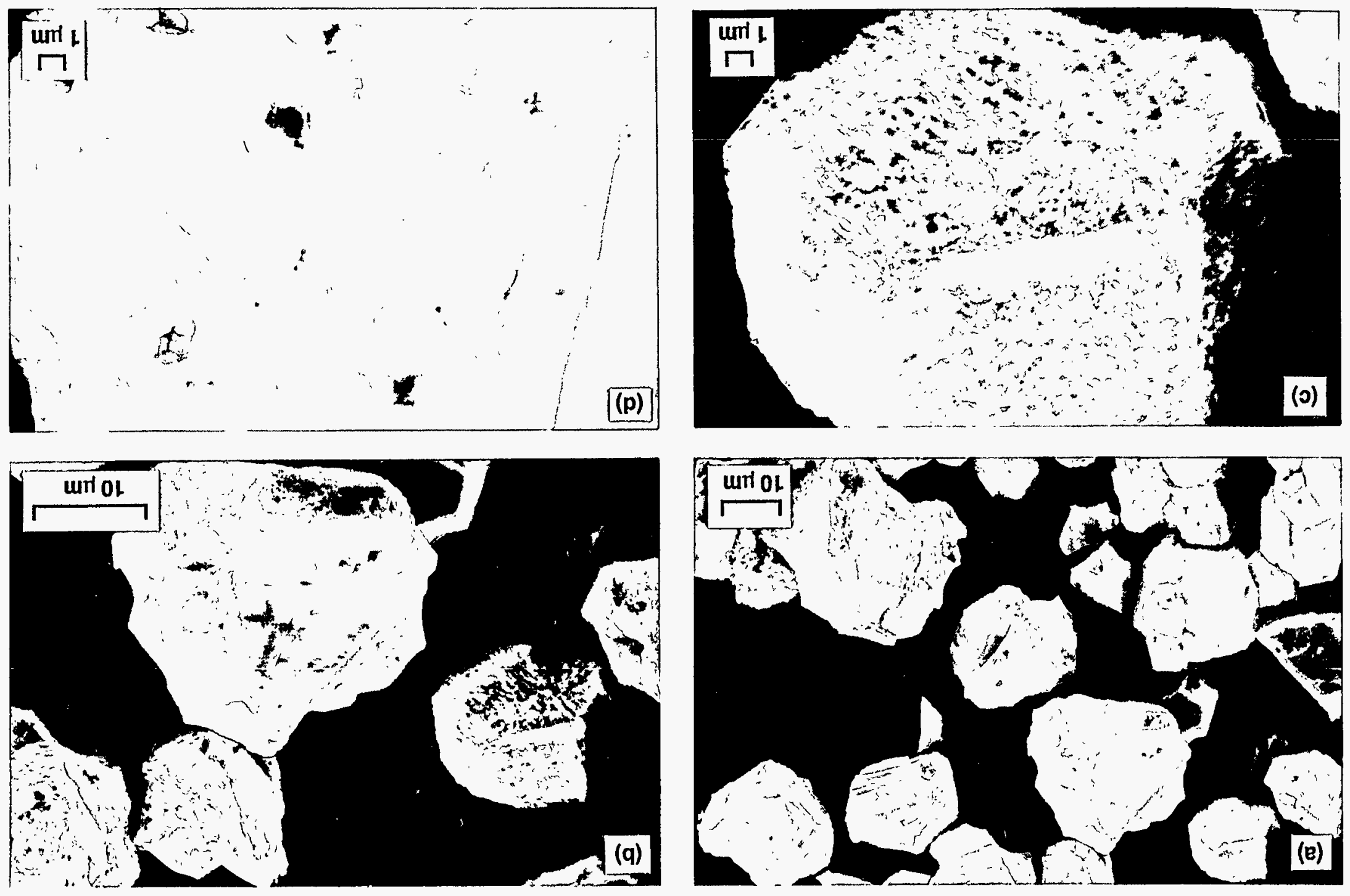

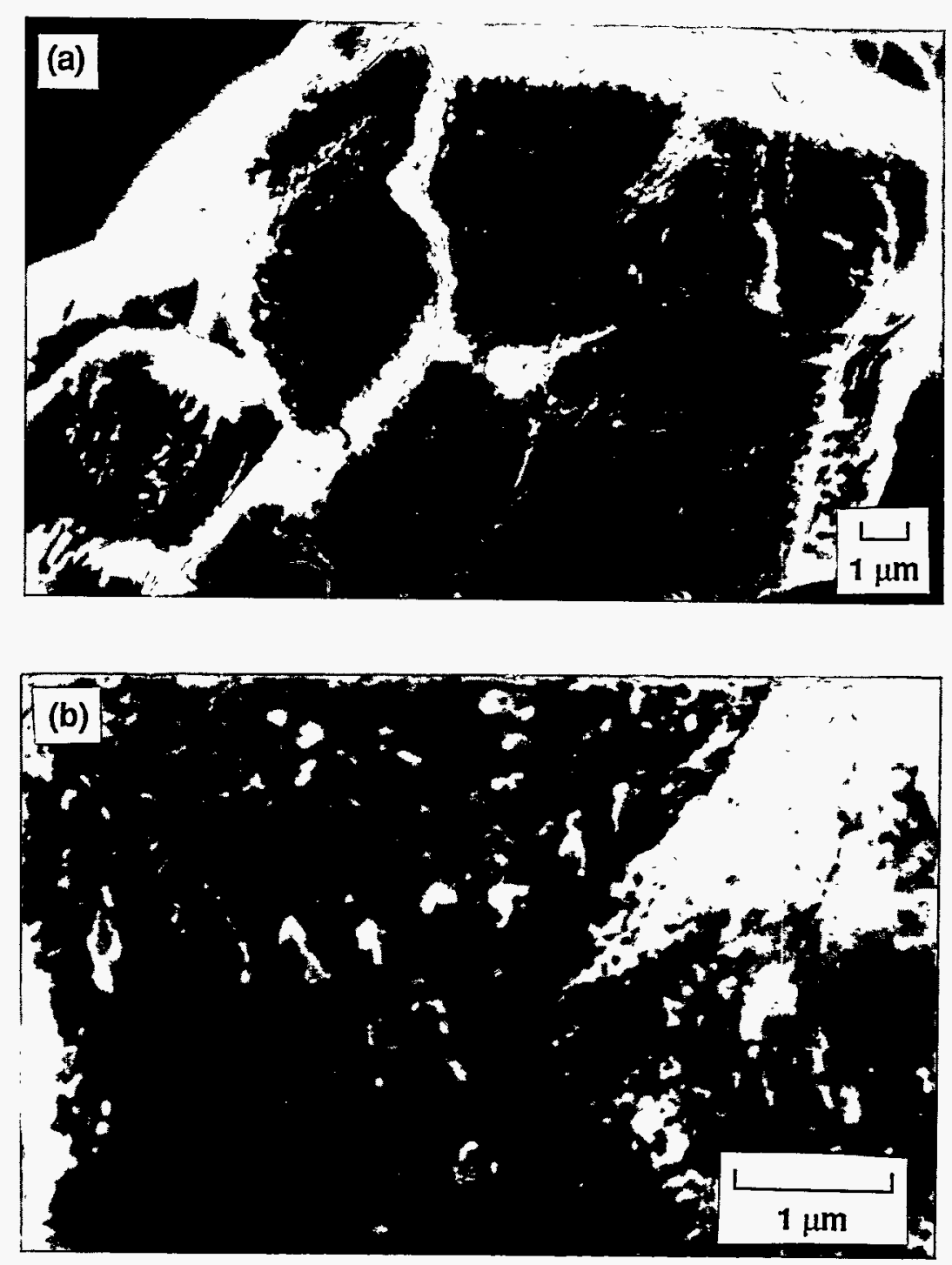

Figure A.51. SEM Photographs of ATM-103 Spent Fuel Grains Leached for 169 Days in $2 \times 10^{-2} \mathrm{M}$ $\mathrm{NaHCO}_{3} / \mathrm{Na}_{2} \mathrm{CO}_{3}$ Solution at $\mathrm{O}_{2}=0.003$ and $0.2 \mathrm{~atm}, \mathrm{pH} 10,21^{\circ} \mathrm{C}$ (see Figure A.27): (a) View of grain, (b) Upper center of a 

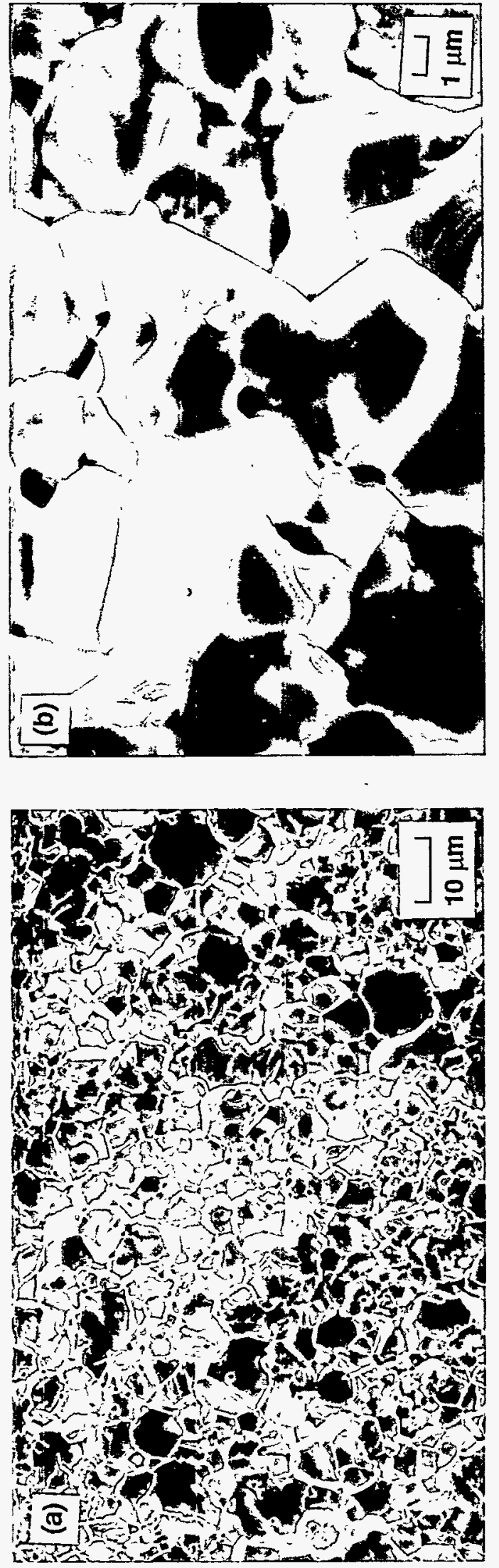

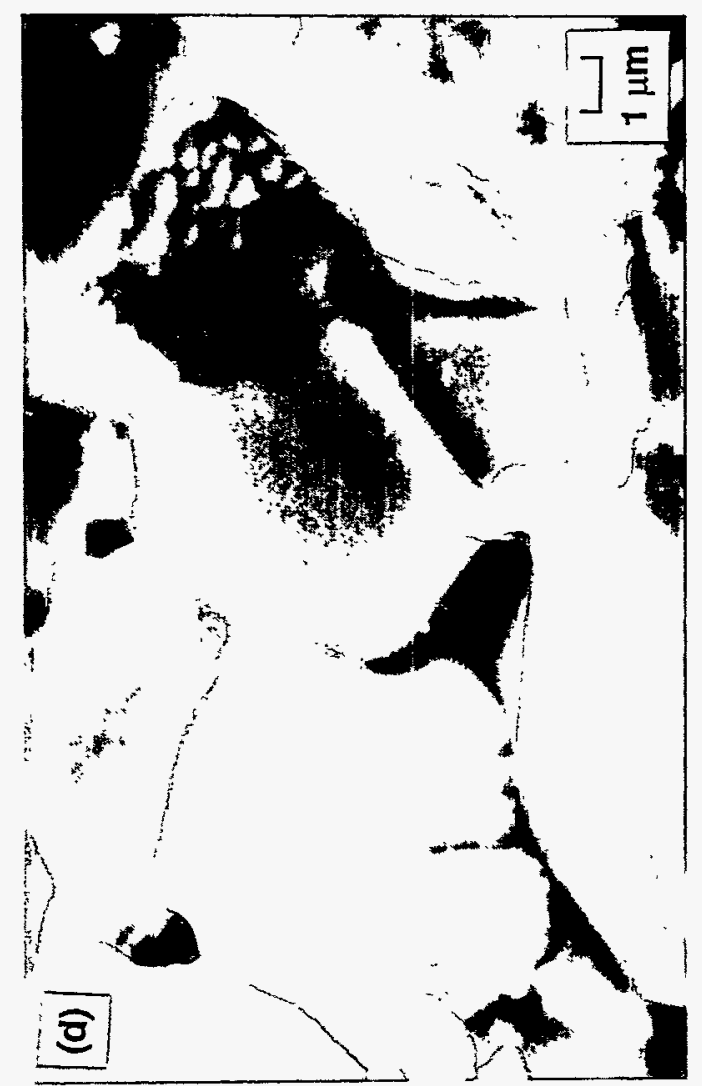

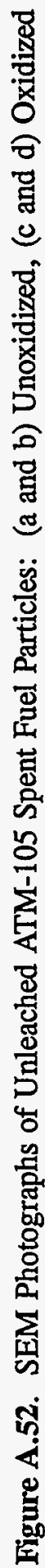

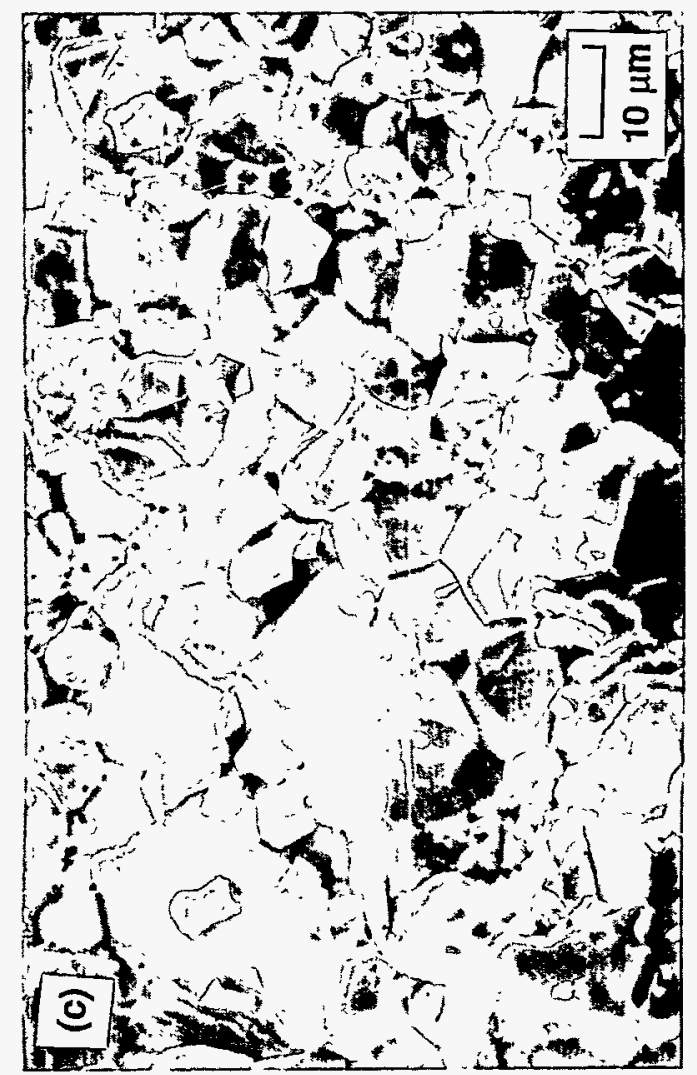



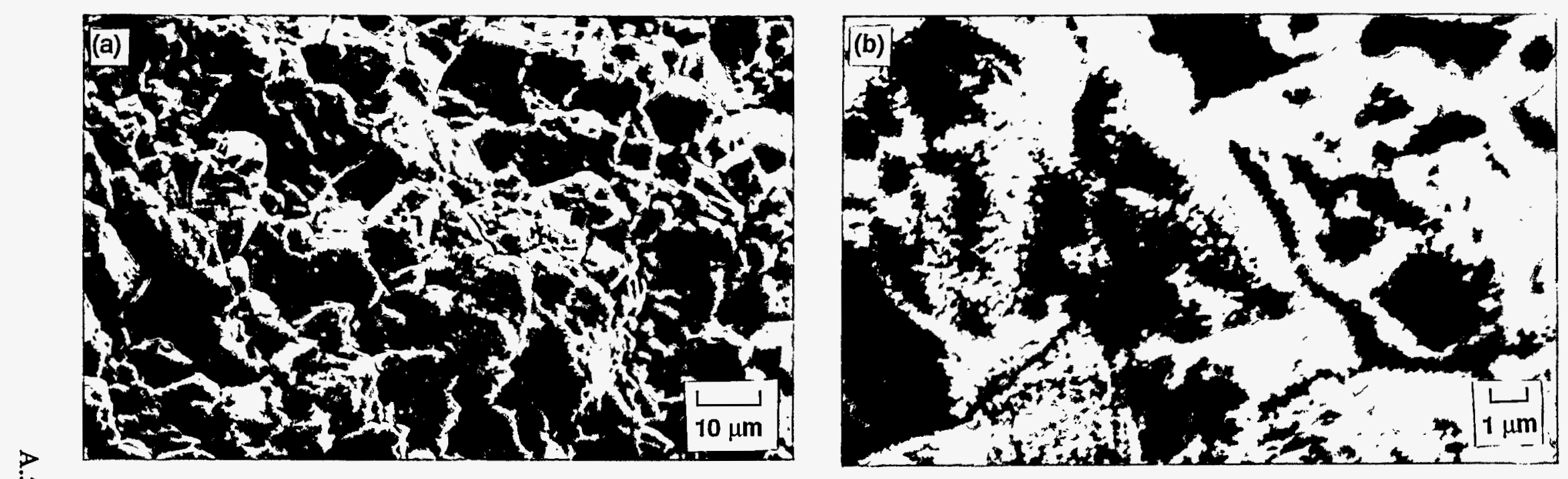

出
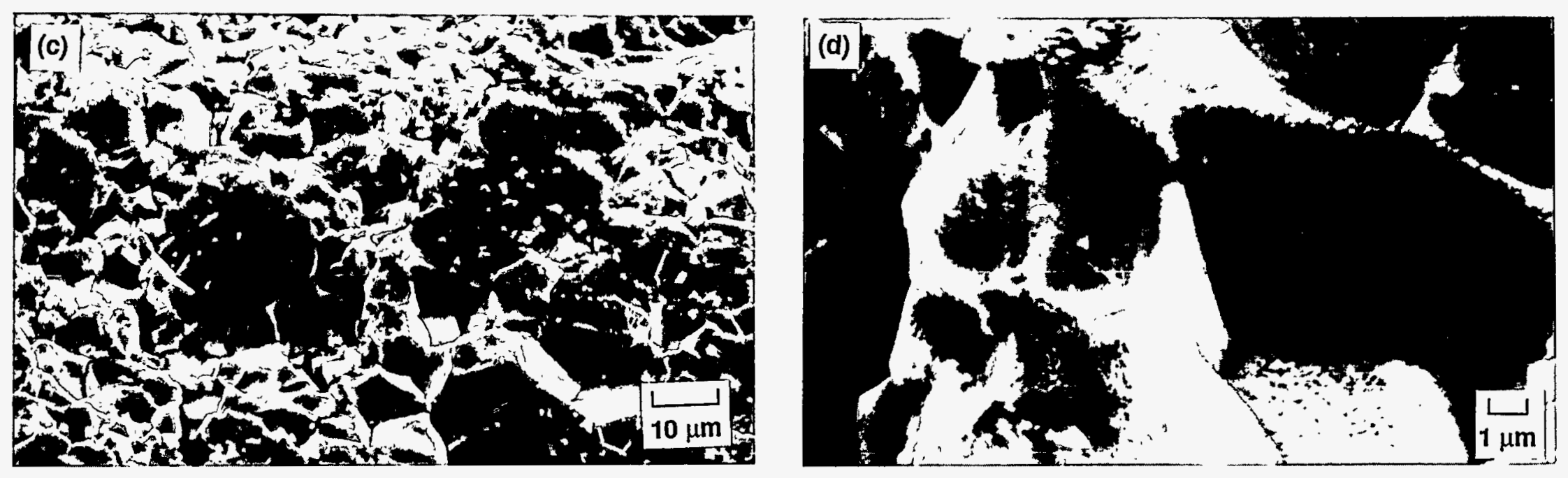

Figure A.53. SEM Photographs of ATM-105 Spent Fuel Particles Leached for 69 Days in $2 \times 10^{-3} \underline{\mathrm{M} \mathrm{NaHCO}} / \mathrm{Na}_{2} \mathrm{CO}_{3}$ Solution at $\mathrm{pH} 9, \mathrm{O}_{2}=0.2 \mathrm{~atm}, 50^{\circ} \mathrm{C}$ (see Figure A.30b): ( $\mathrm{a}$ and b) Unoxidized, (c and d) Oxidized 

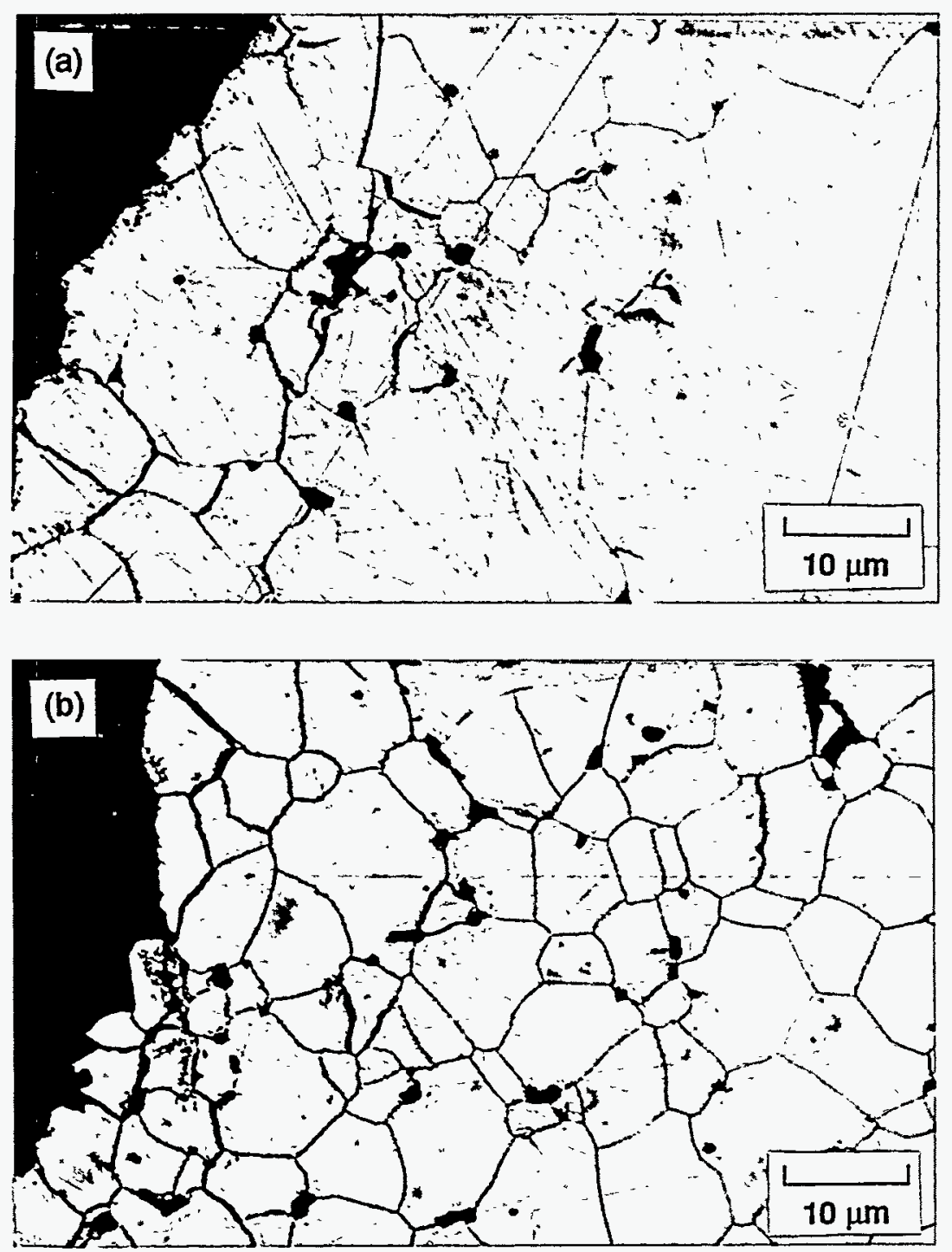

Figure A.54. Cross-Sectioned Particles of a) Unoxidized and b) Oxidized ATM-105 Spent Fuel Leached for 69 Days in $2 \times 10^{-3} \underline{\mathrm{M} \mathrm{NaHCO}}{ }_{3} / \mathrm{Na}_{2} \mathrm{CO}_{3}$ Solution at $\mathrm{pH} 9, \mathrm{O}_{2}=0.2 \mathrm{~atm}$, $50^{\circ} \mathrm{C}$ (see Figure A.30b) 

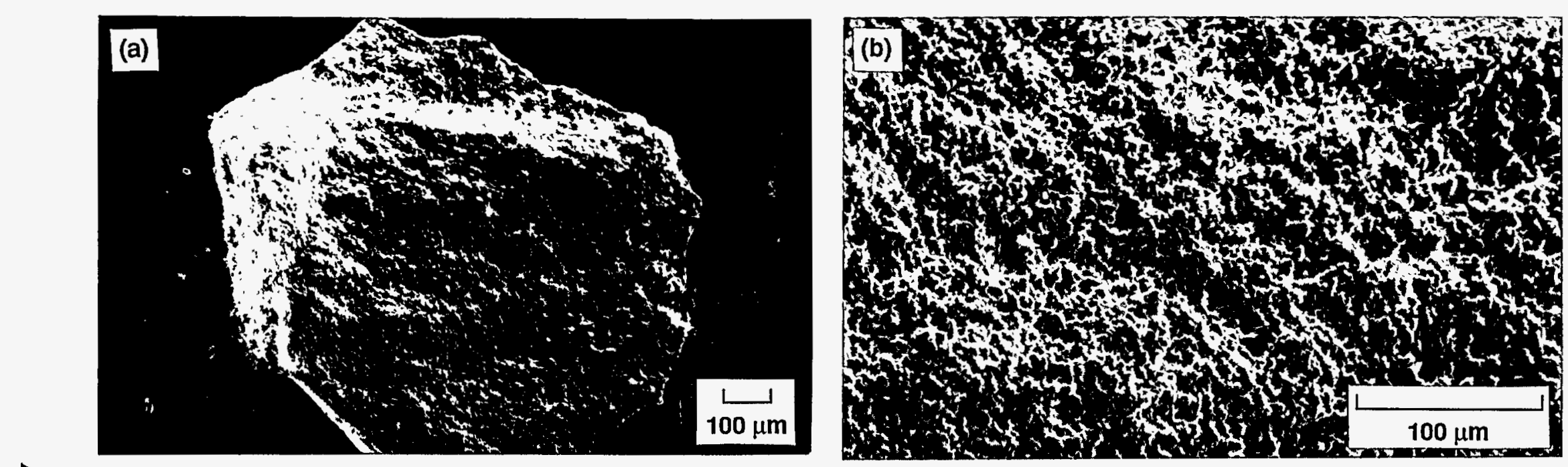

us
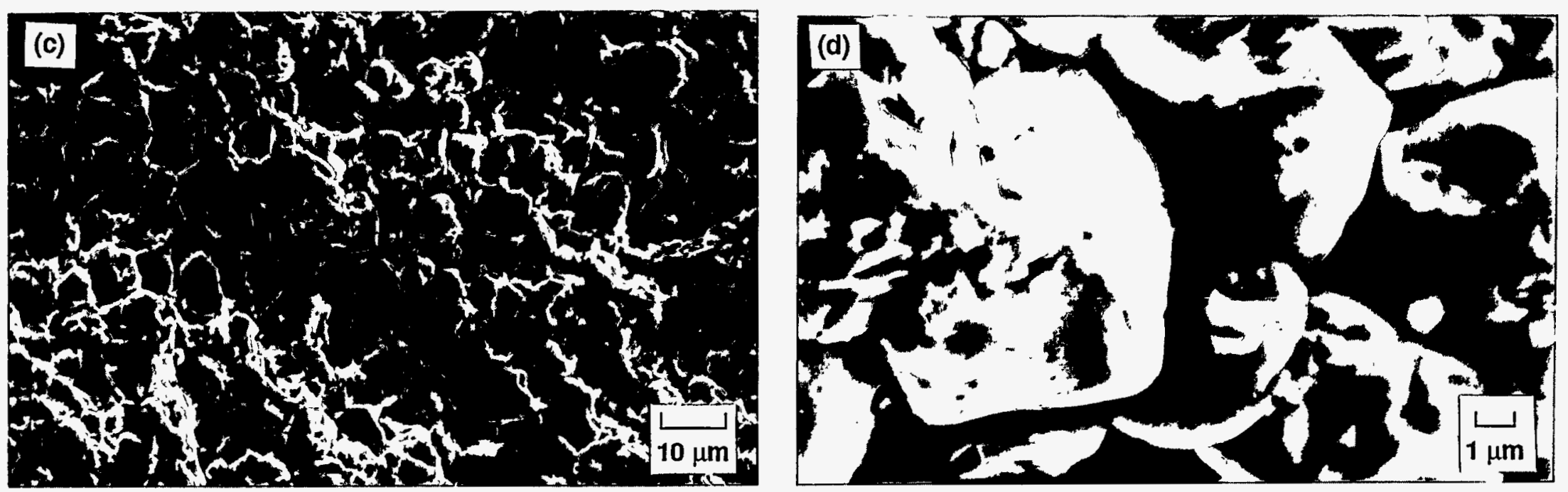

Figure A.55. SEM Photographs of Unoxidized, Unleached ATM-106 Spent Fuel Particle: (a) Overall view, (b) Center of a, (c) Center of b, (d) Center of c 

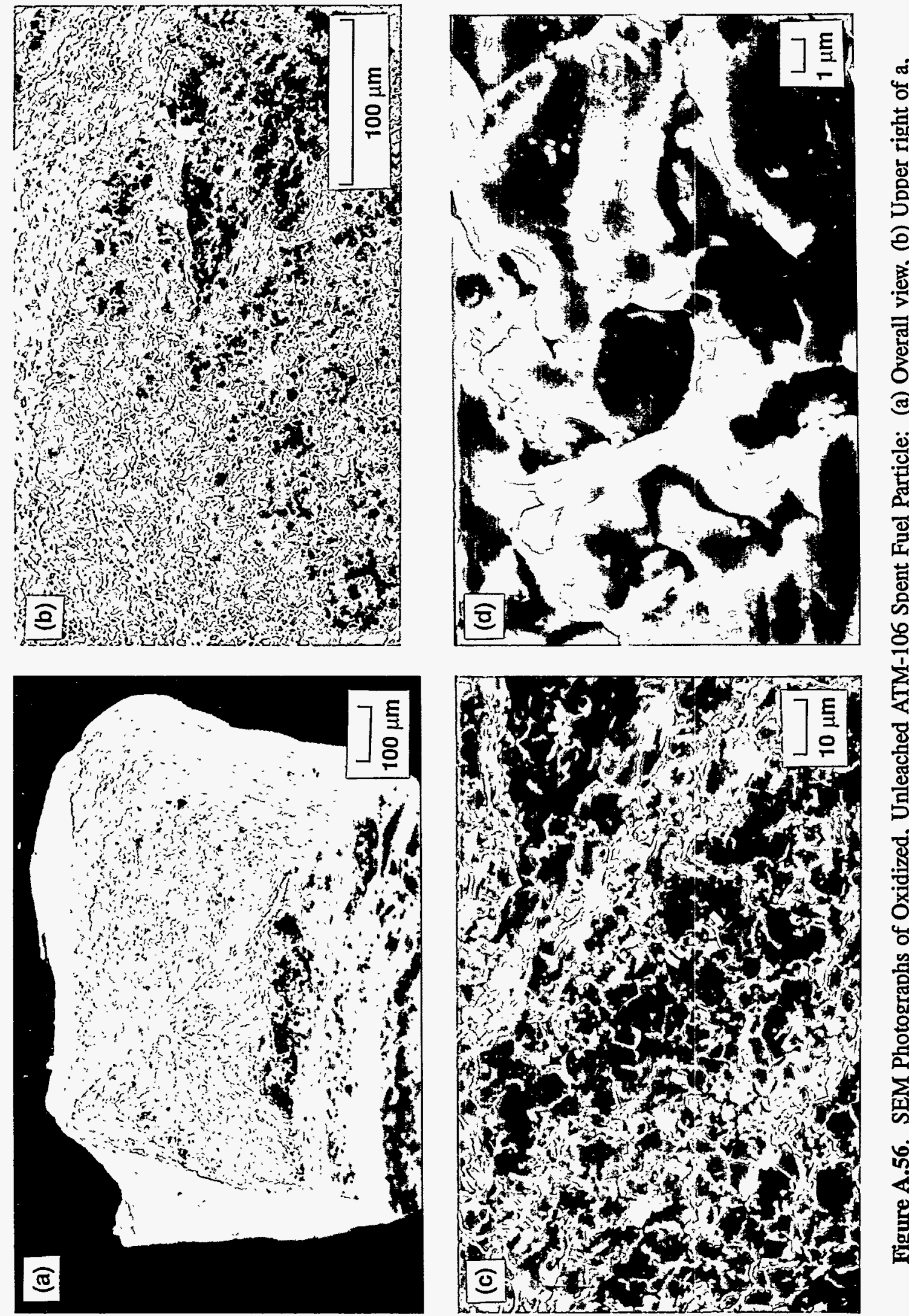
$10+4020$ - 163 3

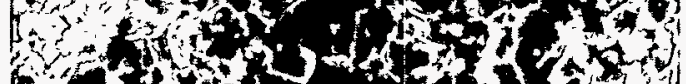
6.

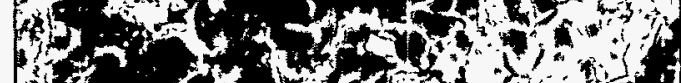

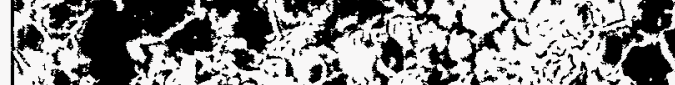

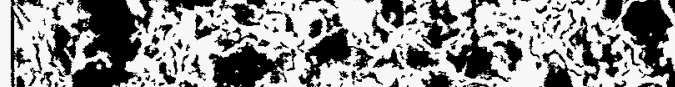
(3) 0 -

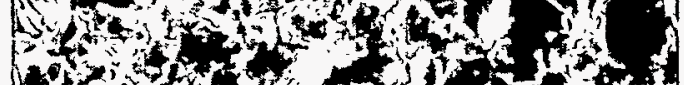

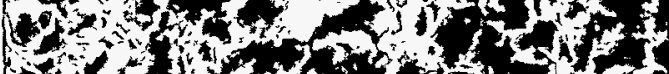

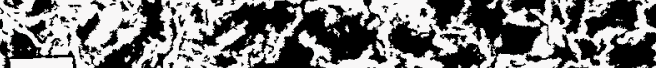

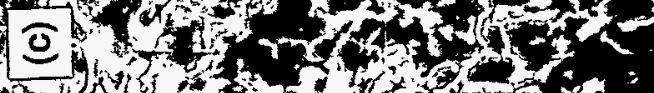

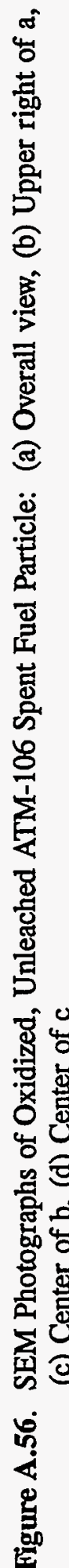



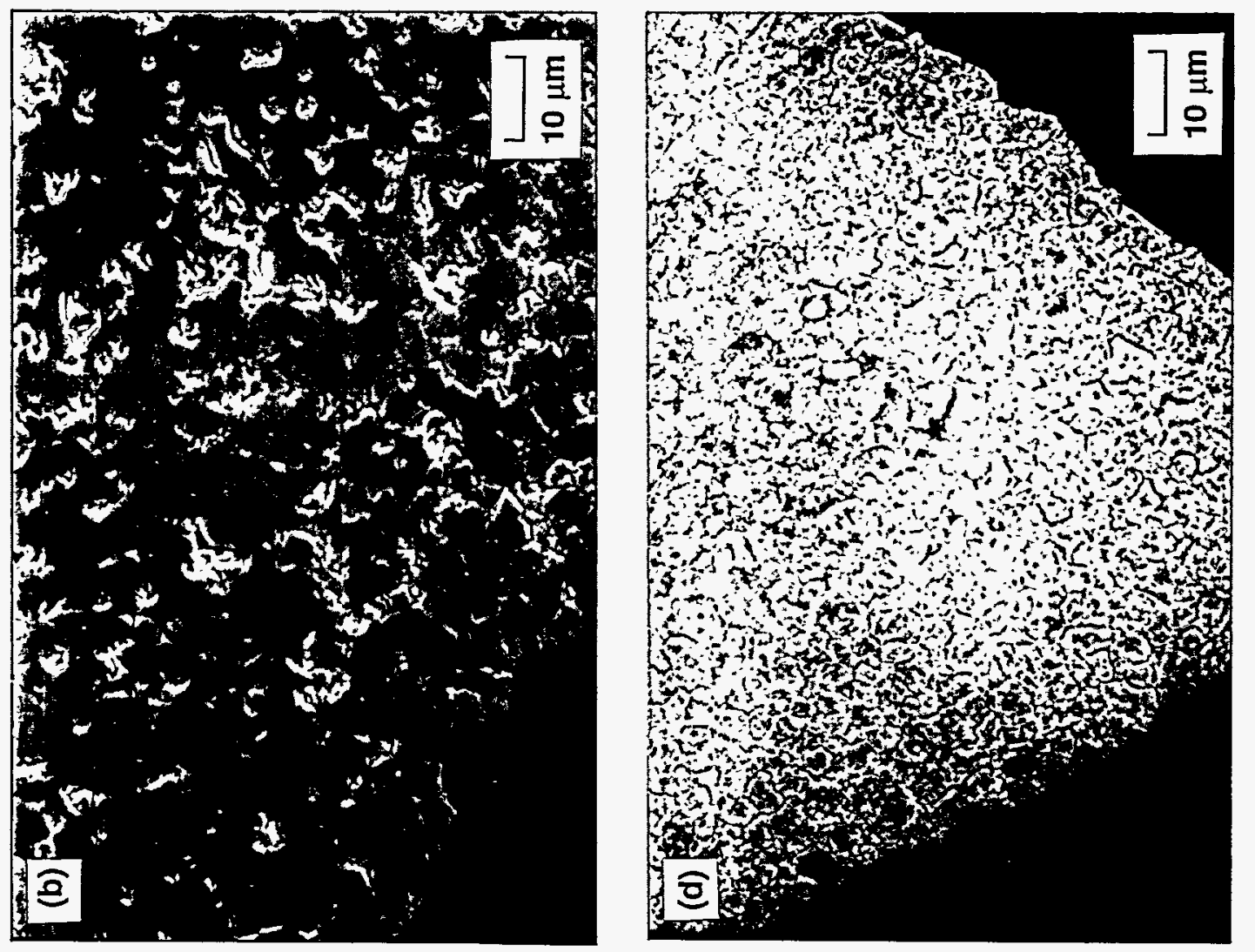

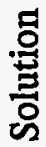

ర్ర

乙
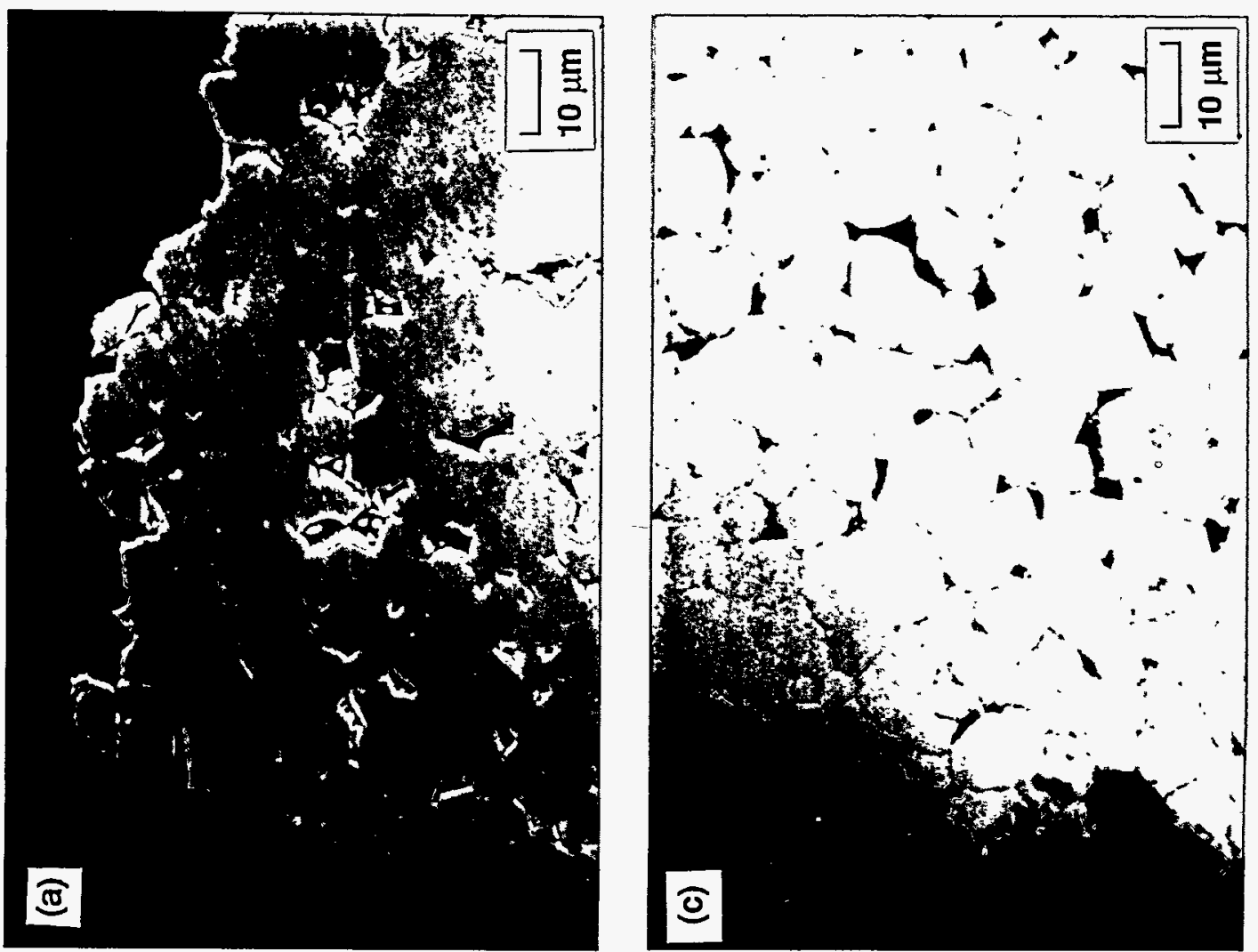

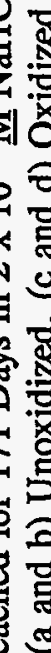

Ф을

至

若

के

ర요

它

U

4ั 종

है

壳

웅

马 II

잉

क

客

एँ

울 


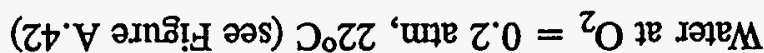

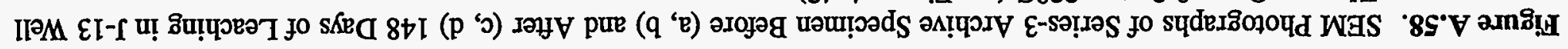
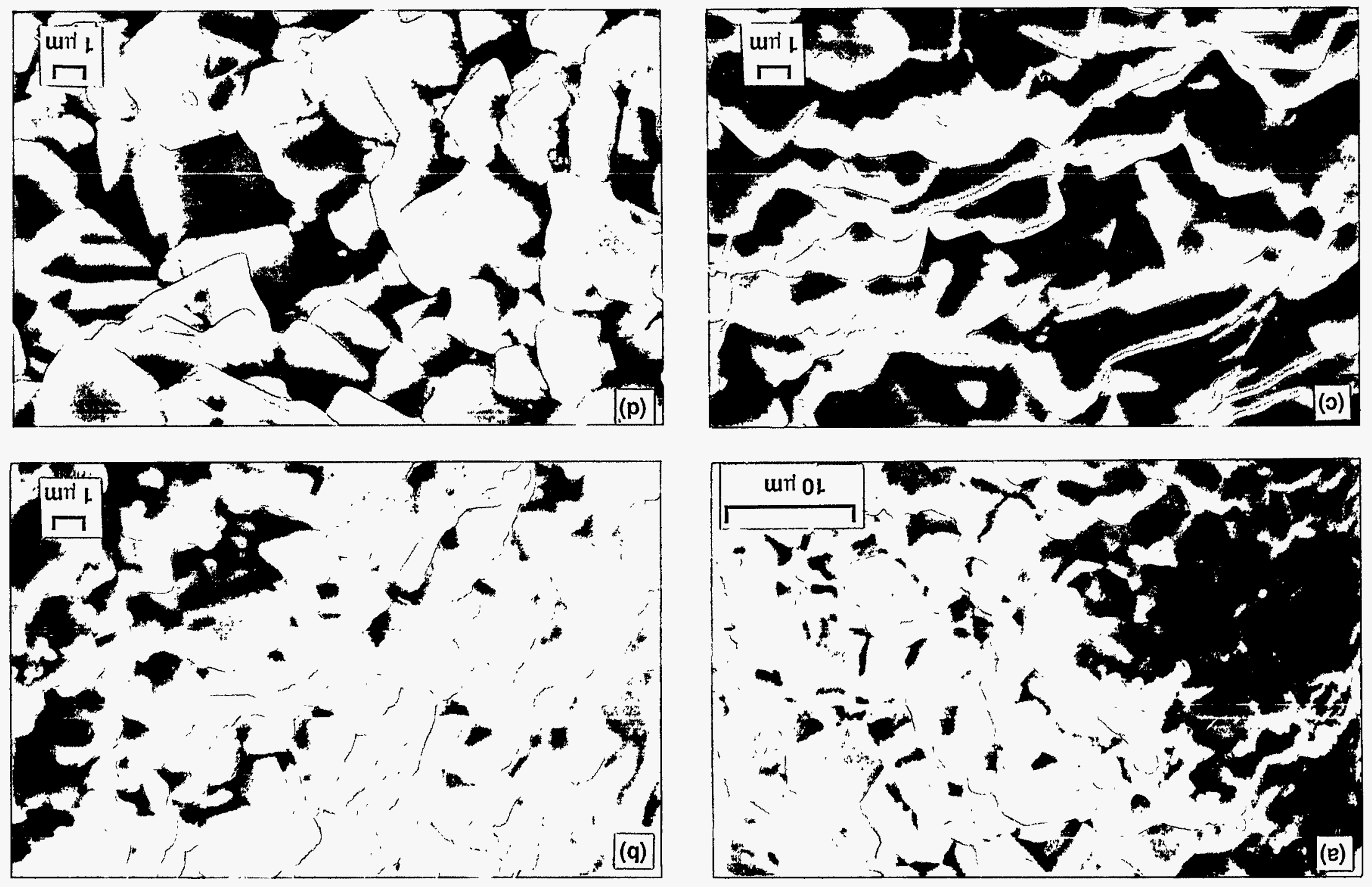

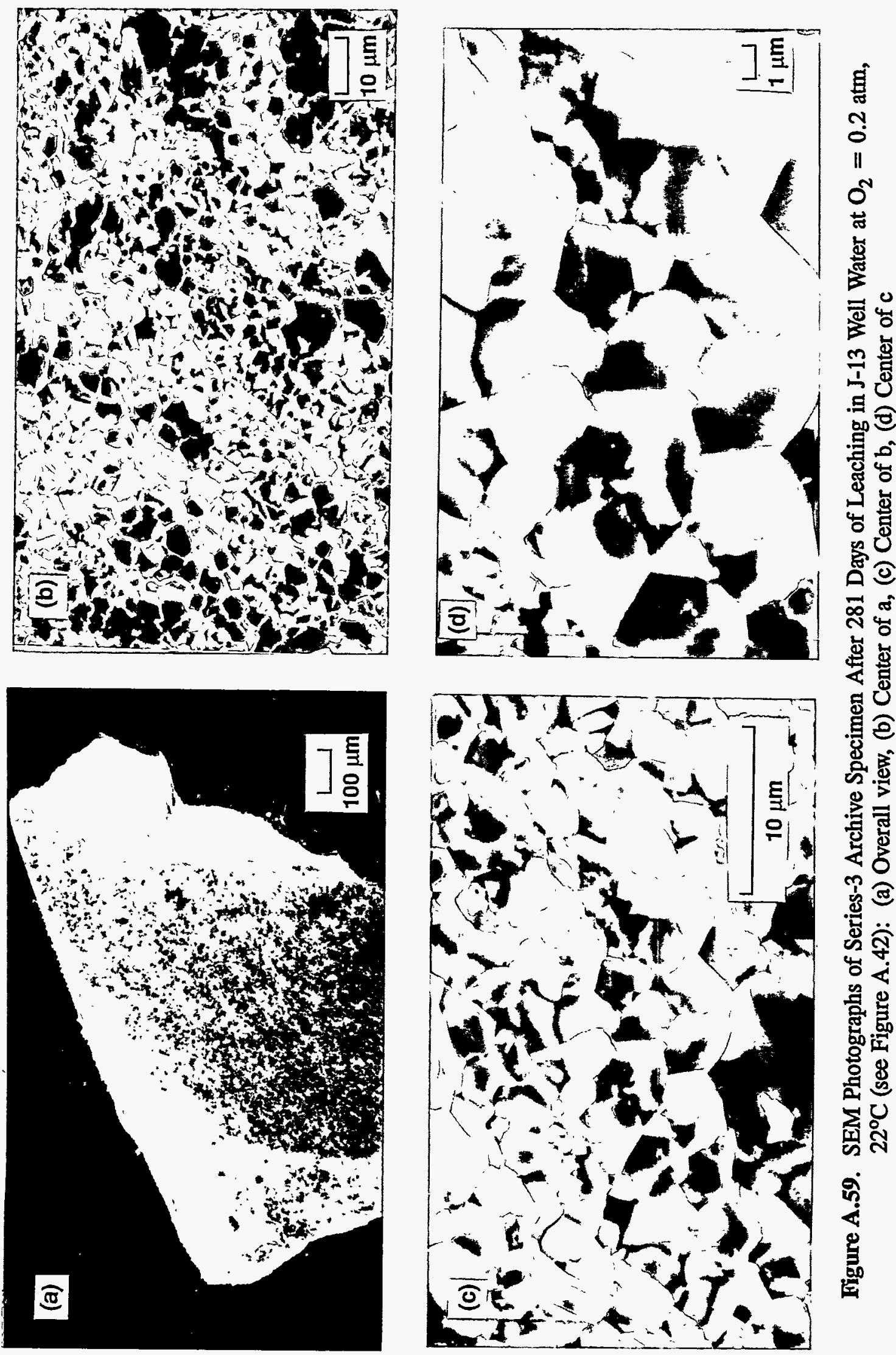

 

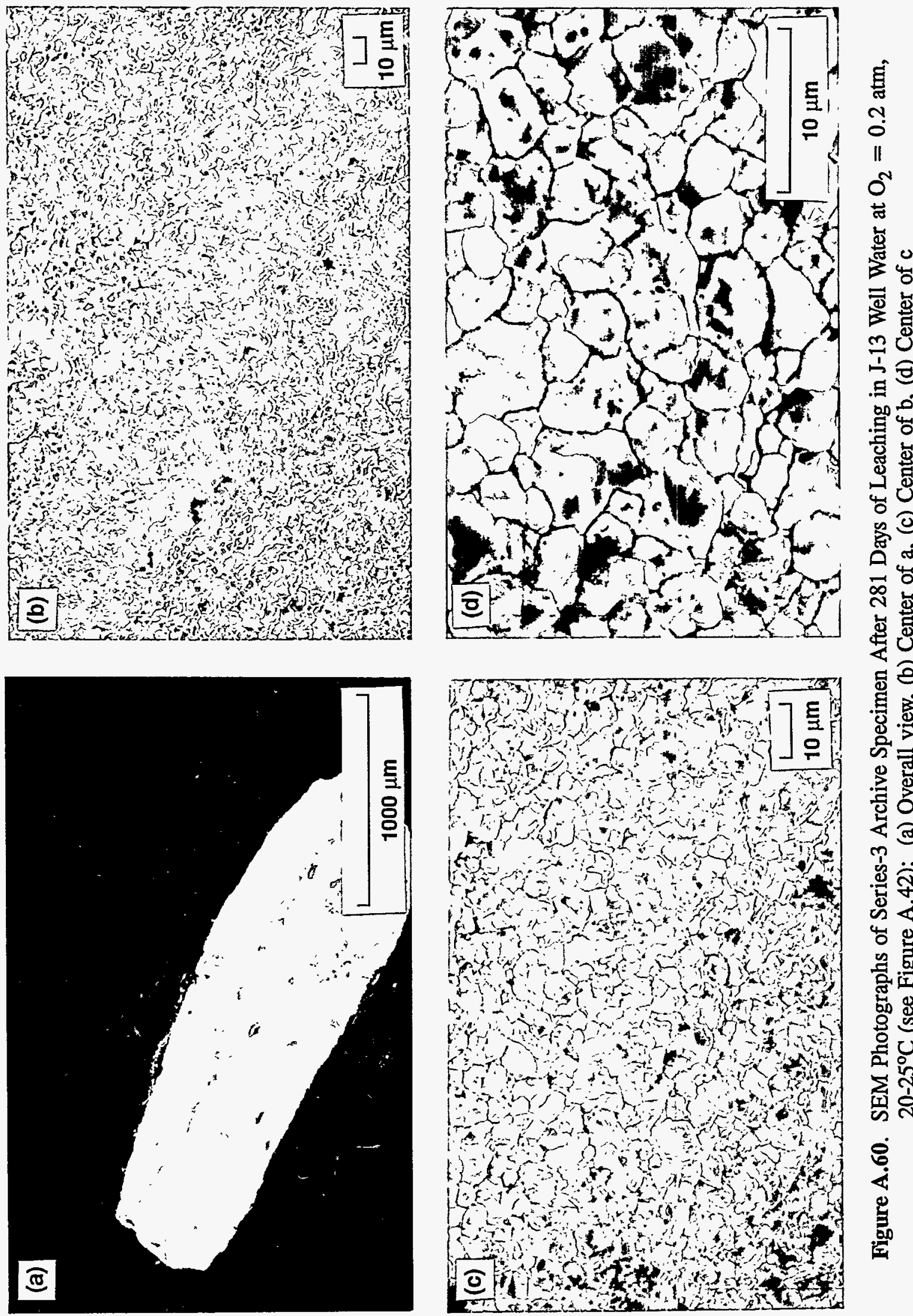


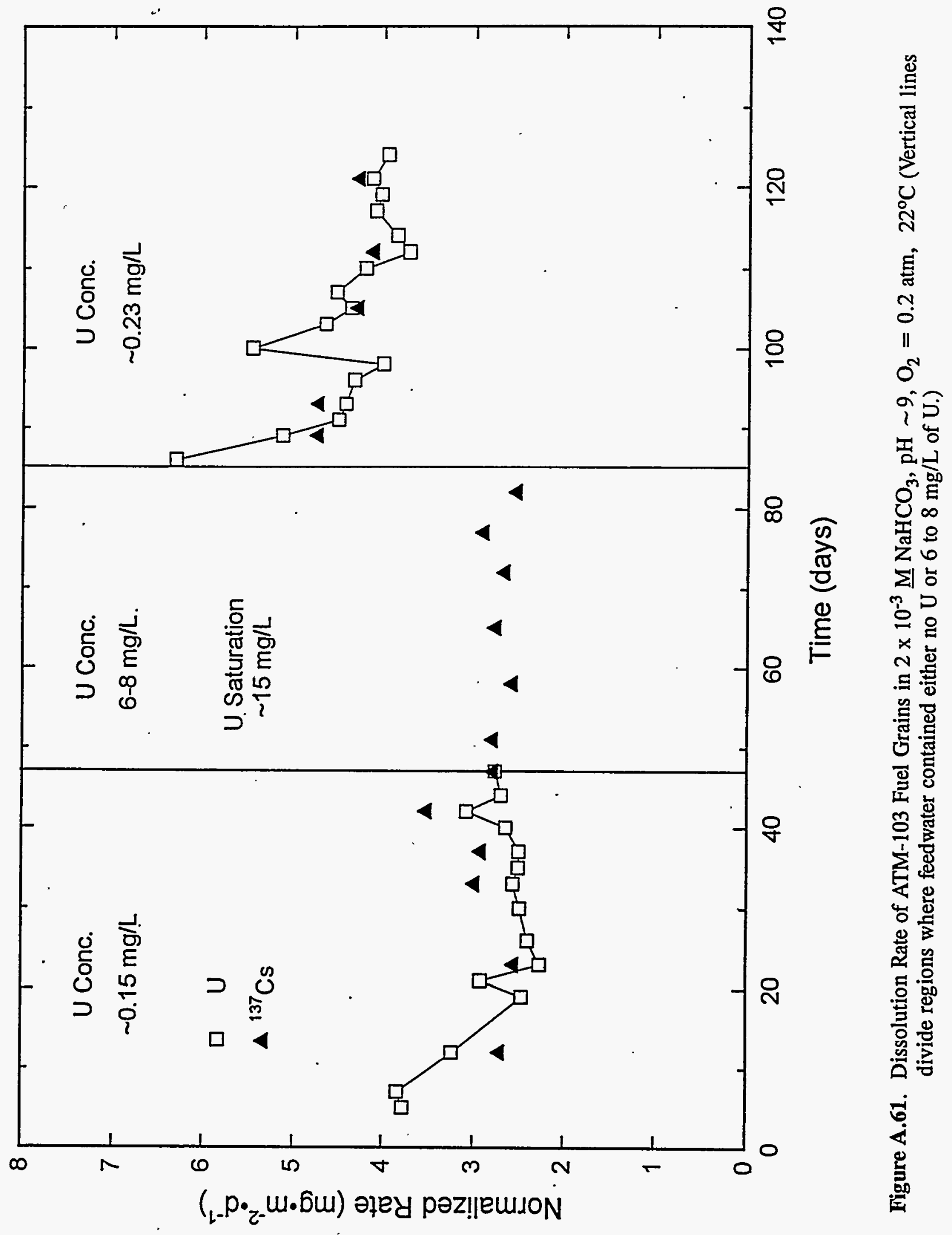




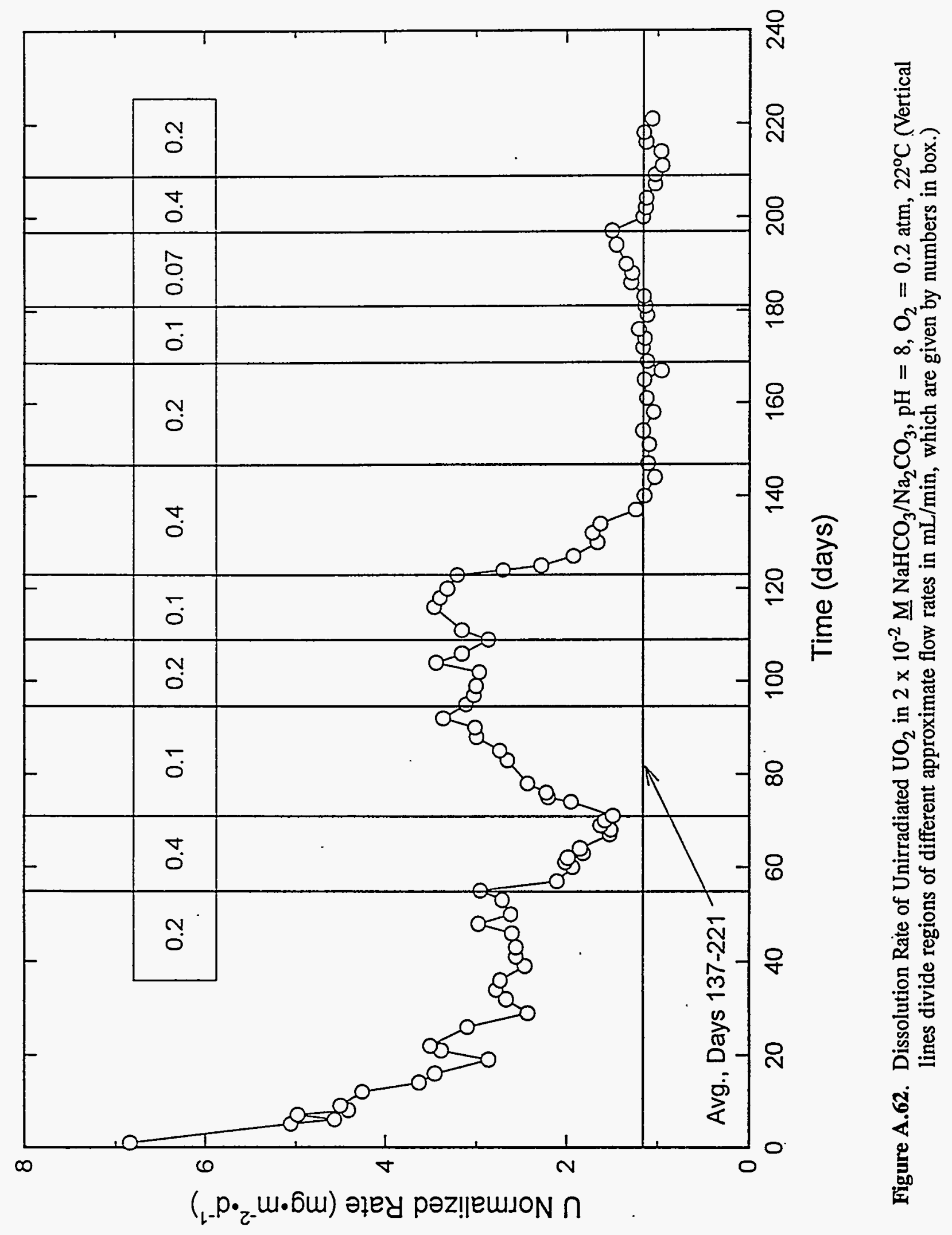




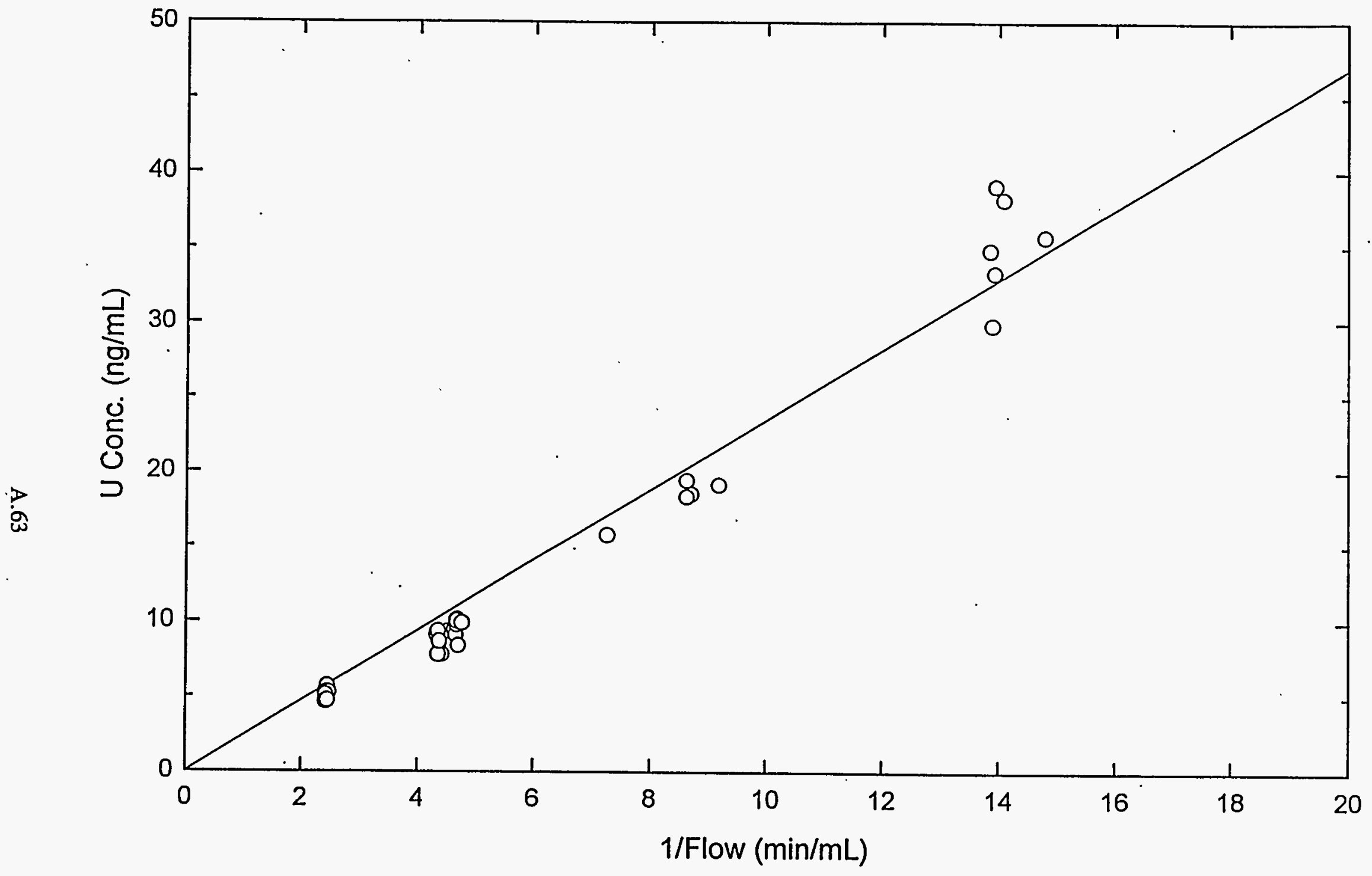

Figure A.63. Dependence of $\mathrm{U}$ Concentrations on Reciprocal Flow for Unirradiated $\mathrm{UO}_{2}$ in $2 \times 10^{-2} \mathrm{M} \mathrm{NaHCO}_{3} / \mathrm{Na}_{2} \mathrm{CO}_{3}$, $\mathrm{pH}=8, \mathrm{O}_{2}=0.2 \mathrm{~atm}, 22^{\circ} \mathrm{C}$ (Data are plotted for day 137 and beyond; the regression line includes all data shown in this figure.) 


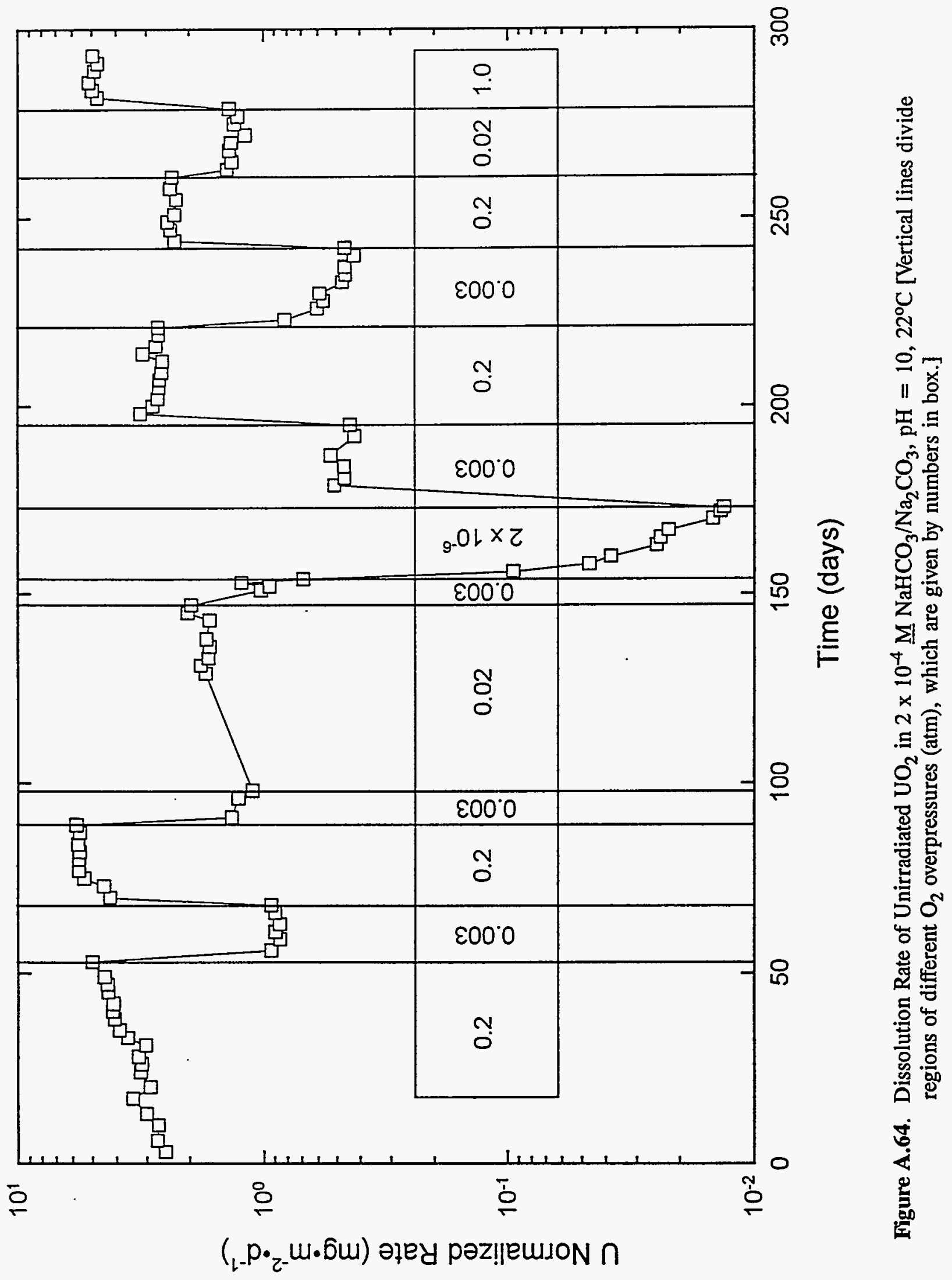




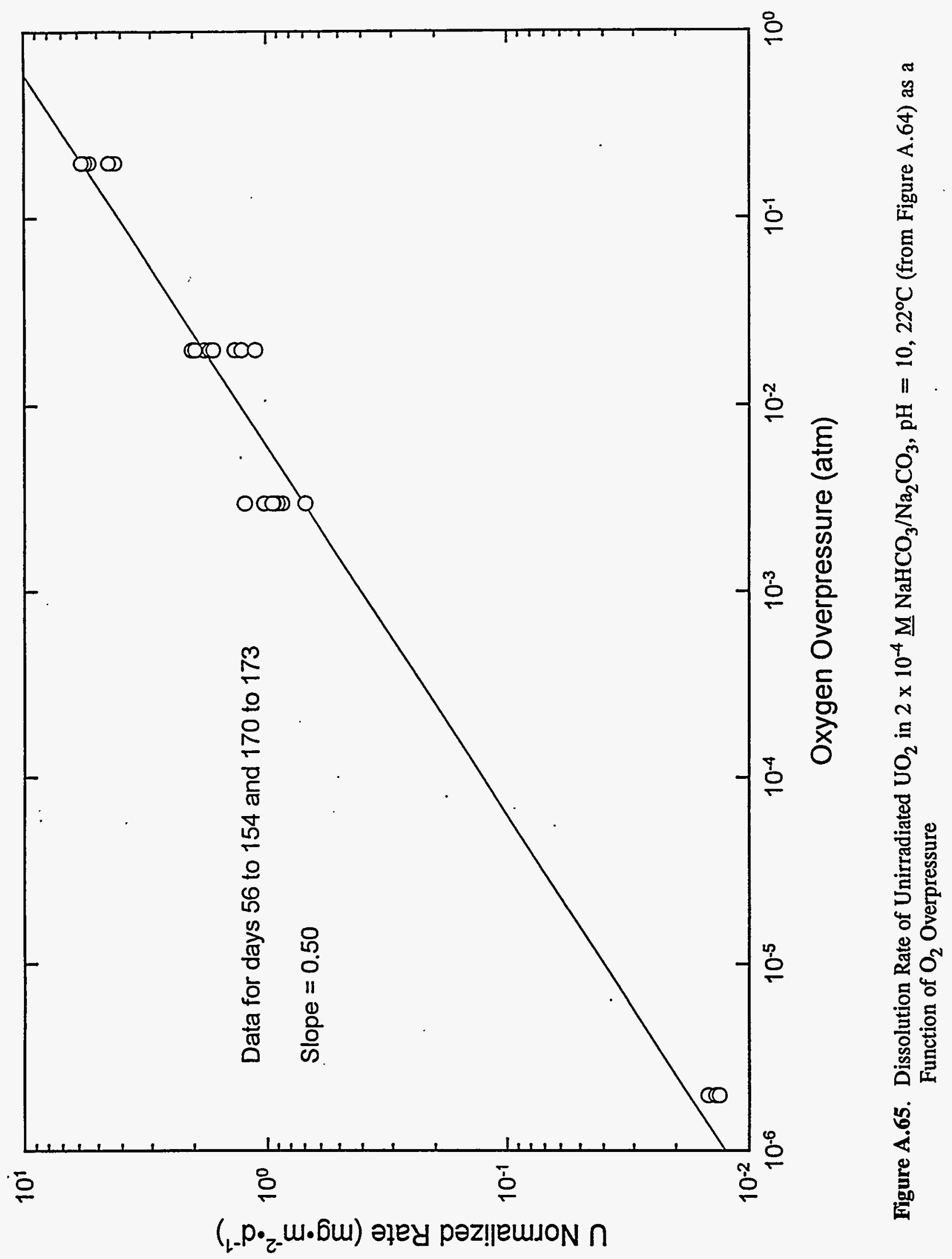




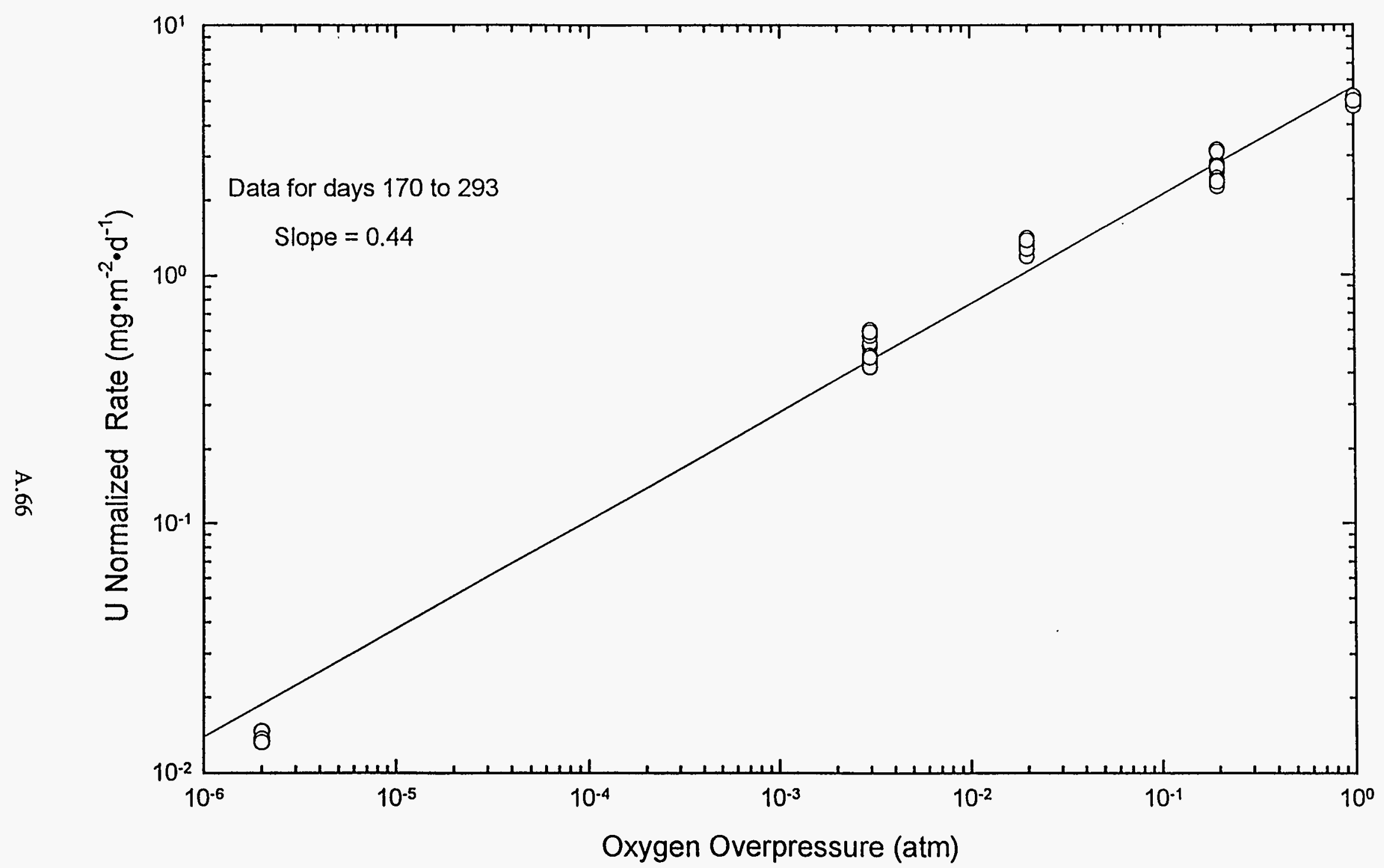

Figure A.66. Dissolution Rate of Unirradiated $\mathrm{UO}_{2}$ in $2 \times 10^{-4} \underline{\mathrm{M}} \mathrm{NaHCO}_{3} / \mathrm{Na}_{2} \mathrm{CO}_{3}, \mathrm{pH}=10,22^{\circ} \mathrm{C}$ (from Figure A.64) as a Function of $\mathrm{O}_{2}$ Overpressure 


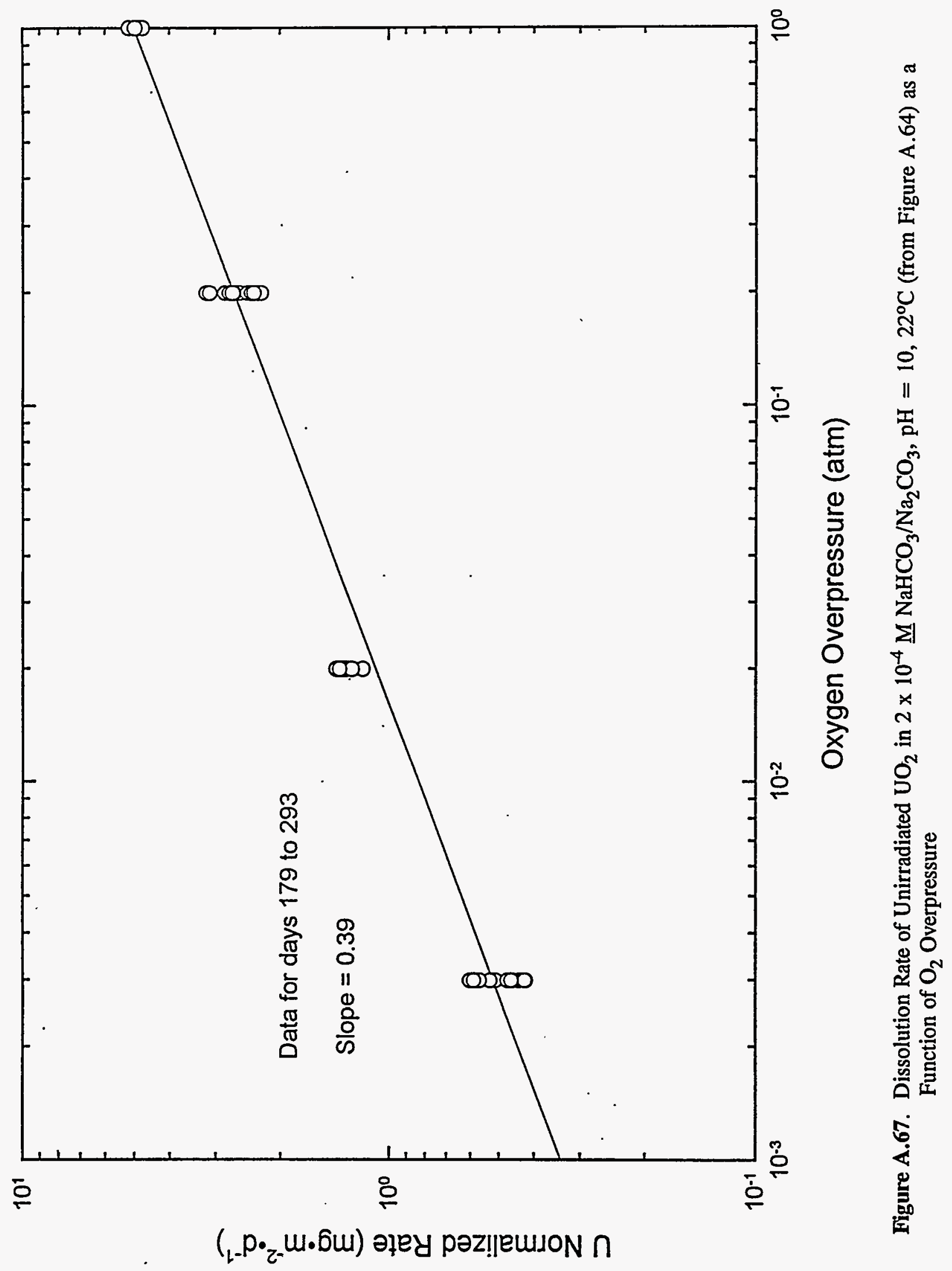


U Normalized Rate $\left(\mathrm{mg} \cdot \mathrm{m}^{-2} \cdot \mathrm{d}^{-1}\right)$

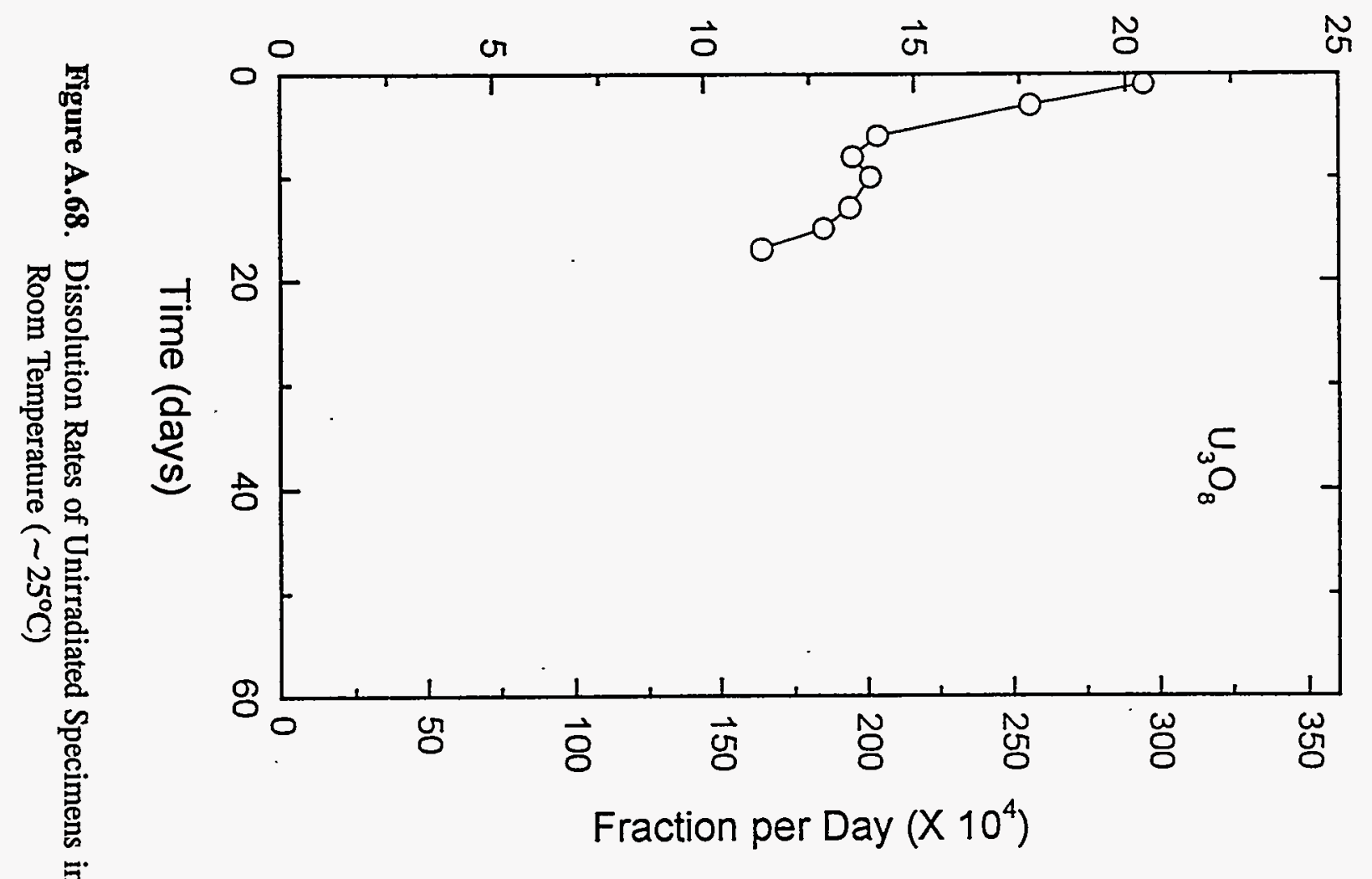

U Normalized Rate $\left(\mathrm{mg} \cdot \mathrm{m}^{-2} \cdot \mathrm{d}^{-1}\right)$

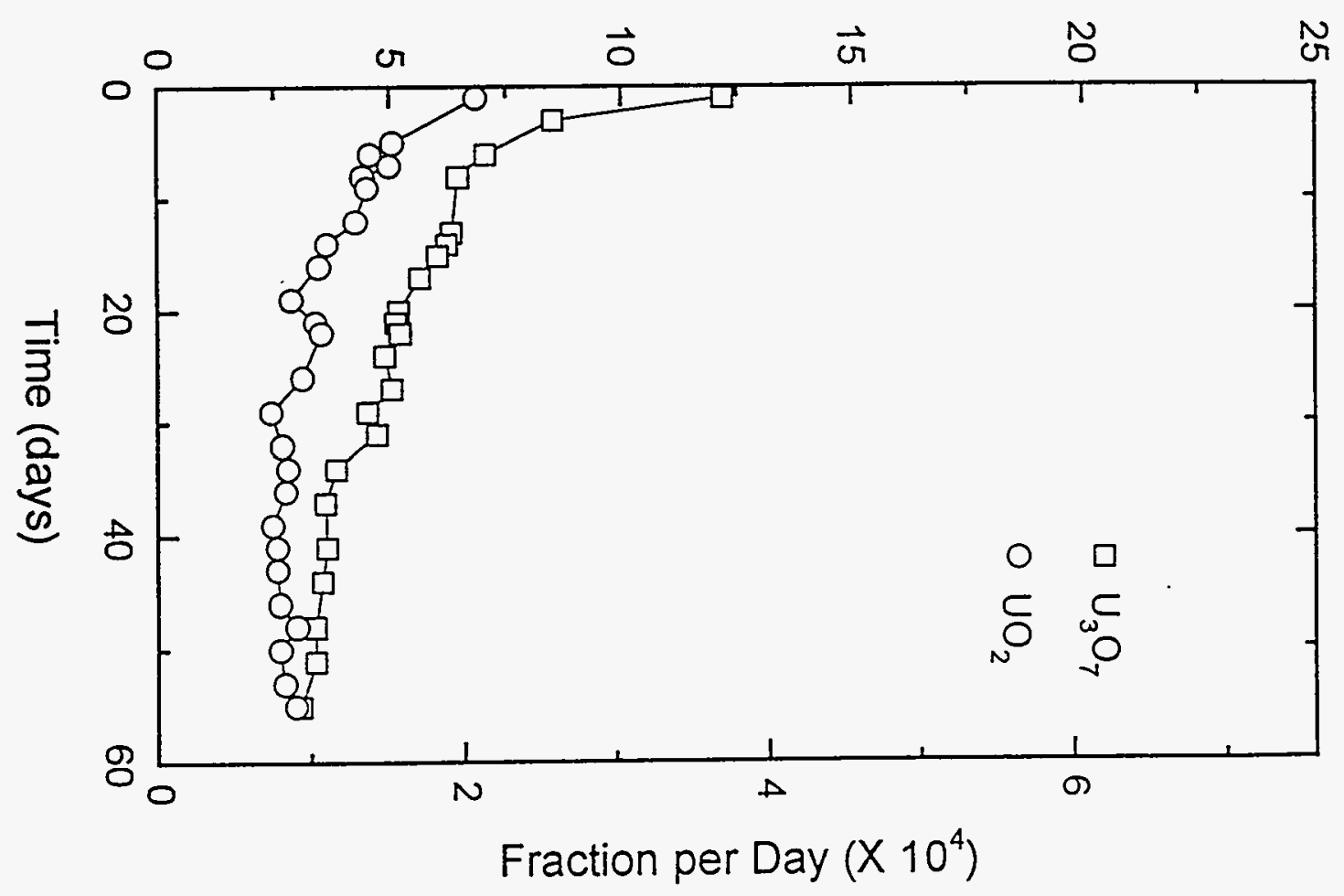




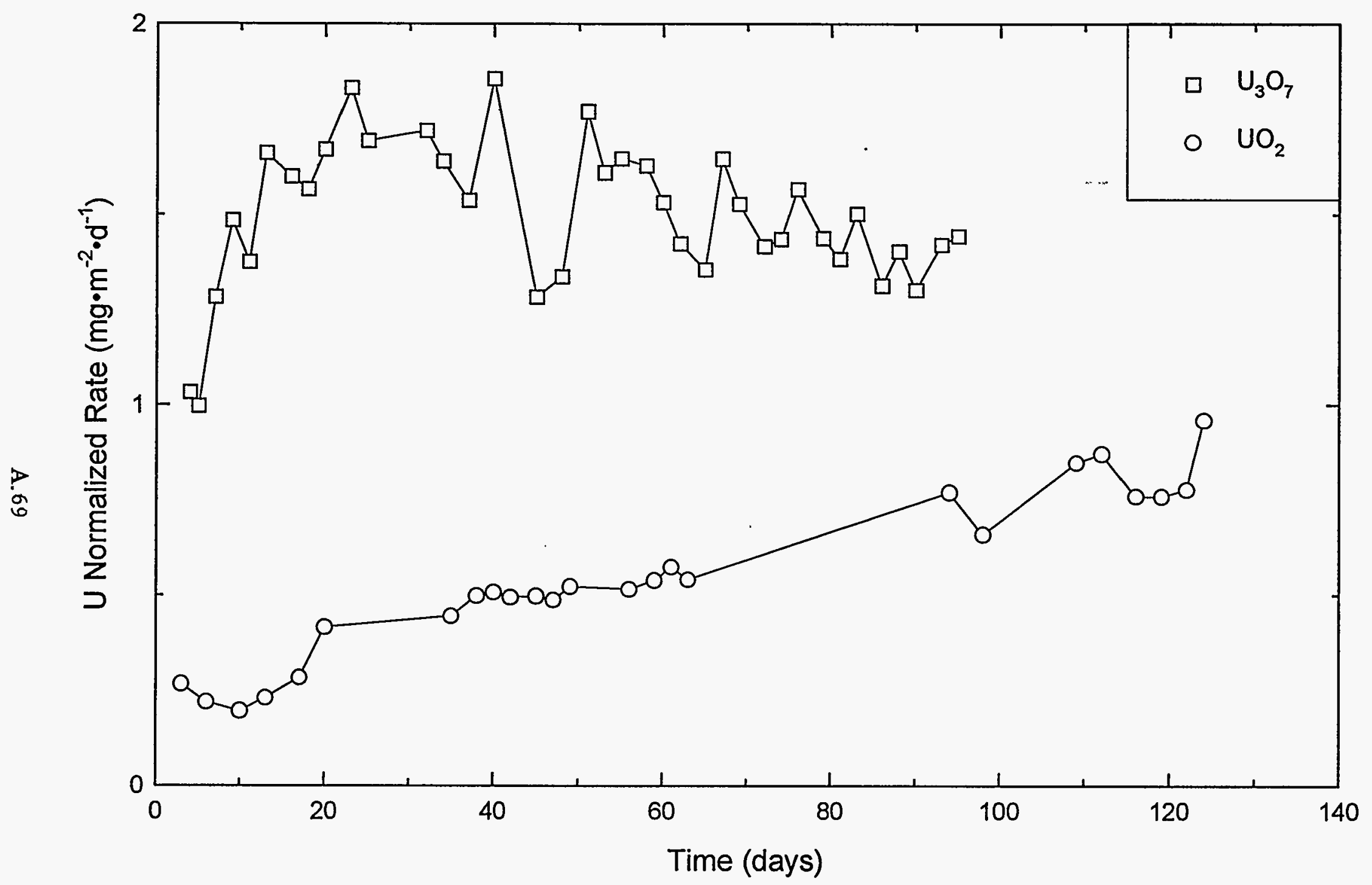

Figure A.69. Dissolution Rates of Unirradiated Specimens in $2 \times 10^{-4} \underline{\mathrm{M} \mathrm{NaHCO}}{ }_{3} / \mathrm{Na}_{2} \mathrm{CO}_{3}, \mathrm{pH}=10, \mathrm{O}_{2}=0.003 \mathrm{~atm}$, Room Temperature $\left(\sim 25^{\circ} \mathrm{C}\right)$ 


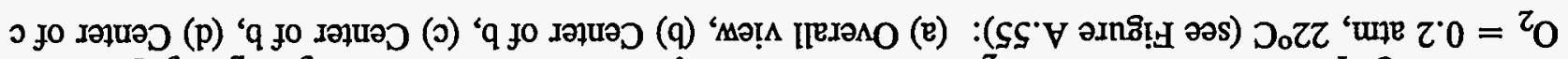

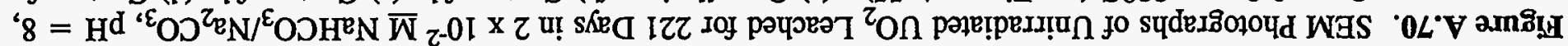
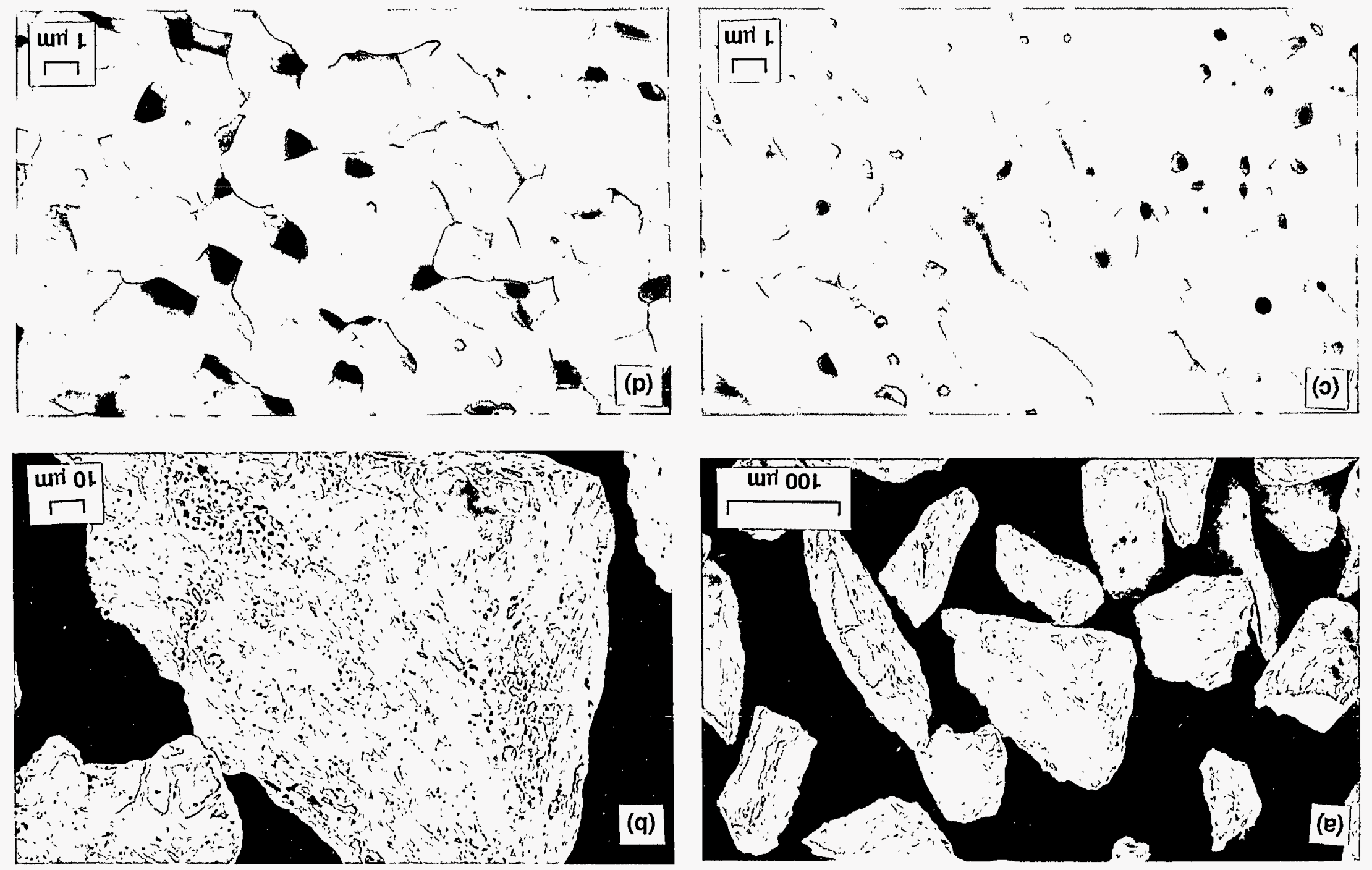


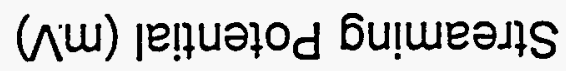

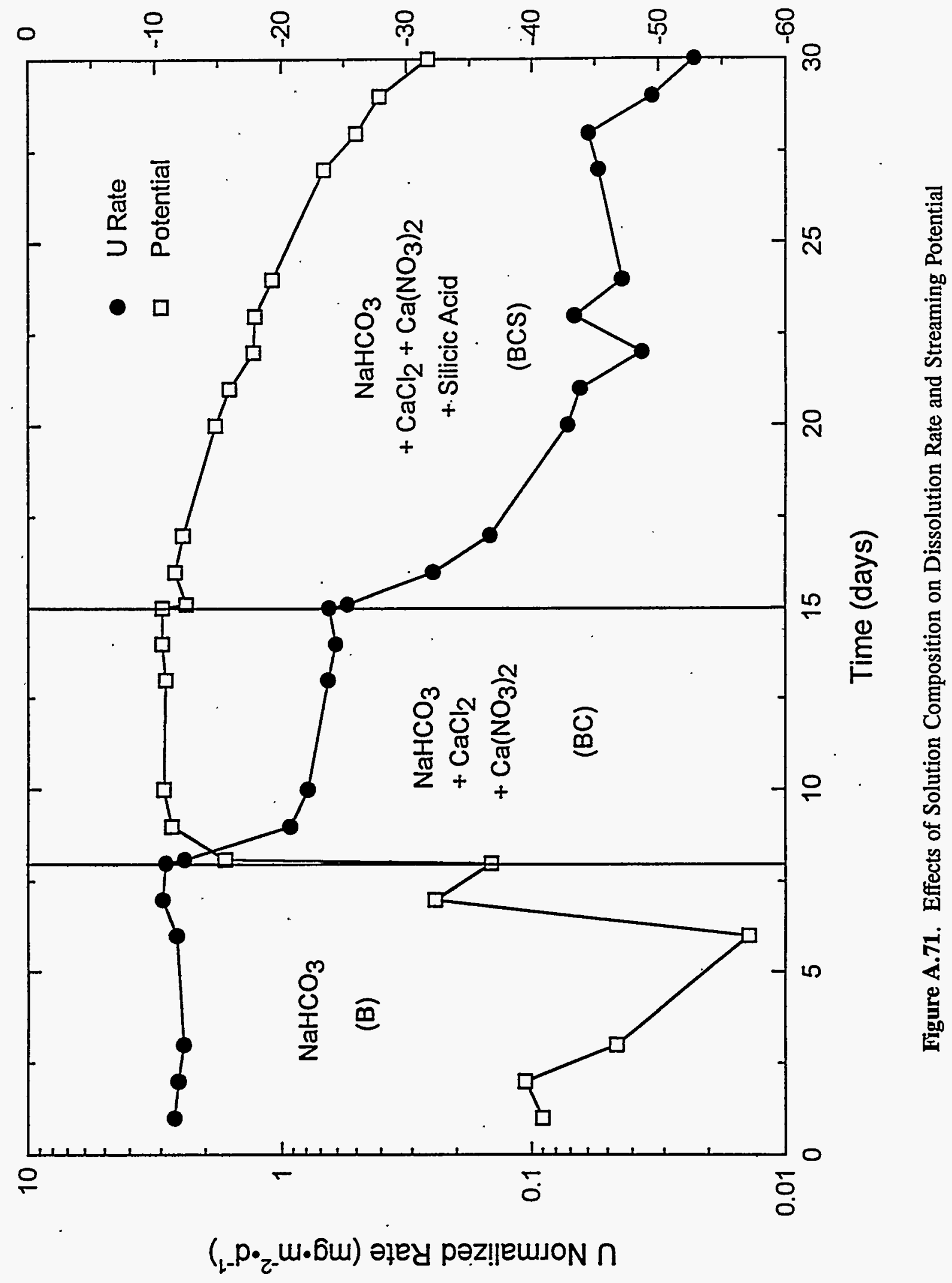




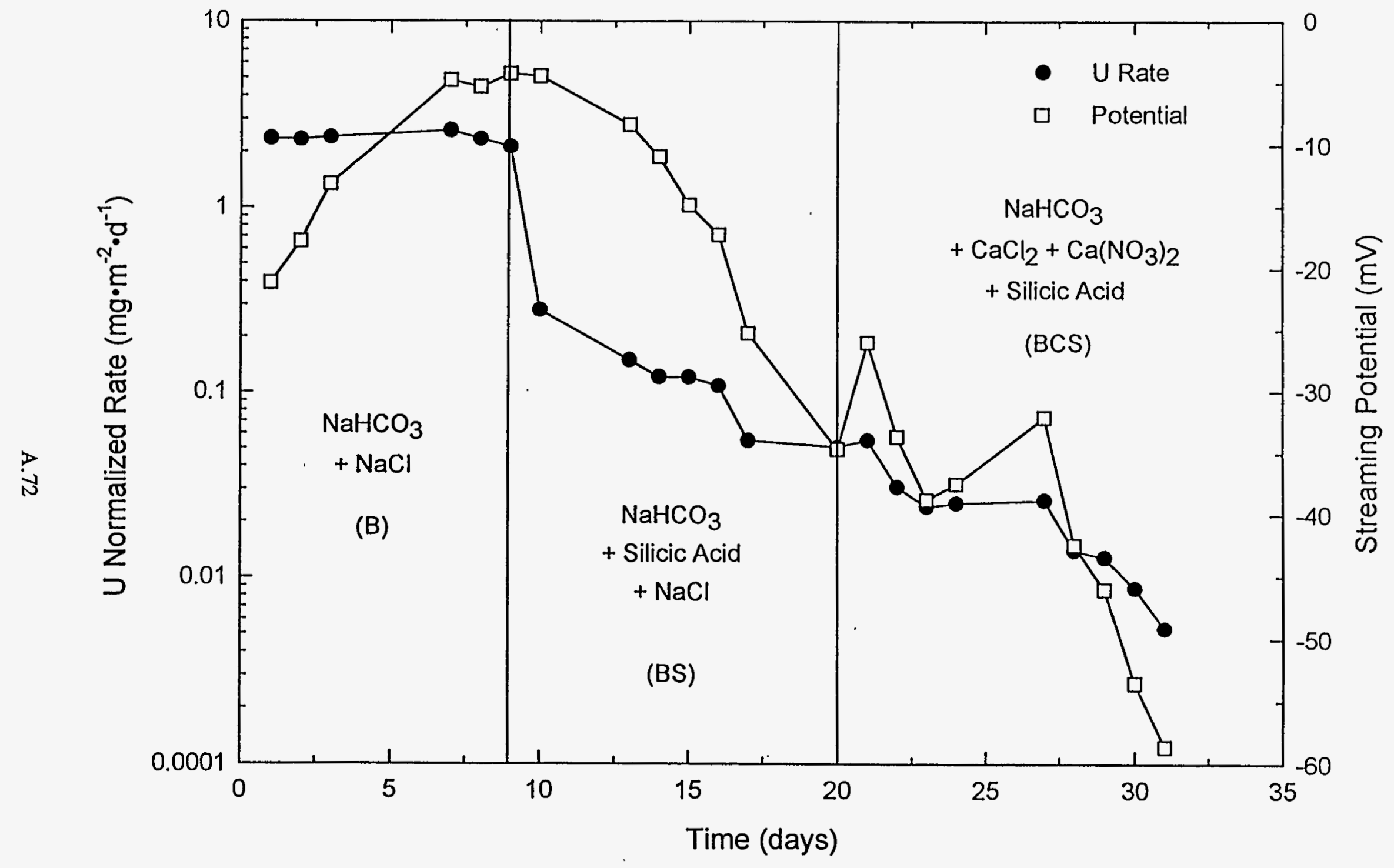

Figure A.72. Effects of Solution Composition on Dissolution Rate and Streaming Potential 


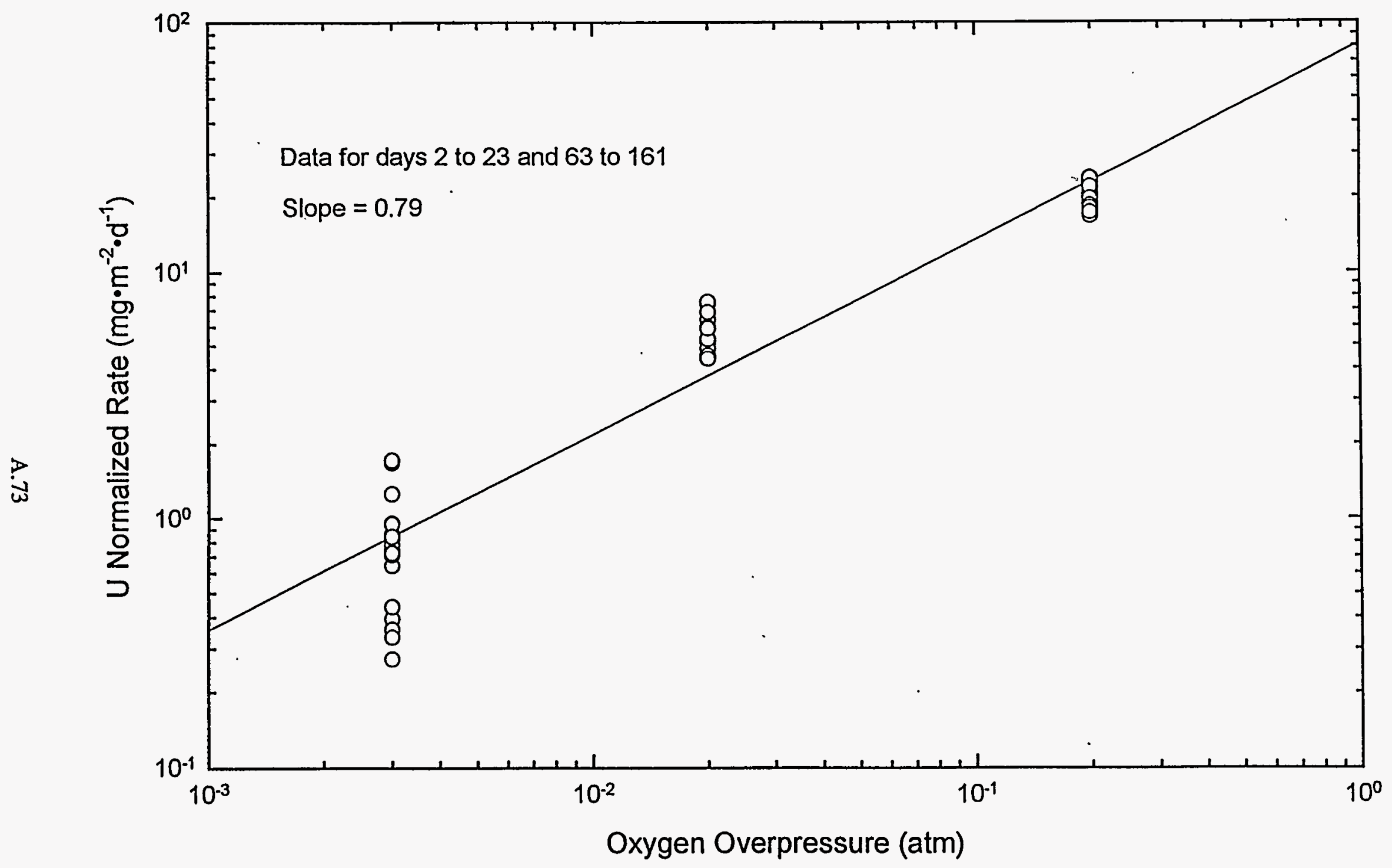

Figure A.73. Dissolution Rate of ATM-103 Spent Fuel in $2 \times 10^{-2} \underline{\mathrm{M} \mathrm{NaHCO}} 3 \mathrm{Na}_{2} \mathrm{CO}_{3}, \mathrm{pH}=10,74^{\circ} \mathrm{C}$ (from Figure A.15) as a Function of $\mathrm{O}_{2}$ Overpressure 



\section{Distribution}

No. of

Copies

Offsite

12 DOE/Office of Scientific.

and Technical Information

5 Department of Energy

Office of Civilian Radioactive Waste

Management

Washington, D.C. 20585

Attn:
A. B. Brownstein
H. J. Hale
W. Lake
W. Lemeshewsky
T. D. Nguyen

C. R. Allen

Nuclear Waste Technical Review Board 1000 E. California Boulevard

Pasadena, CA 91106

M. J. Apted

INTERA Sciences

3609 South Wadsworth Blvd.

5th Floor

Denver, CO 80235

6 Argonne National Laboratory

9700 S. Cass Ave.

Argonne, IL 60439

Attn: A. Anderson

J. L. Bates

J. C. Cunnane

P. Finn

D. M. Strachan

D. Wronkiewicz
No. of

Copies

G. D. Brewer

Nuclear Waste Technical Review Board

The Dana Building, Room 3516

University of Michigan

Ann Arbor, MI 48109-1115

J. E.. Cantlon, Chairman

Nuclear Waste Technical Review Board

2795 Bramble Drive

East Lansing, MI 48823

D. Curtis

Los Alamos National Labs

INC-BU, MS-7514

Los Alamos, NM 87545

3 Department of Earth and Planetary Sciẹnces

University of New Mexico

Albuquerque, NM 87131-1116

Attn: R. Ewing

J. Janeczek

M. Miller

P. A. Domenico

Nuclear Waste Technical Review Board

Geology Department

Texas A \& M University

College Station, TX 77843 
No. of

Copies

L. R. Hayes

Technical Project Officer

Yucca Mountain Project Branch

MS 425

U.S. Geological Survey

P.O. Box 25046

Denver, CO 80225

Technical Project Officer for YMP

N-5, Mail Stop J521

Los Alamos National Laboratory

P.O. Box 1663

Los Alamos, NM 87545

Attn: J.A. Canepa

2 Lawrence Berkeley Laboratories

MS 90-2024

Berkeley, CA 94720

Attn: J. Rudnicki

R. Russo

G. S. Bodvarsson

Head, Nuclear Waste Department

Lawrence Berkeley Laboratory

1 Cyclotron Road, MS 50E

Berkely, CA 94720

15 Lawrence Livermore National

Laboratory

University of California

P.O. Box 808

Livermore, CA 94550

Attn: T. A. Busheck, L-206

C. K. Chou, L-638

W. L. Clarke, L-204

W. Halsey, L-204

L. Lewis, L-195

D. McCright, L-369

W. J. O'Connell, L-195

M. Revell, L-206

R. B. Stout (5), L-201
No. of

Copies

S. A. Steward, L-325

M. Steward, L-201

Lockhead Idaho Technologies Co.

PO Box 1625

Idaho Falls, ID 83415-3423

Attn: Denny Filmore

4 V. F. Reich, Librarian

Nuclear Waste Technical Review Board

1100 Wilson Blvd., Suite 910

Arlington, VA 22209

L. Reiter

Nuclear Waste Technical Review Board 1100 Wilson Blvd., Suite 910

Arlington, VA 22209

L. E. Shephard

Technical Project Officer for YMP

Sandia National Laboratories

Organization 6310

P.O. Box 5800

Albuquerque, NM 87185

L. S. Costin

Technical Project Office for YMP

Sandia National Laboratories

Organization 6310

P.O. Box 5800

Albuquerque, NM 87185

4 Southwest Research Institute

Center for Nuclear Waste

Regulatory Analyses

6220 Culebra Road

San Antonio, TX 78228

Attn: H. Manaktala

B. Sagar

N. Sridhar

J. Walton 
No. of Copies

U.S. Department of Energy DOE Nevada Operations Office P.O. Box 98518

Las Vegas, NV 89193-8518

Attn: Technical Oper. Officer

U.S. DOE-HQ EM-37

Trevion RM 334

19901 Germantown Road

Germantown, MD 29805

Attn: John Baker

21 U.S. Department of Energy

Yucca Mountain Site

Characterization Project Office

101 Convention Center Drive

P.O. Box 98608

Las Vegas, NV 89193-8608

Attn:

R. W. Andrews/M\&O

W. E. Barnes/YMSCO

J. A. Blink/LLNL

J. R. Dyer/YMSCO

N. Z. Elkins/LANL

R. Fish/M\&O

L. D. Foust/TRW

D. J. Harrison/YMSCO

D. C. Haught/YMSCO

J. Lee/M\&O

B. Mann/M\&O

J. K. McCoy/M\&O

C. M. Newbury/YMSCO

A. M. Simmons/YMSCO

E. T. Smistad/YMSCO

D. Stahl/M\&O

P. Stephens/REECO

D. P. Stucker/YMSCO

A. E. Van Luile/YMSCO

M. D. Voegele/M\&O

T. M. Williamson/M\&O
No. of

Copies

$6 \quad$ U.S. Department of Energy

1000 Independence Avenue, S.W.

Washington, DC 20585

Attn: J. C. Bresee (RW-10)

S. J. Brocoum (RW-22)

C. Kouts (RW-4)

R. A. Milner (RW-40)

G. J. Parker (RW-322)

S. Rousso (RW-50)

Senior Project Manager for Yucca Mountain

Repository Project Branch

Division of Waste Management

U.S. Nuclear Regulatory Commission

Washington, DC 20555

Librarian

YMP Research and Study Center

MS407

P.O. Box 98521

Las Vegas, NV 89193-8521

Division of Waste Management

U.S. Nuclear Regulatory Commission

Washington, DC 20555

Attn: Tae Ahn

E. D. Verink

Nuclear Waste Technical Review Board 4401 N.W. 18th Place

Gainesville, FL 32605

D. Warner North

Nuclear Waste Technical Review Board

Decision Focus, Inc.

4984 El Camino Real

Los Altos, CA 94062

Distr.3 
No. of

Copies

Westinghouse Electric Corp.

Bettis Atomic Power Laboratory

PO Box 79

Westmisslin, PA 15122-0079

Attn: Dr. Carl A. Detrick

\section{Foreign}

7 AECL Research

Whiteshell Laboratories

Pinawa, Manitoba R0E 1L0

Canada

Attn:
B. Hocking
L. Johnson
D. Shoesmith
S. Stroes-Gascoyne
S. Sunder
J. Tait
P. Taylor

\section{J. A. Gago Badenas}

Empresa Nacional De Residuos

Radiativos

c/o Emilio Vargas. 7

28043 Madrid SPAIN

H. Bischoff

Freie Universität Berlin

FG Radiochemie

Fabeckstr. 34-36

14195 Berlin

F.R. Germany

Attn: H. Bischoff

G. Marx

J. Bruno

Intera Information Technologies SL

Parc Tecnologic del Valles

08290 Ceranyola

Spain
No. of

Copies

\section{J. De Pablo \\ Universitat Politecnica Catalunya \\ Department of Chemical Engineering \\ Diagonal 647 \\ 08025 Barcelona \\ Spain}

2 Studsvik Nuclear AB

S-611 82 Nykoping

Sweden

Attn: H. Christensen

Attn: U. Eklund

3 European Institute for Transuranic

Elements, CEC

Postfach 2340 D-76125

Karlsruhe

Federal Republic of Germany

Attn: M. Coquerelle

D. Bottomley

H. Matzke

B. Finch

University of Manitoba

Dept. Geological Sciences

240 Wallace Building

125 Dysart Road

Winnipeg, Manitoba . R3T 2N2

R. Forsyth

Caledon-Consult

Stenbrinken 7

S 61134 Nykoping

Sweden

I. Hiroshi

JAERI

Tokai

Ibaraki

319-11, JAPAN 
No. of

Copies

2

KFK/INE

Postfach 3640

D-76021 Karlsruhe

Federal Republic of Germany

Attn:
A. Loida
B. Grambow

2 MBT Tecnologia Ambiental Centre d'Empreses de Noves Tecnologies

Parc Tecnològic del Vallès 08290 Cerdanyola - ESPAÑA

Attn: I. Casas

K. Spahiu

F. J. Méndez

CIEMAT

Avda. Complutense, 22

28040 Madrid

Spain

K. Ollilla

Technical Research Centre of Finland

VTT Chemical Technology

P.O. Box 1404

FIN-02044

VTT Finland

J. Paul

Commissariat á L'Energie Atomique

Centre D'Etudes de la Vallee du Rhone

Departement du Retraitement, des

Dechets et du Demantellement

Section de Developpement des

Materiaux de Confinement

B.P. 171-30207 Bagnols-sur-Ceze

CEDEX
No. of

Copies

2 SKB

Box 5864

S-10240 Stockholm

SWEDEN

Attn: P. Sellin

L. Werme

J. Serrano

Centro de Investigasciones Energeticas

Instituto de Technologia Nuclear

Avenida Complutense 22

28040

Madrid, Spain

M. Skalberg

Chalmers University of Technology

Department of Nuclear Chemistry

S-412 96 Goteborg

Sweden

K. Spahiu

MBT Tecnologia Ambiental

Centre d'Empreses de Noves

Tecnologies

Parc Tecnològic del Vallès

08290 Cerdanyola - ESPAÑA

\section{Onsite}

DOE Richland Operations Office

D. C. Langstaff, K8-50

3 Westinghouse Hanford Company

C. N. Wilson (3), H5-27 
PNL-10540

UC-802

No. of

Copies

28

Pacific Northwest Laboratory

M. J. Altenhofen, K7-34

Y. Chen, K2-38

R. E. Einziger, P7-14

D. W. Engel, K5-12

P. W. Eslinger, K6-77

W. J. Gray (10), P7-14

S. C. Marschman (2), P7-18
No. of

Copies

B. P. McGrail, K2-38

L. E. Thomas, P8-16

V. Statler, P7-14

C. I. Steefel, K3-61

R. E. Williford, K2-44

Publishing Coordination

Technical Report Files (5) 